This item was submitted to Loughborough's Research Repository by the author.

Items in Figshare are protected by copyright, with all rights reserved, unless otherwise indicated.

\title{
An investigation into the affective properties of sporting goods based on cycling experience
}

PLEASE CITE THE PUBLISHED VERSION

PUBLISHER

Loughborough University

\section{PUBLISHER STATEMENT}

This work is made available according to the conditions of the Creative Commons Attribution-NonCommercialNoDerivatives 4.0 International (CC BY-NC-ND 4.0) licence. Full details of this licence are available at: https://creativecommons.org/licenses/by-nc-nd/4.0/

\section{LICENCE}

CC BY-NC-ND 4.0

\section{REPOSITORY RECORD}

Kuo, Jo-Yu. 2018. "An Investigation into the Affective Properties of Sporting Goods Based on Cycling Experience". Loughborough University. https://hdl.handle.net/2134/36346. 


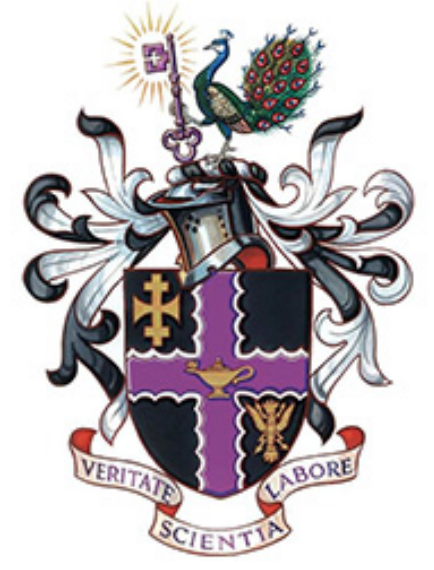

\section{AN INVESTIGATION INTO THE AFFECTIVE PROPERTIES OF SPORTING GOODS BASED ON CYCLING EXPERIENCE}

KUO JO-YU

Wolfson School of Mechanical Electrical and Manufacturing Engineering 2018 


\title{
AN INVESTIGATION INTO THE AFFECTIVE PROPERTIES OF SPORTING GOODS BASED ON CYCLING EXPERIENCE
}

\author{
KUO JO-YU
}

Wolfson School of Mechanical Electrical and Manufacturing Engineering

A thesis submitted to the

Loughborough University and Nanyang Technological University

in partial fulfilment of the requirement for the joint degree of

Doctor of Philosophy

2018 


\section{Acknowledgement}

My sincere gratitude goes to my research supervisors, Assoc Prof Chen Chun-Hsien and Dr Jonathan Roberts for their invaluable guidance and continuous support throughout this work. They have taught me how to frame my ideas clearly, inspired me to learn and carry out a meaningful research in such a friendly and creative environment. I would also like to thank the examiners for giving helpful comments and constructive suggestions for greater improvement in this thesis.

This study would have been impossible without the support of the Institute for Sports Research in Nanyang Technological University. Also thanks to the Sports Technology Institute for sharing their lab and equipment in Loughborough University. I am deeply grateful to all professionals for their collaborations in Taiwan, Singapore and the United Kingdom as well as to all participants who obligingly gave me their time in the case studies.

Thank you to all the friends and family who stuck by during my $\mathrm{PhD}$ study for reminding me that how incredibly lucky I am to have had this opportunity. 


\section{Table of Content}

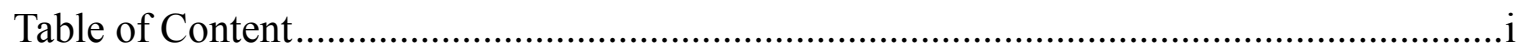

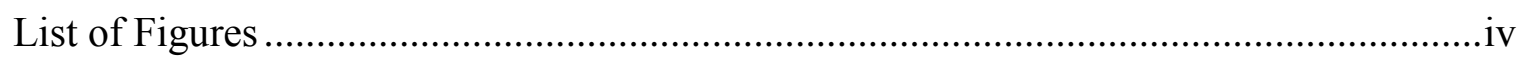

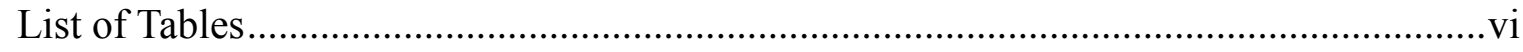

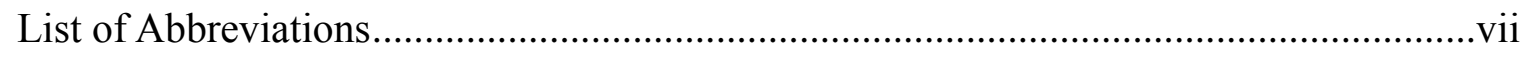

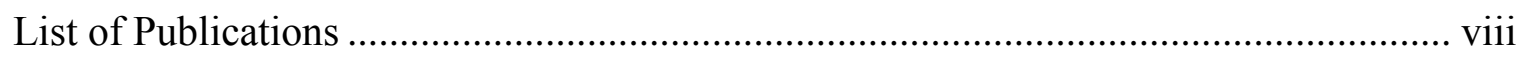

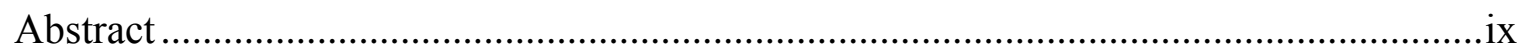

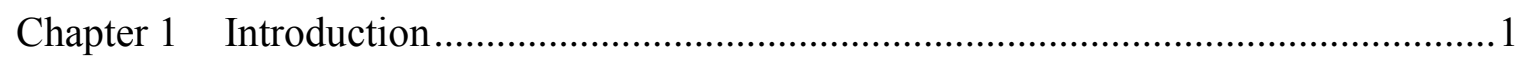

1.1 Background .................................................................................... 1

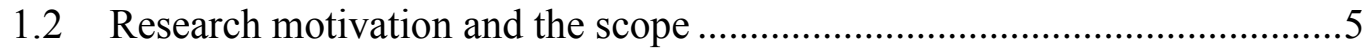

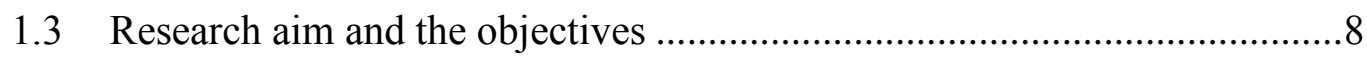

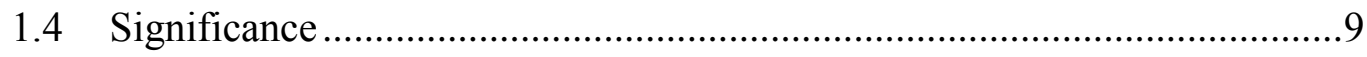

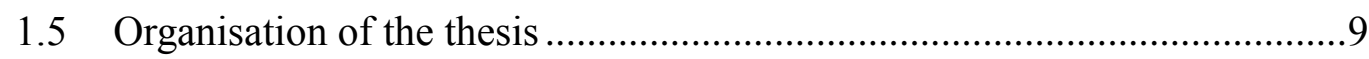

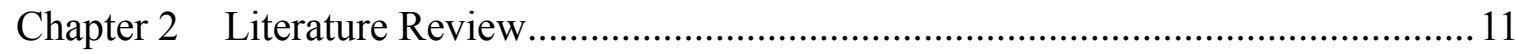

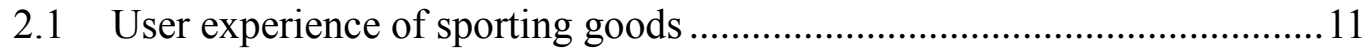

2.1.1 Emotions in sport .............................................................. 13

2.1.2 Emotions in user-product interaction........................................... 16

2.1.3 UX perspective on product emotions............................................ 19

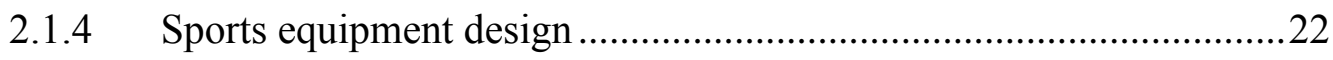

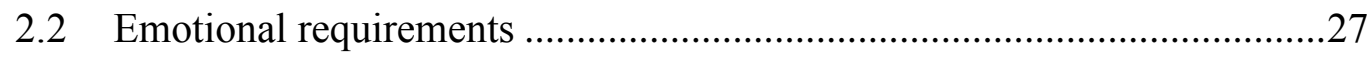

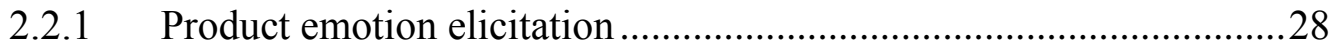

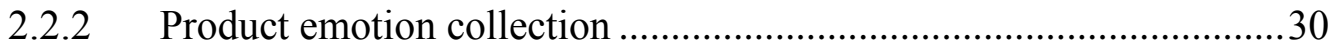

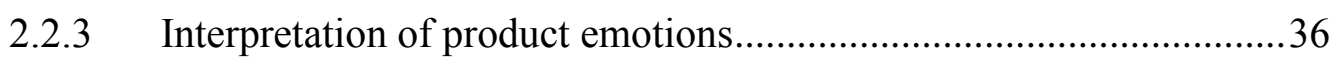

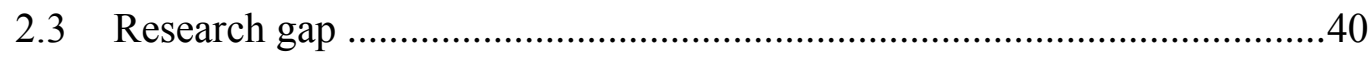

Chapter 3 The UX-based Collection Method …............................................................46

3.1 A conceptual model of cycling experience …........................................46

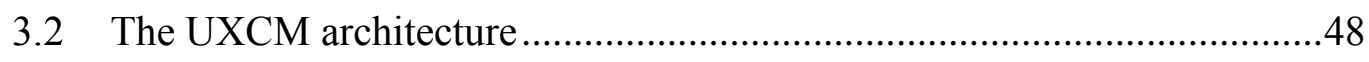

3.2.1 Temporality module .............................................................49

3.2.2 Multisensory module ............................................................. 51

3.3 Selecting the K-words for cycling experience ..................................52 


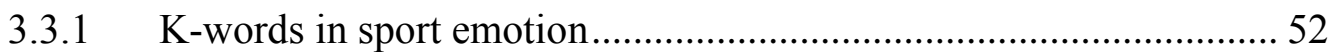

3.3.2 K-words in product personality .................................................... 56

3.3.3 A conceptual model of bicycle saddles experience ............................ 57

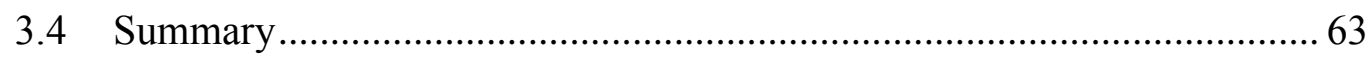

Chapter 4 Temporality of Vision-based Product Quality ................................................ 65

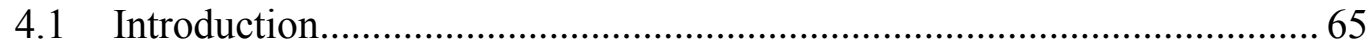

4.1.1 Perceived affordance and attractiveness.............................................. 66

4.1.2 Expert-Novice differences in eye movement .................................... 68

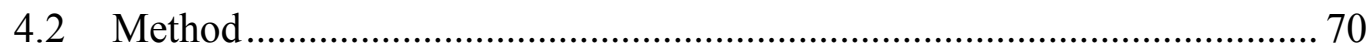

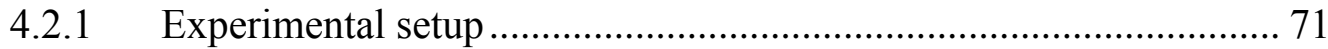

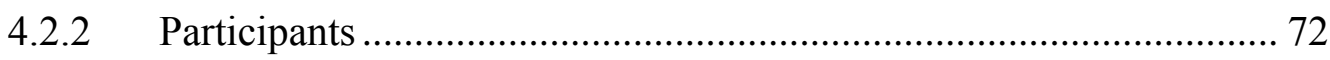

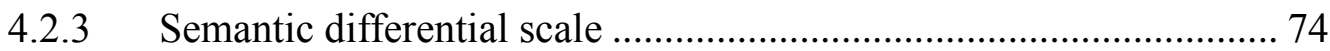

4.2.4 Procedure of eye-tracking experiment …………………………. 75

4.3 Results and discussion ..................................................................... 76

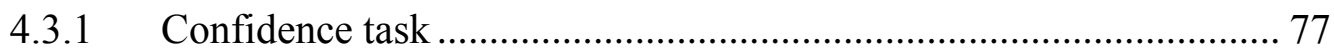

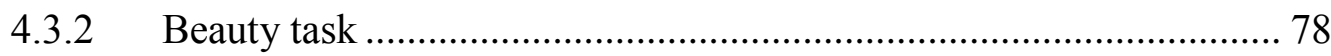

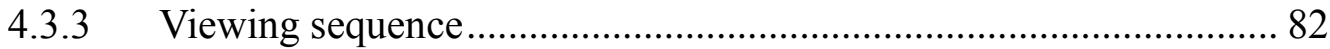

4.3.4 Perceived emotional intensity ..................................................... 82

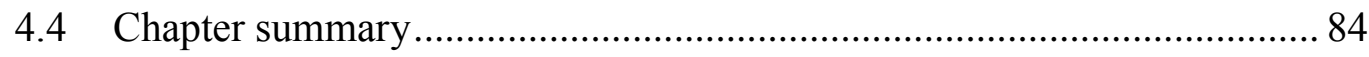

Chapter 5 Analysis of Multisensory Emotional Requirements....................................... 85

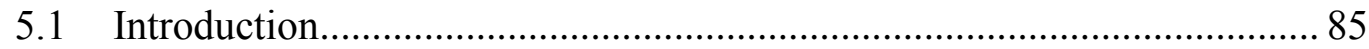

5.1.1 Subjective evaluation of sports equipment...................................... 86

5.1.2 Bicycle saddle and cycling comfort ................................................ 88

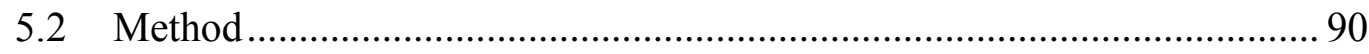

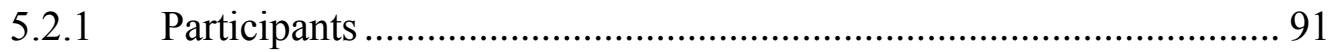

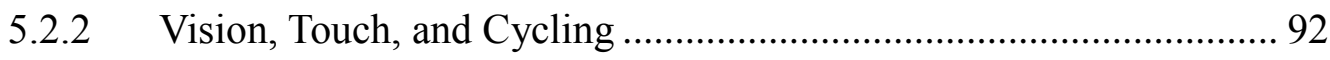

5.2.3 Bike fit protocol.......................................................................... 95

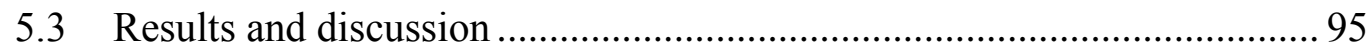

5.3.1 Multisensory perceptions ……………………............................... 96

5.3.2 Sports performance..................................................................... 100 


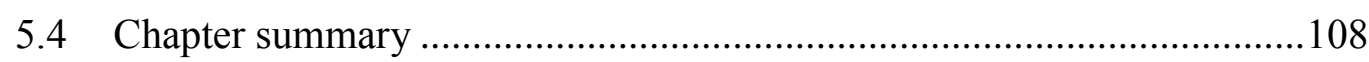

Chapter 6 Conclusions and Future Work ............................................................... 110

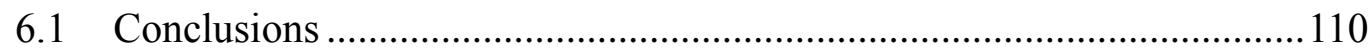

6.2 Limitations and future research ...................................................... 115

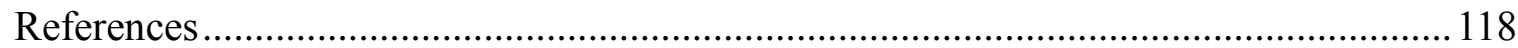

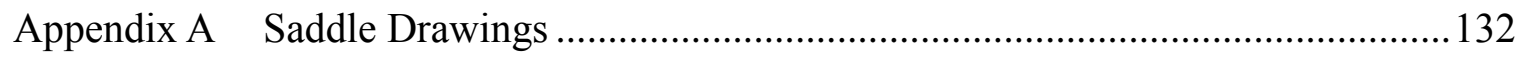

Appendix B Eye Tracking Experimental Data ..................................................... 136

Appendix C Semantic Differential Scale ............................................................ 144

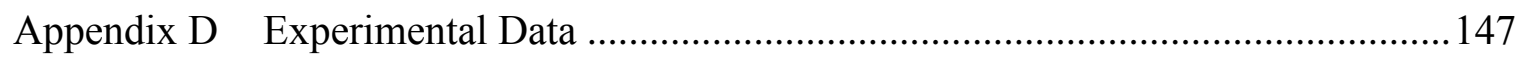

Appendix E A Review of Bike Sizing and Bike Fitting.......................................... 150 


\section{List of Figures}

Figure 1.1 The needs and goals of user experience.................................................... 4

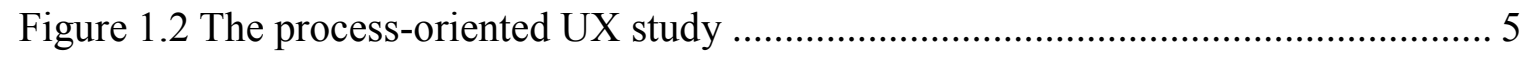

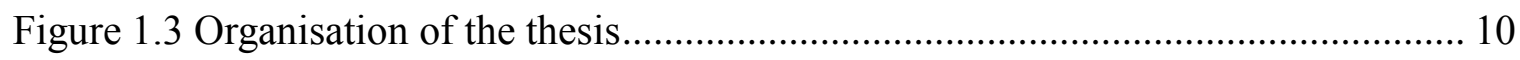

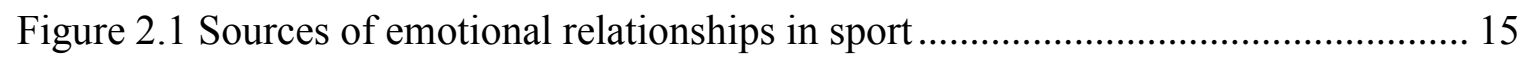

Figure 2.2 The elicitation process of product emotions ............................................. 16

Figure 2.3 The cyclist's anatomical points and contact areas ...................................... 24

Figure 2.4 The technical process of emotional requirements engineering ...................... 27

Figure 2.5 Example of semantic differential scale ....................................................... 34

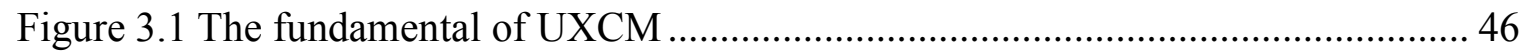

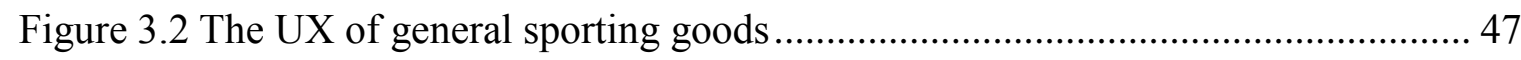

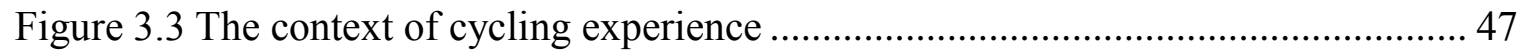

Figure 3.4 The proposed UX-based Collection Method (UXCM) ................................. 49

Figure 3.5 The number of selected riding purposes in UK and SG ............................. 53

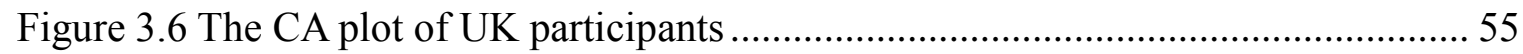

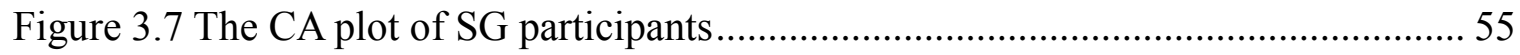

Figure 3.8 The conceptual model of bicycle saddles experience ................................... 62

Figure 4.1 The Areas of Interest (AOI) on each bicycle image..................................... 71

Figure 4.2 The Heat Map of fixation counts for four categories (example).................... 79

Figure 4.3 The Gaze Plot for four categories (example) .............................................. 80

Figure 4.4 Interval estimate of fixation counts/duration for four groups on bicycle parts 81

Figure 4.5 The bicycle images for B09 (left) and B31(right)..................................... 82

Figure 5.1 The top and the side view of two bicycle saddles..................................... 91

Figure 5.2 The environmental setup for cycling sessions ............................................. 94

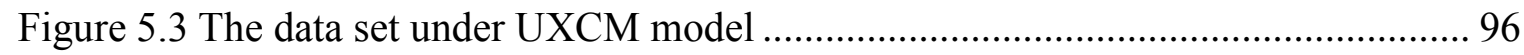

Figure 5.4 Estimated marginal means of K-SE competitive for two saddles................... 98

Figure 5.5 Estimated marginal means of selected K-SE for two saddles........................ 99

Figure 5.6 Estimated marginal means of selected K-PP for two saddles ....................... 100

Figure 5.7 The example of different riding styles for Saddle A drop position ............... 102

Figure 5.8 Estimated marginal means of selected K-SE through riding postures........... 105

Figure 5.9 Estimated marginal means of sports performance on Saddle A.................... 106 
Figure 5.10 Estimated marginal means of K-SE comfortable through perceptions ........107

Figure 5.11 Estimated marginal means of K-words for Saddle A and Saddle B ............109

Figure 6.1 The bike fit method from a joint angle and anthropometry perspective ........153 


\section{List of Tables}

Table 2.1 The semantic spaces in the literature .......................................................... 18

Table 2.2 Previous studies of comfort in sports equipment and sports experience........... 22

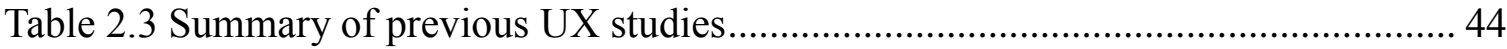

Table 2.4 Summary of previous UX studies (continued) .......................................... 45

Table 3.1 Questions to measure the cyclists' involvement level .................................. 50

Table 3.2 The adjectives describing positive emotions experienced by athletes ............. 52

Table 3.3 The shortlisted $20 \mathrm{~K}$-words for cycling experience..................................... 56

Table 3.4 The counts of words that participants used to describe their own saddles ........ 58

Table 3.5 The list of open-ended interview questions ................................................ 59

Table 4.1 The basic information about participants .............................................. 74

Table 4.2 Tests of between-subjects effects (fixation count)...................................... 76

Table 4.3 Tests of between-subjects effects (fixation duration) ................................... 76

Table 4.4 The comparison of fixation count and duration on bicycle parts .................... 77

Table 4.5 Tests of between-subjects effects (emotional intensity on B09) ..................... 83

Table 5.1 The product specification of two bicycle saddles........................................ 90

Table 5.2 The number of participants in each interaction .......................................... 91

Table 5.3 The p-value of the repeated measured ANOVA (vision, touch) ...................... 97

Table 5.4 The average cadence and power output on two saddles ............................... 101

Table 5.5 The p-value of three-way ANOVA for Saddle A (cycling) ............................ 103

Table 5.6 The p-value of three-way ANOVA for Saddle B (cycling)........................... 104

Table 6.1 Estimated marginal means of fixation count for four categories..................... 136

Table 6.2 Estimated marginal means of fixation duration for four categories ............... 137

Table 6.3 Estimated marginal means of $20 \mathrm{~K}$-words through perceptions for Saddle A 147

Table 6.4 Estimated marginal means of $20 \mathrm{~K}$-words through perceptions for Saddle B 148

Table 6.5 The sports performance for all participants ................................................ 149 


\section{List of Abbreviations}

$\begin{array}{ll}\text { UX } & \text { User Experience } \\ \text { UXCM } & \text { UX-based Collection Method } \\ \text { UCD } & \text { User Centred Design } \\ \text { SDS } & \text { New Product Development } \\ \text { RRC } & \text { Regulartic Differential Scale } \\ \text { HRC } & \text { High-involvement Road Cyclist } \\ \text { LRC } & \text { Low-involvement Road Cyclist } \\ \text { IPI } & \text { Individual Profile Index } \\ \text { KES } & \text { Kansei Engineering System } \\ \text { K-words } & \text { Kansei words } \\ \text { K-SE } & \text { K-words in Sport Emotion } \\ \text { K-PP } & \text { K-words in Product Personality }\end{array}$




\section{List of Publications}

- Kuo, J.Y., Chen, C.H., \& Roberts, J. (2017). The subjective impression of bicycle saddles in different contexts. In Proc. of the $24^{\text {th }}$ ISPE International Conference on Transdisciplinary Engineering (TE2017), pp. 303-310, Singapore, July 10-14, 2017. (The Best Paper Award of TE2017).

- Kuo, J.Y., Chen, C.H., \& Roberts, J. (2016). An elicitation technique for customer emotional requirements based on multisensory user experience. In Proc. of the $23^{\text {rd }}$ ISPE International Conference on Transdisciplinary Engineering (TE 2016), pp. 1081 1090, Curitiba, Brazil, October 4-7, 2016.

- Kuo, J.Y., Chen, C.H., \& Roberts, J. (2016). Perceived comfort on women's bicycle saddles. In Proc. of the $2^{\text {nd }}$ International Conference in Sports Science \& Technology, 5p, Singapore, December 12-13, 2016.

- Chang, D., Chen, C.H., \& Kuo, J.Y. (2016). A product conceptualization strategy based on crowd innovation. In Proc. of the $23^{\text {rd }}$ ISPE International Conference on Transdisciplinary Engineering (TE 2016), pp. 1038-1047, Curitiba, Brazil, October 47, 2016.

- Kuo, J.Y., Chen, C.H., Koyama, S., \& Roberts, J. (2014). Expert-novice differences in positive emotional demands of sports equipment: A case study of bicycle. In Proc. of the $1^{\text {st }}$ International Conference in Sports Science \& Technology, 6p, Singapore, December 11-12, 2014.

- Kuo, J.Y., Chen, C.H., \& Roberts, J. (2013). A framework for understanding the emotional impacts in virtual sport training. Virtual and Physical Prototyping, 8(4), 235239. 


\section{Abstract}

Contemporary customers seek products that meet their emotional needs as well as performing an anticipated function. The existing process of evaluating customers' emotional requirements in a Kansei engineering system (KES), however, cannot fully reflect the user experience (UX), particularly for those products that involve physical interactions. Therefore, the research aim of this thesis is to apply KES for sports equipment design using bicycles as a case study.

After conducting a thorough literature review and interviewing regular road cyclists, the thesis proposes a so-called UX-based collection method (UXCM). The UXCM consists of two modules, viz., temporal and multisensory, that represent the key UX characteristics. In addition to the qualitative interviews, an adapted semantic differential scale (SDS) and eye-tracking technique were applied to collect the customer's emotional requirements. The first case study of the visual impression of bicycle images was designed to test the hypothesis that cyclists' demands on cognitive-focused emotions (confidence) and affective-focused emotions (beauty) will change as their levels of involvement increased over time. The second case study investigated the impact of multisensory perceptions on Kansei words (K-words) among high-involvement road cyclists (HRC) and lowinvolvement road cyclists (LRC) using two bicycle saddle designs.

The outcomes of this research include: (i) a K-words database covering two semantic spaces, viz., K-words in sport emotion (K-SE) and K-words in product personality (K-PP) for cycling experience; (ii) a conceptual UX model of bicycle saddle experience; the empirical evidence by which (iii) a customer's overall impression towards a bicycle did not change with one's increased involvement while functional components appealed more 
to experts than to novice cyclists; (iv) a list of emotional requirements on bicycle components; (v) an understanding that the visual appearance of bicycle saddles differently affect the physical performance of HRCs and LRCs; and (vi) it finds that cyclists' riding postures also contribute to certain product emotions depending on the nature of the saddle.

Because the UXCM rectifies the process of selecting representative K-words, the results of this research can help designers collect a customer's emotional requirements through a valid UX evaluation to support the new product development (NPD) of sporting goods. More importantly, the present findings show that comfort is only one of the subjective feelings that affect an athlete's physical performance in terms of sports equipment design. Designing a bicycle component with more types of positive emotions (e.g., competitiveness) for different market segments would benefit the bicycle industry. 


\section{Chapter 1 Introduction}

This chapter begins by introducing the background of user experience (UX), and follows with a description of its benefits in new product design and development. The chapter then states the research motivation and the scope (Section 1.2), the research aim and the objectives (Section 1.3) along with its significance (Section 1.4). It concludes with a summary of the structure of this thesis (Section 1.5).

\subsection{Background}

The study of user experience (UX) has enjoyed great interest for product designers because the advantage it brings to new product development (NPD). UX was first introduced in the late 1990s as a reflection of the evolution of design studies. Its current focus has shifted from making products work functionally to shaping users' experiences of pleasures through a product, service or system (Norman, 2002). Due to the progression of manufacturing technology, industrial designers can now create reliable and durable models efficiently. Even so, research has shown that nearly half of returned products are actually well-functioning (den Ouden, Yuan, Sonnemans, \& Brombacher, 2006), and it is of importance to have the capability to develop value-added products for commercial success (Ernst, 2002). The growing demand for value-added products has steadily compelled designers to utilise advanced approaches when creating commodities to ensure that those items are not only functional and shaped well but that they can also bring pleasure and reflect customers' personal values. To address this problem, designers need to answer: How does a customer favour one design over another? 
The spirit of UX submits that humans are not just information processors, and any evaluation of human actions/emotions should first consider the eliciting stimulus (e.g., motivations). A cyclist, for example, who intends to compete in a race, may select a different riding posture from those who primarily use a bike to travel to the shop. If a product meets a customer's exact expectations (affordance), the product would elicit a positive first impression and the user would enjoy it more. This notion applies both to product functionality and to emotional preference. Even though various models in a product family (e.g., saddles) can fulfil the same cognitive requirement (e.g., durability), appearances can elicit different impressions emotionally.

Before the emergence of UX as a field of study, several similar design methodologies have been developed, including user-centred design (UCD), which supports design decisions according to a user's expectations of functional requirements and emotional needs. In comparison with UCD, the study of UX extends the user's everyday experiences to the contextual and socio-cultural levels (Marcus, 2006). In other words, it encourages designers to focus on scenario planning, and it investigates product experience as a series of continuous actions (e.g., using a website to buy costumes for Halloween). The 'experience' aspect of user experience uses a rich term that can mix various definitions; it can refer to the practical skills a person acquires over time, an after-impression one possesses about objects or events, or it can simply express how one feels at a certain moment. Despite disagreement on the nature of UX, in the field of product design and development, this thesis understands a pleasurable user experience (UX) as an overall impression of product satisfaction. 


\section{$\underline{\text { User-oriented/phenomenon }}$}

Generally, there are two facets to the study of UX. First, a user-oriented UX study aims to help designers comprehend users' behaviours and the reasons users act in a specific way or make certain decisions. Researchers have proposed several theoretical models; for example, the UX hierarchy-of-needs model (Anderson, 2011), which derives from Maslow's pyramid (Maslow, Frager, Fadiman, McReynolds, \& Cox, 1970), shows that within the context of one task a user's needs can be fulfilled at various levels, such as functional, reliable, usable, convenient, pleasurable and meaningful (Figure 1.1). According to the activity theory, human behaviour is caused, motivated and driven by inherent consciousness (Kuutti, 1996). The behaviours can be further defined by distinct goal-directed levels as shown in Figure 1.1. The motor-goals, for instance, refer to how the action is operated, and do-goals refer to what the user's action is. In the field of product design, motor-goals and do-goals are often related to pragmatic quality (Hassenzahl, 2004). In contrast, the be-goals (the hedonic quality) is related to why the user is motivated, which is also closely connected to personal identification (Carver \& Scheier, 2001).

For many years, usability evaluation (e.g., a cognitive evaluation of the task completion time or error rate) was considered the sole requirement of a recognisable and reliable human-computer interaction. A meta-analysis study (Hornbæk \& Law, 2007), however, pointed out that task completion time does not always have a significant correlative relationship with a user's satisfaction. The phrase 'what is beautiful is usableô suggests that aesthetic quality can promote product usability (Sonderegger \& Sauer, 2010; Tractinsky, Katz, \& Ikar, 2000; Tuch, Roth, Hornbæk, Opwis, \& Bargas-Avila, 2012). The phrase recalls that product experience is mixed with visceral, behavioural and reflective 
levels (Norman, 2004). Sometimes the reflective feelings matter more. For instance, the small souvenir a customer buys on a family trip is designed to trigger a meaningful experience and its functionality may have little impact on the customer's satisfaction (Figure 1.1).

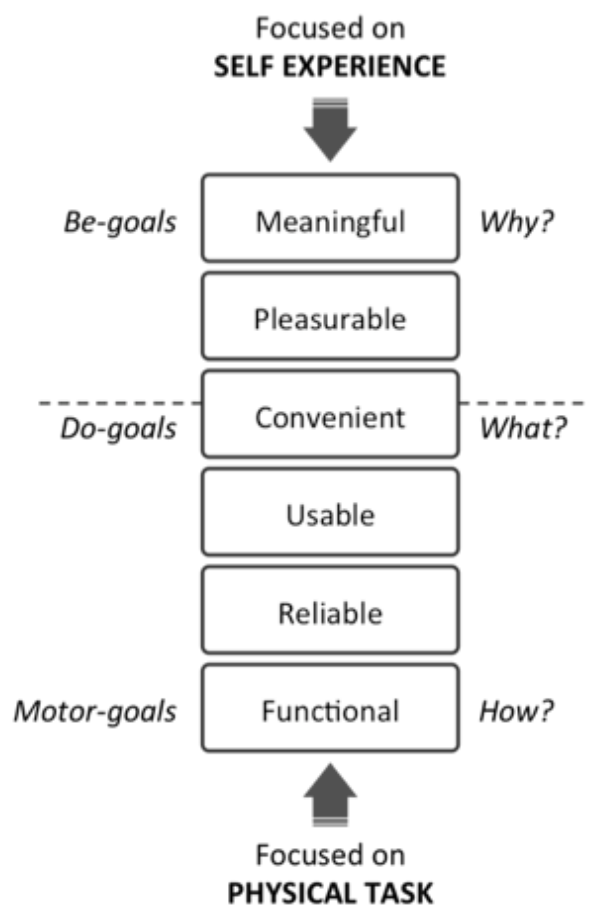

Figure 1.1 The needs and goals of user experience

Adapted from (Anderson, 2011; Carver \& Scheier, 2001)

In general, a UX study assists a designer to ask the relevant questions and to find the correct solutions. It facilitates the identification and illustration of a context model that will help a designer empathise with a user's attitude towards products (particularly for her or his ambiguous and psychological needs).

\section{Process-oriented/practice}

A UX investigation is not limited to one person but can represent a group of people. Therefore, a process-oriented UX study may be driven by new product development (NPD) in order to apply best practices to the industry (Figure 1.2). Using the UX techniques in 
support of NPD can help designers better capture customer expectations and preferences prior to production in addition to reducing cost (Bias \& Mayhew, 2005) and enhancing user satisfaction (Kujala, 2003). The techniques involve the iterative process utilising a systematic approach to managing customer's requirements, generate innovative ideas, and evaluate design solutions. Three basic stages are covered in the requirement management: elicitation, collection and interpretation.

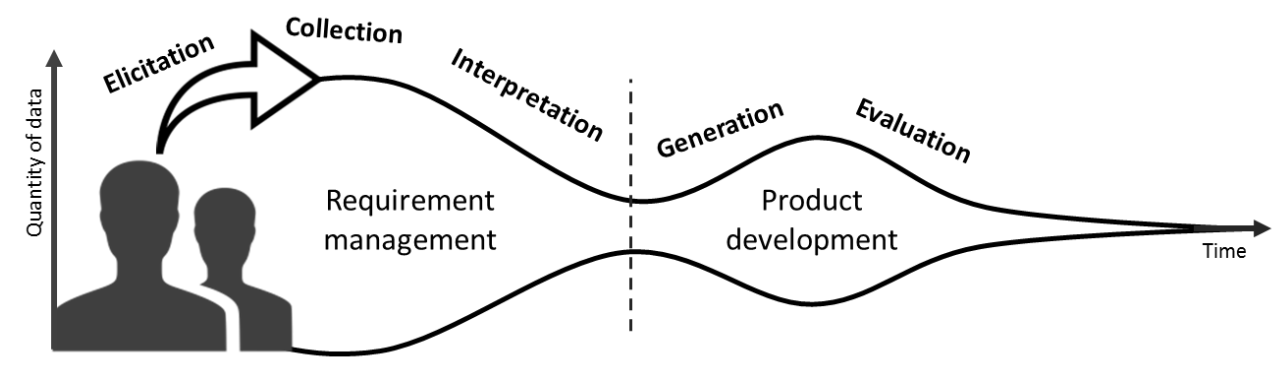

Figure 1.2 The process-oriented UX study

At the early stage of elicitation, customers are given the opportunity to express themselves and actively communicate with the designers. However, the initial UX content retrieved from users' stories is often raw, extensive and complicated because it is presented in a narrative format. Accordingly, many UX tools including qualitative and quantitative methods have been developed. For example, Kansei ${ }^{1}$ engineering system (KES) is a methodology translating customer emotional needs into functional properties (Nagamachi, 2002). More details will be discussed in Section 2.2.

\subsection{Research motivation and the scope}

As mentioned, the study of UX has proven to be a promising design methodology for handling useful and meaningful customer requirements in new product development (NPD). Instead of treating a user as a processor of the information - that is, one who responds only

\footnotetext{
${ }^{1}$ Kansei refers to the human feelings in Japanese.
} 
after receiving external stimulus - the UX study 'proposes a strong notion of mediationall human experience is shaped by the tools and sign systems we useô(Nardi, 1996). However, translating the UX information into a Kansei engineering system (KES) can be a challenging task because the emotional experiences triggered by a product are not as straightforward as the functional requirement. For example, if the customers want a lightweight bicycle, the design goal is obvious and clear to evaluate (e.g., weight measurement). A friendly bicycle, on the other hand, could imply a want for a comfortable saddle or smooth gear shifting or it could signal a wish for easy-to-carry on a train.

There are hundreds of product categories and every category has a unique pattern of user-product interaction. Can a typical UX approach apply to all types of products when different human perceptions dominate the product experience? For instance, customers might ask for a soft bicycle saddle (touch) whereas the screen interface is more important for a tablet (vision). After reviewing a number of UX studies (Table 2.3 and Table 2.4), this author noticed that the majority of KES studies based evaluation on visual perception only, leaving the structure of product emotions unclear for selecting the representative Kansei words. These gaps should be addressed by proposing a conceptual UX model to apprehend the key factors in a UX evaluation when the tangible products act as facilitators that trigger a user's behavioural and emotional reactions. Therefore, the proposed UXbased collection model (UXCM) will focus on the semantic domain of KES (Figure 3.4). It will analyse two UX characteristics (temporality and multisensory) identified from the literature.

This study will focus on sports equipment design. It specifically investigates the affective properties of sporting goods based on cycling experience. The bicycle provides a case study of sporting goods for two reasons. First, cycling is a physical activity that attracts 
a wide range of customers, and a growing cycling population around the world suggests different levels of involvement in sports participation (Bailey et al., 2010). This study will mainly collect regular road cyclists' (RRCs) emotional requirements for the UX of road bikes, which are designed for use on paved roads or racing tracks to provide greater stability whilst sitting on the saddle. Secondly, a bicycle contains many parts (such as the saddle and wheels) that can be customised to meet a cyclist's requirements. Preferences for certain parts may result not only form visual likings but also from requirements for physical performance. This process of product personalisation can help users develop more emotional attachment with a product (Mugge, Schoormans, \& Schifferstein, 2009), which makes the cycling experience a suitable emotional input for KES in this study. 


\subsection{Research aim and the objectives}

The aim of this research is to apply the Kansei engineering system (KES) for sports equipment design using cycling experience as a case study. The objectives are:

1) A thorough review of the UX of sports equipment and an analysis of research gaps are presented to identify the shortcomings within existing KES research.

2) Validate the proposed UX-based collection method (UXCM) on whether a user's temporal and multisensory experience affect Kansei words evaluation at the early stage of KES.

3) An eye-tracking experiment is designed to test the hypothesis that customers with a higher level of involvement (temporal experience) have different end-user experience for sporting goods requesting more cognitive-focused emotions (confidence).

4) A case study of bicycle saddle design demonstrates the UX-based collection method with three different user-product interactions (multisensory experience) with respect to the Kansei words in two semantic spaces (Sport Emotion and Product Personality).

5) Validate the hypothesis that positive emotions evoked by sports equipment can improve an athlete's physical performance. 


\subsection{Significance}

The fulfilment of the research objectives will contribute towards the field of new product development. The proposed original UX-based collection method (UXCM) can integrate the temporal and multisensory characteristics of product experience, and demonstrate the new applicability of a Kansei engineering system (KES). It provides information on the quality issue of emotional input in a KES, particularly on the semantic domain, which is critical in a UX evaluation for collecting the customer emotional requirements.

As the continued growth of the sports industry also requires innovation in sports equipment design (PwC, 2016), this study provides an understanding of its emotional impact on an athlete's performance. The results of the experiments promise to heighten manufacturer awareness about creating products that satisfy not only athletes' physical comfort, but also other positive product impressions (such as confidence, beauty, competitiveness, pride) as emotional resources in a sporting activity.

\subsection{Organisation of the thesis}

Figure 1.3 illustrates the organisation of the thesis and its division into six main sections. Chapter 1 begins with a brief introduction of user experience as an object of study. Based on the literature review in Chapter 2, the research problems are identified. Next, Chapter 3 outlines the UX of sporting goods in a conceptual model. Subsequently, two case studies of cycling experience are presented in Chapter 4 and Chapter 5, respectively. Finally, Chapter 6 discusses the conclusions and future developments. 


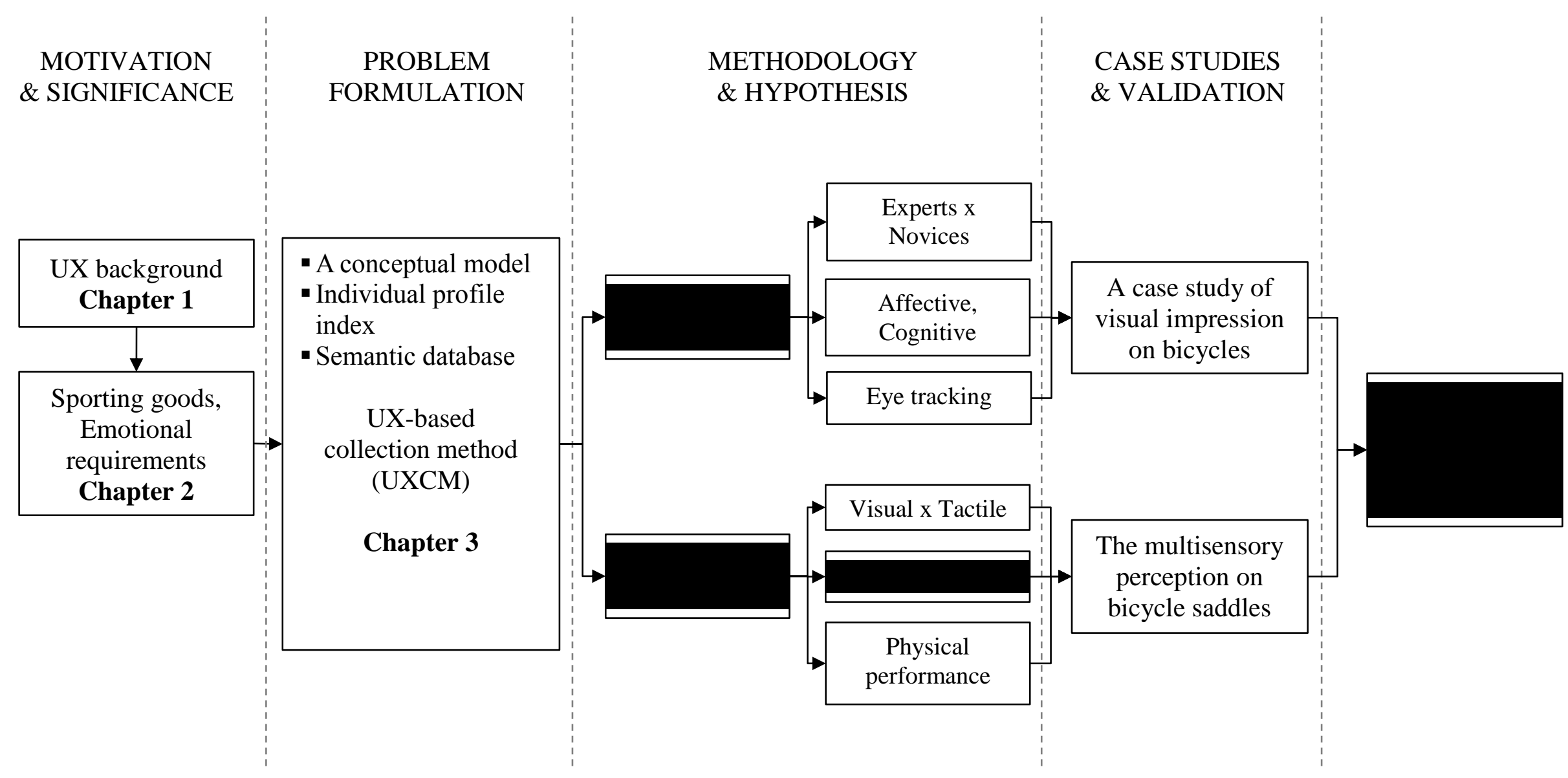

Figure 1.3 Organisation of the thesis 


\section{Chapter 2 Literature Review}

This chapter reviews the state-of-the-art research on the UX of sporting goods. It is divided into three sections. The first part (Section 2.1) defined product experience in sport, the emotions in a user-product interaction, and sports equipment design from a multisensory perspective. Section 2.2 then reviews the existing methodologies and applications of analysing emotional requirements stage by stage, namely elicitation, collection, and interpretation. Finally, the research gaps are identified in Section 2.3.

\subsection{User experience of sporting goods}

First, the section discusses the fundamentals of sports experience and indicates the UX differences among product categories. Currently, the discussion of product experience revolves around the concept of affordance. The term affordance was coined by Gibson (1978), and it has become the predominant approach since Norman (1988) introduced it to the realm of design psychology. Gibson (1978) proposed this concept to explain how the features of objects influence human perception. When an object's physical appearance (e.g., a large round-shaped rock) can afford the human intention (e.g., to sit down), the human will perceive its affordance and act it out (e.g., afford to be seated). Some researchers think that the concept of affordance should be extended to support other psychological needs too (Pucillo \& Cascini, 2014; Still \& Dark, 2013); for example, the look of a beach chair should afford the user to feel relaxed. Designers advocate this concept because they believe that a user should be able to enjoy a product that provides good affordance for reducing rookie mistakes via intuitive interactions. Moreover, customers can lose interest in a very short time based on their first impression of a product. In the field of human-computer interaction 
(HCI), for example, users only take 50 milliseconds to form a good/bad impression of a desktop interface (Lindgaard, Fernandes, Dudek, \& Brown, 2006) or a mobile interface (Miniukovich \& De Angeli, 2014).

However, the concept of affordance does not seem to fully match the sports experience. Sporting goods are by definition designed for a sporting activity. Since customers buy the product to carry out a motor skill, an effortless first movement (small working memory) may not be attractive to them. The product is expected to gradually coordinate with a user's arms, legs, and body regardless of whether the customer is a beginner or an expert. The other distinction between the UX of consumer goods and sporting goods is how a user's needs and expectations change before, during, and after the interaction (Hassenzahl \& Tractinsky, 2006). A good first impression due to an intuitive interaction with a product does not always promise that the latter will grow on the user in the long run. Some researchers have therefore suggested that a comprehensive UX study needs to be conducted in a chronological order (Kujala, Roto, Vaananen-Vainio-Mattila, Karapanos, \& Sinnela, 2011) to treat the user-product interaction as a progressive, continuous, and long-term strategy. For instance, the more time users spend on the consumer product, the less they may be dependent on its functional features, and the more they may start looking for emotional attachment (Karapanos, 2013) or a surprising experience.

On the other hand, the sports experience involves an athlete's journey of learning the required skills in a sporting activity. According to the model of long-term athlete development, before their retirement, athletes will experience several phases of skill development from fundamental to learning to play and practice, training to train, training to compete, and training to win (Balyi, Way, \& Higgs, 2013). It takes an average of 10 
years' deliberate training for one person to reach expert performance (Ericsson, Krampe, \& Tesch-Römer, 1993). The majority of research on sports science follows this trend and aims to train athletes to act faster, jump higher, and be stronger. As players practice and adjust their postures to maximise physical performance day after day, their physiological training plans, personal health conditions, and emotional preferences will also change over time (Smith, 2003). In comparison with the UX of consumer products, athletes may not be interested in a surprising product experience, but may seek an emotional incentive to maintain their involvement.

\subsubsection{Emotionsin sport}

Before discussing the impact of emotions in sports experience, the following is a note on the terminology of affect, mood, and emotion. Theoretically, affect is a broader domain that encompasses one's feelings, mood, and emotion. Mood is a state that has a relatively longer duration than an emotion, which is triggered by a stimulus event (Ekkekakis, 2012). For instance, an injured athlete can remain in a bad mood for some time, whereas the joy of celebrating the winning moment happens quickly. The terminology above is common and used interchangeably in many studies, but the definition of emotion best fits the objective of this research.

There are two major theories of emotion. Some researchers believe that human beings are born with several basic/primary emotions such as anger, happiness, surprise, disgust, sadness, and fear (Ekman, 1999; Ekman \& Friesen, 1971). These function as irreducible building blocks that blend together to form other secondary or tertiary emotions, such as disappointment. On the other hand, the dimensional emotion theorists focus on the intensity of emotions (i.e., arousal) and its valence, such as pleasure/displeasure (Barrett, 1998; 
Russell, 1980; Solomon, 2002). Human emotions are highly diverse and complicated, yet researchers used to focus only on the impact of negative emotions in curing mental illness. Likewise, in the field of sport and exercise psychology, researchers have investigated how elite athletes deal with stress and anxiety or strengthen their emotional regulation skills under high pressure (Jones, 2003; Woodcock, Cumming, Duda, \& Sharp, 2012; Woodman \& Hardy, 2003). For example, Hagtvet and Hanin (2007) proposed a model of the individual zone of optimal functioning (IZOF) to explain the effect of individual interpretation on different anxiety levels. For an athlete, seeing tough competition as a challenge rather than a threat can have different consequences in terms of emotional responses, physiological responses, and sports performance (Jones, 2003; Jones, Meijen, McCarthy, \& Sheffield, 2009).

More recently, researchers have started to notice the benefits of positive emotions in sport; negative and positive emotions are not equivalent to 'bad' and 'good', and both play a large part in competitive sports (Lazarus, 2000; Solomon \& Stone, 2002). Considering that positive emotions can inspire human beings to search for resources and explore opportunities, athletes' positive emotional status can influence their information processing cognitive ability (Laborde \& Raab, 2013; Lench, Flores, \& Bench, 2011). Moreover, such change in an athlete's attention or working memory can help him or her act more efficiently and perform high-intensity exercises (Baron, Moullan, Deruelle, \& Noakes, 2011).

Nevertheless, the emotional relationship between athletes and sporting goods in sports experience has been overlooked in the literature. The sources of emotions in a sporting activity are illustrated by the author in Figure 2.1. The right side shows research topics that address mental preparation, such as imagery technique (Martin, Moritz, \& Hall, 
1999); and athlete-athlete (Totterdell, 2000) and coach-athlete relationships (Nieuwenhuys, Hanin, \& Bakker, 2008).

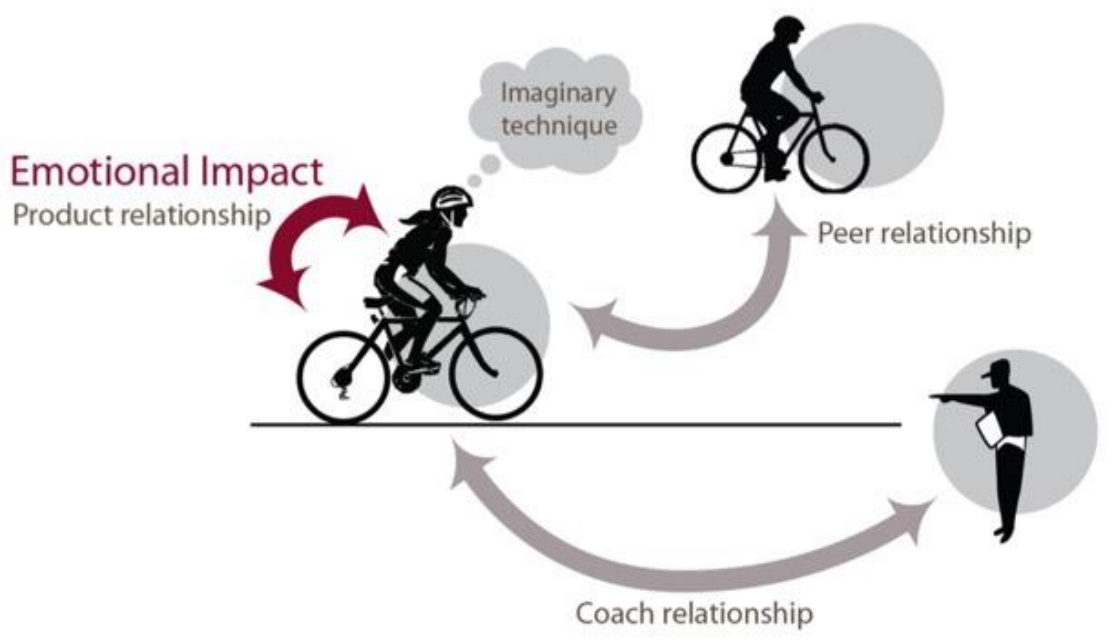

Figure 2.1 Sources of emotional relationships in sport

The left side in Figure 2.1 highlights the emotional impact between athletes and sporting goods. In the field of sport psychology, studies have shown that athletes can 'earn' positive emotions in events, like winning a gold medal or listening to music, but a limited number of studies discuss the impact of positive emotions evoked by an artefact (sports equipment). Many sports involve a tangible product, such as a tennis racket or a golf putter. In fact, many elite athletes choose a particular piece of sports equipment due to a psychological dependency instead of its functional properties (Damisch, Stoberock, \& Mussweiler, 2010). In addition, positive emotions in sports experience are not exclusive to professional players, as both experts and novices can experience enjoyment in sports activities (McCarthy \& Jones, 2007). In a case study of cycling, wearing a helmet could bring recreational cyclists the feelings of calm and relaxation, and led the professional cyclists to feel safer (Ross, Ross, Rahman, \& Cataldo, 2010). 


\subsubsection{Emotions in user-product interaction}

In this study, the emotions evoked by a user-product interaction are called product emotions. According to the cognitive structure of emotions, every emotion is a reaction to an event, agent, and object (Ortony, 1990). Users examine the stimuli of a product and decide whether their emotions will be activated when the condition allows it. The elicitation of conditions can be very subjective. As shown in Figure 2.2, the author claims that the appraisal process in a user's mind is associated with affective and cognitive aspects, and multiple product emotions can be evoked simultaneously. The affective appraisal is based on individual preference such as colour and style, while the cognitive appraisal is related to its functionality, such as ease of use. Considering the diversity of individual needs, it seems impossible for designers to predict which product emotions will be evoked.

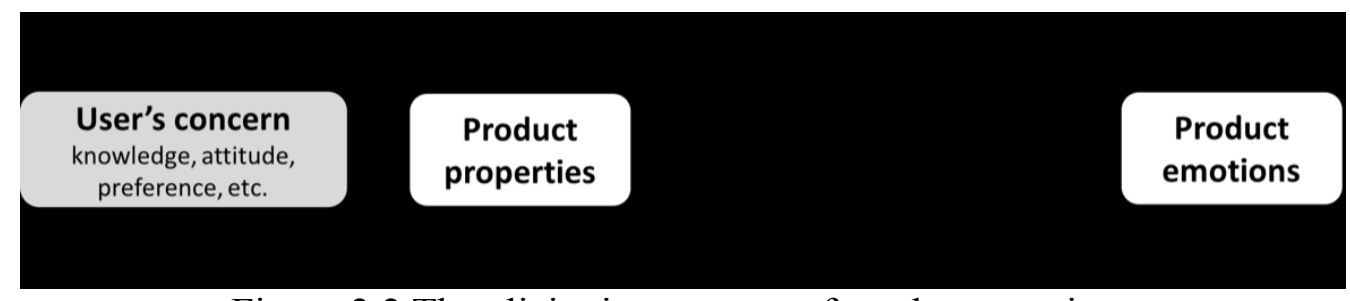

Figure 2.2 The elicitation process of product emotions

However, it is a design strategy to attract more customers by eliciting a positive emotion (e.g., fun) during new product development. Instead of designing the product emotions for an individual, the product can be designed for a group of customers who share similar motivations and goals (i.e., a market segment). Therefore, designers need to consider social-cultural aspects when designing product emotions (Desmet \& Hekkert, 2007). On the other hand, in contrast to eliciting attractive product emotions, it can be helpful to disturb users in some situations. For instance, with products that require extra caution, such as medical devices, the elicitation of a few warning emotions can prevent 
errors and adverse outcomes. Again, this suggests that the investigation of product emotions must always consider the influence of product categories.

It is difficult to define product emotions in comparison to basic human emotions. The latter can also be observed in non-human animals, hence they can be found in primitive means of communication (e.g., non-verbal facial expressions). Alternatively, researchers have collected the words that customers use to describe their feelings about products. Here the author refers to Nagamachi (2002)'s work and calls those descriptors Kansei words (Kwords). The following are some examples:

ๆ Wearing a new suit gives me more confidence.

ๆ I have fun and feel free on the bike.

ๆ I am relaxed sitting in this armchair.

ๆ The gold medal reminds me of how proud and happy I was.

ๆ That toy is safe for my kids.

Some K-words do not technically belong to the category of human emotions because humans tend to anthropomorphise artefacts and read emotional responses from them (Guthrie, 1995). In other words, users use human personality characteristics to describe products (Desmet, Nicolás, \& Schoormans, 2008). When a product is treated as a human, it is a sign of the customer feeling intimacy and enjoyment. This tendency is not only applied to products shaped like human/faces, but also to their pattern of movement (Merchel, Altinsoy, \& Stamm, 2012; Tremoulet \& Feldman, 2000). Some examples of product personality are as follows:

П The wallpaper patterns are lively.

ๆ The kettle is friendly.

П I prefer the traditional package.

I I like the cute shape of the bottle. 
ๆ The car has an honest look.

At this point, the list of K-words could be very long since researchers have combined all possible words in terms of product emotions and product personality. To find the representative K-words, many statistical methods have been applied to identify the semantic spaces (more details in Section 2.2.3). As shown in Table 2.1, for instance, Desmet, Overbeeke, and Tax (2001) used factor analysis to propose three key sources of product emotions: attitudes, goals, and standards. However, the terminology of semantic spaces varies greatly between projects. When K. A. Hsiao and Chen (2006) compared 28 bipolar adjectives between three different product categories (car, sofa, kettle), they extracted four different semantic spaces (trend, potency emotion, complexity).

Table 2.1 The semantic spaces in the literature

\begin{tabular}{lllll}
\hline Authors & Desmet (2012) & $\begin{array}{l}\text { K. A. Hsiao and } \\
\text { Chen (2006) }\end{array}$ & $\begin{array}{l}\text { Desmet et al. } \\
(2001)\end{array}$ & Osgood (1957) \\
\hline $\begin{array}{l}\text { Product } \\
\text { categories }\end{array}$ & 24 articles & Car, sofa, kettle & Mobile phone & Texts \\
\hline Semantic spaces & Activity & $\begin{array}{l}\text { Potency } \\
\text { Trend }\end{array}$ & $\begin{array}{l}\text { Attitudes } \\
\text { Goals }\end{array}$ & $\begin{array}{l}\text { Evaluation } \\
\text { Potency } \\
\text { Object }\end{array}$ \\
& $\begin{array}{l}\text { Interaction } \\
\text { Meaning }\end{array}$ & $\begin{array}{l}\text { Complion } \\
\text { Self }\end{array}$ & Standards & Activity \\
& Other people & & & \\
\hline
\end{tabular}

On the other hand, some researchers have excluded 'non-emotions' from their semantic database. Desmet (2012) reviewed 24 articles, listed 385 positive emotion words, and clustered them into 25 main emotion types with six sources of emotions (activity, object, interaction, meaning, self and other people). Furthermore, Desmet (2012) also provided several examples of how products evoke each emotion type. Since the initial database of K-words was collected from a user's narrative, the way humans think and express themselves might help designers understand the mechanism of product emotions too. 
Experience is a continuous even: for example, when asked to share opinions on sports equipment, users may comment on the product appearance (present), recall their impression of older models (past), or anticipate health and fitness gains (future).

\subsubsection{UX perspective on product emotions}

Imagine the UX of driving a new car. The driver hears the sound of engine starting, feels the texture of the steering wheel, and is fascinated by the smell of new leather seats. As human beings, we live in a multisensory environment and gather everything around us to generate an impression of our world (Hassenzahl, 2010). When we sense something, a signal goes to our brain, and it is not until our mind recognises and interprets that signal that a perceptual process is completed. In this regard, the commonly held definition of human senses is vision (V), audition (A), tactility (T), olfaction (O), and gustation (G).

Each human sense can dominate certain product emotions, but it may vary among product categories. For instance, cutlery that fits comfortably in our hand makes us feel safe through its tactility, but a feeling of safety may be also elicited through auditory feedback, as with the car engine (Schifferstein, 2006). Vision is often considered to be the most important sensation, but the dominant sense might differ between genders (Peck \& Childers, 2003) and cultures (Classen, 1993). Moreover, the dominant sense may shift over time. Fenko, Schifferstein, and Hekkert (2010) conducted a content analysis to generalise the effect of affect, modality, and time on user experience among 93 product categories. They found that both visual and tactile experience contributed most to a pleasant product experience, while the importance of visual perception decreased significantly after buying.

The effect of interaction time is also related to a user's perception of the importance of product emotion types (e.g., cognitive and affective). In a six-month investigation of 
new mobile phones, customers first expressed their feelings about the exciting and creative features, then shifted to features regarding learnability, such as a clear and easy-to-follow interface (Karapanos, 2013; Karapanos, Zimmerman, Forlizzi, \& Martens, 2010). In contrast, in other studies, customers considered the perceived pragmatic quality over the hedonic quality at the early stage of interaction (Hassenzahl, 2004; Norman, 2004). These inconsistent findings may be caused by the choice of product categories, as suggested by Hassenzahl (2004) and Lin and Lu (2007), considering that users are more likely to develop emotional attachment to a product that belongs to them. Therefore, the product becomes more meaningful after some time (Mugge, Schoormans, et al., 2009; Norman, 2004).

Activating a user's feeling does not always involve the dominant sense (Schifferstein, 2006; Spence \& Zampini, 2006). The human brain is a fundamentally multisensory organ and all human senses support one another (e.g., synaesthesia). Hence, it is possible to differentiate between metal and wood through auditory cues created by tapping their surfaces, or to see a material's roughness without touching it (Fujisaki, Tokita, \& Kariya, 2015; Jakesch, Zachhuber, Leder, Spingler, \& Carbon, 2011; Tiest \& Kappers, 2007). This phenomenon can also occur in a user-product interaction: in a case study of using electric toothbrushes (Spence \& Zampini, 2006), a user's tactile perception was affected (feeling rougher) when the auditory feedback changed (the volume increased).

When researchers investigate a multimodal system, a timeline-based affective curve can help visualise and detect users' attention with respect to relevant emotional arousal and valence (Donohue, Woldorff, \& Mitroff, 2010; Hanjalic \& Xu, 2005; Kujala et al., 2011; Schuller et al., 2009). In fact, a considerable amount of research has examined multisensory perceptions in terms of the nervous system, such as event-related potential (ERP) evidence (Calvert, Spence, \& Stein, 2004; Shimojo \& Shams, 2001), but the methods of inducing 
emotions (e.g., films, pictures, or a piece of wood/plastic) in those studies cannot fully represent an interactive product.

On the other hand, the topic of multisensory feedback in sports training has been thoroughly investigated. Athletes rely heavily on timely instructive guidance to adjust their postures; in general, the more complex the action is, the more frequent the feedback should be. However, in their review, Sigrist, Rauter, Riener, and Wolf (2013) note that different types of augmented feedback can increase optimal motor learning according to the task complexity. For instance, terminal visual feedback and auditory movement signification are more efficient than concurrent visual feedback for simple skills. Simple skills are those in which a cyclic motion is repeated, such as road cycling, while gymnastics is a complex action. Unfortunately, these findings on multisensory feedback are mainly based on the external environment, and not the sports equipment.

Due to lack of user-product interaction, other human senses (e.g., hunger) have been excluded from this research. However, the kinaesthetic sense is critical in sports, because athletes use their memory of previous experiences to judge the quality of their current body movements. Such awareness is good for practising motor skills that require muscle memory (e.g., swinging a baseball bat). It should be noted that human body movement can also convey an impression, as a ballet dancer can perform an elegant move. This phenomenon (kinaesthetic) can also apply to a user's action towards a product. For example, a significant relationship was found between the product personality (e.g., lively) and interaction type (seeing, using) when users chose a water bottle (Chowdhury, Karmakar, Reddy, Ghosh, \& Chakrabarti, 2014). However, this finding contradicts Desmet et al. (2008)'s study on a customised device, in which the researchers argue that the visual appearance of an object 
has more influence on product personality (elegant, dominant) than the kinaesthetic interaction.

\subsubsection{Sports equipment design}

Customers nowadays are given many choices in the sports equipment market. To stand out from competitors, manufacturers invest in innovative sports technology, such as advanced materials or techniques with which to produce products. Previously, the research and development in sports equipment design served only elite athletes focusing on practical issues (e.g., ergonomics) to act faster, safer and stronger, and not to those who participated in sports for fun or health (Bailey et al., 2010; Maximilian, Veit, \& Udo, 2007). However, whether players intend to wear or use the product for recreational or professional purpose, they will choose whatever feels most comfortable so they can enjoy it (McCarthy \& Jones, 2007).

The feeling of comfort is not easy to identify because researchers are only able to detect the discomfort threshold when it reaches the point of distracting a player's actions. This threshold is not an on-off switch. If the players intend to endure physical exertion during training, they may not notice the discomfort immediately. Moreover, there is no universal definition of comfort in sports equipment. As shown in

Table 2.2, several factors have been investigated regarding comfort in sports equipment or during the sports experience. Following the concept of UX, the author has reviewed the role of product, individual, and environment in these studies, and marked the relevant human perceptions accordingly with visual (V), tactile (T), auditory (A), and kinaesthetic $(\mathrm{Kc})$.

Table 2.2 Previous studies of comfort in sports equipment and sports experience 


\begin{tabular}{|c|c|c|c|c|}
\hline Case & Product & Individual & Environment & Literatures \\
\hline Cycling & $\begin{array}{l}\text { Handlebar }(\mathrm{T}) \\
\text { Saddle }(\mathrm{T}) \\
\text { Pedal }(\mathrm{T}) \\
\text { Frame }(\mathrm{V})\end{array}$ & $\begin{array}{l}\text { Motivation } \\
\text { Duration }\end{array}$ & $\begin{array}{l}\text { Road surface } \\
(\mathrm{T})\end{array}$ & $\begin{array}{l}\text { Dorey and } \\
\text { Guastavino } \\
\text { (2011) }\end{array}$ \\
\hline Road bike & $\begin{array}{l}\text { Dynamic comfort } \\
(\mathrm{Kc})\end{array}$ & $\begin{array}{l}\text { Static comfort } \\
(\mathrm{T})\end{array}$ & / & $\begin{array}{l}\text { Champoux, } \\
\text { Richard, and } \\
\text { Drouet (2007) }\end{array}$ \\
\hline $\begin{array}{l}\text { Mountain } \\
\text { bike }\end{array}$ & Tire pressure $(\mathrm{T})$ & Speed $(\mathrm{Kc})$ & $\begin{array}{l}\text { Road surface } \\
\text { (T) }\end{array}$ & Wu (2013) \\
\hline Golf club & $\begin{array}{l}\text { Club weight }(\mathrm{T}) \\
\text { Shaft flexibility }(\mathrm{T})\end{array}$ & $\begin{array}{l}\text { Sound }(\mathrm{A}) \\
\text { Club control } \\
(\mathrm{Kc})\end{array}$ & ( & $\begin{array}{l}\text { (Roberts, Jones, } \\
\text { Harwood, } \\
\text { Mitchell, \& } \\
\text { Rothberg, 2001; } \\
\text { Roberts, Jones, } \\
\text { Mansfield, \& } \\
\text { Rothberg, 2005) }\end{array}$ \\
\hline $\begin{array}{l}\text { Bicycle } \\
\text { helmet }\end{array}$ & $\begin{array}{l}\text { Thermal comfort } \\
\text { (T) }\end{array}$ & I & $\begin{array}{l}\text { Temperature } \\
(\mathrm{T}) \\
\text { Humidity (T) }\end{array}$ & $\begin{array}{l}\text { Bruhwiler, Ducas, } \\
\text { Huber, and } \\
\text { Bishop (2004) }\end{array}$ \\
\hline Leg guard & $\begin{array}{l}\text { Weight }(\mathrm{T}) \\
\text { Thermal comfort } \\
(\mathrm{T}) \text { Sensorial } \\
\text { comfort }(\mathrm{T})\end{array}$ & $\begin{array}{l}\text { Fitness (T) } \\
\text { Aesthetics (V) }\end{array}$ & I & $\begin{array}{l}\text { Webster and } \\
\text { Roberts (2009) }\end{array}$ \\
\hline
\end{tabular}

\section{$\underline{\text { Seeing }}$}

Although 'comfort' can be more than a physical state and can include other subjective evaluations such as product aesthetics (Webster \& Roberts, 2009), its visual appearance is often considered as a factor relating to the pre-purchase decision. The reason could be that under playing conditions, users may only see a part of the product, such as the top view of the golf club driver or the handlebar of a bicycle. Furthermore, the visual content with regard to sports equipment design is unlike that processed in an interface, which is informative and communicative. They are mainly coating designs (e.g., a colour palette for the company league), brand/club logos, and symbolic patterns that might reflect social or cultural values. Nevertheless, the equipment's visual appearance can affect athletes' performance too. 
According to colour psychology, colours can be perceived to have different weights and meanings. For example, Elliot and Aarts (2011) examined the link between colours and basic motor functioning, and concluded that perceiving red can enhance one's strength output in a hand grip task. In sport, athletes who wear red have been reported to be more dominant, aggressive, and threatening in many face-to-face situations, such as combat sports (Dreiskaemper, Strauss, Hagemann, \& Busch, 2013; Elliot \& Maier, 2014; Feltman \& Elliot, 2011). In contrast, facing an opponent in blue could lead to less anxiety and more confidence (Recours \& Briki, 2015).

\section{Touching}

While previous research has investigated how humans perceive different materials using measurable physical features, such as smoothness, roughness, slipperiness, stickiness, and hardness (Y. T. Chen \& Chuang, 2014), the tactile perception of sports equipment is not exactly the same. For example, the human tactile perception of a bicycle can be divided into two parts: static comfort and dynamic comfort (Champoux et al., 2007). The static comfort depends on ergonomics, and athletes need to wear the appropriate size of sports equipment that fits their body comfortably for optimal physical performance.

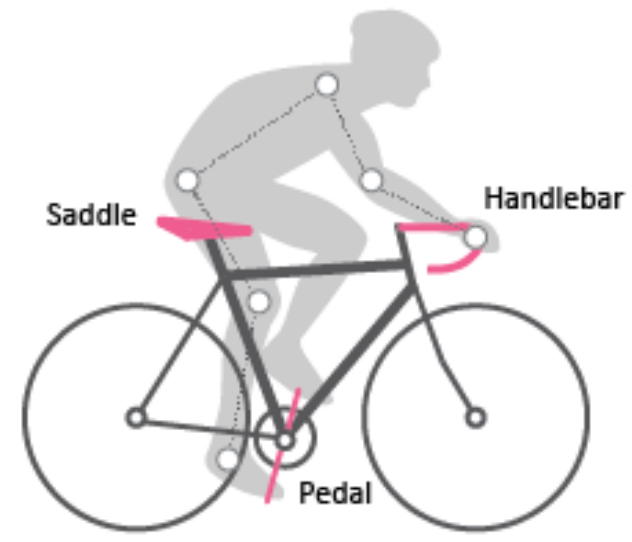

Figure 2.3 The cyclist's anatomical points and contact areas 
During seated cycling, there are five contact points with the human body: the handlebar (two hands), pedals (two feet) and saddle, as shown in Figure 2.3. The white circles in the figure are anatomical marks for bike fit adjustments. Matching riders' anthropometric data (e.g., leg length) and the bicycle's dimensions (e.g., saddle height) could help cyclists transfer power more efficiently and reduce physical pain (Laios \& Giannatsis, 2010). A review of bike fitting methodologies can be found in Appendix E.

On the other hand, the dynamic comfort refers to riders' feelings when they are actually in action. Any discomfort found in the static condition could be exacerbated. For example, a bicycle saddle that is too wide could cause unbearable chafing during cycling (Miller \& Berry, 2007). Depending on the activity for which a bicycle is designed (e.g., onroad or off-road), there are different considerations to improve a rider's perceived vibration, which influences cycling discomfort (Macdermid, Fink, \& Stannard, 2015; Torbic, ElGindy, \& Elefteriadou, 2003). The front and rear suspension system, for instance, can help reduce the vibration transmission on rough terrains for mountain cycling (Wu, 2013). In addition to the issue of comfort/discomfort, Kooijman and Schwab (2013) found that the intensity of vibration also influences the feeling of control, which is related to selfconfidence when users interact with single-track vehicles. Moreover, after being active for an extended period of time, cyclists' thermal comfort will decrease (Filingeri, Redortier, Hodder, \& Havenith, 2014). Finally, it should be noted that the author will use road bikes for the experiment in this study.

\section{$\underline{\text { Hearing }}$}

Users can hear the status/quality of a product according to its sound metrics such as loudness, sharpness, roughness and tonality. For instance, a car driver will notice the door closure sound to determine whether is properly closed (feeling secure), or will identify the 
car type (feeling small) from the engine noise (H.-H. Lee, Kim, \& Lee, 2009; Parizet, Guyader, \& Nosulenko, 2008). In contrast to tactile perceptions, the way humans perceive and react to a sound naturally produces more K-words in their evaluation expressions (Lyon, 2003). Some K-words are triggered because of cognitive evaluation (e.g., secure, small) and some are used to describe the sound attributes (e.g., dull, raspy) of products making constant 'noises' (e.g., car, hoover).

In sports, auditory feedback is mostly applied to avoid overloading visual stimuli in motor training (e.g., non-intrusive tone). Apart from that, impulsive sounds that come from the action of hitting are an important means of assessing sports performance. For a golf player, the loudness and sharpness of the impact sound affect the feeling of a shot (Barrass, Roberts, \& Jones, 2006; Roberts et al., 2005). Nevertheless, Gray (2008) simulated the baseball batting environment and, after conducting a factor analysis on batting efficiency, found that the feeling of a sweet point can only be supported by the integration of visual, tactile, and auditory information. In the case of cycling, auditory feedback may be the noise of the gear shifter, rear derailleur, cassette and brake, etc. 


\subsection{Emotional requirements}

While subjective impression plays a crucial role in product evaluation, designers find it challenging to remove biased opinions in the process of emotional requirements management. Therefore, they apply some objective measurements or invite the customers to take part in the process of product design and development. For example, quantifying users' feelings can help designers make decisions based on a systematic approach such as the Kansei engineering system (KES) instead of their own intuition. The author drew a diagram (Figure 2.4) to illustrate the mechanism of a typical KES.

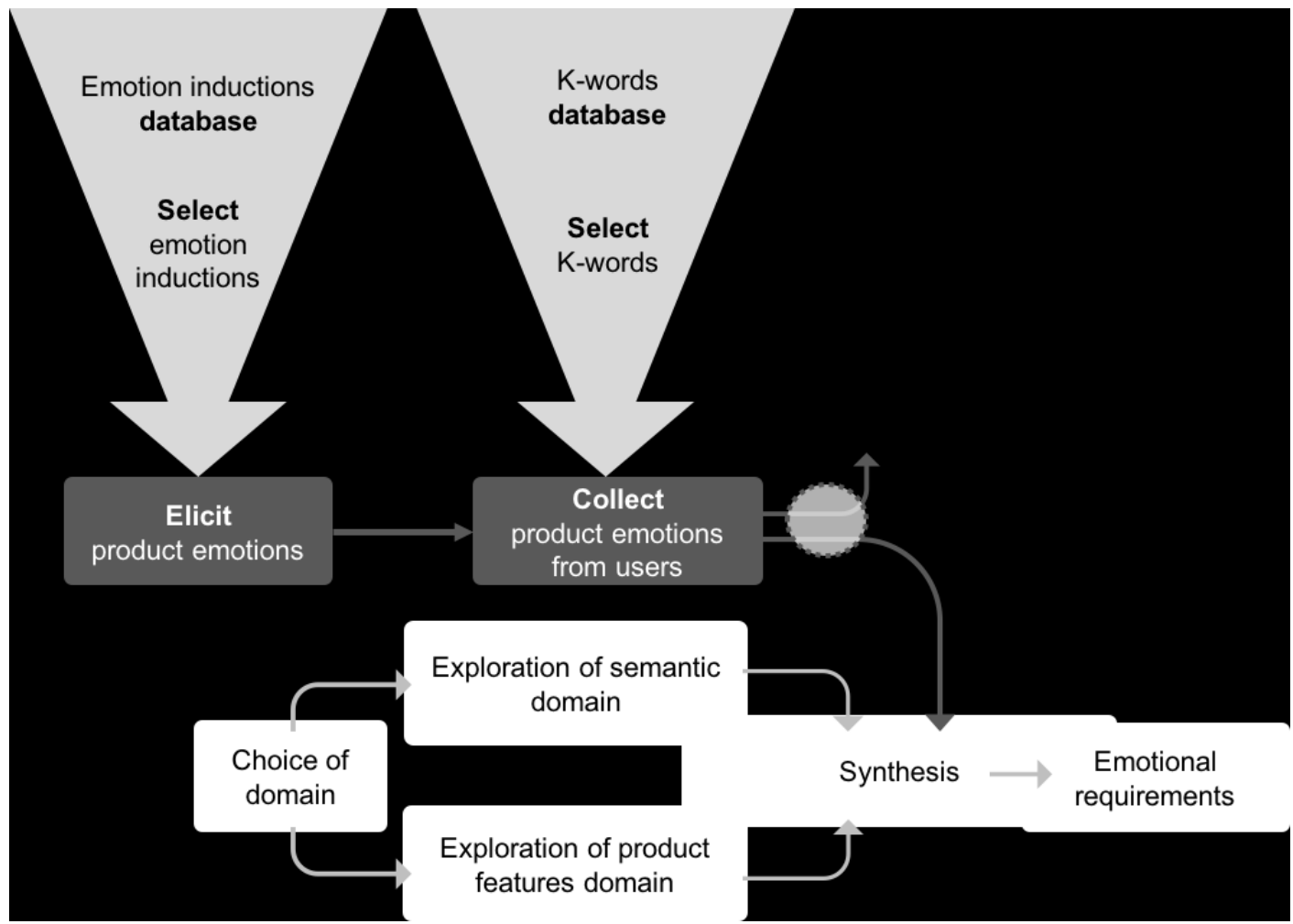

Figure 2.4 The technical process of emotional requirements engineering

There are many types of KES depending on its applications (Nagamachi \& Lokman, 2016). In general, customer emotional requirements are determined through the synthesis of the semantic domain and product features. Therefore, the affective properties are generated in line with three stages: elicitation, collection, and interpretation. Every step has 
to be carefully addressed to cope with users' complex and ambiguous emotional needs. In this regard, this section reviews the technical process and existing analysis approaches, respectively.

\subsubsection{Product emotion elicitation}

A real-time measurement of human emotions is ideal to detect the most accurate and authentic reaction. Because the moment of triggering human emotions is not predictable and can happen in an instance, nonstop tracking ensures that the researcher does not leave out any important data. However, depending on which psychophysical attributes (e.g., heart rate or facial expression) the researcher is measuring, this can sometimes be an inefficient and impractical strategy for new product development. Moreover, nonstop tracking is only suitable for detecting basic human emotions, not product emotions. Alternatively, researchers can choose to reproduce the scenario and prepare inductions for emotion elicitation. The means of inductions can be an image, a film clip, a soundtrack, or even asking the participants to replay a scenario in their minds (Lench et al., 2011; Schifferstein, 2009).

In the field of product design, the influence of the fidelity of emotion inductions on product emotions has been overlooked in the elicitation stage. Due to the research purpose or time and equipment constraints, instead of showing the actual product, there are several ways to show images as emotion inductions in a UX survey. For instance, the whole product can be shown as one image, or displayed together with a few different side views (Guo, Liu, Liu, Wang, \& Wang, 2014), or as a digital prototype. In some cases, the product image can be simplified to grayscale (i.e., no clue of colours and materials) or be presented as several images of the assembled components. For example, S. W. Hsiao and Ko (2013) 
applied the morphological chart and analytic hierarchy process (AHP) to generate ideas by recomposing bicycle parts (handlebar, saddle, bike frame, wheelset, and crank set) based on users' preferences. Nevertheless, any changes that push the actual product experience away can affect the content validity and can make it difficult for designers to implement the results later on.

Depending on the product category, researchers need to choose appropriate emotion inductions (Spence \& Gallace, 2011). Visual and auditory stimuli, for instance, are suitable for investigating the UX of online shopping. Short and impulsive auditory feedback is relatively easy to simulate through the manipulation of the sound metrics (e.g., loudness, sharpness, roughness, tonality). A picture of the product can simulate the look of it, but it still lacks tactile interaction. In that case, without testing physical interaction for tangible products such as sporting goods, hand tools (Vergara, Mondragón, Sancho-Bru, Company, \& Agost, 2011), or coffee makers (Razza, Paschoarelli, Santos, \& Andrade, 2014), the UX investigation risks being misled by an insufficient elicitation process. In other words, the database of elicited product emotions could be incomplete (see also Section 2.1.3). Nevertheless, the emotion induction can sometimes be intentionally designed to be a new/unfamiliar interaction, so it can elicit a user's first authentic reaction (e.g., frustrated) in the multimodal system (Desmet et al., 2008; Saariluomaand \& Jokinen, 2014).

In addition, research has shown that users prefer to have more sensory references to support their purchase decisions (Rahman, 2012). This again implies the importance of emotion inductions that are sensitive to the elicitation contexts, such as seeing a photo, seeing a physical product, touching it, and using it (Fenko et al., 2010; S. Lee, Harada, \& Stappers, 2002; Vergara et al., 2011). Even the device or platform on which the investigator 
presents the emotion inductions (e.g., a picture on the screen or on the paper) has an influence on users' emotional perception.

\subsubsection{Product emotion collection}

Once emotions are elicited, people may feel and respond in many ways, such as changing their behaviours (e.g., approach or avoid), showing expression on their faces (e.g., smiling), or reacting physiologically (e.g., heart racing). Researchers can therefore measure the corresponding reactions to collect the emotions, individually or in combination. In the field of product design, the collected emotional responses are expected to be quantified and transferred into manufacturing specifications. The product emotion collection methods are divided into directly observed and indirectly observed, and are discussed in the following paragraphs.

\section{Direct/psychophysical}

In theory, human emotions can be disclosed by monitoring and analysing physiological signals through central or peripheral nervous responses using methods such as electroencephalograms (EEG), skin conductance, electromyography (EMG), and respiration patterns. The stronger the emotion is, the higher the coordination of the response system is (Davidson, 1992; G. K. Verma \& Tiwary, 2014). Reading human emotions directly through physiological signals can overcome cultural influences and language barriers. For example, instead of analysing the content of the conversation, the researcher can focus on the tone of voice (Picard, 1997).

However, the empirical findings of response system coherence in human emotions are affected by the emotion types (Mauss, Levenson, McCarter, Wilhelm, \& Gross, 2005). A weak correlation has been found when the emotion belongs to the category of secondary 
emotions or is part of cognitive processing (e.g., satisfaction). More specifically, physiological signals have been able to explain the amount of arousal found in basic emotions (e.g., sadness), but not to distinguish discrete/mixed emotions from different types of physiological changes (Lench et al., 2011). Even with the technique of affective computing (Essa \& Pentland, 1997; Picard, 1997), which is a comprehensive recognition system of human facial expression, voices, and physiological signals, the collected emotions only reflect an overall preference (e.g., positive/like or negative/dislike). Likewise, in sports experience, various types of physiological signals (e.g., heart rate variability) have been proven to correlate to an athlete's cognitive performance in areas such as decision-making or coping with stress; however, the assessment of subjective feelings is related to mood, which is not a particular human emotion (Laborde, Brull, Weber, \& Anders, 2011; Laborde \& Raab, 2013).

A thorough review of the relevant literature yielded only a few articles that investigate the relationship between a customer's physiological responses and particular product emotions. Among them, Pierre, Toshimasa, and Oscar (2011) measured participants' brainwave while testing six different pen prototypes. The signals were visualised to a two-dimensional space as the emotional arousal (excitement) and emotional valence (pleasure), and four other emotions were interpreted from the chart (comfort, expectation, irritation, and boredom). In other studies, some researchers tracked users' eye movements to identify the K-word (e.g., sportive, masculine, modern) that linked to a particular product component to support their design decisions (Köhler, Falk, \& Schmitt, 2014; Schmitt, Köhler, Durá, \& Diaz-Pineda, 2014). 


\section{$\underline{\text { Indirect/self-report }}$}

Collecting psychophysical signals is an immediate and continuous measurement, but the emotional experience during a product evaluation is probably only assessable through a self-report study (Wallbott \& Scherer, 1989). An in-depth interview, for instance, can help the investigator gain a better understanding of the reasons behind mixed emotions like tears of joy, which cannot be identified by physiological signals. Depending on the stage of NPD, drawing a UX model requires substantial qualitative content analysis, which is relatively time-consuming and also subjectively interpreted by the investigator. On the other hand, the semantic differential scale (SDS) provides an efficient and flexible method with which to collect product emotions in design practice. It is able to collect secondary human emotions (like confidence) which are essential in user-product interaction but are not easily identifiable from physiological signals. Yet can emotions be described in human language and collected for a self-report study?

Some researchers claim that an emotion word (e.g., happy) is actually a category of various perceptual instances (e.g., a smiley face, the sound of laughing, and the context), as quoted - 'the glue that holds the concept together' (Gendron, Lindquist, Barsalou, \& Barrett, 2012; Lindquist \& Gendron, 2013). On the other hand, Desmet, Hekkert, and Jacobs (2000) argue against the idea that language is the best means through which to interpret human feelings because not everyone can express thoughts perfectly in words. It is also not easy for people to articulate everyday experiences when they are so familiar with routine behaviours that they act almost unconsciously. In addition to the participant's narrative skills, the way the investigator leads the open-ended interview questions can also affect the validity and reliability of the collected data. Accordingly, researchers have developed tools and techniques to attempt to improve the interview process used to 
understand user experience. The contextual inquiry model, for example, can help visualise the user experience into various structures, namely, flow, sequence, artefact, cultural and physical (Beyer \& Holtzblatt, 1998); and the repertory grid technique is a structured interview technique based on the personal construct theory, which has been applied to UX investigation (Kelly, 1955; Tomico, Karapanos, Levy, Mizutani, \& Yamanaka, 2009).

The construct is an evolving concept of how an individual mind interprets this world; everyone has a unique set of elements. Hence, it is possible that an item in the assessment questionnaire provided by the investigator may be considered as an irrelevant construct for the respondent (Karapanos, Martens, \& Hassenzahl, 2009; Karapanos et al., 2010). In the field of sport psychology, there are many well-developed questionnaires for examining athletes' feelings. The assessment items of these structured questionnaires have been verified to collect large amounts of responses efficiently including the stress, anxiety, positive and negative affect schedule (PNAS), profile of mood states, and secondary emotions in the pre-competition situation (Jones, Lane, Bray, Uphill, \& Catlin, 2005; Martens, Vealey, \& Burton, 1990; Selby, Weinstein, \& Bird, 1990; Terry \& Lane, 2000; Watson, Clark, \& Tellegen, 1988).

While a UX questionnaire can be customised to certain product categories (Park, Han, Kim, Moon, \& Park, 2015), many researchers have tried to develop a universal questionnaire that can collect users' attitudes towards all product categories (Hassenzahl et al., 2008), or a sense-specific project. For instance, Nagamachi and Lokman (2011) explored how human beings feel about special words sound like 'tick tack' and 'bang'. They argue that the way the word sounds are pronounced (e.g., vowels and tones) can elicit people's feelings from a list of 20 K-words. Furthermore, by analysing the frequency of vocabulary words participants used to describe their tactile perceptions of 51 material 
samples, the pre-defined K-words could reinforce the convergent validity of the questionnaire (Y. T. Chen \& Chuang, 2014).

In a way, these surveys of human feelings are all based on the concept of semantic differences, a seven-point bipolar Likert scale originally proposed to distinguish between vague wordings (Osgood, 1957), as shown in Figure 2.5. When subjects are asked to use the paired words to assess an object/event/concept, they also express their attitudes/impression regarding the words at the same time. Specifically, Osgood (1957) performed a factor analysis and revealed the three most important factors underlying semantic connotations: evaluation, potency, and activity. He called them the semantic spaces. Thanks to its versatility, the semantic differential scale (SDS) has been successfully applied to many self-report product evaluations (Table 2.3 and Table 2.4).

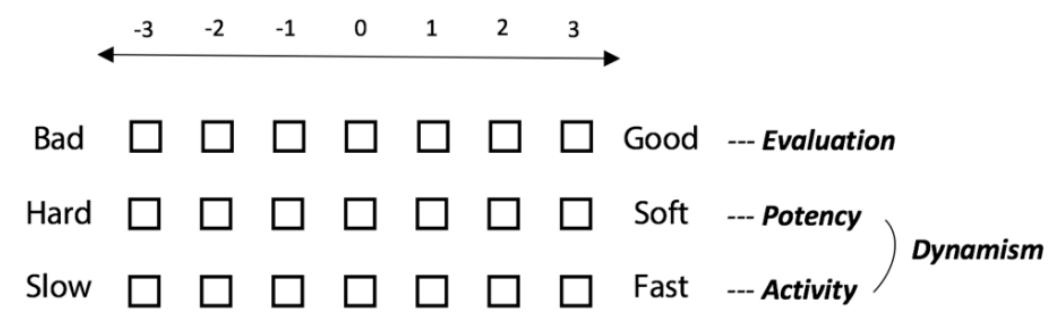

Figure 2.5 Example of semantic differential scale

However, the structure of semantic items in the SDS varies in the field of product design. In general, the preparation starts with collecting as many K-words from customers, designers, and magazines as possible. Then, the K-words are sorted either manually (e.g., affinity diagram) or systemically (Schütte \& Eklund, 2005). In this regard, some investigators adopt bipolar items as per the original design, while some exclude negative/opposite wordings (Desmet, 2012; Hassenzahl et al., 2008). Some claim that any 
words implying human cognitive evaluation (e.g., surprise, anxiety, and confidence) are not 'pure' emotions, and should therefore be removed from the list (Jones et al., 2005; Karapanos et al., 2010; Mauss \& Gross, 2004). To investigate those 'not-emotions', i.e., product personality, they can be identified using a bipolar SDS with $20 \mathrm{~K}$-words (Mugge, Govers, \& Schoormans, 2009). These various standards make it difficult for other researchers to expand upon and validate the collection methods.

A self-report questionnaire like the SDS is built on the assumptions that test subjects will not understand the assessment items differently from what was intended, and that they will answer truthfully. Considering that most of the time (not always), there is only one Kword on both sides of the scale, it is indeed possible that they can be interpreted in different ways. The word happy serve as an example:

I am currently happy (emotion)

I am kind of a happy person (personality)

Hence, it is important for the investigator to ensure that test subjects understand the meaning of the K-words before the collection, and handle the K-words carefully while collecting their responses. For example, the investigator can use an additional SDS to obtain the weighted value of basic emotions in each K-word (Huang, Chen, \& Khoo, 2012b) as a way of deconstructing the secondary emotions; or the K-words can be put on a twodimensional scale. The latter has been proven to allow test subjects to easily assess the product on the $k$-axis despite it not being able to evaluate as many K-words as the traditional SDS due to the spatial arrangement (X. J. Chen, Shao, Barnes, Childs, \& Henson, 2009; Nagamachi, 2011; Russel, Weiss, \& Mendelsohn, 1989).

In addition, Desmet (2003) suggests replacing K-words with a series of animated characters showing emotions through facial expressions, hand gestures, and body posture 
to avoid linguistic misinterpretations. The test subjects can use software to choose from 14 types of emotions, and each of them is paired with customised auditory feedback (Desmet, 2003; Laurans \& Desmet, 2012). This is indeed an alternative for those who have limited vocabulary, such as children, but not all product emotions can be translated into a simple illustration.

\subsubsection{Interpretation of product emotions}

In contrast to the above methods, some researchers interpret the SDS results after completing the collection stage. The interpretation stage can be carried out in two different directions (Figure 2.4, page 27). One direction involves linking a user's feelings (K-words) to the product properties, which are then taken as the emotional requirements (ER) in the synthesis stage of a KES. When designers want to create a comfortable bicycle, they need to determine which parts of the bicycle contribute to this emotional need with respect to detailed manufacturing properties (e.g., the width of a bicycle saddle), not just the components (e.g., saddle) in general.

In this regard, the KES takes advantages of statistical approaches and artificial intelligence algorithms to address the nature of semantic differences (e.g., fuzzy, uncertainty, and complexity), to quantify a user's feelings into dummy variables, and then to ultimately transfer them into the ideal design parameter, such as the length and curve (K. A. Hsiao \& Chen, 2006; Schifferstein \& Hekkert, 2011). In essence, the KES fulfils the tasks with the help of the linear model (e.g., quantification type I) and non-linear model (e.g., neural networks, genetic algorithm, principal component analysis, factor analysis, cluster analysis, conjoint analysis, quantification types II, III, IV). Exploration of the product features domain is beyond the scope of this research, although various types of 
KES applications can be found in several thorough reviews (Nagamachi, 2002; Schütte, 2002).

\section{$\underline{\text { Semantic spaces }}$}

The other interpretation method is conducted in the opposite direction, i.e., identifying what subjective impressions can be interpreted from the product properties. There is a general agreement that designers can shed light on what customers truly care about, and can be inspired by the key elements (i.e., semantic spaces) through exploration of the semantic domain in new product development (Figure 2.4, page 27). As the design subjects in this reverse interpretation method are not limited to a single product, the method can help designers learn customer preferences (e.g., fashion style) based on a group of emotion inductions (Chou \& Chen, 2006; Yamada, Kamiyama, Tachiguchi, \& Unehara, 2013).

In this regard, Choi and Jun (2007) identified four semantic spaces, namely trend, emotion, complexity, and potency, based on three different sizes/types of products. The Kwords that belong to the trend factor (e.g., contemporary-traditional) are very similar to the part of the product personality (Desmet et al., 2008). In fact, if a particular product was investigated, such as drills (Huang, Chen, \& Khoo, 2012a), shoes (Ishihara, Ishihara, Nagamachi, \& Matsubara, 1997; Shieh \& Yeh, 2013), or insoles (M. Camargo, Wendling, \& Bonjour, 2014), the 'title' of semantic spaces would appear to be only applicable to specific study. Depending on the case, the number of key elements normally ranges between three and seven (Kuo, Chen, \& Roberts, 2016). Nevertheless, the purpose of extracting the semantic spaces is not to choose the best 'title', but to find the representatives that can reflect the UX of the target product for subsequent conceptual design. 
Many statistical approaches have been applied to extract the representative semantic spaces from the SDS results (Desmet, 2012; K. A. Hsiao \& Chen, 2006; Krippendorff, 2005; Yang \& Chang, 2012). As with any self-assessment, the investigators need to handle the distorted response set (covariance between semantic items), including issues of individual, scale, and concepts, in a bid to improve its efficiency and validity (Bynner \& Coxhead, 1979). For example, individual perceived importance between K-words and testing habits interferes with the validity of given responses (e.g., individuals tend to give lower scores). One possible solution is to perform a stratified analysis to extract the semantic spaces according to a distributed data structure (Yamamoto, Yoshikawa, \& Furuhashi, 2005).

In the author's opinion, however, the differences in personal constructs should not be treated as only statistical errors. For instance, Tomico et al. (2009) used three metrics (dominance, importance, descriptive richness) to classify semantic items. Furthermore, the quality of valid input data has often been overlooked in the analysis of emotional requirements and may lead to a misleading and inaccurate interpretation. The SDS interpretation can be improved by adding the concept of temporality and multisensory UX characteristics.

\section{$\underline{\text { SDS layout }}$}

Finally, this section reviews some issues with the questionnaire design that investigators need to consider for the SDS layout. Garland (1990) compared three formats of scale points (labelled, unlabelled, and numbered) and found no significant differences in the collected SDS responses. Moreover, the statistical reliability of a questionnaire increases sharply when the scale points are up to seven, and then decreases if they exceed 20. In fact, research has shown that respondents tend to avoid giving lower scores to 
negative wordings in the SDS because it is more socially acceptable to hide them (Kamoen, Holleman, \& van den Bergh, 2013).

According to the tables of previous UX studies (Table 2.3 and Table 2.4), the number of emotion inductions (K-words) ranges from 1 to 57 . However, human beings may not be able to process/compare too many items at once, and doing so interferes with validity too. If a large number is required, one possible solution is to do a pairwise comparison instead of rating each semantic item individually (Petiot \& Yannou, 2004; Roberts, Jones, Rothberg, Mansfield, \& Meyer, 2006; Webster \& Roberts, 2009). Test subjects respond faster using the one-at-a-time format than the all-at-once format in the structured questionnaires (Nosek, Sriram, \& Umansky, 2012). However, this finding may not be applicable when the statement of question items is short and simple, i.e., the K-words on product impression in the SDS.

Currently, there is an inconsistency in the SDS scale type for evaluating K-words in the field of product design. Some researchers have used the bipolar scale type and others the unipolar one; however, these appear to be subjective choices decided by the investigator, with no explanation provided. When Kelly (1955) and Osgood (1957) first developed SDS, it aimed to clarify wordings that were too vague. They both claim that the bipolar type is more suitable in this case. The bipolar SDS scale has three different formats: negation (friendly-unfriendly), opposition (old-new), and non-contiguous (easy-strong).

However, when SDS is applied to the field of product design, the researcher may not always be able to find suitable words with exact opposite meanings (Karapanos \& Martens, 2008). Humans are often reluctant to reveal negative feelings in a survey or in general (Petrov, Fontanari, \& Perlovsky, 2012; Wallbott \& Scherer, 1989); the previous section reviewed reasons why positive emotions are important. Hence, the author suggests that a 
unipolar SDS is more suitable for collecting product emotions in terms of UX evaluation with the use of positive K-words when possible.

\subsection{Research gap}

In the field of product design, the analysis of emotional requirements is better with self-report assessments. This is because while a psychophysical measurement can accurately identify a user's basic emotions (e.g., happiness and fear), it cannot detect secondary and complex product emotions (e.g., cute and friendly). Unfortunately, previous research has yet to provide a robust principle use in selecting the representative K-words to be placed in the self-report questionnaire. Apart from the art of questionnaire design (e.g., the number of assessment items and construct validity), the existing approaches to handling K-words are too literal and inadequate to represent real user experience.

Firstly, although several statistical techniques can be used to reduce the size of the initial K-words pool in a Kansei engineering system (KES), the grouping words are too general to offer a practical implementation. For example, Vergara et al. (2011) grouped three K-words, classical, stylish, and simple, into a semantic space called 'appearance' after conducting a factor analysis. Moreover, grouping words often ignore the diversity of participants in the survey, while individual interests/level of involvement could affect personal judgments. For instance, when users become more familiar with the product, their interests in cognitive demands may decline, and they may look for more affective experience (Karapanos et al., 2010). This implies that there could be an effect of temporality between K-words. As a matter of fact, in the case of sporting goods, a user's task does not focus on delivering a coherent flow or operating sequence (e.g., how many steps does it take from locating the power button to making a cup of coffee). The fact that 
athletes face different end-user experiences and have different affective needs also suggests a tailored approach to managing emotional requirements for sporting goods.

Secondly, the impact of multisensory perceptions is not included in the existing approaches to collecting a user's emotional experience. Not only are some K-words (e.g., slippery) likely to be triggered by certain human senses (e.g., touch), but the dominant human sense can also change over time. Hence, an emotional requirements management system that is developed with a single modality (e.g., visual impression) may not be able to explain the UX of tactile-dominant products like sports equipment. Furthermore, research has shown that a user's mind construct model varies across product categories so as to affect his or her product evaluation (Jordan \& Persson, 2007; Schifferstein, 2009). Nevertheless, the previous research on multisensory perceptions in sports experience is limited to the training stimulus from the external environment.

Finally, a summary of previous UX studies is shown in Table 2.3 and Table 2.4. The author reviewed a number of product evaluations that involved collecting a user's emotional needs, and how they utilised the collected data. This table also serves to check whether the temporality and multisensory concepts have been applied in the semantic difference scale (SDS) with respect to the product categories. The UX tab is divided into three aspects: participant group (whether it compares personal traits/between-subjects design), temporality, and multisensory. According to the tables, not many tests have been run more than once or collected the product experience at different time spans. It can also be noticed that visual perception (V) is the most commonly used for inducing a user's emotions in a product evaluation. However, there is no consistency in the number of emotion inductions either for an image (I) or for an actual product (P). Both self-report (S) and direct measurement (D) have been used in previous studies, but very few have 
explained the process of selecting K-words in the experimental design. Only in two studies, participants were asked to evaluate hand tools, viz., pens and hammers, and compare the K-words between different interactions with them (seeing, touching, and using), but neither of them measured the usability/performance.

The above research gaps are critical to building a reliable KES that can handle the Kwords as an emotional experience, and not just as an emotional response. Accordingly, the UX-based collection method (UXCM) is proposed to investigate the affective properties of sporting goods based on cycling experience. 
The abbreviations/coding indexes in Table 2.3 and Table 2.4 are provided as follows:

V Visual

T Tactile

A Auditory

O Olfactory

G Gustatory

Kc Kinaesthetic

I Image

P Product

R Recall

$I_{(20)} \quad$ The emotion inductions are 20 images

$I_{(20 / 100)}$ The emotion inductions are100 images; each subject evaluates 20 of them

$\mathrm{I}_{(20 \%)} \%$ implied that the emotions are induced with reduced image fidelity

S The collection method is Self-report, SDS format unless otherwise stated

$\mathrm{S}_{(20, \mathrm{~b}, 7)}$ It tests 20 bipolar K-words in a seven-point scale

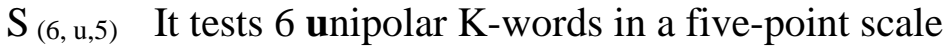

iS $(*) \quad$ i refers to the interview; * refers to no K-words involved

$\mathrm{WS} \mathrm{(10)}_{\mathrm{W}} \mathrm{W}$ refers to pairwise comparison/relative importance/ranking order

$\mathrm{nS} \mathrm{S}_{(10, \mathrm{~b})} \mathrm{n}$ refers to no explanation on how they selected the K-words

$\operatorname{yes}_{(\mathrm{k})} \quad \mathrm{k}$ refers to K-words instead of physical properties/materials

yes(c) c refers to product component instead of physical properties/materials 
Chapter 2 Literature Review

Table 2.3 Summary of previous UX studies

\begin{tabular}{|c|c|c|c|c|c|c|c|}
\hline \multirow{2}{*}{ Literature/Author } & \multirow{2}{*}{$\begin{array}{c}\text { Product } \\
\text { categories }\end{array}$} & \multicolumn{3}{|c|}{ UX } & \multirow{2}{*}{$\begin{array}{c}\begin{array}{c}\text { Emotion } \\
\text { inductions }\end{array} \\
\begin{array}{c}\text { Image/ } \\
\text { Product/Recall }\end{array}\end{array}$} & \multirow{2}{*}{$\begin{array}{c}\begin{array}{c}\text { Collection } \\
\text { method }\end{array} \\
\text { Direct/ } \\
\text { Self-report }\end{array}$} & \multirow{2}{*}{$\begin{array}{c}\text { Interpretation } \\
\text { method }\end{array}$} \\
\hline & & $\begin{array}{c}\text { Participant } \\
\text { group }\end{array}$ & Temporality & Multisensory & & & \\
\hline Schmitt et al. (2014) & car & - & - & $\mathrm{V}$ & $\mathrm{I}_{(2)}$ & $\mathrm{S}_{(4, \mathrm{u}, 5), \mathrm{D}}$ & $\operatorname{yes}_{(\mathrm{c})}$ \\
\hline Köhler, Falk, and Schmitt (2013) & mountain bike & - & - & $\mathrm{V}$ & $\mathrm{P}$ & $\mathrm{S}_{(3, \mathrm{u}, 7), \mathrm{D}}$ & yes(c) \\
\hline S. W. Hsiao and Ko (2013) & bicycle & - & - & $\mathrm{V}$ & $\mathrm{I}_{(20)}$ & $\mathrm{S}_{(10, \mathrm{~b})}$ & yes \\
\hline Köhler et al. (2014) & watch & - & - & $\mathrm{V}$ & $\mathrm{I}_{(4)}$ & $\mathrm{S}_{(6, \mathrm{u}, 5), \mathrm{D}}$ & yes \\
\hline Yamada et al. (2013) & cloth/watch & - & - & $\mathrm{V}$ & $\mathrm{I}_{(7)}$ & $\mathrm{nS}_{(7, \mathrm{~b})}$ & yes \\
\hline Rahman (2012) & jeans & - & - & $\mathrm{V}, \mathrm{T}$ & $\mathrm{P}$ & $\mathrm{iS}(*)$ & yes \\
\hline Webster and Roberts (2009) & leg guard & yes & - & $\mathrm{Kc}$ & $\mathrm{P}_{(2)}$ & $\mathrm{wS}_{(6)}$ & - \\
\hline Roberts et al. (2006) & golf driver & - & - & $\mathrm{Kc}$ & $P_{(5)}$ & $\mathrm{wS}_{(6)}$ & yes \\
\hline Roberts et al. (2005) & golf & - & - & A & $\mathrm{P}$ & $\mathrm{S}$ & yes \\
\hline Shieh and Yeh (2013) & shoes & - & - & $\mathrm{V}$ & $\mathrm{I}$ & $\mathrm{S}$ & yes \\
\hline M. Camargo et al. (2014) & insoles & - & - & $\mathrm{V}, \mathrm{T}$ & $\mathrm{P}_{(1)}$ & $\mathrm{S}_{(21, \mathrm{u}, 5), \mathrm{D}}$ & yes \\
\hline Nagamachi (2011) & mattress & - & yes & $\mathrm{T}$ & $\mathrm{P}_{(20)}$ & $\mathrm{S}_{(5, \mathrm{u}, 5)}$ & - \\
\hline Wang (2011) & CNC tools & - & - & $\mathrm{V}$ & $\mathrm{I}_{(57)}$ & $\mathrm{S}_{(15, \mathrm{~b}, 7)}$ & yes \\
\hline Schütte and Eklund (2005) & rocker switch & - & - & $\mathrm{T}$ & $\mathrm{P}_{(14)}$ & $\mathrm{S}_{(29, \mathrm{u}, 7)}$ & yes \\
\hline Tomico et al. (2009) & pen & yes & - & $\mathrm{T}$ & $\mathrm{P}_{(6)}$ & $\mathrm{S}_{(8, \mathrm{u}, 5)}$ & yes \\
\hline Pierre et al. (2011) & pen & - & - & $\mathrm{V}, \mathrm{T}, \mathrm{Kc}$ & $\mathrm{P}_{(6 \%)}$ & $\mathrm{D}$ & - \\
\hline K. H. Chen and Hwang (2013) & stylus & - & - & $\mathrm{V}, \mathrm{T}, \mathrm{A}$ & $\mathrm{P}$ & $\mathrm{S}$ & - \\
\hline Spence and Zampini (2006) & e-toothbrush & - & - & $\mathrm{A}, \mathrm{Kc}$ & $P_{(1)}$ & $\mathrm{S}_{(2, \mathrm{~b}, 100)}$ & - \\
\hline Huang et al. (2012a) & drill & - & - & $\mathrm{V}$ & $\mathrm{I}_{(13)}$ & $\mathrm{S}_{(16 / 32, \mathrm{u}, 7)}$ & $\operatorname{yes}_{(\mathrm{c})}$ \\
\hline Vergara et al. (2011) & hammer & yes & yes & $\mathrm{V}, \mathrm{T}, \mathrm{Kc}$ & $\mathrm{I}+\mathrm{P}_{(4 / 8)}$ & $\mathrm{S}_{(25, \mathrm{~b}, 7)}$ & - \\
\hline
\end{tabular}


Chapter 2 Literature Review

Table 2.4 Summary of previous UX studies (continued)

\begin{tabular}{|c|c|c|c|c|c|c|c|}
\hline \multirow{2}{*}{ Literature/Author } & \multirow{2}{*}{$\begin{array}{l}\text { Product } \\
\text { categories }\end{array}$} & \multicolumn{3}{|c|}{ UX } & \multirow{2}{*}{$\begin{array}{c}\text { Emotion } \\
\text { inductions } \\
\text { Image/ } \\
\text { Product/Recall }\end{array}$} & \multirow{2}{*}{$\begin{array}{c}\begin{array}{c}\text { Collection } \\
\text { method }\end{array} \\
\text { Direct/ } \\
\text { Self-report }\end{array}$} & \multirow{2}{*}{$\begin{array}{c}\text { Interpretation } \\
\text { method }\end{array}$} \\
\hline & & $\begin{array}{l}\text { Participant } \\
\text { group }\end{array}$ & Temporality & Multisensory & & & \\
\hline Fujisaki et al. (2015) & wood & - & - & $\mathrm{V}, \mathrm{T}, \mathrm{A}$ & $\mathrm{I}+\mathrm{P}_{(22)}$ & $S_{(23, b, 7)}$ & yes \\
\hline Choi and Jun (2007) & plastic & - & - & $\mathrm{V}$ & $\mathrm{P}_{(4)}$ & $S_{(37, b, r)}$ & yes \\
\hline Petiot and Yannou (2004) & table glasses & - & - & $\mathrm{T}$ & $\mathrm{P}_{(15)}$ & $S_{(17, b, 7)}$ & - \\
\hline X. J. Chen et al. (2009) & packaging & - & - & $\mathrm{V}, \mathrm{T}$ & $P_{(37)}$ & $\mathrm{S}_{(6, \mathrm{~b}, 20), \mathrm{D}}$ & yes \\
\hline Huang et al. (2012b) & perfume bottle & - & - & $\mathrm{V}$ & $\mathrm{I}_{(15 \%)}$ & $\mathrm{S}_{(8, \mathrm{u}, 7)}$ & - \\
\hline Chowdhury et al. (2014) & water bottle & - & - & $\mathrm{Kc}$ & $\mathrm{P}_{(2)}$ & $\mathrm{S}_{(20, \mathrm{u}, 5), \mathrm{D}}$ & yes \\
\hline Yang (2011) & camera & - & - & V & $\mathrm{I}_{(25 / 100)}$ & $S_{(7, b, 5)}$ & yes \\
\hline Karapanos et al. (2009) & website & - & - & $\mathrm{V}$ & $\mathrm{I}_{(8)}$ & $\mathrm{S}_{(18 / 118, \mathrm{u}, 7)}$ & - \\
\hline Yamamoto et al. (2005) & laptop & yes & - & $\mathrm{V}$ & $\mathrm{I}_{(30)}$ & $S_{(21, b, 7)}$ & - \\
\hline Chou and Chen (2006) & mixed/phone & - & - & $\mathrm{V}$ & $\mathrm{I}_{(6 / 36)}$ & $\mathrm{S}_{(7, \mathrm{u}, 7)}$ & yes \\
\hline Karapanos et al. (2010) & mobile phone & - & yes & recall & $\mathrm{R}$ & iS & - \\
\hline Yang and Chang (2012) & mobile phone & - & - & $\mathrm{V}$ & I & $\mathrm{S}$ & - \\
\hline Desmet et al. (2001) & mobile phone & - & - & $\mathrm{V}, \mathrm{T}$ & $\mathrm{P}$ & $\mathrm{S}_{(\mathrm{pic})}$ & - \\
\hline Schifferstein (2006) & 15 mixed & - & - & $\mathrm{V}, \mathrm{T}, \mathrm{A}, \mathrm{O}, \mathrm{G}$ & $\mathrm{R}$ & $\mathrm{S}$ & - \\
\hline Fenko et al. (2010) & 93 mixed & - & yes & $\mathrm{V}, \mathrm{T}, \mathrm{A}, \mathrm{O}, \mathrm{G}$ & - & iS & - \\
\hline Y. T. Chen and Chuang (2014) & 51 mixed & yes & - & $\mathrm{T}$ & $\mathrm{P}_{(51)}$ & iS & - \\
\hline Mugge, Govers, et al. (2009) & car, hoover & - & - & $\mathrm{V}$ & $\mathrm{I}_{(4 / 16)}$ & $S_{(78, u, 5)}$ & - \\
\hline K. A. Hsiao and Chen (2006) & sofa, kettle, car & - & - & $\mathrm{V}$ & I & $\mathrm{S}$ & - \\
\hline Saariluomaand and Jokinen (2014) & multimodal & - & - & $\mathrm{Kc}$ & $\mathrm{P}_{(1 / 3)}$ & $\mathrm{nS}_{(11, \mathrm{u})}$ & - \\
\hline Desmet et al. (2008) & customised & - & - & $\mathrm{V}, \mathrm{A}, \mathrm{Kc}$ & $\mathrm{P}_{(2)}$ & $\mathrm{S}_{(7, \mathrm{u}, 7)}$ & yes $(k)$ \\
\hline Merchel et al. (2012) & customised & - & - & $\mathrm{T}, \mathrm{A}$ & $\mathrm{P}_{(6)}$ & $\mathrm{S}_{(28, \mathrm{~b}, 7)}$ & yes \\
\hline
\end{tabular}




\section{Chapter 3 The UX-based Collection Method}

This chapter illustrates a conceptual model of the cycling experience. Firstly, the UX-based collection method (UXCM) is proposed based on the two UX characteristics (temporality and multisensory) identified from the literature review. Next, the UXCM architecture addresses the issue of handling K-words in the existing Kansei engineering system (KES). Lastly, different collection methods are compared in order to build the K-words database for subsequent case studies in this study.

\subsection{A conceptual model of cycling experience}

The ground idea of UXCM is shown in Figure 3.1. The picture on the left shows how an existing KES manages product emotions - many discrete and distinct product emotions are triggered in a UX context, and they are later used to set up the design strategy. This model is based on the assumption that UX can be summed up individually as each product emotion is independent (Zhou, Xu, \& Jiao, 2011).
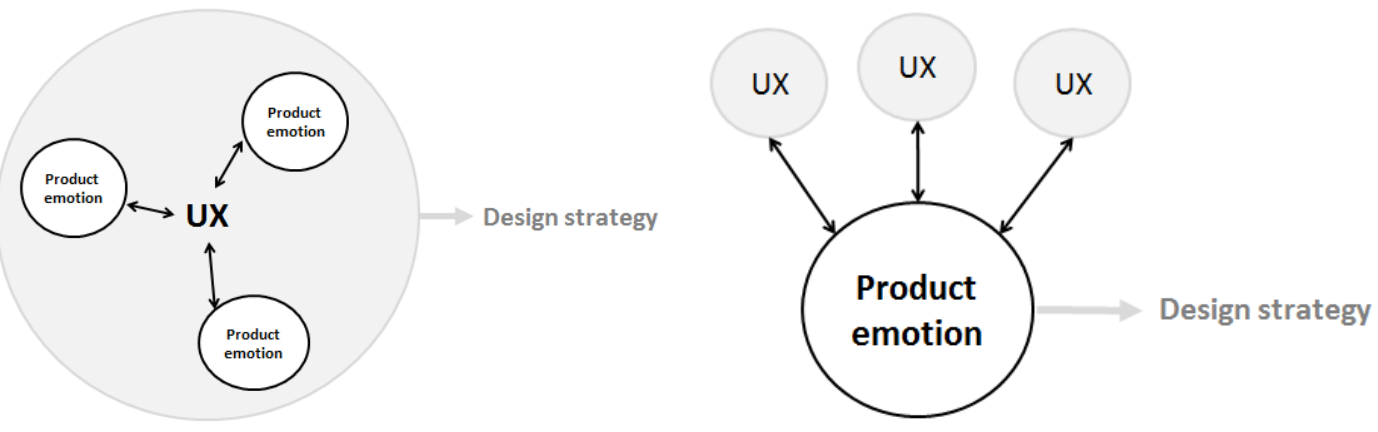

Figure 3.1 The fundamental of UXCM

However, the author argued that accumulating users' emotional responses cannot truly represent their emotional experiences. For example, the UX of sporting goods includes the player, the task, sports equipment, and the environment (Figure 3.2). Each 
domain can be extended and grown into a complex system (Figure 3.3), hence, it is hard to determine/evaluate all variables simultaneously within one context.

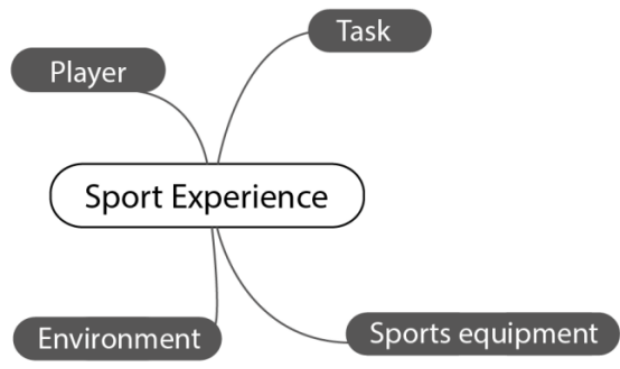

Figure 3.2 The UX of general sporting goods

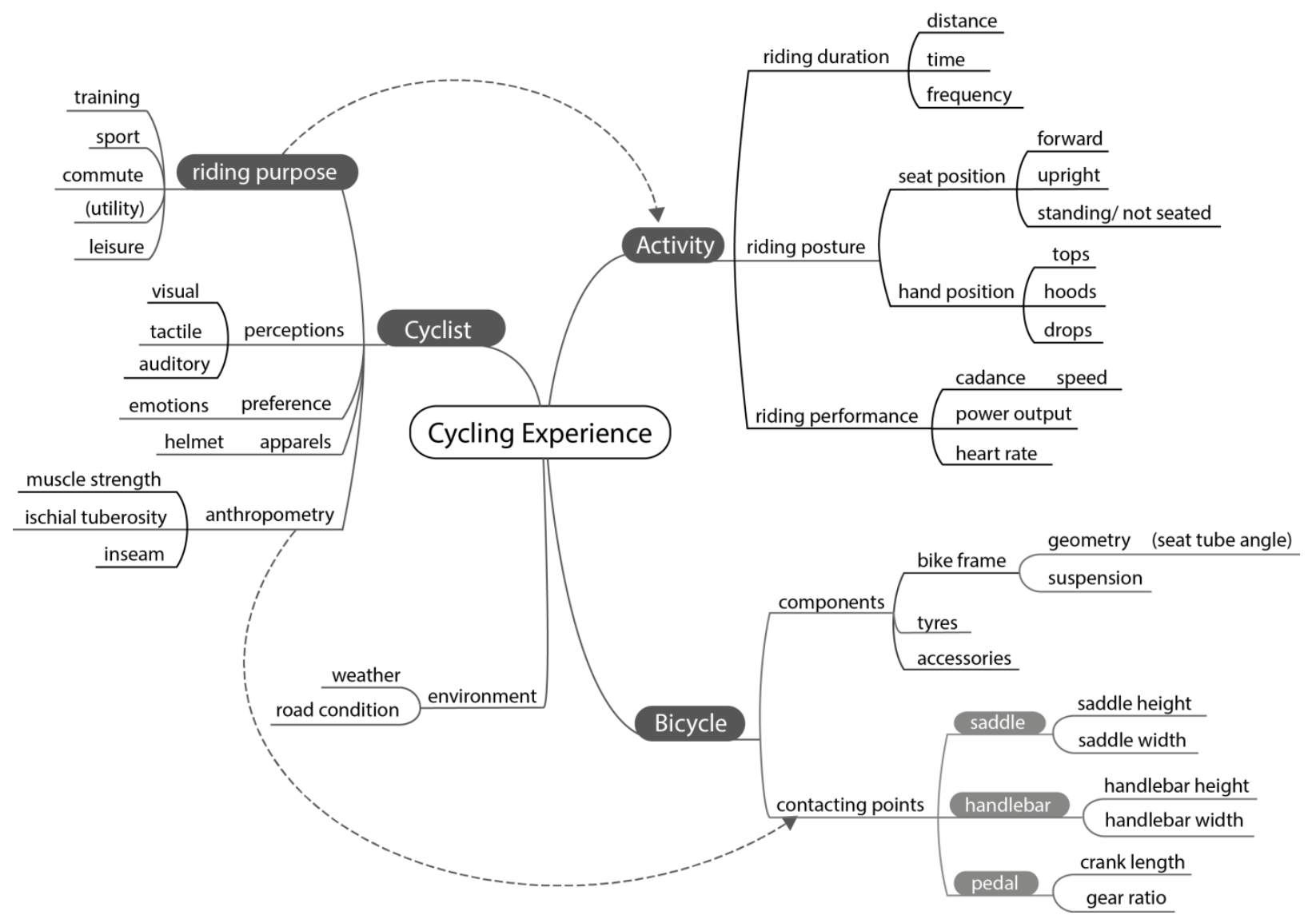

Figure 3.3 The context of cycling experience 
In the case of cycling, a cyclist's riding purpose (e.g., training) will affect the context of the task, such as the longer riding duration, the forward riding posture, and higher power output. To perform the intended activity, a cyclist will adjust contact points between his or her body and the bicycle - this suggests an ergonomics issue. Moreover, a cyclist's attitudes and preferences are part of product experience evaluation (Desmet \& Hekkert, 2007; Hassenzahl, Diefenbach, \& Göritz, 2010). Thus, it can be noted that the cycling experience illustrated in Figure 3.3 is neither complete nor exhaustive.

According to the conceptual act theory of constructed emotion (Barrett, 2006; Barrett, Mesquita, \& Gendron, 2011), human emotion is a consequence of many contextual factors and is activated under suitable conditions. This notion can better explain the phenomena of an overall product impression by integrating the UX information into the process of collecting K-words, so as to address the complexity of contextual factors (Figure 3.1, right). Therefore, product emotions can even be assessed based on both physical and emotional experience. The next section will explain how the proposed UXCM can be applied to the product design and development.

\subsection{The UXCM architecture}

Based on the literature review in Chapter 2, two UX characteristics, viz., temporality and multisensory have been identified to develop the UX-based collection method (UXCM) for a specific product category—sporting goods. The UXCM is introduced to support the stage of exploring semantic domain in a typical KES (Figure 3.4), and help designers analyse a user's emotional needs. In this study, the input of UXCM is the cycling experience, which will be translated into a pool of K-words. The UXCM selects the representative K-words to build the semantic database according to two UX characteristics. 
The output of UXCM can be a set of K-words (emotional requirement, ER) that is retrieved to apply for a specific product component (e.g., bicycle saddle).

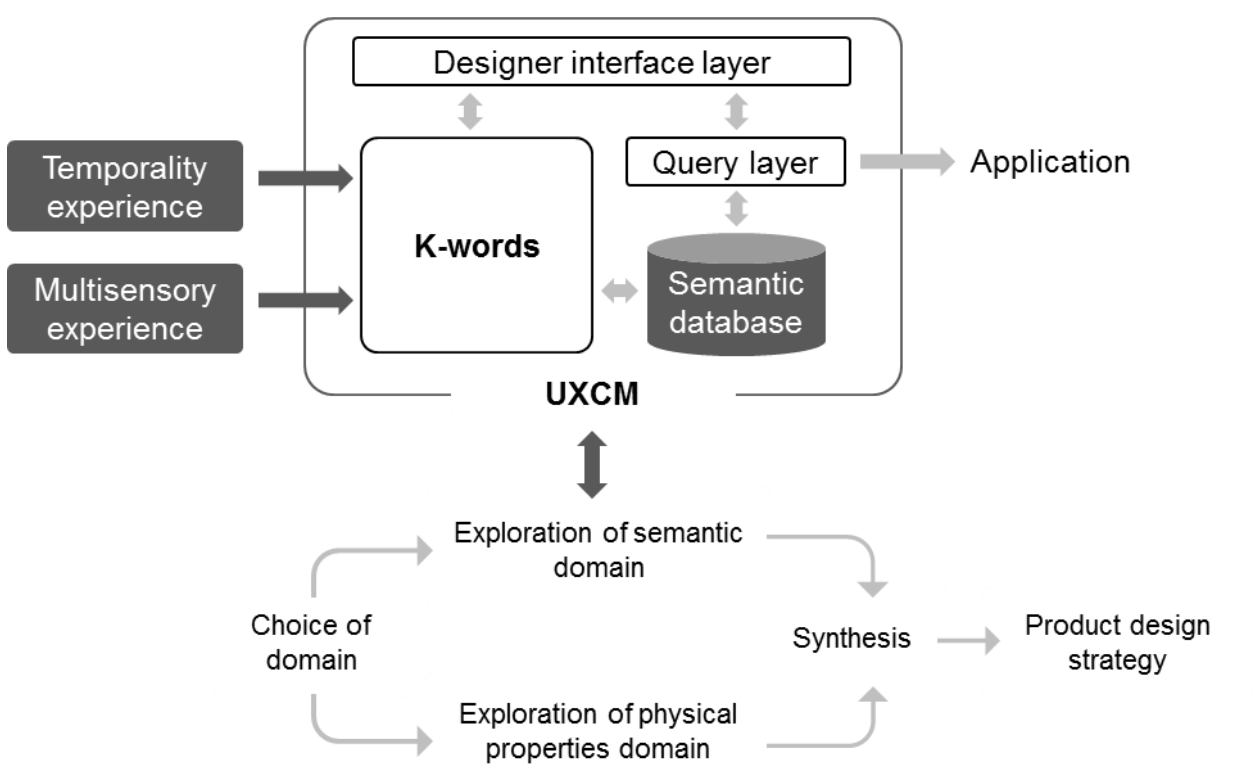

Figure 3.4 The proposed UX-based Collection Method (UXCM)

\subsubsection{Temporality module}

In the field of sports science, researchers have investigated how an athlete's physical and psychological performance progress over a period of time, such as endurance training (Hawley \& Stepto, 2001) and mental preparation (Thelwell \& Greenlees, 2003). Yet the module of temporality in UXCM focuses particularly on one's emotional experience towards sporting goods. Although it is possible to record an athlete's emotional feedback for days, weeks or even months, human's measurement construct model can reform in this timeframe, with individual differences (Kelly, 1955). In other words, the reliability of the collected responses may not be consistent in a chronological study (Law, van Schaik, \& Roto, 2014; Veen \& Vink, 2016). Not to mention that one's personality traits will influence his or her need for touch (Peck \& Childers, 2003), or for visual aesthetics (Bloch, Brunel, \& Arnold, 2003). In this light, the author proposed the individual profile index (IPI) to 
assess a cyclist's level of involvement. Table 3.1 shows 14 close-ended items that were designed to identify the regular road cyclists (RRC). Aspects of personal, fact and situational questions are included according to the theory of involvement inventory (Zaichkowsky, 1994).

Table 3.1 Questions to measure the cyclists' involvement level

\begin{tabular}{cl}
\hline No & Questions \\
\hline 1 & Do you have one or more road bike(s)? \\
2 & Do you ride your road bike three days or more in a week? (Fact) \\
3 & Do you ride more than 30 miles in a week? \\
4 & Do you track your heart rate when you cycle? \\
5 & Do you cycle for competition at any level? \\
6 & Do you have more than two years' experience riding on your road bike? \\
7 & Do you wear padded cycling shorts when you ride? \\
8 & Do you have cycling shoes? \\
9 & I feel that bicycle is an important part of my life. \\
10 & I get a saddle sore at some points during my riding. (Situational) \\
11 & I am a member of a cycling club. (Personal) \\
12 & I feel that brand means a lot to me. \\
13 & I think that bike fitting is essential for me. \\
14 & I am interested in reading product reviews about bicycles. \\
\hline
\end{tabular}

The UX of bicycles can be a little complicated because the bicycle is not only sports equipment for training or for health, but can also be a transportation vehicle (Bailey et al., 2010). In fact, an enthusiastic cyclist would spend more time and energy on the bikes, and it may be internalised as his/her personal identity. However, not all contexts above can be supported by the conventional definition of sports motivation, viz., doing it for others or out of self-interest (Fortier, Vallerand, Briere, \& Provencher, 1995). It is noted that the concept of IPI is similar to the test of dominant hand usage - if the respondent matches 12 out of 14 items in the test, he/she would be identified as an eligible RRC. 


\subsubsection{Multisensory module}

In the context of cycling, the visual appearance of the bike frame, the feeling of the handlebar and the noise from gears or brakes are all likely to evoke a cyclist's emotions. Although all types of human perceptions (seeing, touching, and hearing) can contribute to the UX of sporting goods, researchers may focus on only one human sense depending on the research objective. In fact, the majority of UX studies (Table 2.3 and Table 2.4) examined the visual perception only due to the process of emotion elicitation in UX evaluations as it is more time-consuming if it involves physical interactions. Even so, the ease of physical interaction is relatively important for users evaluating the UX of some product categories that involve a whole-body movement, such as bicycles. In rare cases, a thorough investigation into the user's affective experience from the point of view of multisensory can be found in the literature (Vergara et al., 2011).

With this intention, the author believes that it would be helpful to explore the correlation between semantic spaces of K-words database and users' multisensory perceptions. The findings can be used to establish a principle of selecting reprehensive Kwords - especially in the case that tactile stimuli are not available in the experimental setting. For instance, research has shown that some types of product emotions are influenced by a particular human sense (Desmet et al., 2008; Schifferstein, 2006). Desmet et al. (2008) evaluated a few customised prototypes and concluded that product appearance (visual perception) evoked stronger emotional intensity of K-words in product personality (K-PP) than physical interactions (tactile perception) did. Accordingly, a case study of the multisensory perceptions on saddle experience will be investigated in Chapter 5. 


\subsection{Selecting the K-words for cycling experience}

In the following sections, the author compared K-words that selected through different approaches. The K-words selected by the closed-ended questions were based on two semantic spaces, namely sport emotion and product personality, which were previously defined in Chapter 2. Another group of K-words were selected by the open-ended questions and were drawn into a conceptual model. Although these experiments were conducted on different occasions, the findings showed how the collection methods affected the structure of K-words database.

\subsubsection{K-words in sport emotion}

In order to understand what emotions are experienced in a competition, Jones et al. (2005) interviewed 264 athletes and sorted their feelings into a list of adjectives. After removing the negative emotions, the list (Table 3.2) was adopted as the initial semantic database for K-words in Sport Emotion (K-SE) in this study.

Table 3.2 The adjectives describing positive emotions experienced by athletes

\begin{tabular}{llll}
\hline K-words in Sport Emotion (K-SE) & & \\
\hline Adrenaline Rush & Ecstatic & Focused & Pleased \\
Anticipation & Elated & Fulfilled & Pleasure \\
Calm & Energetic & Happy & Proud \\
Competitive & Enjoyment & Important & Relaxed \\
Confident & Enthusiastic & Joyful & Relieved \\
Content & Excited & Motivated & Satisfied \\
Determined & Exhilarated & & \\
\hline
\end{tabular}

Next, the author designed a simple questionnaire, posted it on Facebook groups and online forums targeting cyclists based in Singapore (http://www.togoparts.com, posted in Sep 2014) and the United Kingdom (http://www.bikeradar.com, http://www.cyclechat.net, posted in Nov 2015). The participants were asked to provide their cycling backgrounds 
(e.g., gender, riding purpose) and to choose the most common positive sport emotions they experienced in cycling. Each participant could only choose one riding purpose in this survey, and five corresponding sport emotions (i.e., K-SE) based on that purpose.

In total, the number of complete responses was 121 from the UK and 179 from Singapore. The results of correspondence analysis (CA) using statistical software R were plotted in Figure 3.6 and Figure 3.7, respectively. Each coordinate refers to one particular positive emotion (categorical data). The distances between the coordinates of positive emotions to four red coordinates refer to the relationship between the respondent's riding purpose (training, sport, commute, leisure) and 26 positive emotions. Ecstatic, for example, is plotted far to the origin in the SG chart, and not even present in the UK chart because none of the UK respondents selected it. In comparison, the coordinates in the SG chart are closer to the origin, which means they are about average on all sport emotions being measured. Yet interestingly, for both SG and UK charts, Calm was found to have a strong corresponding relationship with bicycle commuting while Happy was related to leisure cycling. This finding supports previous research that Ross et al. (2010) concluded on recreational cyclists' emotional experience.

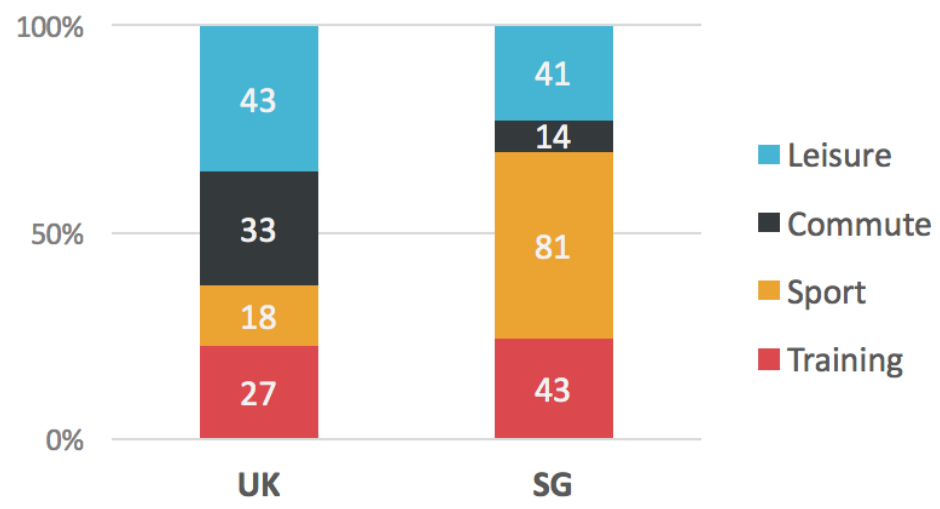

Figure 3.5 The number of selected riding purposes in UK and SG 
In fact, nearly half of SG cyclists (81 out of 179) were reported to ride for sport, and only $8 \%$ for commuting (Figure 3.5). Although it could be affected by the fact that personal construct varies according to the cultural background (Tomico et al., 2009; Yamamoto et al., 2005), another possible reason may be the geographical difference between two countries (e.g., fewer bicycle commuters in Singapore because of its hot weather). As a result, it is noted that the author shall invite the participants who share similar socialcultural background for further experiment.

Regarding the selection of the representative K-words, researchers have pointed out that at least 20 semantic items are required to support the construction of semantic spaces (Bynner \& Coxhead, 1979; Kelly, 1955). Despite previous studies which have shown that only 20-25 classifications of emotion words (in English) have essential different meanings (Desmet, 2012; Petrov et al., 2012; Shaver, Schwartz, Kirson, \& O'connor, 1987), it should be noted that Kansei words (K-words) used in the field of product design, are not totally equivalent to emotion words in the field of psychology (Gendron et al., 2012; Lindquist \& Gendron, 2013). This is because the definition of a K-word could cover any descriptors related to a user-product interaction, for example, the actual numbers of K-words ranged from 2 to 78 in a semantic differential test in previous UX studies (Table 2.3 and Table 2.4).

Next, the author removed any K-SE that was chosen below $1 \%$ of all K-SE, Important, Ecstatic, Joyful, Relieved, Excited, Anticipation, Adrenaline rush and Elated. If two words have similar semantic content, such as Pleasure (7\%) and Pleased (3\%), they will be depicted as overlapping on the plots. In this case, the author kept the one selected by a higher percentage of participants. The final list of K-SE is shown in Table 3.3. 


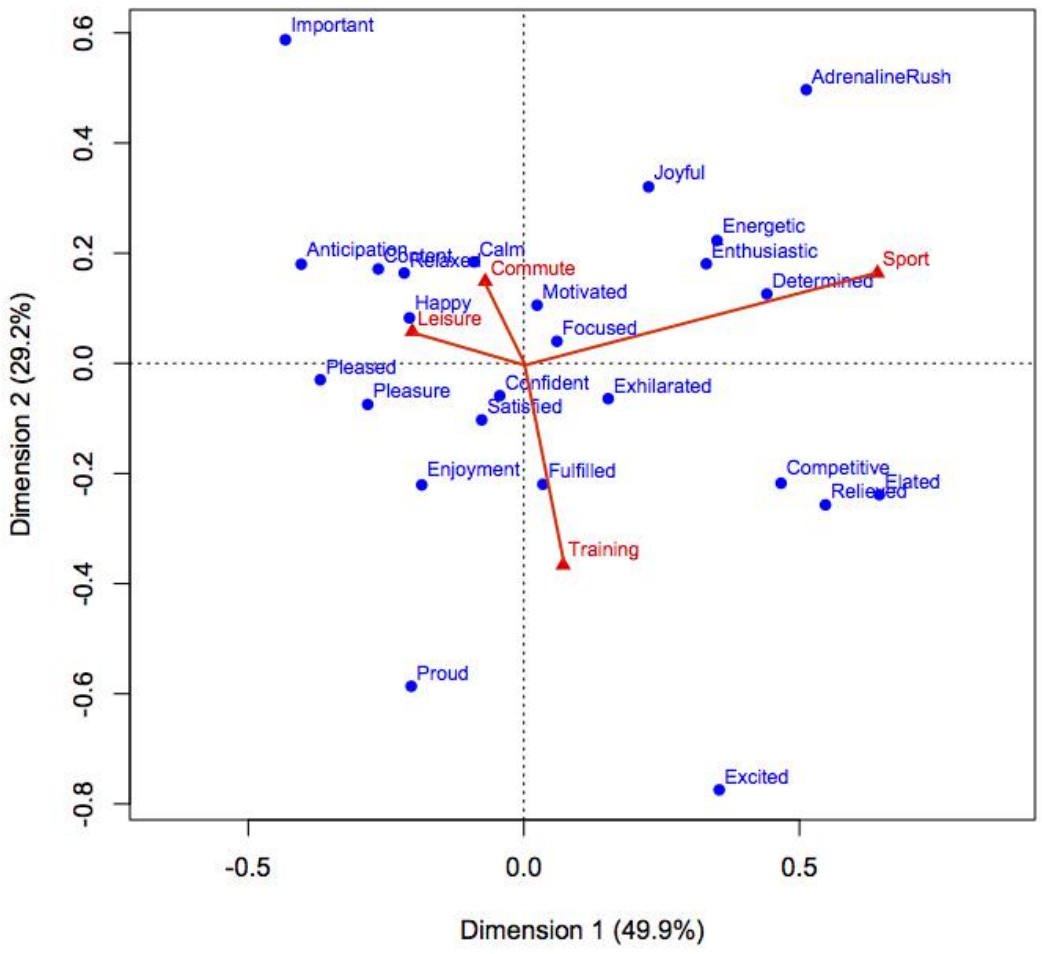

Figure 3.6 The CA plot of UK participants

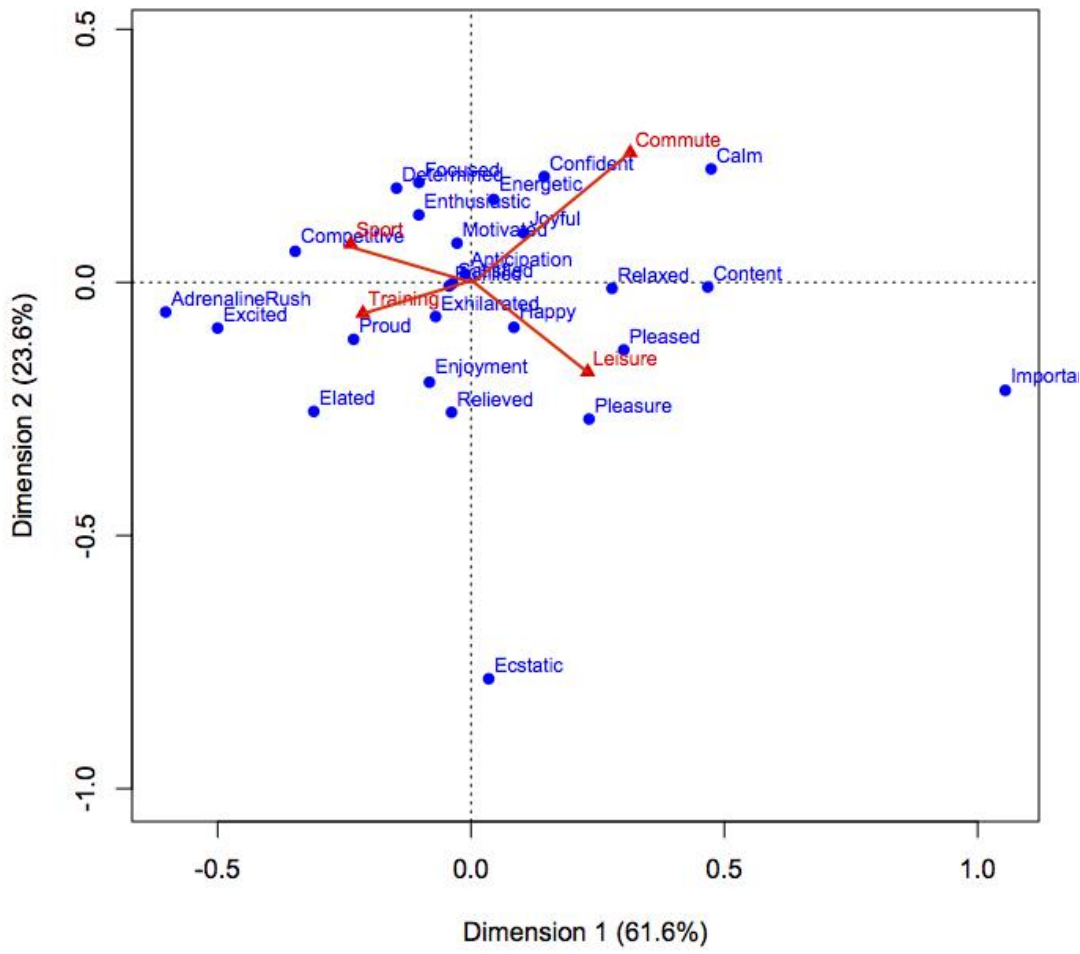

Figure 3.7 The CA plot of SG participants 


\subsubsection{K-words in product personality}

The initial semantic database for K-words in Product Personality (K-PP) was collected from three pieces of litterateurs. First, K-words were retrieved from the product personality testing scale (Mugge, Govers, et al., 2009). This scale initially had $20 \mathrm{~K}$-words, but the author removed K-words that have a negative valence (e.g., Boring, Untidy), being part of sport emotions (e.g., Relaxed), and those that were ambiguous without contextual information (e.g., Open, Aloof).

The second piece of literature used was a motorbikes project (Singh \& Das, 2009) because the UX of motorbikes is very similar to the UX of bicycles. They both have two wheels and are designed for a single rider in sport (or transportation). The initial K-words in this study included: Formal, Traditional; Comfortable, Friendly, Popular, Professional; Emotional, Extraordinary, Heavy, International, Sharp, Sporty. Likewise, the author selected the representative K-words according to their clusters. Furthermore, the psychophysical adjectives, viz., Rough and Warm, were adopted from a study of a user's touch perception (X. Chen, Barnes, Childs, Henson, \& Shao, 2009). Finally, 20 Kansei words are shortlisted in Table 3.3.

Table 3.3 The shortlisted $20 \mathrm{~K}$-words for cycling experience

\begin{tabular}{cc}
\hline Semantic Spaces & K-words \\
\hline Sport Emotion (K-SE) & $\begin{array}{c}\text { Calm, Comfortable, Competitive, Confident, Determined, } \\
\text { Energetic, Enthusiastic, Pleasure, Proud, Relaxed. }\end{array}$ \\
Product Personality (K-PP) & $\begin{array}{c}\text { Cute, Dominant, Traditional, Friendly, Honest, } \\
\text { Interesting, Pretty, Rough, Sporty, Warm. }\end{array}$ \\
\hline
\end{tabular}




\subsubsection{A conceptual model of bicycle saddles experience}

Subsequently, the author continued to draw a conceptual model of bicycle saddles experience. In comparison to the previous model (Figure 3.3, page 47), this model focuses on the positive experience (enjoyment) for one product (saddle). Moreover, it was built up using words provided by participants from the same study (open-ended interview).

The participants were recruited from local road cycling clubs based in the Midlands regions of England. The experiments were conducted at Loughborough University with ethical approval granted in June 2016. Advertisements for volunteers were posted on Facebook groups and distributed on campus; no specific profession was required as long as participants rode on a regular basis. Male cyclists were excluded because of gender differences in anthropometry which affects the design of bicycle saddles (Potter, Sauer, Weisshaar, Thelen, \& Ploeg, 2008).

First, participants received an information sheet and a briefing and then signed the consent form. They were invited to draw their own saddle and use three keywords to describe it (Appendix A). Participants were allowed to draw more than one if they own several saddles. This was not a memory task; rather, it was a way to help them bring out a vivid picture in their minds in terms of the characteristics of bicycle saddles. They were therefore allowed to use indicators or captions to explain the meaning of their chosen words. All 33 participants are English, with one German and one Slovenian, with an average age of 38 years old $(S D=11.8)$. One participant turned out not to be a road bike owner, and another two being failed to save full recordings; in total, three participants were removed prior to further analysis.

In total, $142 \mathrm{~K}$-words were collected (Table 3.4) and were grouped into three categories, viz., overall impression, product properties and others. Each category has a 
number of sub-categories. Over half of the words $(55 \%)$ that participants used to describe their own saddles fall under the category of product properties, including firmness, texture, the facts-of-shape, the feel-of-shape, colour, weight and status. This finding was expected to be used as a baseline for the semantic database in saddle design.

Table 3.4 The counts of words that participants used to describe their own saddles

\begin{tabular}{|c|c|c|c|c|c|c|}
\hline \multicolumn{2}{|c|}{ Overall impression (34\%) } & \multicolumn{3}{|c|}{ Product properties $(55 \%)$} & \multicolumn{2}{|c|}{ Others $(11 \%)$} \\
\hline $\begin{array}{l}\text { (general) } \\
12 \text { comfortable } \\
7 \text { uncomfortable } \\
4 \text { comfy }\end{array}$ & $\begin{array}{l}\text { (positive) } \\
1 \text { flexible } \\
1 \text { supportive } \\
1 \text { reliable } \\
1 \text { effective } \\
1 \text { suitable } \\
1 \text { satisfied } \\
1 \text { efficient } \\
1 \text { happy } \\
1 \text { good } \\
1 \text { easy }\end{array}$ & $\begin{array}{l}\text { (firmness) } \\
7 \text { hard } \\
4 \text { firm } \\
2 \text { solid } \\
1 \text { stiff } \\
1 \text { flat } \\
5 \text { padded } \\
4 \text { soft } \\
1 \text { cushion }\end{array}$ & $\begin{array}{l}\text { (facts-shape) } \\
5 \text { hole } \\
5 \text { narrow } \\
3 \text { wide } \\
1 \text { slim } \\
1 \text { long }\end{array}$ & $\begin{array}{l}\text { (colour) } \\
7 \text { black } \\
3 \text { white } \\
2 \text { pink } \\
2 \text { grey } \\
1 \text { red } \\
1 \text { strip of } \\
\text { pink } \\
1 \text { blue }\end{array}$ & $\begin{array}{l}\text { (gender) } \\
1 \text { girly } \\
1 \text { man } \\
1 \text { woman } \\
1 \text { female }\end{array}$ & $\begin{array}{l}\text { (purpose) } \\
2 \text { race } \\
1 \text { functional } \\
1 \text { tested } \\
1 \\
\text { necessary } \\
1 \text { chair } \\
1 \text { fit for } \\
\text { purpose }\end{array}$ \\
\hline $\begin{array}{l}\text { (negative) } \\
4 \text { painful } \\
1 \text { numbness } \\
1 \text { scratch } \\
1 \text { hurts } \\
1 \text { annoying } \\
1 \text { restricting } \\
1 \text { bad } \\
1 \text { awkward } \\
1 \text { not } \\
\text { enjoyable }\end{array}$ & $\begin{array}{l}\text { (neutral) } \\
2 \text { basic } \\
1 \text { okay } \\
1 \text { moderately }\end{array}$ & $\begin{array}{l}\text { (texture) } \\
2 \text { smooth } \\
1 \text { slick } \\
1 \text { slippy } \\
1 \text { slidey } \\
1 \text { leather } \\
\text { covered }\end{array}$ & $\begin{array}{l}\text { (feels-shape) } \\
1 \text { odd } \\
\text { looking } \\
1 \text { unique } \\
1 \text { stylish } \\
1 \text { strange } \\
\text { shaped } \\
1 \text { unobtrusive } \\
1 \text { shiny } \\
1 \text { pretty } \\
\text { looking }\end{array}$ & $\begin{array}{l}\text { (weight) } \\
2 \text { light } \\
1 \text { heavy } \\
-- \\
\text { (status) } \\
2 \text { new } \\
1 \text { cheap } \\
1 \\
\text { unavailable }\end{array}$ & & $\begin{array}{l}\text { (posture) } \\
2 \text { middle } \\
1 \text { position } \\
1 \text { area } \\
1 \text { sweet } \\
\text { point/sit }\end{array}$ \\
\hline
\end{tabular}

After the drawing session, all participants were asked to answer six open-ended questions. The analysis of the interview was performed on a transcription website (http://otranscribe.com). In an attempt to minimise interviewer bias, the author only assisted in clarifying the questions participants were confused with. The participants were able to freely express themselves and with no time limit; the whole process was audio or video recorded depending on how comfortable they were in front of the camera. 
Six interview questions (Table 3.5) were written on a sheet of paper and given to them after the drawing session. All participants answered in the same order starting from the context-based topic. Questions 1 and 2 were designed to learn about each participant's cycling background, including their riding purposes and motivations, which have a major impact on people's concerns and priorities (Dorey \& Guastavino, 2011). Question 3 was designed to probe an enjoyable cycling experience since it was the interest of this study. Subsequently, the participant's attitudes (Question 4) and expectations (Question 5) on a bicycle saddle were collected. Finally, an activity-related topic (Question 6) helped recall how it (the saddle) feels on the bike.

Table 3.5 The list of open-ended interview questions

\begin{tabular}{cl}
\hline No & Questions \\
\hline 1 & What inspired you to use a road bike? How long have you been riding? \\
2 & Is this your first road bike? How many bikes do you have? \\
3 & Best moment so far on the bike? \\
4 & How would you describe your saddle? How do you feel about it? \\
5 & What factors do you consider whether these saddles meet your needs? \\
6 & How did you come to your current bike setup? How does it work? \\
\hline
\end{tabular}

Generally, road cyclists all have the desire of going faster and further. Once they expected to sit on the saddle over a period of time or distance, the saddle comfort issue became more inevitable.

é I want something that is comfortable for long distances, so when I am doing 7090 miles, I want to be able to sit comfortably in the saddle, and I don't want it to rub and chaff or give me blisters or any of the uncomfortable bit because I want to be able to get on the bike and ride again in the next few days. (RRC9)

é but I don't particularly enjoy riding day after day, because I know it's going to hurt. $(R R C 23)$ 
Of all the participants, $66 \%$ said that they are constantly seeking a more comfortable seat. In fact, the more time each cyclist spent in this trial-and-error process, the closer her relationship with the saddle became (Mugge, Schoormans, et al., 2009). Some might eventually get attached to a particular one while some admitted it was a decision to compromise.

é sometimes I sit on it and feel, I can do better but obviously trying to find a better saddle is not an easy task. (RRC19)

é my saddle is the result of trying many saddles, with a lot of pain. (RRC32)

é I have a bit of love-hate relationship with bike saddles, and I don't think you'll ever get a particularly, or a totally comfortable saddle. (RRC39)

é I've had a specialized saddle which was on my very first bike. Iôve moved it on every road bike I've had. I am very happy with this, it and I understand each other. (RRC16)

é lôve had several. Got onel really like but it don't sell anymore. (RRC30)

Regardless, the participants tended to determine her preferences depending on the context. $40 \%$ of participants were able to express explicitly what type or shape of the saddle they felt more comfortable with. Also, $20 \%$ of the participants pointed out the correlation between saddle comfort and riding positions, and acknowledged the benefit of the right bike fit.

é For me, I kind of lookat the weight and the width, because that's like a big factor, because I am racing. I found that the comfortable part needs to have a cut-out, so anything that is flat and padded, especially when you down the drops and trying to get into aggressive position. (RRC17)

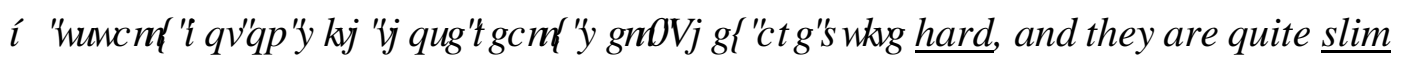
line, and they got kind of dome top. I don't like the one is deep in,

Ifound that they get crap pressure points, and that's really uncomfortable. (RRC12) 
é I think I amal ways more comfortable on the saddle with a hole in the middle, and I, generally speaking, like a fairly narrow, neat saddle. (RRC16)

In addition to the physical comfort, $30 \%$ of the participants mentioned that it is important that the look of the saddle matches the bike style. It is mainly related to personal taste and fashion choices, but still contributes largely to an enjoyable saddle experience considering the words' frequency (e.g., colour) in the semantic database. Furthermore, research has shown that whether the product styles match one another can change the customer's impressions too (Ross et al., 2010; Yamada et al., 2013).

é because a big part of cycling is you don't want a nice-looking bike and then a saddle that just looks too big, doesn't look racing-like, or the colours don't suit it. (RRC21)

é I also want it to look quite nice because the rest of my bike does. (RRC28)

é which I got because it is soft and comfy. I have a black one and a white one. White is a terrible colour. (RRC36)

Additionally, how participants described their best moment on a bike (Question 3) threw some light on the unknown cause of cycling comfort in the literature (Ayachi, Dorey, \& Guastavino, 2015; de Looze, Kuijt-Evers, \& van Dieen, 2003; Ellegast et al., 2012). It is noticed that $63 \%$ of the participants are also involved in other sports (e.g., triathlon and cross-training). Positive cycling experience, therefore, seems to mostly happen in a significant event, such as winning a medal or achieving a personal best. Occasionally, it has nothing to do with competitive cycling — such as clipping in and not falling off for the first time. The author has labelled such events as achievement between Cyclist and Context in the model. Apart from their favourite way of riding, weather, road condition, scene or other contextual factors, the riding buddy has some influences too. 


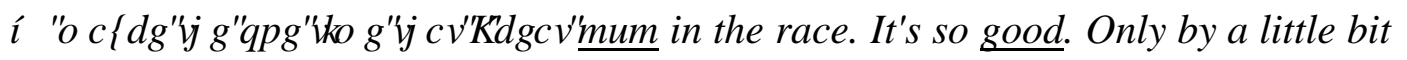
but I still beat her in the race. (RRC30)

é only three women, and being able to keep up with other guys (RRC18).

... it was reduced to 80 miles from 100 because of the weather. It rained the whole time, and it was just flooded, but because I was with friends, and it was just hilarious. $(R R C 21)$

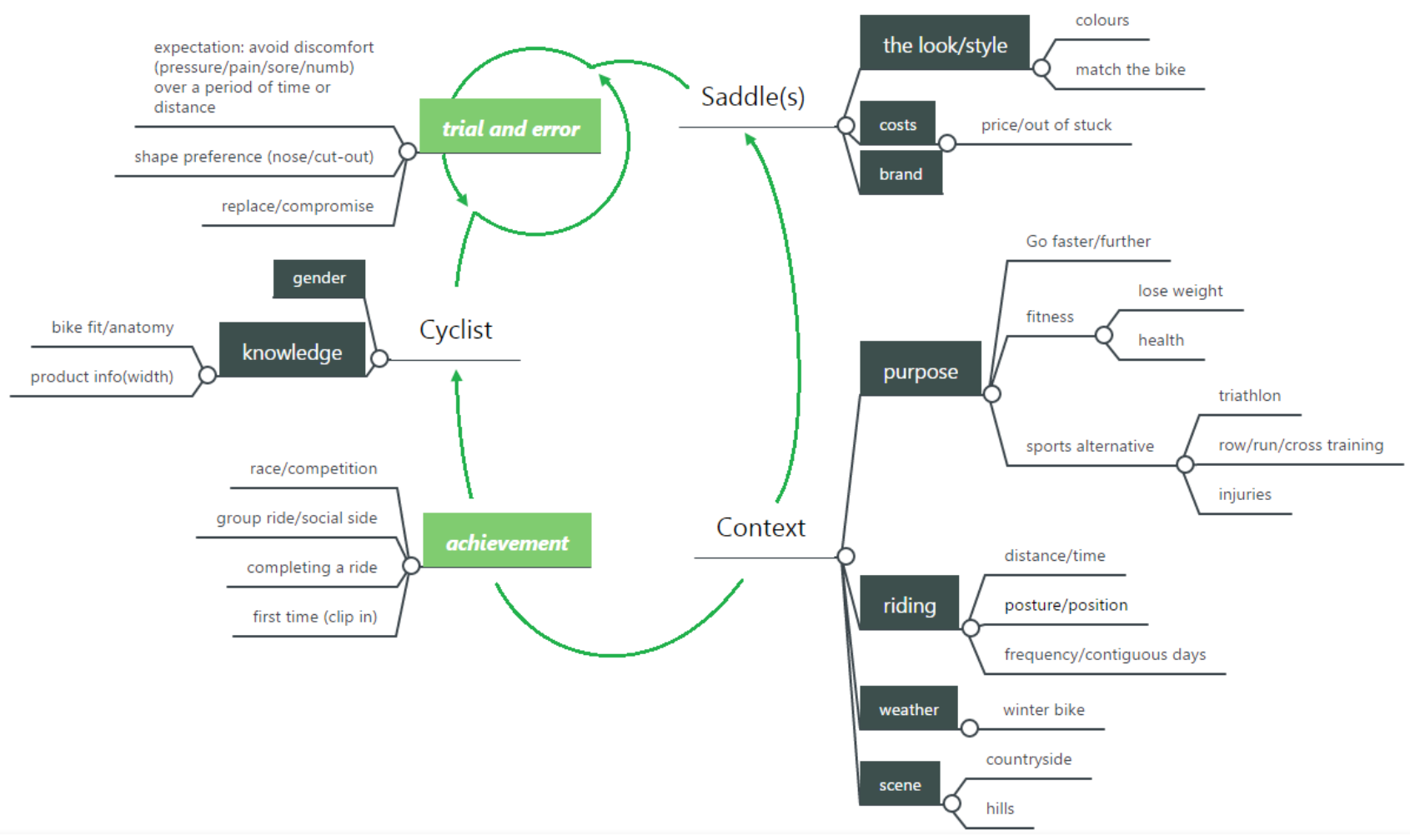

Figure 3.8 The conceptual model of bicycle saddles experience

Previous research has pointed out that human experience often consists of three traits, viz., subjective reflections, physiological changes, and action tendencies (DiSalvo, Hanington, \& Forlizzi, 2002; Scherer, 2005). In this study, the proposed conceptual model (Figure 3.8) suggested three essential aspects, viz., the cyclist, the saddle, and the context. Although the author did not use post-questionnaires to validate this model (Barrass, Roberts, Jones, Hague, \& Dickens, 2008; Roberts et al., 2001), those identified aspects were not 
only consistent with previous comfort models (de Looze et al., 2003), but also integrated the activity/behaviours domain from other models (Schmidt, Beigl, \& Gellersen, 1999; Vink \& Hallbeck, 2012).

Judging from the interview responses, the UX of bicycle saddle was not dictated by the physical discomfort. Although the participants knew clearly what negative feelings they wanted to avoid (e.g., chafing), they would use K-words related to preferable product properties (e.g., shape) to support their statement on perceived comfort level—which is more of an abstract concept. Overall, the dynamic characteristic of saddle experience (between the cyclist and the saddle) is an iterative process of balancing physical discomfort (e.g., pressure, pain, sore) and psychological comfort (e.g., style, preference, cost). In addition to the product itself, 'achievement' can also strengthen cycling enjoyment in terms of positive product experience.

\subsection{Summary}

According to the literature review, the fundamentals and architecture of the proposed UX-based collection method (UXCM) were illustrated in Figure 3.1 and Figure 3.4. In order to build the semantic database for cycling experience, the author conducted several surveys to collect K-words within different semantic spaces. The investigation of K-words in Sport Emotion (K-SE) through online questionnaires showed how its structure was affected by the limitations of geographical regions and cultural backgrounds. The final 20 K-words include the list of K-words in Product Personality (K-PP) collected from relevant articles too. Additionally, a conceptual model of bicycle saddles was built using the coded interview responses to learn how cyclists describe a positive product experience with 
contextual factors. It is noticed that the key connection in this model (trial-and-error) supports the temporality of UX - a user's feelings change with increased involvement.

Accordingly, the author will consider two modules of UXCM in terms of the temporality (Chapter 4) and multisensory experience (Chapter 5). This further investigation aims to test whether the UXCM is able to rectify the K-words database of sporting goods in a bid to fulfil a user's emotional requirements in sports experience. 


\section{Chapter 4 Temporality of Vision-based Product Quality}

The present chapter investigates the temporal characteristic of UX-how a customer's cognitive and affective needs change over time. The unipolar semantic differential scale was applied, and the eye movements of a group of novice cyclists and a group of expert cyclists were recorded as they looked at various types of bicycle images.

\subsection{Introduction}

Some research suggests that market success depends on providing consumers a pleasurable experience as much as it depends on helping them complete a task quickly and completely (Buxton, 2007; Jordan, 1998). The more positive feelings a product evokes, the more the users enjoy it, and the more successful the product will be. Designers therefore always attempt to prevent or evoke certain emotions in new product development (NPD), such as a pleasurable look, touch or sound of the product (Rodríguez Ramírez, 2014). As the visual impression plays a big part in perceptions of product quality, particularly in the early phase of NPD (e.g., proposing conceptual ideas with sketches only), designers use it as an intuitive and effective tool for targeting users' emotional preferences. Thus, the evaluation of vision-based product quality has become an important topic in the study of UX.

In the evaluation of a user-product interaction, Karapanos (2013) argued that time is the key to understanding the product experience. Due to changes in personal knowledge, standards, and motivations over time (Khalid \& Helander, 2006), the feelings that a customer experienced are different from the first time using the product. For instance, skilled athletes may seek stronger exercise intensity (i.e., cognitive experience) in a long 
term. Such change, however, may be influenced by the tested product types. To cite one key distinction between product types, the UX of sporting goods that are attached to the human body is different from the UX of consumer products that cannot be worn (Kuru \& Erbuğ, 2013).

\subsubsection{Perceived affordance and attractiveness}

Based on the look of a product, a user develops several emotional impressions, which are called product emotions. The human feelings evoked by a user-product interaction are not like the basic human emotions such as happiness and sadness. They are more subtle and complex underlying individual consideration of consequences; for example, the user is satisfied with the product (Desmet \& Schifferstein, 2012; Khalid \& Helander, 2006). Moreover, several product emotions can happen simultaneously during the interaction; it is hard to distinguish these emotions' valence and arousal levels via physiological reactions (e.g., heart rate and facial expression).

In general, users evaluate every product emotion from both a cognitive and affective point of view. Researchers have variously called these types of evaluation pragmatic and hedonic (Hassenzahl, 2004), typicality and arousal (Blijlevens, Carbon, Mugge, \& Schoormans, 2012), affordance and interactive aesthetic (Xenakis \& Arnellos, 2013). The cognitive-focused evaluation refers to a user's satisfaction in usability (e.g., if it works efficiently); the affective-focused emotions focus on reflecting personal preferences (e.g., if it looks pretty). However, the boundary between these two evaluations is not always clear. Some researchers think that the concept of affordance could be extended to support other psychological needs too (Pucillo \& Cascini, 2014; Still \& Dark, 2013), for example, the look of a beach chair should afford the user to feel relaxed. As customers are often asked 
to evaluate an overall product impression, the halo effect may cause them to evaluate a beautiful product as usable (Hoegg, Alba, \& Dahl, 2010; Norman, 2002; Seva, Gosiaco, Santos, \& Pangilinan, 2011; Sonderegger \& Sauer, 2010; Tractinsky et al., 2000).

Beauty, as they say, is in the eye of the beholder. A product that is considered visually appealing by the designer may not resonate with the public. Although some aesthetics principles, for example, symmetry, harmony and the golden ratio of geometric proportion (Hekkert \& Leder, 2008) are common or related to innate human preferences, they are not all easy to be tested or applied to a product's appearance (Kumar \& Garg, 2010). Customers may also consider a product to be both attractive and practical if it supports their selfexpression of identity (Anderson, 2011; Crilly, Moultrie, \& Clarkson, 2004; Haug, 2016). It is noted that in this study, beauty and attractiveness are used interchangeably to refer to affective-focused product emotion.

Standards of beauty can change as well. Technology may drive a change in the appearance of a product in a particular category (e.g., flip phones have become touchscreen phones) but the change becomes normal and therefore attractive to users. On the other hand, products that seemed beautiful when they were first introduced may seem normal and boring because they do not change over time. Sports equipment does not change much because the regulations of the sport restrict its form. Yet modern trends (e.g., colours that come into favour over time) can change its appearance and enhance product attractiveness. While the investigation of dynamic UX seems to start with determining a suitable period (e.g., weeks or months) for a particular product category, analyzing dynamic UX based on how heavily users get involved in a product instead of a certain period has advantages.

First, everyone needs a different amount of time to adapt to a new product. When a novice user spends enough time on a product and becomes an expert, the end-user 
experience will change accordingly in personal knowledge, standards and anticipation (Karapanos, 2013; Khalid \& Helander, 2006). The reason that causes users to look for different product emotions from those they used to require is not time, but the measurement model in their minds because of the increasing product familiarity, the amount of exposure to or experience with the product (Blijlevens, Mugge, Ye, \& Schoormans, 2013; Choi \& Jun, 2007). Secondly, integratipi " j g" eqpegr v" qh" wugtÍl" lpxqrxgo gpv" ngxgn' cmqy u" researchers to evaluate a user-product interaction within a contextual level, which includes ewurqo gtul'"wuci g"j cdku"cpf "r tqf wev"r tghgt gpegu'lp"xctkquu"ukwc kqpuOHqt 'kpurcpeg."dle \{eng" customers who ride daily in a short distance (e.g., commuters), may not focus on the aerodynamic efficiency of bikes as professional cyclists would. Understanding this can also ensure designers of new products focus on the correct family of product features for different market segments.

\subsubsection{Expert-Novice differences in eye movement}

In addition to the semantic differential test, researchers have applied the eye tracking technique to understand the product evaluation made by an expert or a novice. As physiological measurements (e.g., tracking gaze behaviours) can directly retrieve human knowledge and collect subjects' unconscious actions and inexpressive feelings (Iwatsuki, Hirayama, \& Mase, 2013; Köhler et al., 2014; Schmitt, Köhler, Durá, \& Diaz-Pineda, 2013). In this regard, the experts are capable of identifying more product features than novices, and they refer to subtle elements while judging the appearance of an object (Kavakli \& Gero, 2002; Miura, 2000). Novices, on the other hand, are more likely to be attracted to a non-traditional product feature (Mugge \& Schoormans, 2012). In the field of sports, an athlete's visual search strategy is one of the factors to determine his or her development of 
expertise. However, previous studies were limited to the cognitive aspects, such as assessing environmental information or picking up perceptual cues in physical activities (Mann, Williams, Ward, \& Janelle, 2007). To the best of the author's knowledge, how athletes perceive affective properties of sporting goods has yet to be addressed.

Moreover, research has shown that customers use different strategies to evaluate a product depending on which category it belongs to (Lin \& Lu, 2007; Spence \& Gallace, 2011). For example, a bicycle has multiple parts with respect to the modular design principle. Each part is manufactured and designed by different suppliers who focus on certain components. In light of this, S. W. Hsiao and Ko (2013) applied a morphological chart and the semantic differential test to study the appearances of handlebars, saddles, frames, wheelsets, and crank sets in terms of customer preferences. Their study suggested that a single component can contribute to the evaluation of vision-based product quality aside from the overall impression brought up from the shape design (e.g., bike frame). However, from a manufacturing perspective, this evaluation does not provide many benefits to designers in practice. The presentation of separate components may not be an ideal elicitation method for users to perceive genuine product emotions because its emotion inductions may not be strong enough.

This study, therefore, would apply the eye tracking technique to explore vision-based product quality of bicycles and attempt to understand how it can be influenced by subjects' different levels of involvement (experts and novices). The findings aim at helping designers create product emotions tailored to certain components based on the relationship between subjective preferences and artefacts (Schmitt et al., 2013). 


\subsection{Method}

The experiment was designed based on the hypothesis that a customer's perceived cognitive needs for sporting goods will increase over time. To test this hypothesis, the author applied the adapted semantic differential scale to measure the cognitive-focused emotion (confidence) and the affective-focused emotion (beauty). Also, the eye tracking technique was applied to identify the affective properties of the bicycle components.

First, a pilot study was designed to select suitable emotion inductions (i.e., bicycle images) for the eye tracking experiment. In total, 43 bicycle owners ( 22 females, 21 males) with average age 28.42 years $(S D=7.18)$ completed an online questionnaire. Using a fivepoint scale, they were asked to evaluate the level of perceived positive emotions for 40 bicycle images. The bicycle images were collected from several bike company websites (Appendix B), therefore, they were real products launched in the market, and the latest models were picked to reduce the influence of design trends. If there was no statistical evidence according to the ANOVA (Analysis of Variance) results, showing that a subject's gender and bicycle type affected their ratings for a bike image, then that image was eligible for the next stage. As a result, 10 bicycle images including the time trial bike, road bike, utility bike, and hybrid bike were selected. The average response of selected images ranged between 2.2 (lowest) and 3.7 (highest).

The adapted semantic differential scale (SDS) was used to capture users' attitudes in all tasks for this study. Two K-words, viz., confidence and beauty, which were identified from Chapter 3, were selected to represent the cognitive-focused and the affective-focused emotions respectively. Confident is from K-words in Sport Emotion (K-SE). In sports, confidence is of great importance to an athlete, and it is raised from many sources, such as the feeling of controlling the bicycle (trait confidence) and the self-satisfaction of keeping 
the body in shape (state confidence). It is also an essential emotion when using a consumer product; the customer would feel unconfident if a product has poor affordance (Jordan, 1998; Vealey, Hayashi, Garner-Holman, \& Giacobbi, 1998). Pretty/Beautiful is from Kwords in Product Personality (K-PP). An easy reference to distinguish the subtle difference between the original K-word, Pretty and Beautiful is the size of the object. Beautiful is often used to describe a big object (bicycle) while Pretty is more suitable for a smaller delicate object (bicycle saddle).

\subsubsection{Experimental setup}

To draw attention to the bicycle components, 21 Areas of Interest (AOI) were marked with different colors in Figure 4.1, namely the brake lever, cassette, crank set, chain stay, down tube, fork, front brake, front derailleur, front tire, handlebar, head tube, pedal, rear brake, rear derailleur, rear tire, saddle, seat post, seat stay, seat tube, stem, and top tube. The participants were not informed that these AOIs had been assigned.

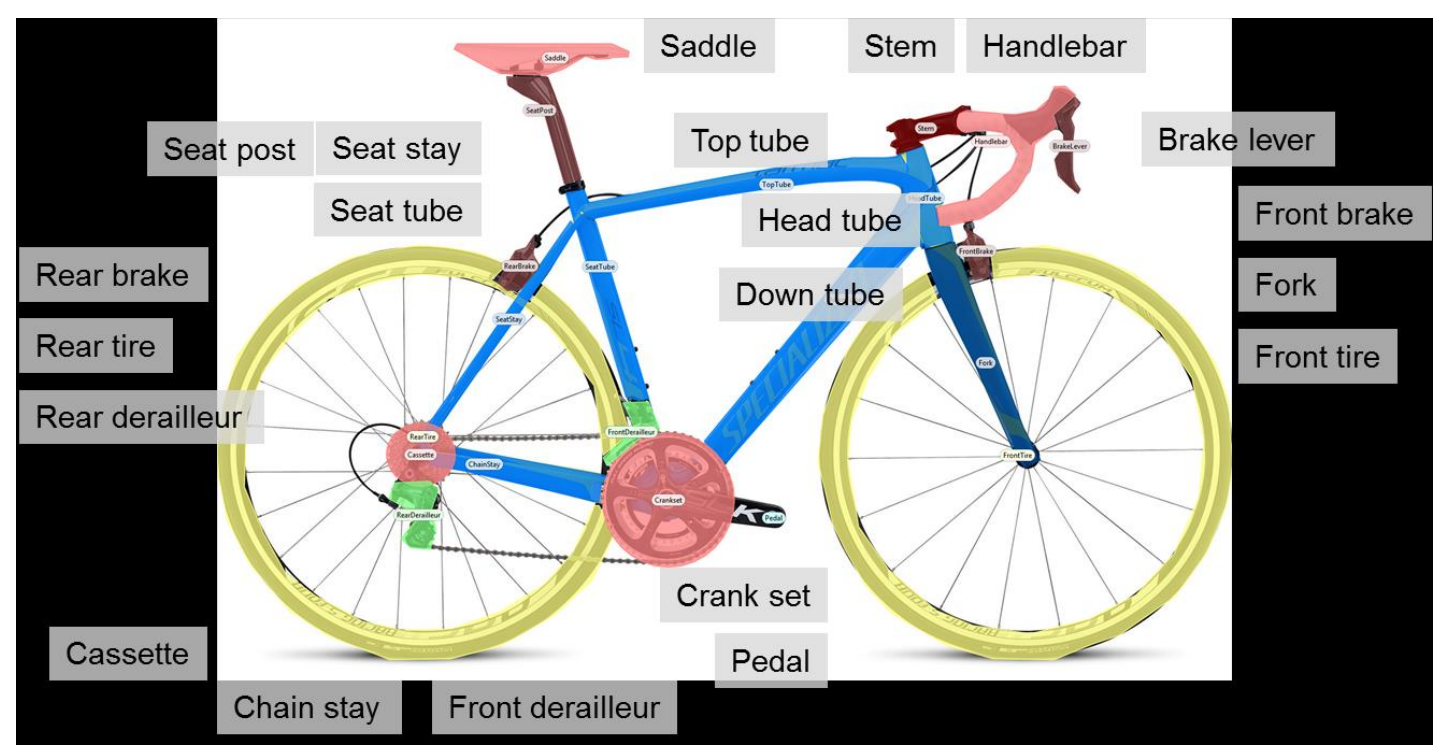

Figure 4.1 The Areas of Interest (AOI) on each bicycle image 


\subsubsection{Participants}

The ethics approval (NTU-IRB) for this eye tracking experiment was granted by Nanyang Technological University in March 2015. The recruitment advertisement was stated as paid studies posted on Facebook groups, and flyers were distributed at local bike shops in Singapore. Initially, the author received 129 responses from cyclists who were interested in this experiment. The eligible subjects were chosen based on gender balance and cycling background. It excluded anyone who had no experience cycling because the current study focuses on how heavily they get involved in cycling, not on their task familiarity, so non-cyclists were not relevant (Williams \& Davids, 1995). As shown in 
Table 4.1, they were divided into two groups, experts and novices. The subjects who participated in cycling for elite training or sport were considered to be experts because personal motivation can change one's visual attention (Visschers, Hess, \& Siegrist, 2010).

In order to compute the required sample size, the author used the standard deviation (SD) that was calculated for 27 subjects (first batch of the experiment) to estimate the expected SD. Then, a priori power analysis was conducted in $\mathrm{G}^{*}$ power (Faul, Erdfelder, Buchner, \& Lang, 2009), with the power defined as $80 \%$ and confidence level as $95 \%$. The author picked the results of three AOIs (crank set, down tube, saddle) in two tasks to compute the sample size, and the required total numbers for between-subject, withinsubject and interaction effect ranged between 6 and 40. In total, 55 cyclists ranging from 21 to 44 years of age $(M=25.4, S D=5.1)$ were recruited to join the eye-tracking experiment. 
Table 4.1 The basic information about participants

\begin{tabular}{cccccc}
\hline Group & Number & Purpose & $\begin{array}{c}\text { Frequency } \\
\text { in a week }\end{array}$ & $\begin{array}{c}\text { Average } \\
\text { distance per } \\
\text { ride }\end{array}$ & $\begin{array}{c}\text { Average } \\
\text { duration per } \\
\text { ride }\end{array}$ \\
\hline Expert & $\begin{array}{c}25(10 \\
\text { females, } 15 \\
\text { males })\end{array}$ & $\begin{array}{c}\text { 12 Training } \\
13 \text { Sport }\end{array}$ & $3-7$ days & $54 \mathrm{~km}$ & 115 minutes \\
\hline Novice & $\begin{array}{c}30(15 \\
\text { females, } 15 \\
\text { males })\end{array}$ & $\begin{array}{c}\text { 14 Commute } \\
16 \text { Leisure }\end{array}$ & $\begin{array}{c}\text { Less than } 2 \\
\text { days }\end{array}$ & $7 \mathrm{~km}$ & 32 minutes \\
\hline
\end{tabular}

\subsubsection{Semantic differential scale}

Vj g"gxcnuc kqp"etkgtkc"wugf "hqt"wugt "go qukpcn'"gzr gtkgpeg"y gtg"pqv"y gm/f ghlpgf "lp" r tgxkquu"uwf kgu."eqxgtlpi "o cp \{ "v\{r gu"qh"gxcnмc kqp"s wgukqp."uxej "cu"uv\{ ng"r tghgtgpeg." r gtegkxgf "hwpe kqpcrkv\{."cpf "qdlgevkg"heevqtu"kng"y g"y lf y "qh"r tqf wew0Y j gp'k"'eqo gu"ıq" c" r tghgtgpeg" ej qkeg." lpf kxkf ucn' f gekukqp/o cmlpi " utcvgi \{ " o c \{ " ecwug" f lhitgtgp" i c| g" dgj cxkqutu'*T glf .'O ceF qpcnf.'(' 'F w."4235+OIn this study. 'the adapted semantic differential scale (Kuo et al., 2016) was applied to capture two product emotions, viz., confidence and beauty, which represent the cognitive-focused and the affective-focused emotions respectively.

Confidence is an essential emotion that customers can experience when interacting with a product; they would feel unconfident if a product has poor affordance (Jordan, 1998; Vealey et al., 1998). In sports, confidence is of great importance to an athlete as well, and it can have many sources. The confidence of riding a bicycle may come from the feeling of controlling the bicycle (trait confidence) and the self-satisfaction of keeping the body in shape (state confidence). Accordingly, the definitions of confidence were provided to r ct tekr cpu"cu'ÈVj g"xkgy "qp"\{ qut"qy p"cdkkv\{ "kq'f q"uqo gy lpi ."qxgteqo g"egt rckp"qduxcengu" or work vq'ko r tqxg"c"unkmó 


\subsubsection{Procedure of eye-tracking experiment}

Three investigators conducted the eye-tracking experiments following a single procedure. Subjects were tested individually in the laboratory with the investigator sitting nearby to make sure the eye tracker was functioning. Participants first received an information sheet and a briefing and then signed the consent form. Next, the investigators asked them to sit up straight, comfortably and adjusted the eye contact distance to around $65 \mathrm{~cm}$ to the screen according to the investigator's measurement. After the investigator calibrated the eye tracker (model: Tobii TX300, sampling frequency at $60 \mathrm{~Hz}$ ), the participants were asked to run a pilot session looking at a bike image to familiarize themselves with the experimental interface. The subjects needed to gaze at nine calibration points within $20^{\circ}$ gaze angle all over the screen. Throughout the recording, one or both subjects' eyes have to be found over 95\% duration.

The order of two evaluation tasks (confidence and beauty) were assigned randomly with a five-minute break in between followed by a semi-structured interview. At the beginning of each task, the subjects looked at a red dot on the centre of the screen for three seconds to set a baseline starting point. Each bicycle image was displayed for ten seconds, then disappeared. Next, a five-point scale was shown on the screen and the subjects evaluated the intensity level of perceived positive emotion using a computer mouse. The sequence of the ten selected bicycle images was random All sessions were scheduled to be completed in one hour.

In order to uncover a user's visual attention towards bicycle components, the results of fixation count (the number of fixations within an AOI) and fixation duration (the average time of fixations within an AOI) were exported from Tobii Studio version 3.2.2. An eye fixation is composed of multiple gaze points if they are within a pre-defined minimum 
distance from each other, this experiment follows the classification algorithm by defaulted fixation filters in Tobii Studio (Olsen, 2012). The Statistical Package for the Social Science (SPSS) was used to analyse the data.

\subsection{Results and discussion}

The two-way repeated measures ANOVA revealed significant differences in both fixation count, $F(1,53)=3.97, p=0.05$, and fixation duration $F(1,53)=4.82, p=0.03$, between cyclist groups as shown in Table 4.2 and Table 4.3. One of the heat maps of fixation count is shown in Figure 4.2 (page 79), and the colours indicate the respective amounts of visual fixation. The remaining heat maps can be found in Appendix B. The interval estimates of fixation count and fixation duration on all bicycle parts are plotted in Figure 4.4 (page 81), and its database is attached in Appendix B.

Table 4.2 Tests of between-subjects effects (fixation count)

\begin{tabular}{lrrrrrr}
\hline Source & $\begin{array}{r}\text { Type III Sum } \\
\text { of Squares }\end{array}$ & df & Square & F & Sig. & $\begin{array}{r}\text { Partial Eta } \\
\text { Squared }\end{array}$ \\
\hline Intercept & 176896.369 & 1 & 176896.369 & 2301.385 & .000 & .977 \\
Level & 305.339 & 1 & 305.339 & 3.972 & .050 & .070 \\
Error & 4073.854 & 53 & 76.865 & & & \\
\hline
\end{tabular}

Table 4.3 Tests of between-subjects effects (fixation duration)

\begin{tabular}{lrrrrrr}
\hline Source & $\begin{array}{r}\text { Type III Sum } \\
\text { of Squares }\end{array}$ & df & Mean Square & F & Sig. & $\begin{array}{r}\text { Partial Eta } \\
\text { Squared }\end{array}$ \\
\hline Intercept & 10858.253 & 1 & 10858.253 & 1913.647 & .000 & .973 \\
Level & 27.326 & 1 & 27.326 & 4.816 & .033 & .083 \\
Error & 300.728 & 53 & 5.674 & & & \\
\hline
\end{tabular}

In Table 4.4, it only shows the bicycle components which had the statistical significant difference between the two groups and in which categories that they pay more attention. Basically, all subjects were attracted towards and appreciated the design of the 
bike frame easily, but expert cyclists tended to transfer their visual attention shortly to focus on functional components (crank set and front tire) in both Confidence and Beauty tasks. The novice cyclists observed each bicycle component relatively easily for Confidence, but gazed longer at the saddle, chain stay, and front derailleur.

Table 4.4 The comparison of fixation count and duration on bicycle parts

\begin{tabular}{ccccc}
\hline & \multicolumn{2}{c}{ Fixation Count } & \multicolumn{2}{c}{ Fixation Duration } \\
Group & Confidence & Beauty & Confidence & Beauty \\
\hline Expert & Front tire & $\begin{array}{c}\text { Crank set, } \\
\text { Rear derailleur }\end{array}$ & $\begin{array}{c}\text { Crank set, Down tube, } \\
\text { Front tire, Fork, Head } \\
\text { tube, Seat tube, Top tube }\end{array}$ & $\begin{array}{c}\text { Crank set, } \\
\text { Rear derailleur, } \\
\text { Stem }\end{array}$ \\
\hline Novice & $/$ & Seat Post & $\begin{array}{c}\text { Saddle, Chain stay, } \\
\text { Front derailleur }\end{array}$ & Seat post \\
\hline
\end{tabular}

The results of LSD Post-hoc test revealed that crank set, down tube and pedal are different from all other bicycle components $(p>0.05)$ in terms of fixation count and fixation duration. According to the collected data (Figure 4.4, page 81), crank set and down tube can be identified as main sources of product emotions. The pedal, however, can be interpreted as an unimportant visual reference in this experiment, and be removed for further analysis. Besides, some collected bicycle images were missing the pedal part; Bicycle companies tend to provide product images without pedals because of compatibility issue between cycling shoes and pedals.

\subsubsection{Confidence task}

Interview data revealed that experts and novices have distinctly different opinions as to which bicycle components evoke a feeling of Confidence. Novices cared about the quality of the saddle because they usually felt pain in their bones after sitting for a long ride. In contrast, experts thought it would be easier to replace the saddle with another model 
to reduce the discomfort, but not the crank set. Hence, expert cyclists preferred to focus on the components that would benefit their sports performances more since they pursue a faster cycling experience.

Experts also gazed longer at the bike frame, including the fork, down tube, head tube, seat tube and top tube for Confidence. The results show that they spent some time inspecting details such as the material, texts and model number as a reference for Confidence based on their knowledge.

\subsubsection{Beauty task}

Both expert and novice cyclists were attracted to the design of the bike frame for Beauty, although the results revealed their preferences toward specific bicycle components.

ๆ Novices gazed longer and more frequently for Beauty at the seat post

Il Experts looked more frequently and gazed longer for Beauty at the crank set and the rear derailleur in comparison to novice cyclists. The design of the stem attracted experts' visual attention for Beauty.

Novice cyclists seemed to judge the attractiveness of a bicycle based on the look of the 'tube parts'. Therefore, it is suggested that designers should take the seat post as an extension of the bike frame by, for example, creating some matching patterns and colourful coating. On the other hand, the appearances of the crank set and rear derailleur had more influence on experts' visual attention than novices'. 


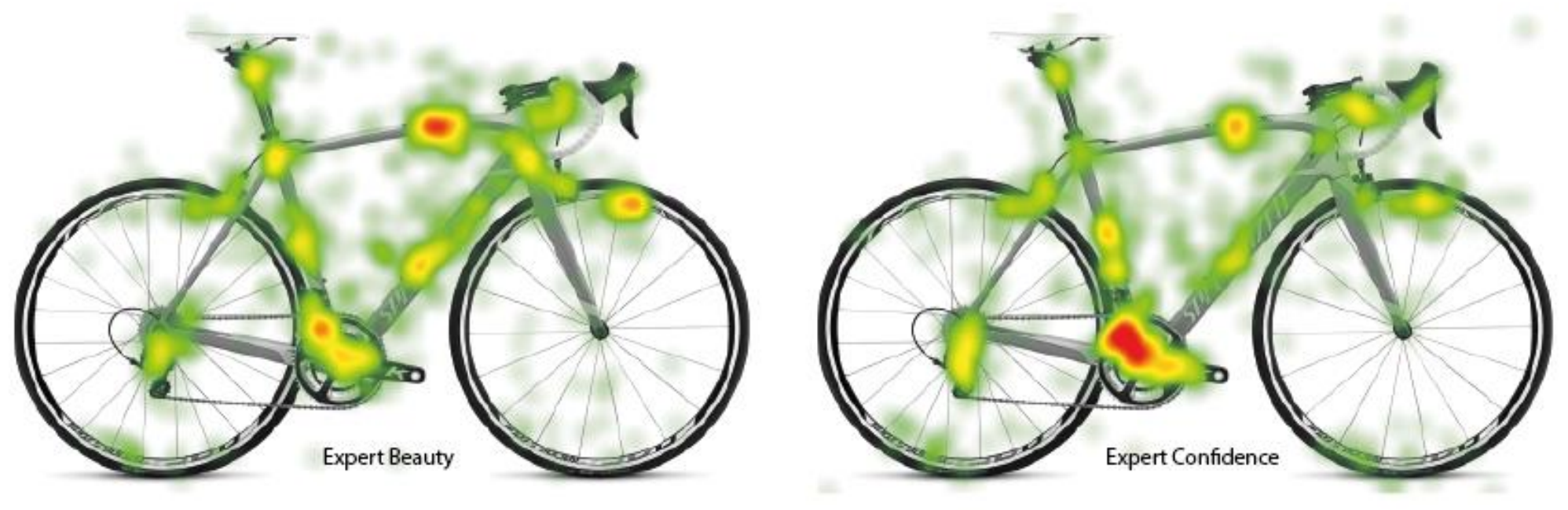

22 counts

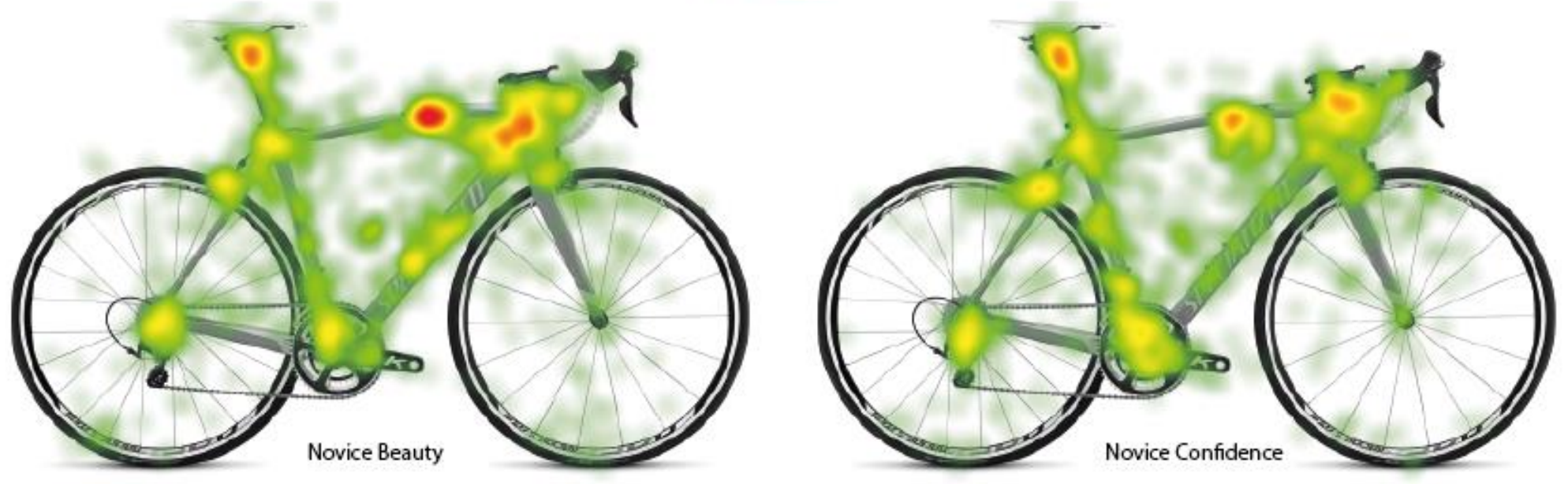

Figure 4.2 The Heat Map of fixation counts for four categories (example) 
Chapter 4 Temporality of Vision-based Product Quality
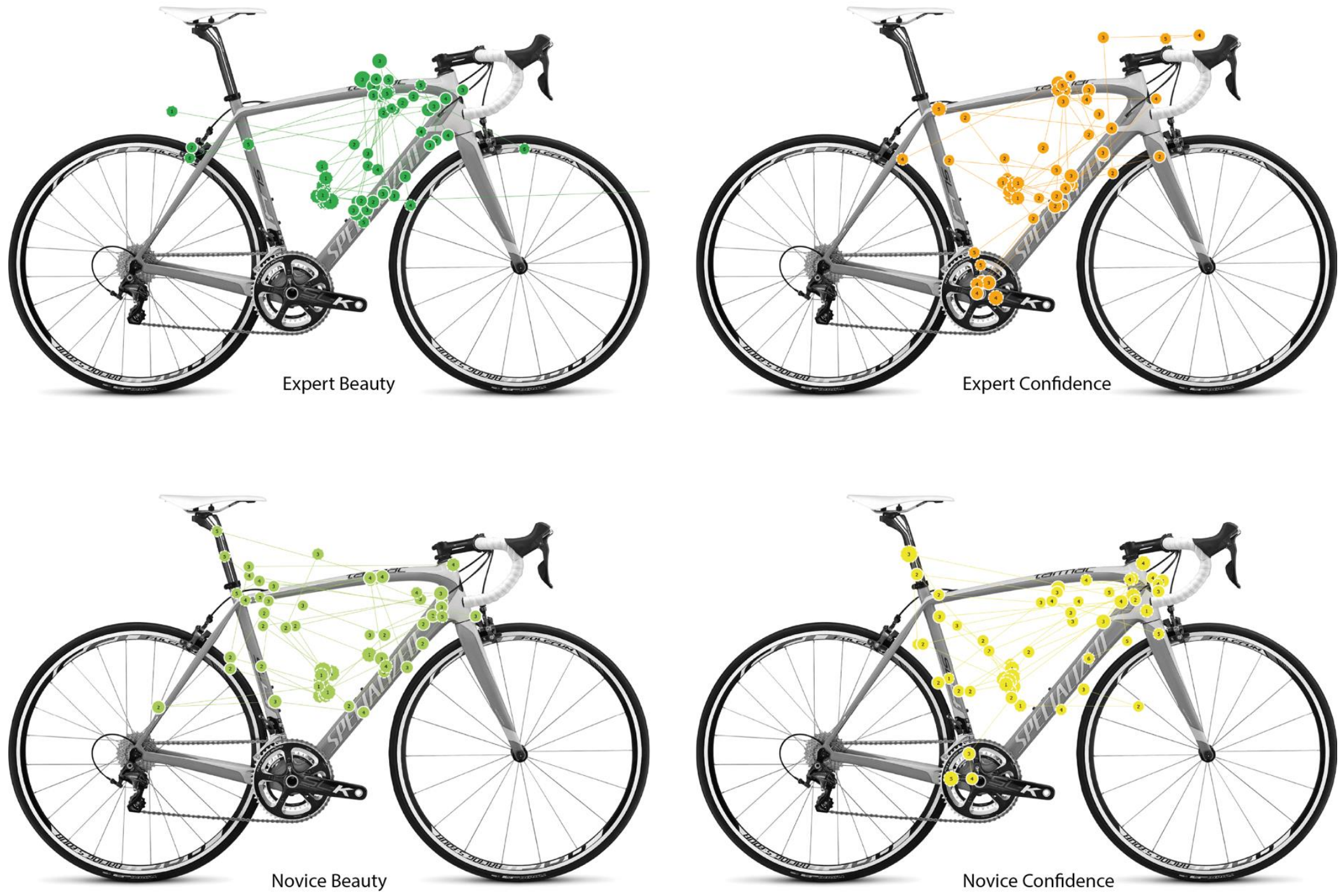

Figure 4.3 The Gaze Plot for four categories (example)

80 

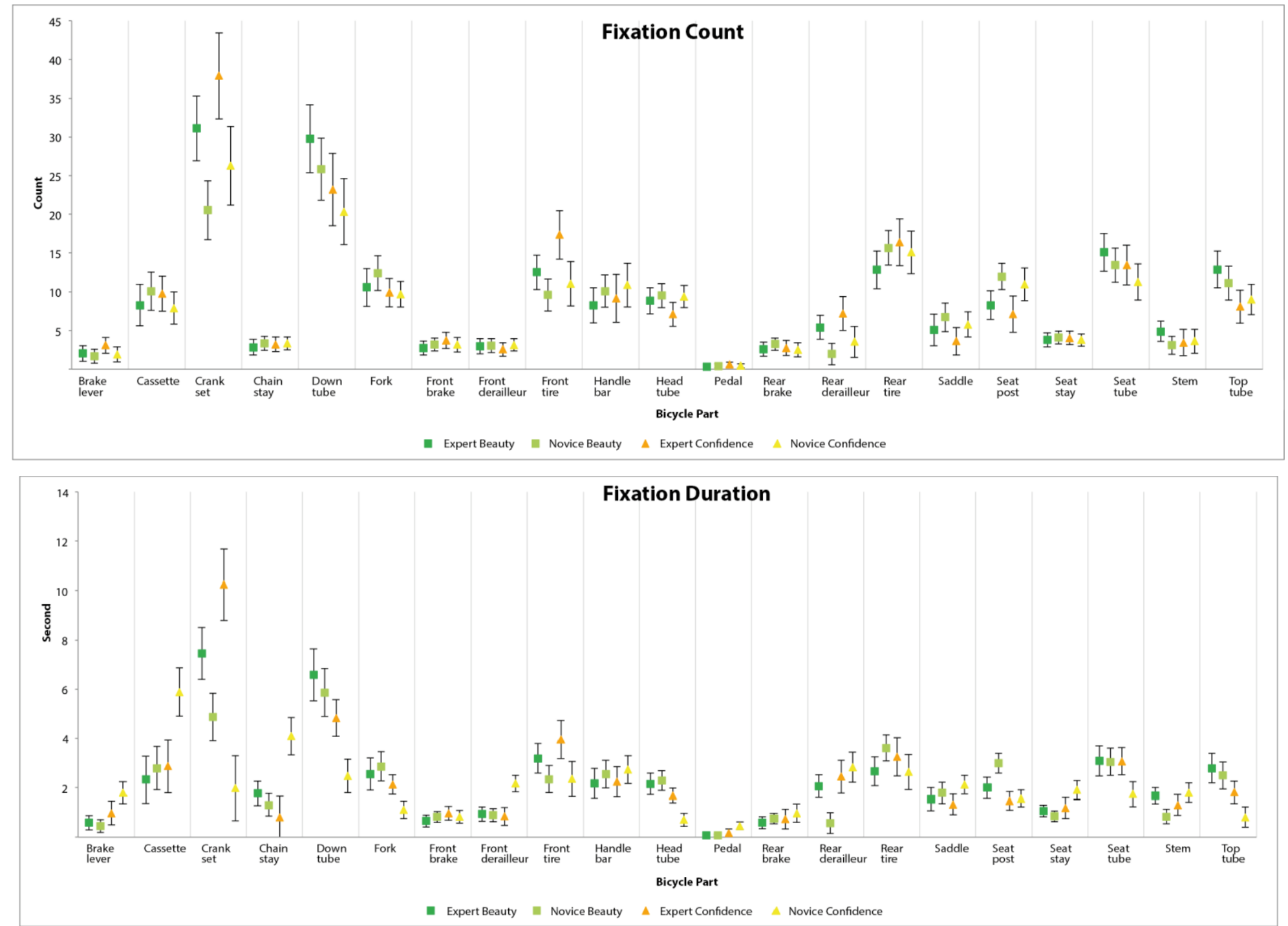

Figure 4.4 Interval estimate of fixation counts/duration for four groups on bicycle parts 


\subsubsection{Viewing sequence}

The Friedman and Wilcoxon test was conducted to analyse each subject's viewing sequence of each bicycle image. It tested the first 20 points of fixation. One sample bicycle (B18) displayed in the viewing sequence for each of the four categories is shown in Figure 4.3. Although previous research indicated that users would first gaze at the top tube and down tube, followed by the seat tube and head tube (Liu \& Chang, 2009), there was not enough evidence supporting a clear viewing order in this study. One big difference between these two studies was that Liu and Chang (2009) used simulated bicycle images (e.g., no colour, brand name or model label); therefore, it is possible that the individual bicycle designs gained subjects' visual attention differently, while the author tried to evoke genuine product emotions by keeping them all.

\subsubsection{Perceived emotional intensity}

Finally, there was no significant difference in perceived emotional intensity between experts and novices among all bicycle images, except two, viz., B09 $(F=4.42, p=0.04)$ and B31 $(F=15.5, p<0.001)$, as shown in Figure 4.5.
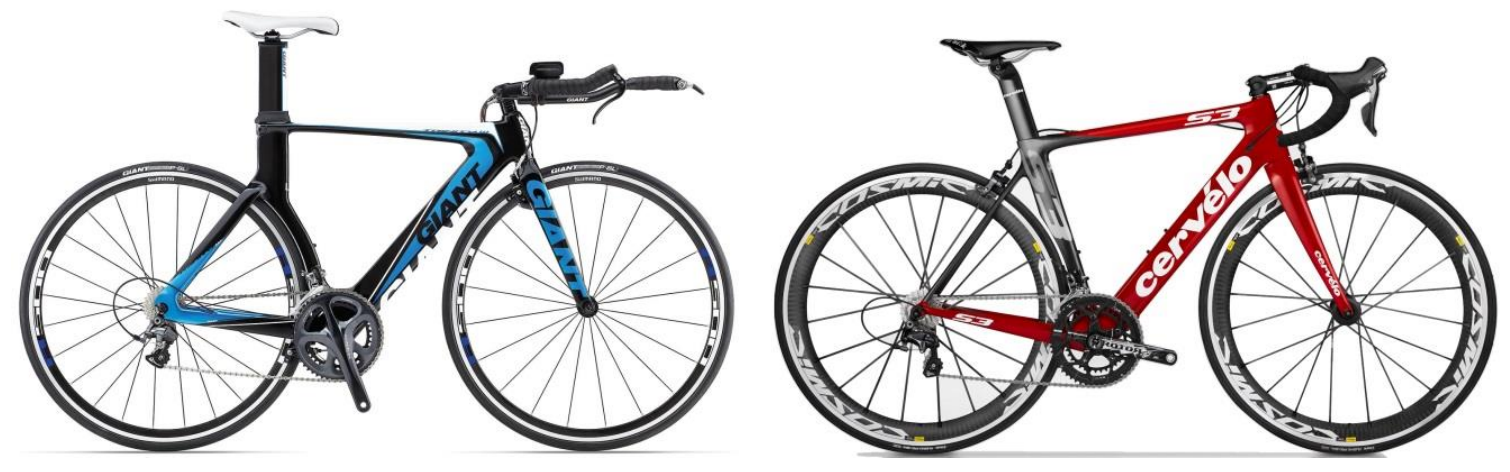

Figure 4.5 The bicycle images for B09 (left) and B31 (right) 
According to the result of the two-way ANOVA test, novices responded with more emotional intensity to the bicycle that had a thicker down tube and seat tube. For novice cyclists, these bicycle components may appear more attractive because the thicker tubes have more space in which to show off its design. This result is also consistent with the analysis of visual fixation and visual counts that the tube is novices' primary emotional reference. In addition, experts and novices only differed significantly in their opinions ( $F$ $=5.81, p=.018)$ of the time trial bike (B09) in terms of confidence and beauty, as shown in Table 4.5. Interestingly, expert cyclists felt less confident $\left(M_{\text {novice }}=2.9, M_{\text {expert }}=2.2\right)$ about this bike and considered it less beautiful $\left(M_{\text {novice }}=3.13, M_{\text {expert }}=3.08\right)$ than novice cyclists did.

Table 4.5 Tests of between-subjects effects (emotional intensity on B09)

\begin{tabular}{|c|c|c|c|c|c|c|}
\hline Source & $\begin{array}{r}\text { Type III Sum } \\
\text { of Squares }\end{array}$ & $\mathrm{df}$ & Mean Square & $\mathrm{F}$ & Sig. & $\begin{array}{r}\text { Partial } \\
\text { Eta } \\
\text { Squared } \\
\end{array}$ \\
\hline Corrected Model & $14.681^{\mathrm{a}}$ & 3 & 4.894 & 3.807 & .012 & .097 \\
\hline Intercept & 882.985 & 1 & 882.985 & 686.828 & .000 & .866 \\
\hline Task & 7.469 & 1 & 7.469 & 5.810 & $.018 *$ & .052 \\
\hline Level & 4.585 & 1 & 4.585 & 3.566 & .062 & .033 \\
\hline Task x Level & 3.469 & 1 & 3.469 & 2.699 & .103 & .025 \\
\hline Error & 136.273 & 106 & 1.286 & & & \\
\hline Total & 1053.000 & 110 & & & & \\
\hline Corrected Total & 150.955 & 109 & & & & \\
\hline
\end{tabular}

a. R Squared $=.097($ Adjusted R Squared $=.072)$

Overall, the findings suggest that all participants tend to like and dislike the same bicycles ( 8 out of 10 bikes) and that they make a similar overall impression. However, they changed their viewing strategies towards the product components when they had more experience on the bike. This suggests the drawback of evaluating vision-based product quality of a multicomponent product using a typical semantic differential test. More specifically, when customers respond with similar emotional preferences, they might in 
fact perceive product emotions from different parts. Judging from the results, novices seemed to recognise one type of product emotion for a single component at one time. That is, each component has its own dominant emotional attribute from the view of novices'. In contrast, some components, such as the crank set and the rear derailleur could trigger an expert's cognitive-focused and affective-focused emotions together. It appears that customers who are more familiar with sporting goods would choose functional components as a source of product attractiveness.

\subsection{Chapter summary}

An investigation into the emotional attributes of multicomponent products based on the visual impression was conducted to address the unclear dynamic user experience of sporting goods. It started with reviewing a user's product evaluation on the perceived affordance and attractiveness over time, discussing the influences of tested product categories and the expert-novice difference in eye movement. The results suggest that the level of involvement in cycling did not determine participants' overall cognitive-focused emotion (confidence) or affective-focused emotion (beauty). Yet different product components evoked their emotions.

This experiment demonstrated the need to investigate vision-based product quality and the potential benefits of applying objective measurements for multicomponent products in new product development. The fact that customers' visual attention varies between product components depending on their level of involvement can provide a list of emotional requirements for the sports industry to match in different market segments (Table 4.4). 


\section{Chapter 5 Analysis of Multisensory Emotional Requirements}

The present chapter investigates the multisensory module of UXCM, and its influence on the structure of emotional requirement (ER) database for a Kansei engineering system (KES). A group of regular road cyclists are invited to interact with two bicycle saddles either seeing or touching it while their emotional experiences are collected through the format of Kansei words (K-words). Moreover, it examines whether the perceived product emotions evoked by the saddles can affect one's cycling performance.

\subsection{Introduction}

Despite research has shown that positive emotions play an important role in athletes' performances, few studies have attempted to account for the impact of sports equipment design (Baron et al., 2011; Lazarus, 2000; Woodman \& Hardy, 2003). One of the reasons for this could be that research on emotions in sport generally only refers to human mental states whereas human feelings can also be evoked by a user-product interaction. Athletes may even choose a particular piece of sports equipment due to a psychological dependence instead of its functional properties (Damisch et al., 2010). In this regard, humans tend to anthropomorphize artefacts by reading emotional responses from them, such as when a user describes a helmet as being 'cute' (Desmet et al., 2008; Guthrie, 1995). Although these feelings or product impression cannot be identified objectively, e.g., by way of a physiological signal, they can be captured by self-report assessments such as the semantic differential scale (SDS). Researchers have collected these 'feeling' words, which appear as 'product emotions', 'semantic words' and 'Kansei words' interchangeably in the literature (Nagamachi, 2011). Next, the following sections will present the application of SDS to sports equipment design. 


\subsubsection{Subjective evaluation of sports equipment}

In the field of product design, semantic differential scale (SDS) has been applied to serve as an efficient method to identify customers' emotional needs. In general, users would give ratings to pre-defined semantic items (e.g., K-words) which the designer retrieves from the semantic database. The definitions of each item need to be explained to the participants clearly before the test begins. Afterwards, the structure dimensions are reduced to extract the semantic spaces for further application. However, the reliability of the SDS can be affected by both the experiment design and inter-subject factors. For example, it is assumed that there is not a linear relationship between a user's feelings and product properties while the SDS is built on interval scales. A visual analogue scale might be able to avoid the anchor effect (Bressel, Bliss, \& Cronin, 2009), but is incomparable to statistical methods that have been proposed to deal with the nonlinear data structure (Nagamachi, 2002; Schütte, 2002). On top of that, the list of semantic items may not have the same weighted values towards the product in each participant's mind, or some of the K-words may be dependent on one another and reinforce the same concept.

In order to address the issue of reliability, Huang et al. (2012b) deconstructed each product emotion on the SDS list into basic human emotions. M. Camargo et al. (2014) calibrated the personal structure of K-words using adopt relevant indexes to calculate the importance (e.g., Shapley value) or the interaction between two K-words. In the case of packaging design, F. R. Camargo and Henson (2015) stated that the bipolar SDS (paired K-words) can be improved if the dichotomous value (yes/no) was applied to analyse the probability of endorsing a short statement towards the product based on the Rasch measurement theory. The Rasch model is part of item response theory and suggests that collected survey responses are affected by the subject's capability; in a way, a subject's 
capability is similar to an athlete's level of involvement in sports experience. In the author's opinion, even though using the short statement can overcome the issue of word/language vagueness, it does not really fit in the Kansei engineering system if it is expected to determine the coefficient of product properties.

On the other hand, the author argues that how the participants interact (from a multisensory perspective) with the product can also affect the reliability of the semantic differential scale. For instance, the participants judge the product through several sensory channels simultaneously, which would influence the way they think about the K-words unconsciously (Spence \& Zampini, 2006). In the case of an evaluation of hammers, Vergara et al. (2011) first extracted six semantic spaces using factor analysis and compared them among three user groups (professional, enthusiast, trainee) and four types of user-product interactions (low-fidelity vision, high-fidelity vision, touch, touch-in-action). Unfortunately, in their work, there was an inconsistency in using the format of K-words (mixing negation and opposition). For the sake of clarity, the author would use the same semantic spaces (K-SE, K-PP) stated in Chapter 3 to explain their results.

Vergara et al. (2011)'s analysis showed that lightness (light/heavy) is the only factor that has an interaction effect between the user group and interaction type. No significant differences were found between the interaction types for the K-words in product personality (K-PP) such as strong/weak, stylish/conventional despite these pairs actually being from two different semantic spaces (2 out of 6). In contrast, there was a significant difference between K-words related to the emotions (K-SE) such as pleasant/unpleasant, comfortable/uncomfortable as well as the dynamic effect (vibrate/not vibrate); this holds particularly between the phases of touch and touch-in-action according to the post hoc test. However, the subjective evaluation of sports equipment in the Kansei research usually 
only requires the participant to rate their feelings based on a product image (S. W. Hsiao \& Ko, 2013).

\subsubsection{Bicycle saddle and cycling comfort}

The bicycle saddle was chosen to be the sample product for analysing a cyclist's multisensory emotional requirements following the previous study (Kuo, Chen, \& Roberts, 2014). Compared to other parts of the bicycle, the saddle is easier to interchange between trials. Its design is intended to address a common subjective issue - saddle soreness (Bressel et al., 2009; Potter et al., 2008). However, according to the conceptual models drawn in Section 3.3.3, there is no 'best' bicycle saddle that fits everyone perfectly due to different anthropometric profiles, but three main factors constitute a comfortable bicycle saddle experience. Apart from the uncontrollable environmental factor (e.g., weather and road condition), riders can still find a way to make themselves feel physically comfortable during the cycling activity. For instance, the width of bicycle saddles should be able to support the rider's seat bones (i.e., ischial tuberosity) so there is less pressure on the soft tissue areas. In this regard, competitive cyclists tend to lean forward and sit on the anterior regions of the saddle to maximise power output. While enjoying a leisurely ride, riders are most likely to sit upright with their upper body straight.

A cyclist's weight will load on five contact points (saddle: 1, handlebars: 2 , pedals:

2) when they are on the bike. Research has shown that the saddle interface pressure should not be the only reference with which to identify a positive saddle experience because its stability can change when cyclists sit on a smaller area, e.g., seat without a saddle nose (Bressel et al., 2009). This statement has also been supported by many other studies, e.g., the changes in pedal force and pressure distribution on the handlebar between different seat 
positions (Ayachi et al., 2015; R. Verma, Hansen, de Zee, \& Madeleine, 2016). Therefore, it is of importance to discuss cyclists' physical discomfort on the saddle in concurrence with their riding behaviours.

Depending on different theoretical grounds, the comfort evaluation may be measured on two scale types. In the sense that the feeling of comfort is treated as the absence of discomfort as it is determined by the discomfort threshold (not uncomfortable) on a unipolar scale, such as the rated perceived exertion scale (Borg, 1982). When comfort and discomfort are located at opposite ends of a continuous bipolar scale, it implies that the user can rate in its middle to express a neutral state - feel-nothing. On the other hand, Zhang, Helander, and Drury (1996) stated that comfort and discomfort should be evaluated separately. After classifying 43 descriptors in the context of a seated workplace, they concluded that discomfort-related factors (e.g., fatigue, pain, stiffness) and comfort-related factors (e.g., happiness, calmness, luxuriousness) were grouped into two distinct semantic spaces. Furthermore, their findings implied that discomfort was mainly caused by unpleasant physical conditions, whereas the positive effect of comfort can be affected by impressions of the product's aesthetics, user-product activity, and the user's expectations (de Looze et al., 2003; Vink \& Hallbeck, 2012). These additional impressions, however, are greatly reduced if physical comfort is inadequate.

In this work, the author will attempt to clarify how users' perceived product emotions are influenced by their multisensory perceptions and to what extent that the physical activity (cycling posture) may affect a user's subjective impression. The experiment was designed to adapt the unipolar SDS to test the following hypotheses:

ๆ The collection method (user-product interaction) in a Kansei engineering system (KES) can affect the perceived emotional intensity (K-words) in terms of semantic 
spaces (K-SE, K-PP).

Il Positive emotions that evoked by sports equipment can improve one's physical performance.

\subsection{Method}

In this study, only female participants aged 20 and over were eligible for this experiment because of gender difference in pelvic width (Guess et al., 2011; Potter et al., 2008), which may lead to different saddle experience. In this experiment, saddle samples (Figure 5.1) were manufactured by the bike company Giant Manufacturing Co. Ltd, specifically designed for female customers. One was designed to be more comfortable for forward pelvic positions (Saddle A, model: Liv Contact SL) and the other was designed for the upright pelvis position (Saddle B, model: Liv Connect). Their design specifications are shown in Table 5.1. The brand logo and the model numbers were not removed as they were considered to be part of the product design, and their influence was deemed negligible since the two samples were from the same product line.

Table 5.1 The product specification of two bicycle saddles

\begin{tabular}{cccccc}
\hline Saddle & Designed for & Width & Firmness & Flatness & Weight \\
\hline A & forward position & $145 \mathrm{~mm}$ & hard & curved & $230 \mathrm{~g}$ \\
\hline B & upright position & $165 \mathrm{~mm}$ & soft padded & flat & $330 \mathrm{~g}$ \\
\hline
\end{tabular}




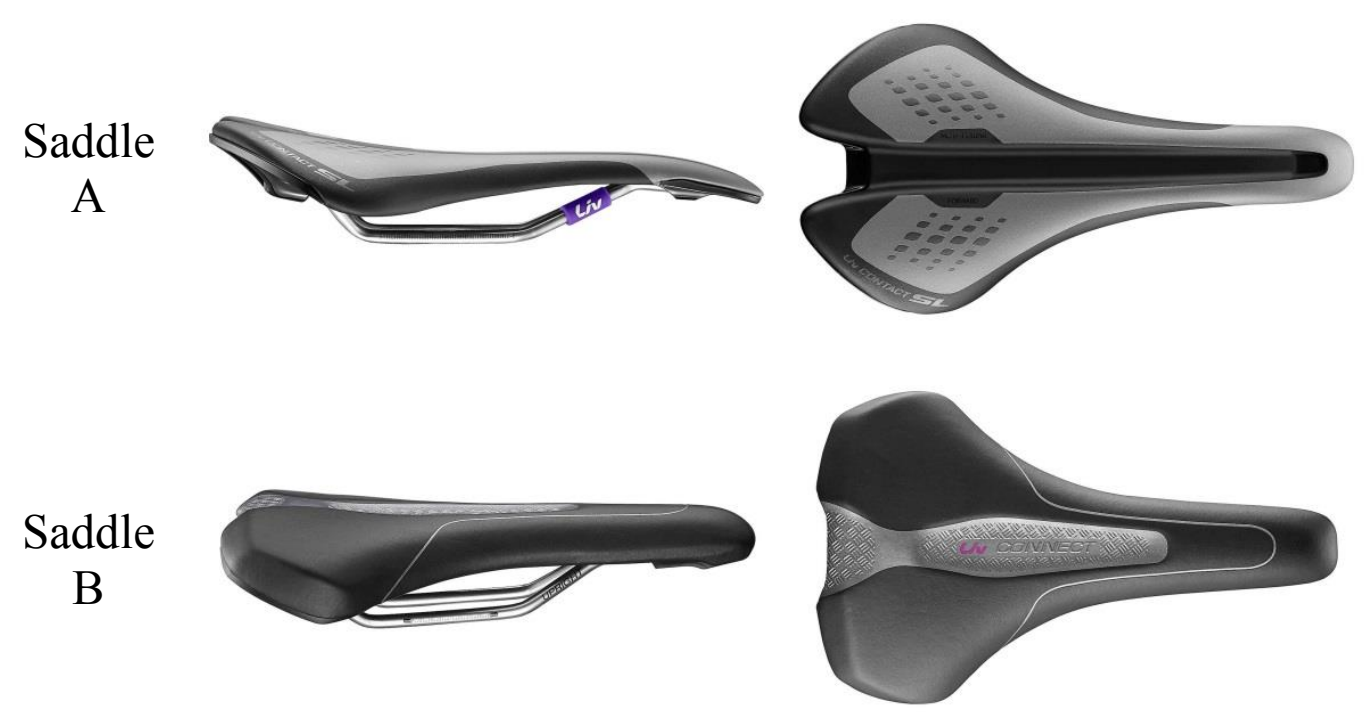

Figure 5.1 The top and the side view of two bicycle saddles (source: Giant Manufacturing Co. Ltd.)

\subsubsection{Participants}

This project was held at the Sports Technology Institute at Loughborough University, England. Over the two-month period, 40 female cyclists based in the Midlands regions of England volunteered to participate in this experiment. A part of the participant group also participated in a previous study (Section 3.3.3). Most participants were English, with one German, one Slovenian, and one French. The average age was 37 years old $(S D=12.19)$, with an average height of $165.85 \mathrm{~cm}(S D=6.76)$, an average weight of $63.3 \mathrm{~kg}(S D=7.87)$, and average ischial tuberosity width of $132.8 \mathrm{~cm}(S D=10.68)$. Out of all participants, 21 of them met the $80 \%$ of criteria in the IPI test (Kuo et al., 2016) were identified as highinvolvement participants. As shown in Table 5.2, 12 of 21 High-involvement Road Cyclists (HRC) and 8 of 19 Low-involvement Road Cyclists (LRC) tested the saddles with visual reference. The number of subjects required for each factor was validated using $\mathrm{G}^{*}$ power for $80 \%$ power at $5 \%$ alpha level. 
Table 5.2 The number of participants in each interaction

(V=Vision, T=Touch, $\mathrm{C}=$ Cycling, HRC=High-involvement Road Cyclist, LRC=Low-involvement Road Cyclist)

\section{Session}

\begin{tabular}{ccccc} 
& Vision & Touch & \multicolumn{2}{c}{ Cycling } \\
& $\mathrm{V}$ & $\mathrm{V}+\mathrm{T}$ & $\mathrm{C}-\mathrm{V}$ & $\mathrm{C}+\mathrm{V}$ \\
\hline HRC & 21 & 21 & 9 & 12 \\
LRC & 19 & 19 & 11 & 8 \\
Total & 40 & 40 & 20 & 20 \\
\hline
\end{tabular}

\subsubsection{Vision, Touch, and Cycling}

First, the investigator measured each participant's anthropometric dimensions such as height, weight, and inseam. There were three sessions (Vision, Touch, Cycling) to be completed for each participant. In the Vision session, the participant saw the photos (top view and side view) of two bicycle saddles at one time on the screen, and filled out the adapted SDS (Appendix C). The range of the scale was set from zero to six (seven-point scale) so it could still record a participant's perceptions even if she felt indifferent to the presented K-words. The same K-words were evaluated across the three sessions, but the order was presented randomly in the SDS. There was no time limit in the Vision session.

In the Touch session, the participants were allowed to use their hands to touch the saddles. When it comes to evaluation of human tactile perception, the touch process involves holding the object with hands and feeling the edges and textures in order to do a shape recognition task called active touch. This can be exemplified in a scenario where a customer checks new saddles in the bike shop. Nevertheless, wearing sports equipment or sitting on a saddle mounted on a bike is more like a passive touch (object moved against the body). Since the comfort evaluation is affected by the body regions (Vink \& Hallbeck, 
2012), the participants were asked to further test the saddles in action so as to collect their sports performance. There was no time limit in the Touch session.

In the Cycling session, subjective feelings were collected after participants were given a chance to ride on each of the two saddles. It required the participants to be at least $150 \mathrm{~cm}$ tall or have an inside leg measurement of at least $60 \mathrm{~cm}$ in order to use the bike ergometer (model: Wattbike trainer). The environmental setup is shown in Figure 5.2. Considering the different cycling backgrounds of the participants, no padded cycling shorts and cycling shoes were required in this experiment. The participants were asked to stretch their bodies before sitting on the bike ergometer, and to warm up properly before the trial started.

In order to simulate the cycling activity, for each saddle, the participants needed to cycle at a given cadence for three minutes with hands-on-hoods and hands-on-drops positions. Depending on the IPI score (Kuo et al., 2016), the allocated cadence ranged between 80RPM-100RPM (crank revolutions per minute, RPM), and workload between 100W-200W. However, they were allowed to ride using their preferred seat position depending on their personal riding habits. The participants' sports performances were recorded by the Wattbike Monitor (model B) and GP Manager (version 6.2; gebioMized, 2013), which has 64 sensors collecting pressure distribution at a sampling rate of $60 \mathrm{~Hz}$. 


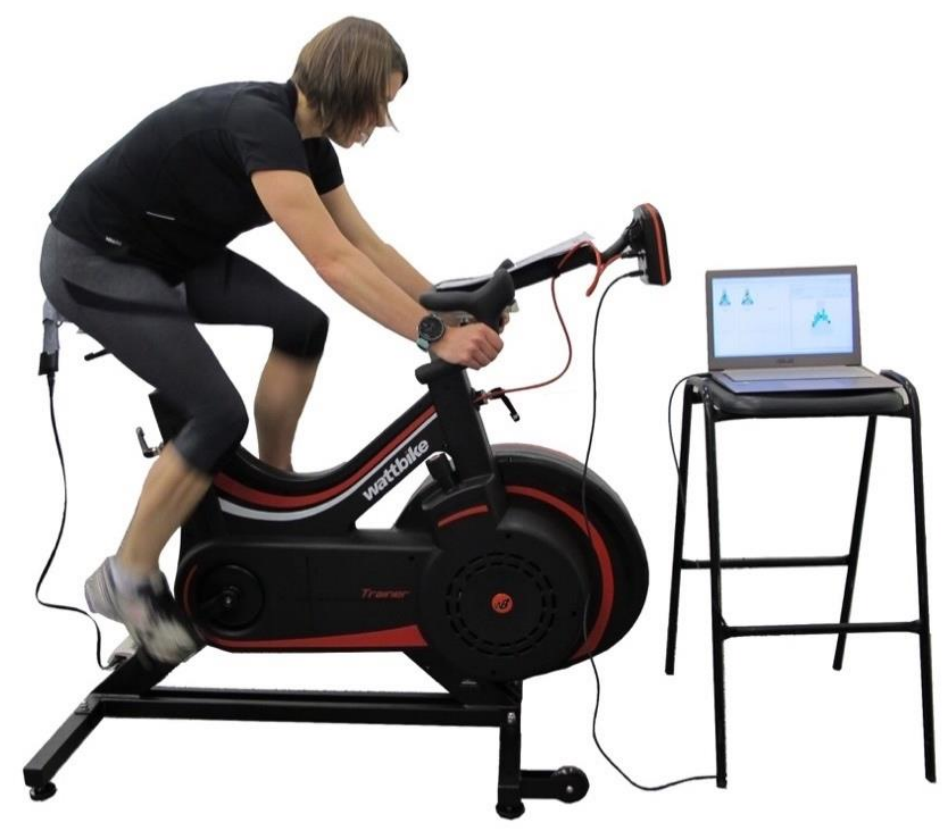

Figure 5.2 The environmental setup for cycling sessions

There was a 10-minute break in between the two saddle tests. The test order of saddle samples was assigned randomly in this experiment considering that previous research has shown that participants' prior sensation might influence their ratings in a seating comfort evaluation (Veen \& Vink, 2016). The author also planned to have half of the participants test the bicycle saddles while minimising visual influence (control group). They followed the same procedure but were not able to see which saddle they were riding on, and they did not know the purpose of the experiment (single-blind trial). All three sessions were scheduled to be completed in 50 minutes, with an additional 10 minutes allocated to bike fitting. 


\subsubsection{Bike fit protocol}

In order to maximise a cyclist's performance, a proper bike fit needs to integrate several factors, such as bike geometry, body dimensions, muscle strength, and riding posture (see a review of bike fit protocol in Appendix E). There are five contact points that can be adjusted, including the saddle, the handlebar, and the pedals on a road bike. In this experiment, a bike fitting process was conducted before the trials in order to reduce the risk of injury. Basically, it followed the fitting instructions provided by Giant and Wattbike so as to fit the geometry of Wattbike trainer model, in which the seat post angle is $75^{\circ}$. The following steps are:

1. Fit the seat height with the inseam length; the saddle needs to be horizontal.

2. Fit the handlebar height (or saddle drop) according to the upper body length and flexibility.

3. Move the saddle position forward/afterward to check if the leg extension aligns with the angle of the seat post.

4. Check if the participants can move their hands smoothly between two handlebar positions (hoods and drops).

\subsection{Results and discussion}

Each participant generated a data set of $20 \mathrm{~K}$-words x 3 interactions x 2 saddles. The

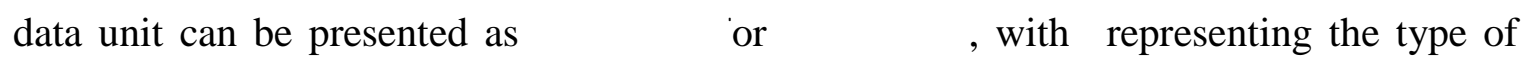
interaction, य़ representing the number of participants, ग़ represents the K-words, ॐँand' representing the saddle sample. Due to the semantic differential scale being printed on paper, on a few occasions, the participant missed out the item and the investigator did not correct it immediately. As a result, 28 out of 4,800 data points $(0.58 \%)$ were missing, and later were replaced by the average value of the series. 

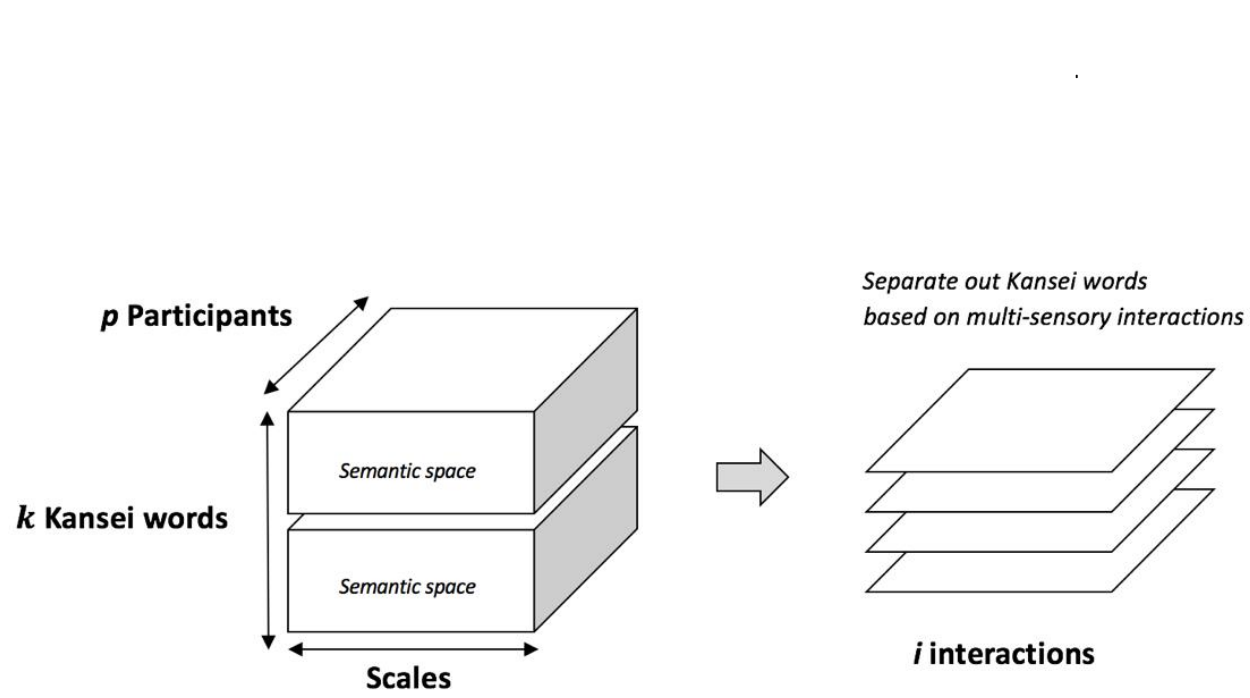

Figure 5.3 The data set under UXCM model

The independent variables were the interaction types, participant groups and saddle types, the dependent variables were the ratings of $20 \mathrm{~K}$-words. The ANOVA tests were performed using SPSS and the results are discussed in the following sections. Although the size of the collected samples did not match the minimum number for confirmatory factor analysis (CFA) or exploratory factor analysis (EFA) that was recommended in the literature, the author noticed that after collecting around 15 responses, the distribution of the data set appeared to be stable.

\subsubsection{Multisensory perceptions}

The initial K-words database was collected from two semantic spaces (K-SE and K$\mathrm{PP})$ respectively. It included $10 \mathrm{~K}$-words in Sport Emotion (K-SE) and $10 \mathrm{~K}$-words in Product Personality (K-PP). Table 5.3 shows the significance values $(p)$ for each K-word between seeing (Vision) and touching (Touch) the saddles. The $p$-values less than 0.05 are marked with an asterisk (*). The between-subject factor was the cyclists' level of involvement; the within-subject factors were the saddles (2) and perceptions (2). Judging 
from Table 5.3, it was evident that the subjective impressions for each saddle were not quite the same because 15 of $20 \mathrm{~K}$-words had significant differences in emotional intensity except pleasure, traditional, $\underline{\text { comfortable, }} \underline{\text { rough and cute. }}$

Table 5.3 The p-value of the repeated measured ANOVA (vision, touch)

\begin{tabular}{|c|c|c|c|c|c|c|c|c|}
\hline & \multicolumn{2}{|c|}{ Between } & \multicolumn{5}{|c|}{ Within-subjects effect } & \multirow[b]{2}{*}{ PSL } \\
\hline & K-words & Level & Saddle & $\begin{array}{l}\text { Saddle } \\
\mathrm{x} \text { Level }\end{array}$ & Perception & $\begin{array}{c}\text { Perception } \\
\text { x Level }\end{array}$ & $\begin{array}{c}\text { Perception } \\
\text { x Saddle }\end{array}$ & \\
\hline \multirow{10}{*}{ 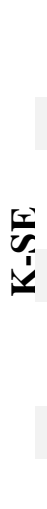 } & pleasure & $.024 *$ & .611 & .355 & .265 & .618 & .232 & .875 \\
\hline & calm & .062 & $.025 *$ & .765 & .050 & .342 & $.011 *$ & .634 \\
\hline & relaxed & .162 & $.002 *$ & .786 & $.009 *$ & .313 & $.001 *$ & .491 \\
\hline & determined & .280 & $.001 *$ & $.042 *$ & .192 & .108 & .969 & .060 \\
\hline & energetic & .382 & $.001 *$ & $.012 *$ & $.034 *$ & .573 & .875 & .154 \\
\hline & competitive & .440 & $.001 *$ & $.033 *$ & .286 & .528 & .949 & $.048^{*}$ \\
\hline & comfortable & .138 & .689 & .206 & .573 & .677 & .183 & .883 \\
\hline & proud & .352 & $.001 *$ & .439 & .083 & .416 & .257 & .785 \\
\hline & confident & .674 & $.001 *$ & .058 & .154 & .454 & .533 & .533 \\
\hline & enthusiastic & .352 & $.001 *$ & .439 & .083 & .416 & .257 & .785 \\
\hline \multirow{10}{*}{$\frac{\hat{A}}{\hat{A}}$} & cute & .166 & .074 & 699 & $.001 *$ & .364 & .426 & .911 \\
\hline & warm & .972 & $.009 *$ & .730 & $.001 *$ & $.043 *$ & .637 & .850 \\
\hline & traditional & $.029 *$ & .061 & .635 & $.008 *$ & .863 & .377 & .576 \\
\hline & friendly & .212 & $.005^{*}$ & .278 & $.001 *$ & .056 & .179 & .813 \\
\hline & interesting & .739 & $.001 *$ & .644 & .131 & .662 & .082 & .845 \\
\hline & pretty & .295 & $.024 *$ & .696 & .053 & .780 & .965 & .476 \\
\hline & honest & .524 & $.030 *$ & .128 & $.028 *$ & .470 & $.010^{*}$ & .196 \\
\hline & sporty & .493 & $.001 *$ & .092 & .402 & .493 & .858 & .699 \\
\hline & dominant & .429 & $.001 *$ & .202 & .917 & .917 & .148 & .062 \\
\hline & rough & .279 & .668 & .668 & .259 & .555 & .990 & .807 \\
\hline
\end{tabular}

Despite the two saddles being very different styles, they delivered/elicited the same emotional impression for both HRCs and LRCs for all K-words except pleasure and traditional. The group of HRC tended to feel that both saddles were traditional. It is assumed that HRC has seen more types of bicycle saddles, and the product samples in this experiment are standard market design. Among all K-words, competitive was the only one had a three-way interaction effect on the emotional intensity. Figure 5.4 showed that all 
participants perceived Saddle A as a more competitive item comparing to Saddle B, this impression remains under different user-product interactions.
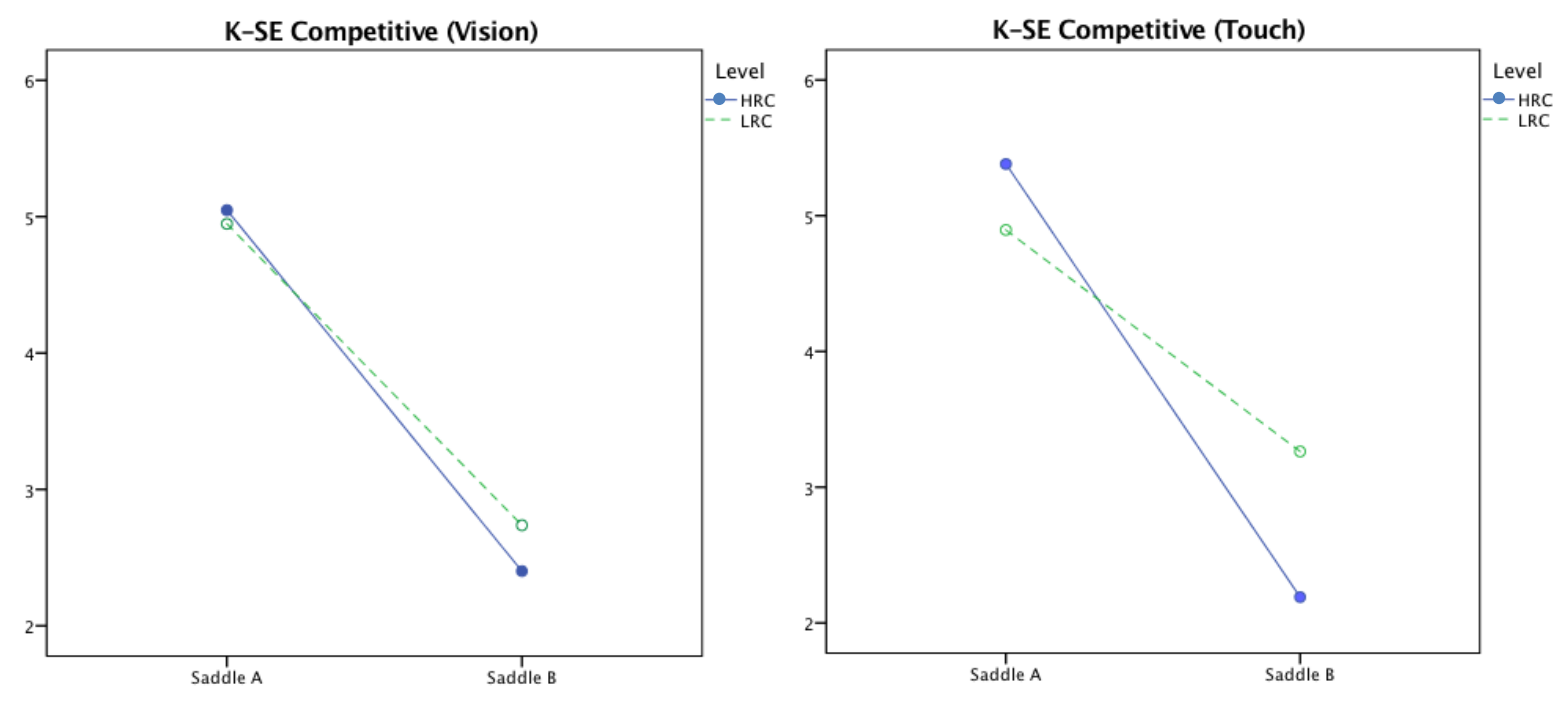

Figure 5.4 Estimated marginal means of K-SE competitive for two saddles

Nevertheless, some of the K-words were perceived differently with respect to emotional intensity between the phases of 'seeing' the photo image and 'touching' the actual saddle. When HRC and LRC touched the saddles, their impressions were both stronger, with average emotional intensity rising from $3.02(S D=.25)$ to $3.5(S D=.27)$ for HRC; and $2.29(S D=.26)$ to $2.71(S D=.28)$ for LRC. The significant main effect of perception was found in seven K-words; two of them were categorised in K-SE (relaxed, $\underline{\text { energetic) }}$ and five of them were in K-PP ( $\underline{\text { cute, }} \underline{\text { traditional, friendly, warm and honest). }}$. However, most of the changed impressions, apart from cute and traditional, seem to have responses to the saddle designs. According to the study of vision-based product quality in Section 4.3, there was no significant difference between high-involvement participants and low-involvement participants when it came to the confident and beauty evaluation. The finding was consistent in this experiment and applied to more types of product emotions (18 of $20 \mathrm{~K}$-words in this case). 
When the participants were allowed to touch the saddles, they perceived Saddle B as being more relaxed than Saddle A (Figure 5.6). In contrast, the impression of energetic was expressed less in reference to Saddle B, especially within the HRC group. This finding appears to support the idea of Saddle B was designed for sitting upright on a leisure ride.
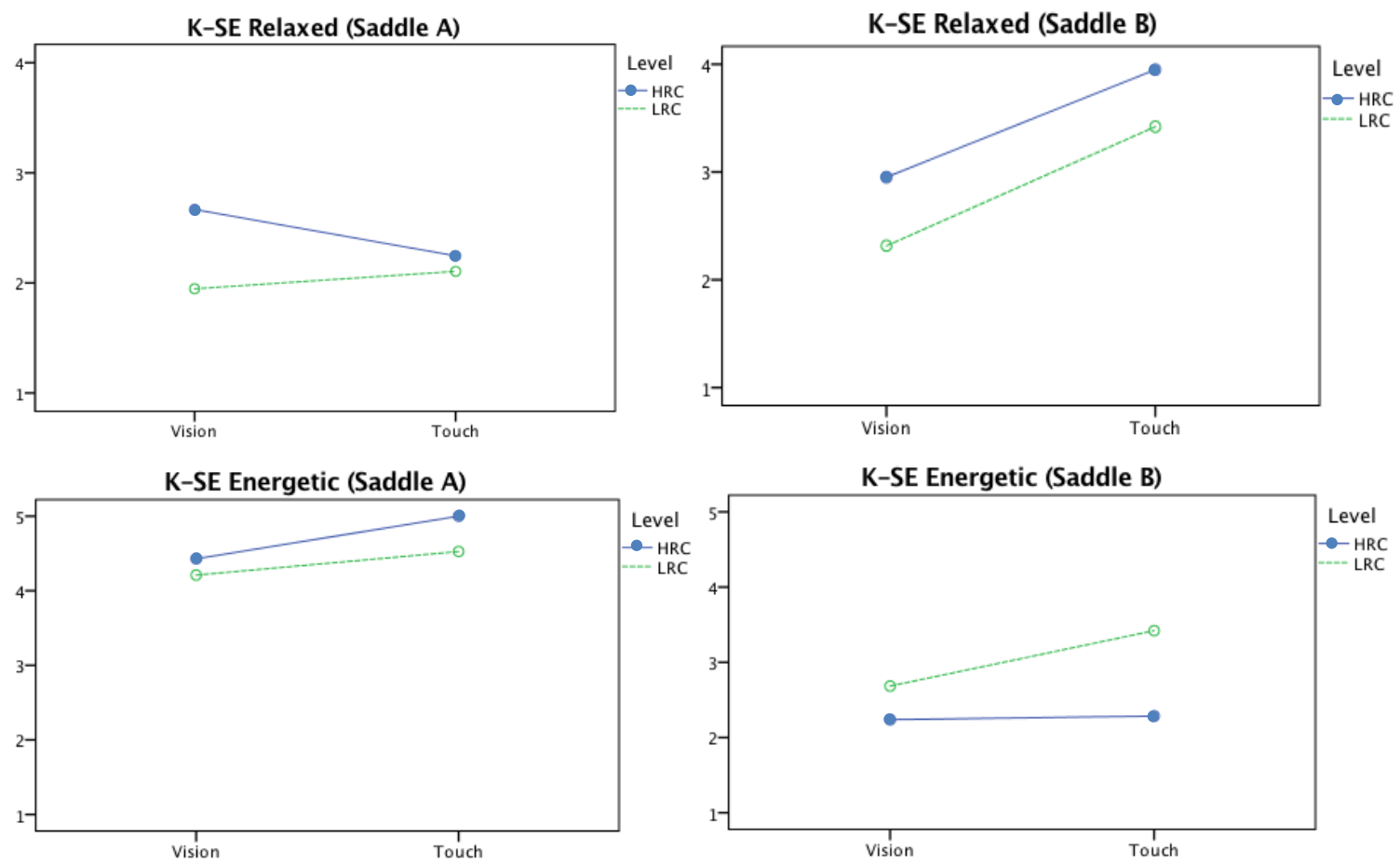

Figure 5.5 Estimated marginal means of selected K-SE for two saddles

Regarding the K-words in Product Personality (K-PP), the emotional intensity of cute, $\underline{\text { traditional and friendly all increased for both saddles during the touch session while honest }}$ only increased in the case of touching Saddle B (Figure 5.6). Out of all K-words, warm was the only one which had an interaction effect with a user's levels and perceptions (Table 5.3). The need for touch in evaluating the impression of warm appeared to be stronger for the LRC group considering the larger growth between the perceptions for each saddle. LRC started with the lower perceived intensity $1.63(S D=.29)$, then increased to $2.78(S D=.30)$; and HRC from $1.97(S D=.28)$ to $2.48(S D=.29)$. The detailed results of the $95 \%$ confidence 
interval for mean, and the estimated marginal means of each K-word for the two saddles are attached in Appendix D.
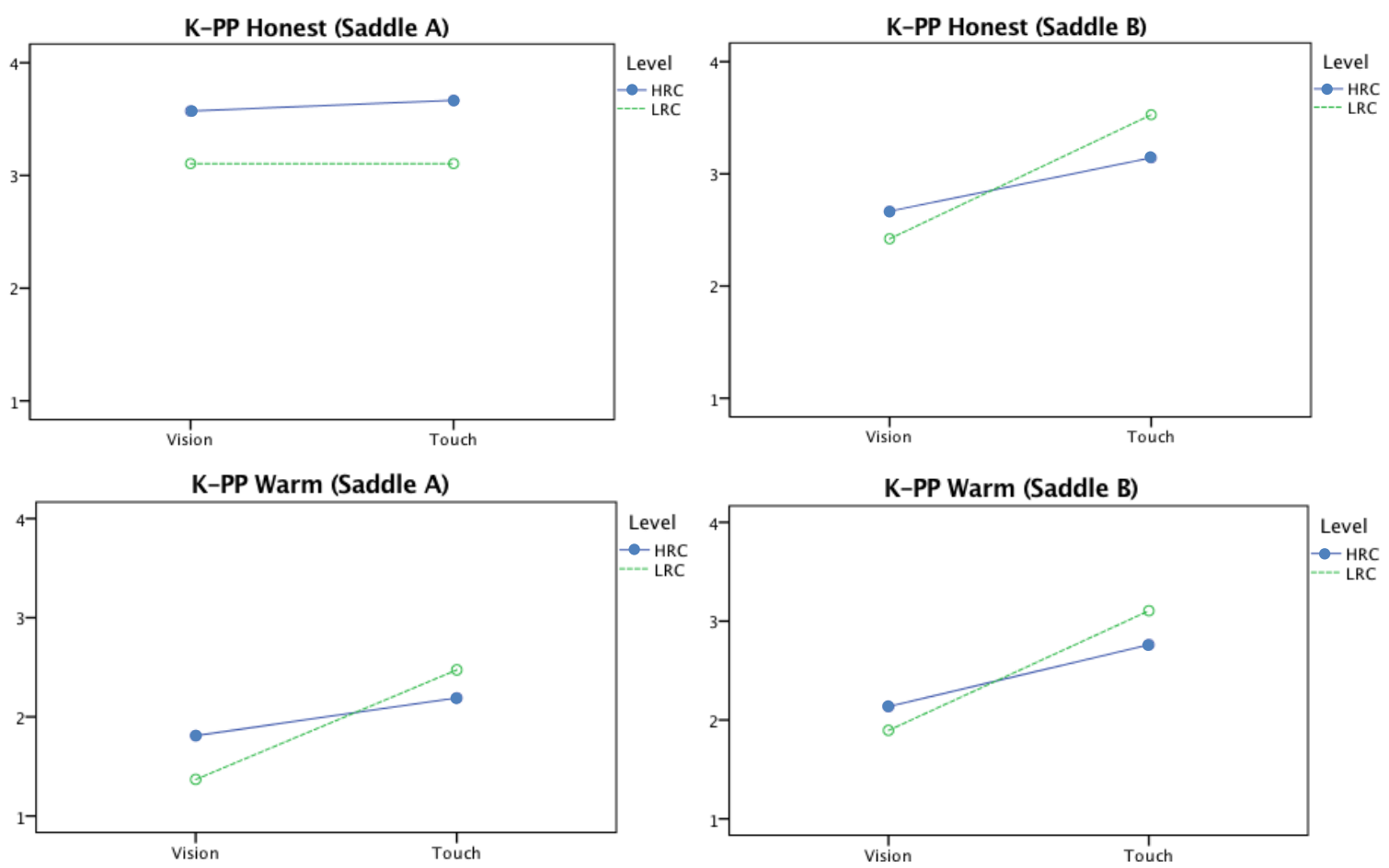

Figure 5.6 Estimated marginal means of selected K-PP for two saddles

Overall, the valence of a user's positive emotion tended to increase when they touched the product. Deepening on the semantic attribute of the K-words, tactile perception can be a 'confirmation' of a user's expectation. According to the results of this experiment, it happened more often in the case of K-words in Product Personality (K-PP). In the next section, the author further analysed the relationship between the K-words and a cyclist's sports performance, viz., cycling speed, riding posture and power output.

\subsubsection{Sports performance}

Due to administrative errors, there were several incomplete records: six participants for Saddle A with hands-on-drops position, one participant for Saddle B with hand-onhoods position, and seven participants for Saddle B with the hands-on-drops position. The 
missing data were replaced by the averages of series from the same participant based on the assumption that the participant can remain a stable cycling speed and power output for each position.

Since each participant has a different body weight, the measured pressure distribution was standardised before the analysis. The cycling experience, however, cannot be interpreted only by the mean/max seat pressure on the bicycle saddle. It should be focused on the 'activity'. Regardless of individual riding purpose, the references related to kinaesthetic sense, such as speed, riding position, and power output (physical effort) can better interpret a dynamic activity (cycling). In this experiment, the average cadence and average power output for the two saddles are shown in Table 5.4. When the participants moved their hands from the hoods of the handlebar to the drops position, their speed and power increased slightly.

Table 5.4 The average cadence and power output on two saddles

\begin{tabular}{llccc}
\hline & \multicolumn{2}{c}{ Cadence(RPM) } & \multicolumn{2}{c}{ Power output (W) } \\
& Hood & Drop & Hood & Drop \\
\hline \multirow{2}{*}{ Saddle A } & $\mathrm{M}=90.53$, & $\mathrm{M}=92.43$, & $\mathrm{M}=124.9$, & $\mathrm{M}=134.76$, \\
& $\mathrm{SD}=10.28$ & $\mathrm{SD}=9.33$ & $\mathrm{SD}=29.36$ & $\mathrm{SD}=27.5$ \\
\multirow{3}{*}{ Saddle B } & $\mathrm{M}=90.43$, & $\mathrm{M}=91.91$, & $\mathrm{M}=123.75$, & $\mathrm{M}=132.42$, \\
& $\mathrm{SD}=10.04$ & $\mathrm{SD}=9.28$ & $\mathrm{SD}=30.19$ & $\mathrm{SD}=28.07$ \\
\hline
\end{tabular}

Subsequently, the loaded pressure area $\left(\mathrm{mm}^{2}\right)$ in anterior and posterior regions was recorded and exported by GP Manager. In Figure 5.7, the numbers indicate the loaded area, and the highest pressures are coloured in red, followed by yellow, green and blue. When the weight/pressure are loaded more in anterior than posterior region, it implies that the participant is sitting towards the front of the nose (left image in Figure 5.7), and can be categorised as having a forward riding posture. In contrast, those have an upright riding posture are shown on the right side of Figure 5.7. As a result, 21 participants sat forward 
(upright: 19) on Saddle A, and 27 participants sat forward (upright: 13) on Saddle B with the hands-on-hoods position.

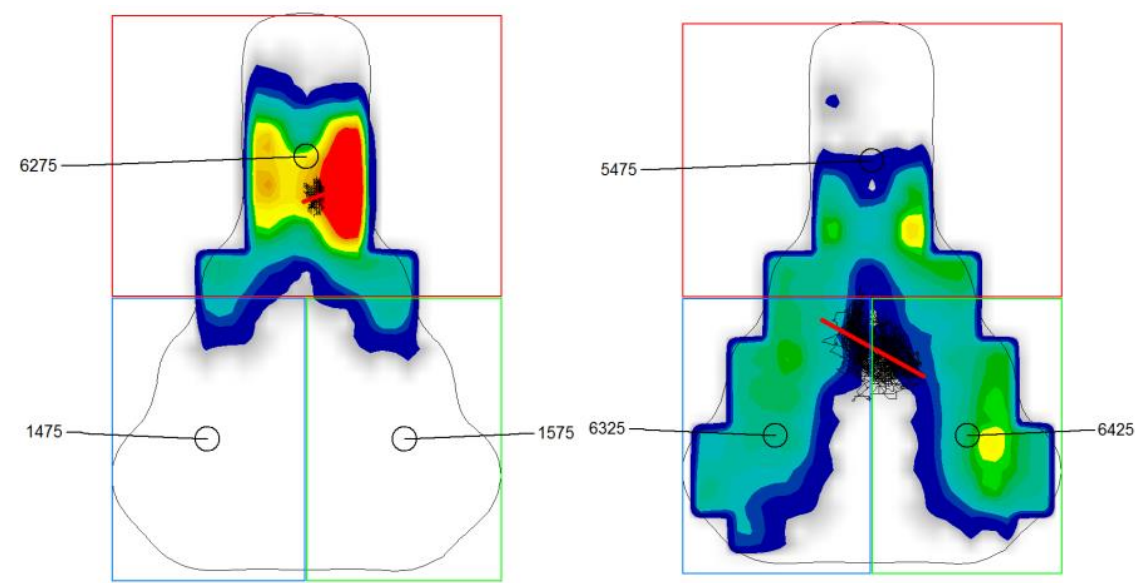

Figure 5.7 The example of different riding styles for Saddle A drop position

Next, two saddles were discussed separately, and a three-way ANOVA was conducted using SPSS to calculate the influence of the independent variables (user's group, riding postures and perceptions) on the dependent variables (K-words, sports performance). The user's group included two levels (HRC, LRC), the riding postures included two types (forward, upright), and the perceptions were made with or without visual reference. The results of significant value $(p)$ are shown in Table 5.5 and Table 5.6. 
Table 5.5 The p-value of three-way ANOVA for Saddle A (cycling)

\begin{tabular}{|c|c|c|c|c|c|c|c|c|}
\hline & $\begin{array}{r}\text { Saddle A } \\
\text { K-words }\end{array}$ & Level & Posture & Perception & $\begin{array}{l}\text { Level x } \\
\text { Perception }\end{array}$ & $\begin{array}{l}\text { Level x } \\
\text { Posture }\end{array}$ & $\begin{array}{l}\text { Perception } \\
\text { x Posture }\end{array}$ & PPL \\
\hline \multirow{2}{*}{ 它 } & cadence & .306 & .277 & .613 & $.006 *$ & .221 & .827 & .968 \\
\hline & power & .166 & .535 & .623 & $.005 *$ & .106 & .960 & .811 \\
\hline \multirow{10}{*}{$\begin{array}{l}\underline{y} \\
\underline{u} \\
\underline{v}\end{array}$} & pleasure & .143 & $.009 *$ & .234 & $.018 *$ & .085 & .722 & .866 \\
\hline & calm & .903 & .236 & .954 & $.035^{*}$ & $.046^{*}$ & .204 & .951 \\
\hline & relaxed & .097 & .309 & .174 & .237 & .416 & .404 & .874 \\
\hline & determined & .586 & .493 & .141 & .358 & .523 & .214 & .493 \\
\hline & energetic & .577 & $.045^{*}$ & .149 & .295 & .095 & .477 & .466 \\
\hline & competitive & .641 & .244 & $.044 *$ & .429 & .723 & .662 & .233 \\
\hline & comfortable & .125 & $.004^{*}$ & $.010^{*}$ & $.047 *$ & .210 & .745 & $.015^{*}$ \\
\hline & proud & .061 & .278 & $.027 *$ & .226 & .398 & .159 & .714 \\
\hline & confident & .122 & .150 & .108 & .271 & .188 & .365 & .926 \\
\hline & enthusiastic & .203 & $.013^{*}$ & .464 & .289 & .119 & .406 & .442 \\
\hline \multirow{10}{*}{$\frac{\hat{a}}{\underline{1}}$} & cute & .972 & .206 & .305 & $.013 *$ & .062 & .064 & .414 \\
\hline & warm & .919 & .533 & .233 & $.044 *$ & $.014^{*}$ & .695 & .293 \\
\hline & traditional & .790 & .719 & .210 & $.022 *$ & .145 & .748 & .748 \\
\hline & friendly & .438 & .092 & .281 & $.031 *$ & .203 & 909 & .796 \\
\hline & interesting & .586 & .670 & .434 & .080 & .157 & .412 & .526 \\
\hline & pretty & .644 & .339 & .086 & .059 & .462 & .198 & .510 \\
\hline & honest & .457 & $.036^{*}$ & .571 & .159 & .248 & .516 & .879 \\
\hline & sporty & .735 & .122 & $.041 *$ & .159 & .490 & .286 & .490 \\
\hline & dominant & .406 & .213 & .062 & .385 & .129 & .844 & .141 \\
\hline & rough & .472 & .204 & .057 & .374 & .897 & .077 & .885 \\
\hline
\end{tabular}

Out of all K-words, the significant effect of perceptions was found in four K-words (competitive, comfortable, proud and sporty) for Saddle A and none for Saddle B. The findings implied a participant's impression was more likely to be affected by the appearance of Saddle A in comparison to Saddle B. For instance, the main effect of perception yielded an $\mathrm{F}$ ratio of $F(1,32)=5.36, p=.027, \eta p^{2}=.14$ on the impression of proud for Saddle A, an average score of $2.42(S D=.32)$ without visual reference, but a score of $3.47(S D=.33)$ with visual reference. Likewise, the impression of competitive for Saddle A, $F(1,32)=4.4, p=.044, \eta p^{2}=.12$, average scored $3.13(S D=.42)$ without visual reference, and increased to $4.4(S D=.43)$ with visual reference. The look of Saddle A also 
elicited more sporty feelings in cycling experience, $F(1,32)=4.52, p=.041, \eta p^{2}=.12$, with an average score of $4.44(S D=.40)$, but which was reduced to $3.25(S D=.39)$ if no visual reference was provided.

Table 5.6 The p-value of three-way ANOVA for Saddle B (cycling)

\begin{tabular}{|c|c|c|c|c|c|c|c|c|}
\hline & $\begin{array}{r}\text { Saddle B } \\
\text { K-words } \\
\end{array}$ & Level & Posture & Perception & $\begin{array}{c}\text { Level x } \\
\text { Perception }\end{array}$ & $\begin{array}{l}\text { Level x } \\
\text { Posture }\end{array}$ & $\begin{array}{c}\text { Perception } \\
\text { x Posture }\end{array}$ & PPL \\
\hline \multirow{2}{*}{ 它 } & cadence & .538 & .462 & .125 & $.029 *$ & .665 & .949 & .500 \\
\hline & power & .488 & .885 & .108 & .053 & .952 & .743 & .657 \\
\hline \multirow{10}{*}{$\begin{array}{l}\text { 穿 } \\
\underline{1}\end{array}$} & pleasure & .867 & .321 & .409 & .484 & .626 & .442 & .703 \\
\hline & calm & .771 & .229 & .985 & .620 & .188 & .469 & .156 \\
\hline & relaxed & .970 & .454 & .198 & .638 & .608 & .549 & .556 \\
\hline & determined & .076 & .639 & .833 & .483 & .981 & .732 & .460 \\
\hline & energetic & .190 & .449 & .925 & .201 & .969 & .694 & .503 \\
\hline & competitive & .146 & .448 & .743 & .814 & .937 & .545 & .939 \\
\hline & comfortable & .623 & .809 & .272 & .755 & .579 & .565 & .779 \\
\hline & proud & .087 & .562 & .447 & .593 & .475 & .987 & .686 \\
\hline & confident & .115 & .286 & .664 & .426 & .380 & .693 & .489 \\
\hline & enthusiastic & $.026^{*}$ & .217 & .720 & .528 & .229 & .632 & .481 \\
\hline \multirow{10}{*}{$\frac{\hat{a}}{\hat{1}}$} & cute & .299 & .377 & .085 & .416 & .073 & .470 & .074 \\
\hline & warm & .299 & .377 & .085 & .416 & .073 & .470 & .074 \\
\hline & traditional & .471 & .364 & .181 & .155 & .511 & .863 & .176 \\
\hline & friendly & .509 & .431 & .990 & .878 & .343 & .199 & .387 \\
\hline & interesting & .678 & .838 & .723 & .255 & .614 & .971 & .457 \\
\hline & pretty & .521 & .671 & .058 & $.022 *$ & .142 & $.008^{*}$ & $.001 *$ \\
\hline & honest & .706 & .685 & .567 & .922 & .337 & .869 & .373 \\
\hline & sporty & .554 & .162 & .327 & .908 & .495 & .526 & .981 \\
\hline & dominant & $.042 *$ & .969 & .555 & .902 & .271 & .719 & .814 \\
\hline & rough & .338 & .849 & .527 & .118 & .442 & .659 & $.046^{*}$ \\
\hline
\end{tabular}

In addition, the high-involvement road cyclists (HRC) appeared to care more about the look of bicycle saddles than low-involvement road cyclists (LRC). For example, when the HRC group saw Saddle A in the cycling session, they reported stronger feelings of pleasure, cute, traditional and friendly; if they saw themselves testing Saddle B, they would report a lower impression of pretty. However, these changes in saddle experience can be caused by riding posture as well. 
As shown in Table 5.5 and Table 5.6, the effect of riding posture was statistically significant for five K-words (pleasure, energetic, comfortable, enthusiastic and honest) for Saddle A and none for Saddle B. Note the evaluation of pleasure in Figure 5.9, LRC enjoyed Saddle A more when they sat in an upright position $(M=4.5, S D=.70)$, although the pleasure feelings dropped slightly when they saw the saddle $(M=3.6, S D=.81)$. In regard to the impression of calm for Saddle A, LRC felt most calm $(M=3.5, S D=.63)$ when riding in an upright position (without visual reference), while HRC felt calmer $(M=3.0$, $S D=.63$ ) in the forward position (with visual reference).
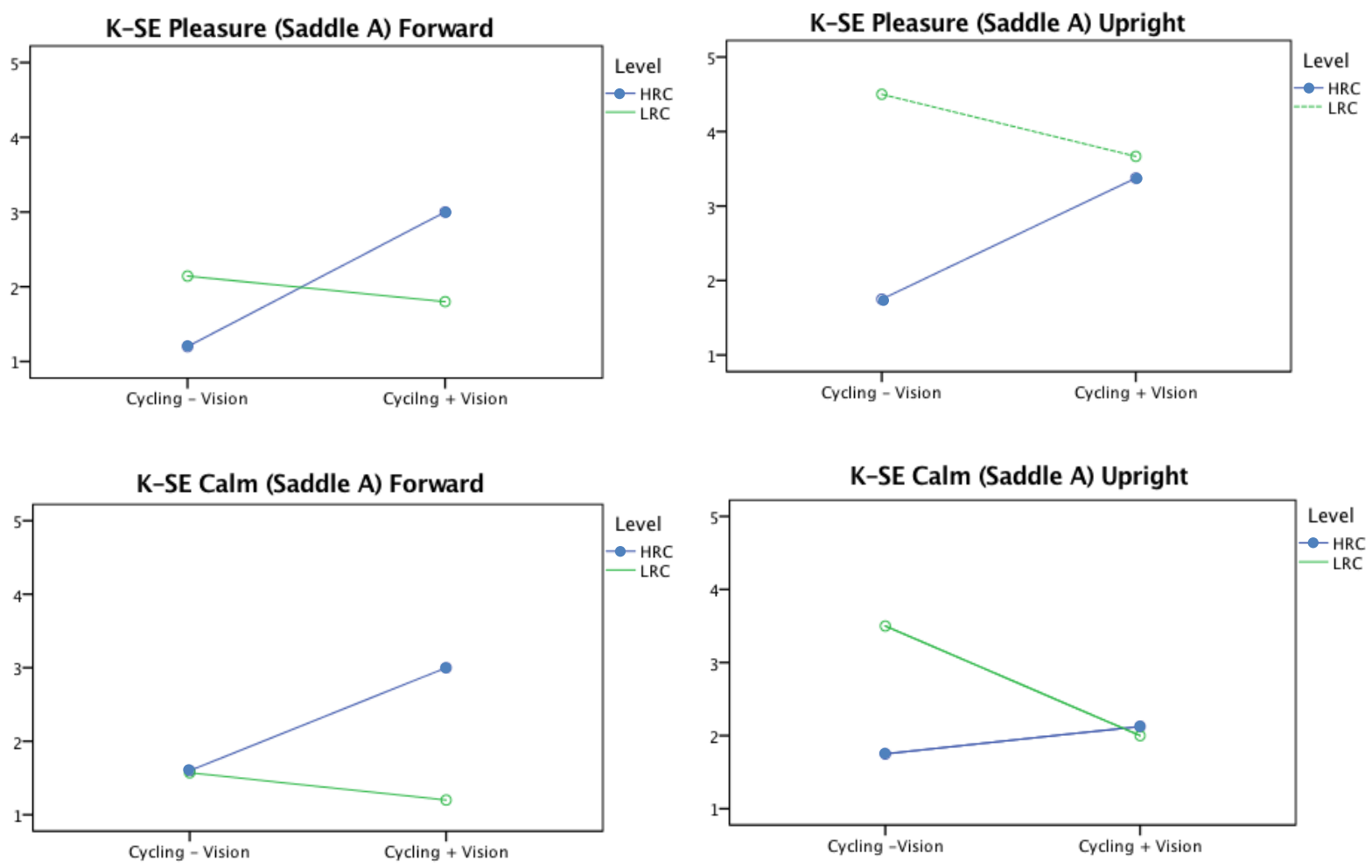

Figure 5.8 Estimated marginal means of selected K-SE through riding postures 
On top of that, Figure 5.9 illustrates the significant interaction effect between a user's involvement level and visual reference/perceptions, $F(1,32)=8.83, p=.006, \eta p^{2}=.22$, showing that HRC rode faster $(M=97.2 .4, S D=2.87)$ when they knew that they were sitting on Saddle A in the cycling session; the cadence without visual references was average 86.4 RPM $(S D=3.15)$. In contrast, LRC became slower, dropping from an average of 92.4 RPM $(S D=2.94)$ to 84.7 RPM $(S D=3.43)$ if they knew that they were sitting on Saddle A. Similarly, it yielded the ratio of $F(1,32)=9.30, p=.005, \eta p^{2}=.23$, and the average power output of HRC group increased from $119.3 \mathrm{~W}(S D=8.96)$ to $141.9 \mathrm{~W}(S D=$ 8.18), while the LRC group dropped again from $133.7 \mathrm{~W}(S D=8.38)$ to $102.3 \mathrm{~W}(S D=$ 9.76). In the case of Saddle B, the same interaction effect was found in the cadence, $F(1$, 32) $=5.21, p=.029, \eta p^{2}=.14$, but there was no significant effect on the power output.
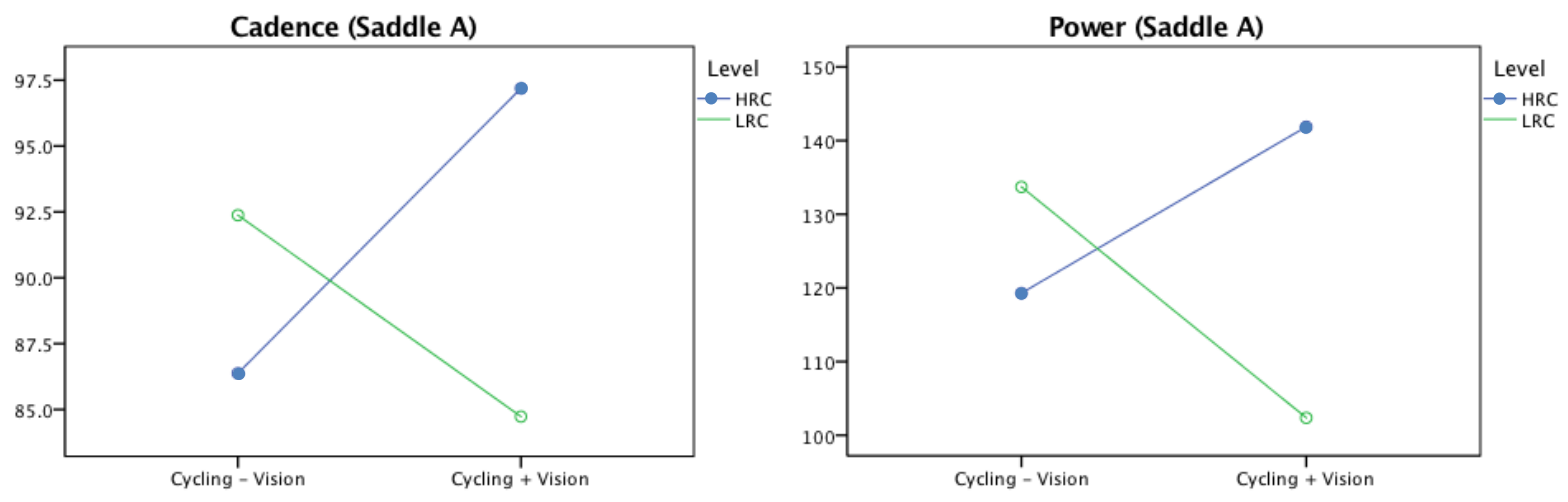

Figure 5.9 Estimated marginal means of sports performance on Saddle A

In this experiment, 19 participants did not sit in the recommended riding position for Saddle A, and 27 participants did not sit in the recommended riding position for Saddle B. The six-minute cycling session may have been long enough to identify the threshold of physical discomfort. Yet surprisingly, neither the cadence nor power output was affected by riding posture, despite the saddles being originally designed for a specific riding posture (Saddle A for the forward position, Saddle B for the upright position) according to the 
manufacturer. In a way, this finding supported Zhang et al. (1996)'s statement that there were different contributions (physically and psychologically) to the measurement of comfort and discomfort.
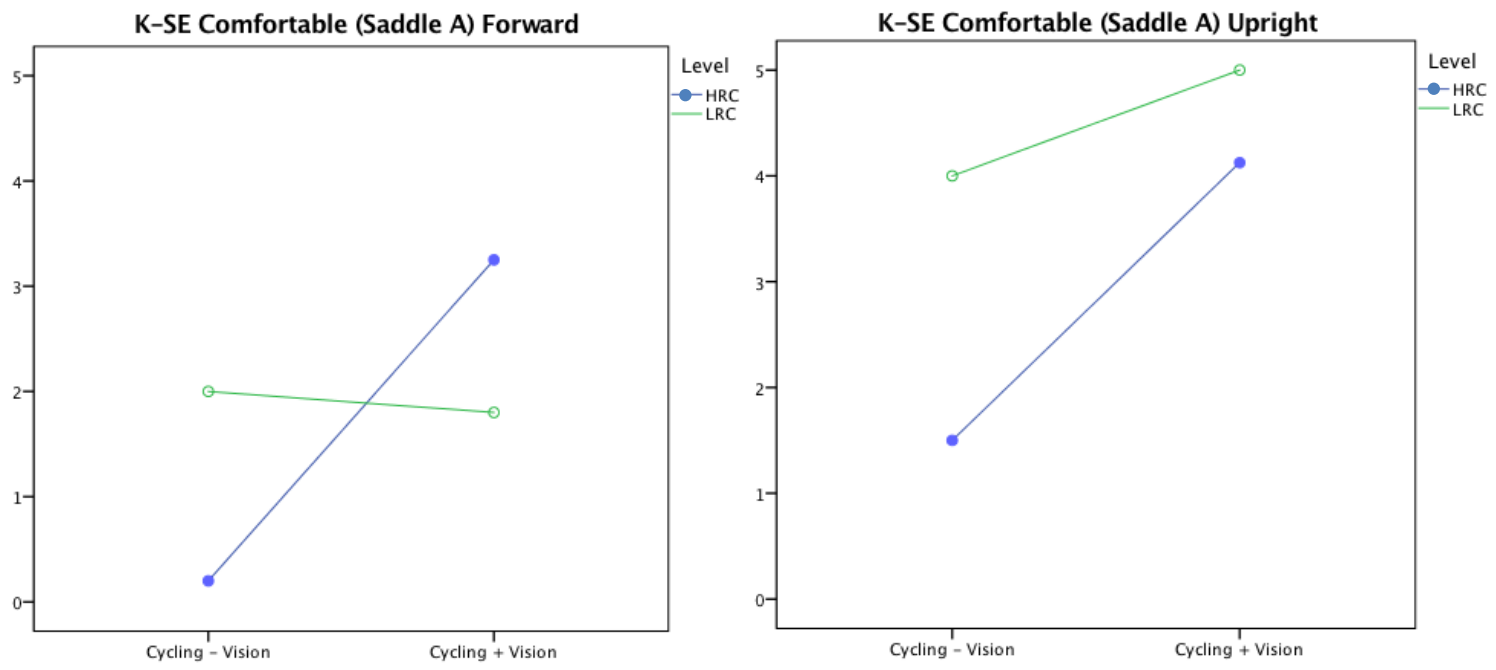

Figure 5.10 Estimated marginal means of K-SE comfortable through perceptions

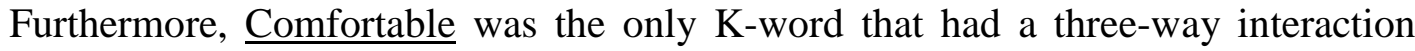
effect on Saddle A. Regardless of riding posture, both user groups felt more comfortable riding Saddle A in an upright position, $F(1,32)=9.72, p=.004, \eta p^{2}=.23$, and reported a higher level of comfortable if they saw it, in particular for the HRC group whose perceived comfort level increased greatly from an average of $0.85(S D=.60)$ to $3.69(S D=.55)$ as shown in Figure 5.10. Finally, the estimated marginal means of all K-words for the two saddles through participants' perceptions are shown in Figure 5.11. The figure clearly demonstrates that users' emotional impressions of Saddle A were influenced more by multisensory interactions as the distances between lines were wider than those shown in the chart for Saddle B. 


\subsection{Chapter summary}

The intention of this experiment was to test the hypotheses of UX-based collection method (UXCM) in terms of multisensory emotional requirements in the saddle experience. The relationship between $20 \mathrm{~K}$-words and user-product interactions (Vision, Touch, Cycling) were discussed. It first investigated the effect of cyclists' visual and tactile perceptions on two semantic spaces (K-SE and K-PP) using the unipolar semantic differential scale (SDS). The results showed that higher emotional intensity was more likely to be found in the K-words in Product Personality (K-PP) when the tactile feedback was provided in the collection process.

Next, two bicycle saddles were tested in the cycling session. The experiment results showed that the product appearance could not only elicit a positive emotional impression (e.g., competitive, proud), but could also improve high-involvement road cyclists' performances (cadence, power output) in the context of a certain saddle. Although participants' riding postures (forward, upright) did not have much influence on their physical performance in this experiment, it still affected the emotional intensity of some Kwords (e.g., energetic, enthusiastic, honest). Overall, this case study highlighted the need to handle the product emotion collection method carefully from the multisensory perspective in terms of sports equipment design. 

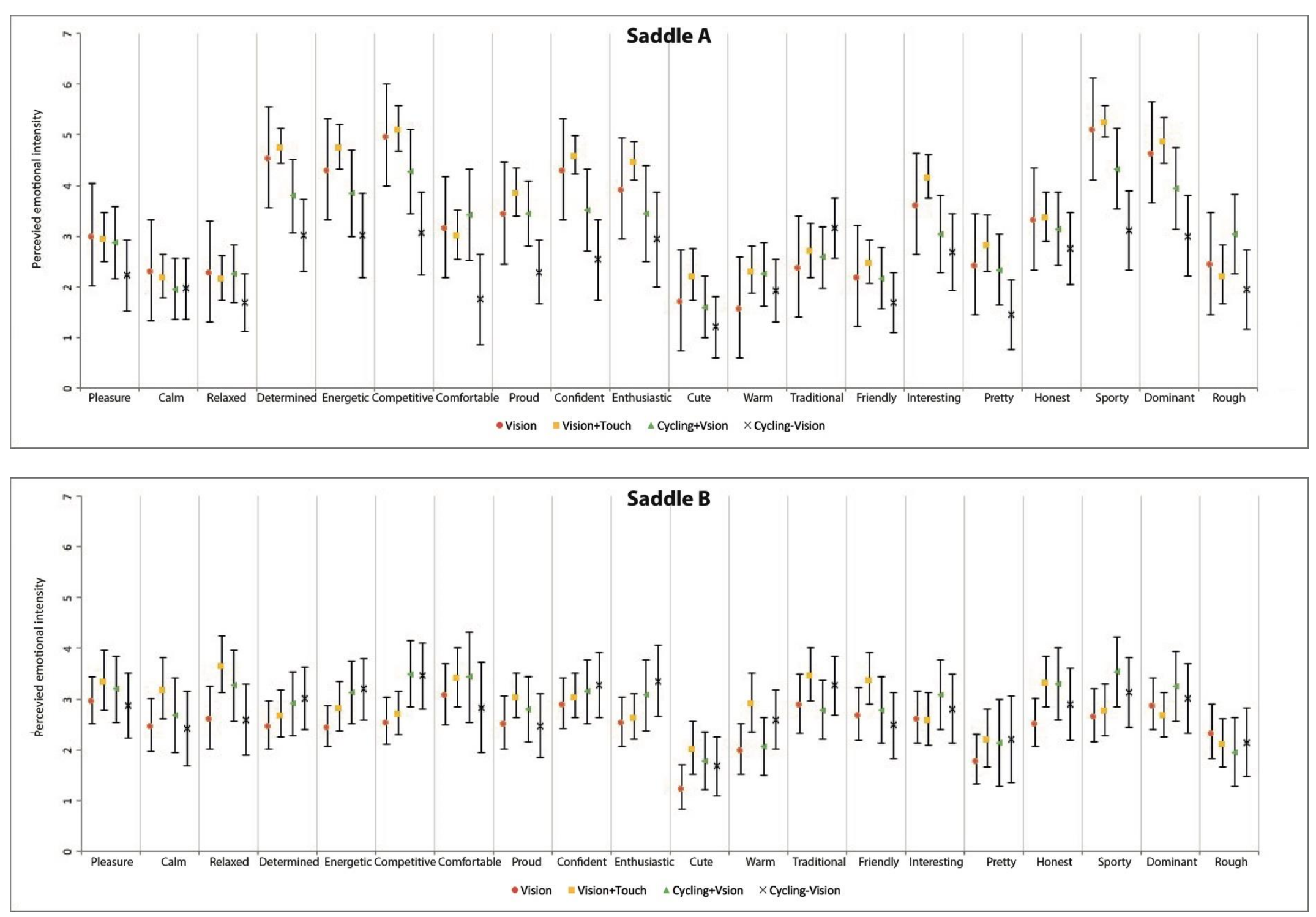

Figure 5.11 Estimated marginal means of K-words for Saddle A and Saddle B 


\section{Chapter 6 Conclusions and Future Work}

\subsection{Conclusions}

This study proposed the original UX-based collection method (UXCM) to address the lack of reliable input data in the existing Kansei engineering system (KES). Currently, the majority of KES studies only focused on the synthesis stage of the semantic domain and product-feature domain in the process of emotional requirement analysis (Figure 2.4). In order to select representative Kansei words (K-words) on a self-report scale, the author clarified what consists of K-words database from UX perspective, not treated it as an issue of terminology like in the literature (Table 2.1). This is important because the influence from users' inputs should be handled with the contextual level. It therefore differentiated emotion words that described human feelings from those expressed by an anthropomorphic habit in human language - users can attribute personality characteristics (e.g., friendliness) to product experience. Thus, two semantic spaces of K-words database, viz., sport emotion and product personality were introduced in the case of sporting goods. In addition, the inconsistent format of semantic differential scale (SDS) that used to evaluate K-words was also found despite its wide use in the existing KES research. According to the conceptual act theory of constructed emotion, it was recommended to avoid the bipolar format, which would skew the meanings of semantic words and cause respondents to misinterpret the questions (Section 2.2.3).

One of the research questions was whether the user experience can be simplified into or represented by K-words. Based on the literature review, two UX characteristics were identified: Temporality and Multisensory. It was assumed that these modules could 
distinguish the evaluation of emotional experience among product categories. For sporting goods, its end-user experience is dissimilar from experiences with consumer goods because as time passes, the exercise routine can become a practice of constant tedious movement, instead of looking for a hedonic quality like surprises. Research has shown that user experience is correlated with interaction time; the longer the customer is exposed to the product, the more her or his expectations (cognitive-focused or affective-focused) change accordingly. The present study, however, argued that dynamic user experience should be investigated according to a user's involvement level, not a chronological order. Furthermore, user-product interactions affect one's perceptions of K-words. For certain product categories like sporting goods, tactile feedback plays an important role in UX evaluation. Some perceptions cannot be triggered without adequate emotion inductions (usually the dominant human senses) in terms of the experimental design. Accordingly, two case studies were conducted to verify the hypotheses in a bid to demonstrate the proposed UXCM, which focuses on the collection process for emotional requirements in the format of K-words.

The initial K-words database was chosen from two semantic spaces including the Kwords in Sport Emotion (K-SE) and the K-words in Product Personality (K-PP). In Chapter 3, the author collected 300 online survey responses in Singapore and the United Kingdom regarding cyclists' attitudes towards sport emotions. The pilot results of a correspondence analysis (CA) showed that a user's motivations (for training, sport, commuting or leisure) affected her or his perceived positive emotions during the cycling experience; the CA plots also confirmed the influence of different cultural backgrounds. As a result, $20 \mathrm{~K}$-words were selected for further UX investigation. 
In the meantime, 33 road cyclists were invited to share their saddle experiences. The K-words that they offered were categorised into overall impression (e.g., comfort), product properties (e.g., hardness), and others (e.g., race). According to the open-ended interview, a conceptual UX model of bicycle saddles was illustrated. It implied that an enjoyable saddle experience was built on the relationships amongst the cyclist, the saddle and the contextual factors. The fact that the cyclists used the trial-and-error strategy to find the right saddle provided more evidence for the temporality characteristic of the UXCM. Finally, the method sowed the seeds for developing the individual profile index (IPI) based on the theory of personal involvement inventory.

The first case study (Chapter 4) aimed to investigate the temporality of vision-based product quality in sports experience. In this regard, 55 participants were divided into either an expert group or a novice group according to their cycling backgrounds. The emotion inductions in this experiment enlisted 10 bicycle images (with more than one type of bicycle), and the participants were asked to evaluate each image in terms of cognitivefocused emotion (confidence) and affective-focused emotion (beauty). The results showed that the level of perceived emotional intensity of the sporting goods did not vary for either emotion types according to a cyclist's increased involvement level, but it verified the author's hypothesis that the UX of sporting goods is different from the UX of consumer goods, which requires more affective-focused emotions as time passes.

Even though the overall impression did not change, the eye-tracking analysis (e.g., fixation counts and fixation duration) revealed otherwise when considering the source of product emotions. For instance, the bicycle saddle was the primary product component that contributed to beginners' confidence, while the front tires and the bike frame elicited the most confidence for experienced cyclists. Likewise, visual attention related to product 
attractiveness shifted from the seat post to the crank set when a user's involvement level increased. In order to conduct a valid UX investigation into multicomponent products, the case study's results suggested to start with one component of the bicycle.

Subsequently, the bicycle saddle was selected to be the second case study (Chapter 5), which further investigated the multisensory emotional requirement. It applied the adapted unipolar SDS (20 K-words on the list), and measured product impressions of two saddles from 40 female road cyclists. With regard to the perceived emotional intensity, some K-words were stronger when the eliciting stimulus was more than just images-with physical contact. Based on the number of collected samples, however, no statistical evidence showed that the types of user-product interactions significantly affected the structure of the K-words database (semantic space).

In addition to evaluating its visual impression and tactile perceptions, this experiment also examined physical performance (Cycling). Previously, the benefits of positive emotions have been proven to be able to keep athletes motivated in tough situations and to attain greater performance (Section 2.1.1) while the emotions discussed mainly cover the human-human relationship in a sporting activity. The fact that the designs of the two saddles evoked very different impressions among the participants imparted that the influence of the appearance of sports equipment on sports performance has probably been underestimated. For instance, the emotional intensity of K-words (e.g., competitive and sporty) decreased accordingly in the cycling session without the visual stimulus. Sports performance (cadence, power output) of the High-involvement road cyclists (HRC) improved when they were allowed to see the saddle during the trials, whereas the riding posture (forward, upright) had no significant impact in this case study. This finding supported the author's idea of 
including product emotions (feelings evoked by the sports equipment) in the emotional assessment for sport.

Overall, this study contributes to the knowledge of Kansei engineering and sports science in the following ways:

(i) Kansei engineering: Due to the lack of guidelines in selecting representative Kansei words, KES often produced the ad-hoc semantic databases that were hard to be applied to other product categories. Therefore, this study proposed an original UX-based collection method (UXCM) to address the issue of users' input from a UX perspective. In comparison with the previous KES studies that treated users' input as a terminology error, the UXCM is built on the assumption that using UX characteristics (from the human) can help KES generalise the outcome towards a wider range of products, in this case, sports equipment. Accordingly, this study utilised two important UX characteristics, viz., temporality and multisensory, and demonstrated the new applicability of a KES. The findings also revealed the structure of the semantic database (K-SE, K-PP) through human perceptions while the effect of multisensory experience on Kansei evaluation was contradicted in the literature. Specifically, it clarified the correlation between semantic spaces and two types of tactile perceptions (touch, cycling/touch-in-action); this submits a solution when finding the Kansei word that best represents the complex user experience.

(ii) Sports science: The outcome of this research contributes not only to the realm of Kansei engineering, but also the sport psychology. Previously in sport psychology, only basic human emotions were included in the emotional assessment. This study expanded the sources of positive emotions in a sporting 
activity—The design of sports equipment (bicycle saddle), even from an athlete's body movement (cycling posture). It further provided empirical evidence that such product impression (e.g., competitiveness) has more influences on highinvolvement users' sports performance regardless of their physical comfort.

\subsection{Limitations and future research}

Despite the UXCM's advantages, this investigation has some limitations. First, only two basic human senses (vision and touch) were investigated in this study. The effect of sound, in addition, can be further explored for the UX of other sports equipment that produces distinct and strong auditory feedback. For instance, when a golf drive hits the ball, the sound coming from the impact might offer the player a sense of confidence or luxury. Cycling is basically an outdoor activity that serves multiple purposes (e.g., sports training, commuting or leisure). The noise from the external environment therefore is likely to drown out the sound (e.g., shifting gears) produced by the bicycle itself. For example, a bicycle racer sprints while enjoying the sound of wind; a bicycle commuter must pay attention to the traffic noise for safety reasons. Because the focus of this thesis was to investigate the affective properties that are related to a product, the experiments were conducted without any distracting auditory stimulus in the laboratory.

Secondly, not everyone is familiar with riding an indoor bike ergometer. The piece of equipment has a fixed top tube length (or handlebar reach), which may not fit each participant's upper body dimensions perfectly. In fact, body-equipment misalignment is a common phenomenon in mass-produced bicycles with few available sizes for all customers. Riding comfort can be improved by adjusting bike parts, such as the seat post length. In this regard, the author noticed that not all participants have prior experience with bike 
fitting services, which may explain why some of them ride their own bikes with aches and pains. Although all participants went through proper bike fitting before the trials, adjustments usually take a longer time to allow the muscles to adapt to those changes. It would be interesting to further develop UXCM for collecting and comparing the evaluation of K-SE (K-words in Sport Emotion) and K-PP (K-words in Product Personality) over a longer ride.

In this study, the author categorised two semantic spaces (K-SE, K-PP) for the Kwords database of sporting goods (bicycle) based on the literature; however, the total number of collected responses (43 female road cyclists) may not comprise enough statistical power to extract these personal constructs. Relevant statistic approaches (e.g., confirmatory factor analysis) normally require a few hundred data points of input. Since the experiments were also designed to collect cyclists' sports performance, measuring several hundred participants for physical performance may not be ideal in this phase. Furthermore, considering that each country has its own cultural background and geographical conditions (e.g., weather and landscape) that influence its residents' attitudes towards different types of sport, the present findings may be only applicable to certain countries (i.e., Singapore and the UK).

Finally, the UXCM examines only one product (the bike saddle) in one case study as an example of bike component design. The present findings may apply best to road cycling performance and extendable to sport activities that consist of repetitive movements (e.g., rowing). More considerations are needed to apply these findings to the sporting goods used for complex actions in a team game, and whether the design of objects (e.g., football) is restricted because of its regulation. A future study could either look deeper into the component specification (e.g., saddle shape or material) with the collected K-words 
database through existing KES approaches, or look wider into the overall experience of cycling (context), which is one of UXCM's advantages. The UX of riding a bicycle can reflect a combination of multiple products because cyclists wear several bike accessories on a ride, which also brings up the issue of style-design matching. In this regard, the UXCM can integrate the temporal and multisensory characteristics into the positive emotions evoked from different products within the same context. Some bike accessories are attached to a human body (e.g., gloves and cycling shoes) and influence cyclists' physical performance directly. Others may have little influence (e.g., a water bottle cage or bike lights). Further applying the UXCM to other types of bicycles/components/accessories to evaluate the product experience and sports performance may be interesting. 


\section{References}

Anderson, S. P. (2011). Seductive interaction design: Creating playful, fun, and effective user experiences. Berkeley, CA: Pearson Education.

Ayachi, F., Dorey, J., \& Guastavino, C. (2015). Identifying Factors of Bicycle Comfort: An Online Survey With Enthusiast Cyclists. Applied ergonomics, 46, 124-136.

Bailey, R., Collins, D., Ford, P., MacNamara, A., Toms, M., \& Pearce, G. (2010). Participant development in sport: An academic review. Sports Coach UK, 4, 1-134.

Balyi, I., Way, R., \& Higgs, C. (2013). Long-term athlete development. Champaign, USA: Human Kinetics.

Baron, B., Moullan, F., Deruelle, F., \& Noakes, T. D. (2011). The role of emotions on pacing strategies and performance in middle and long duration sport events. $\mathrm{Br} J$ Sports Med, 45(6), 511-517. doi: 10.1136/bjsm.2009.059964

Barrass, D., Roberts, J., \& Jones, R. (2006). Assessment of the impact sound in golf putting. Journal of sports sciences, 24(05), 443-454.

Barrass, D., Roberts, J., Jones, R., Hague, R., \& Dickens, P. (2008). The use of structured relationship modelling techniques as a tool to elicit customizable product features. Proceedings of the Institution of Mechanical Engineers Part C-Journal of Mechanical Engineering Science, 222(2), 247-255. doi: 10.1243/09544062jmes761

Barrett, L. F. (1998). Discrete emotions or dimensions? The role of valence focus and arousal focus. Cognition \& Emotion, 12(4), 579-599.

Barrett, L. F. (2006). Solving the emotion paradox: Categorization and the experience of emotion. Personality and social psychology review, 10(1), 20-46.

Barrett, L. F., Mesquita, B., \& Gendron, M. (2011). Context in emotion perception. Current Directions in Psychological Science, 20(5), 286-290.

Beyer, H., \& Holtzblatt, K. (1998). Contextual design: defining customer-centered systems. San Francisco, California: Morgan Kaufmann.

Bias, R. G., \& Mayhew, D. J. (2005). Cost-justifying usability: an update for an Internet age: Morgan Kaufmann.

Blijlevens, J., Carbon, C. C., Mugge, R., \& Schoormans, J. P. (2012). Aesthetic appraisal of product designs: Independent effects of typicality and arousal. British Journal of Psychology, 103(1), 44-57.

Blijlevens, J., Mugge, R., Ye, P. P., \& Schoormans, J. P. (2013). The influence of product exposure on trendiness and aesthetic appraisal. International Journal of Design, 7(1), 55-67.

Bloch, P. H., Brunel, F. F., \& Arnold, T. J. (2003). Individual differences in the centrality of visual product aesthetics: Concept and measurement. Journal of Consumer Research, 29(4), 551-565. doi: 10.1086/346250

Borg, G. A. (1982). Psychophysical bases of perceived exertion. Med sci sports exerc, 14(5), 377-381.

Bressel, E., Bliss, S., \& Cronin, J. (2009). A field-based approach for examining bicycle seat design effects on seat pressure and perceived stability. Applied ergonomics, 40(3), 472-476.

Bruhwiler, P. A., Ducas, C., Huber, R., \& Bishop, P. A. (2004). Bicycle helmet ventilation and comfort angle dependence. European Journal of Applied Physiology, 92(6), 698-701. doi: 10.1007/s00421-004-1114-5 
Buxton, B. (2007). Sketching user experiences: Getting the design right and the right design: Morgan Kaufmann.

Bynner, J., \& Coxhead, P. (1979). Some problems in the analysis of semantic differential data. Human Relations, 32(5), 367-385.

Calvert, G., Spence, C., \& Stein, B. E. (2004). The handbook of multisensory processes: MIT press.

Camargo, F. R., \& Henson, B. (2015). Beyond usability: designing for consumers' product experience using the Rasch model. Journal of Engineering Design, 26(4-6), 121139.

Camargo, M., Wendling, L., \& Bonjour, E. (2014). A fuzzy integral based methodology to elicit semantic spaces in usability tests. International Journal of Industrial Ergonomics, 44(1), 11-17.

Carver, C. S., \& Scheier, M. F. (2001). On the self-regulation of behavior: Cambridge University Press.

Champoux, Y., Richard, S., \& Drouet, J.-M. (2007). Bicycle structural dynamics. Sound and vibration, 41(7), 16-25.

Chen, K. H., \& Hwang, K. L. (2013). Multi-sensory emotion experience - Evaluation on interaction design for handheld devices. Paper presented at the 1st International Conference on Orange Technologies (Icot 2013).

Chen, X., Barnes, C. J., Childs, T. H. C., Henson, B., \& Shao, F. (2009). Materials' tactile testing and characterisation for consumer products' affective packaging design. Materials \& Design, 30(10), 4299-4310. doi: 10.1016/j.matdes.2009.04.021

Chen, X. J., Shao, F., Barnes, C., Childs, T., \& Henson, B. (2009). Exploring eelationships between touch perception and surface physical properties. International Journal of Design, 3(2), 67-76.

Chen, Y. T., \& Chuang, M. C. (2014). The study of tactile feeling and It's expressing vocabulary. International Journal of Industrial Ergonomics, 44(5), 675-684.

Choi, K., \& Jun, C. (2007). A systematic approach to the Kansei factors of tactile sense regarding the surface roughness. Applied ergonomics, 38(1), 53-63. doi: 10.1016/j.apergo.2006.01.003

Chou, C.-J. C., \& Chen, K. (2006). Multiple Kansei Images in Product Form Design. Paper presented at the Wonderground: the 2006 Design Research Society International Conference in Lisbon, Portugal.

Chowdhury, A., Karmakar, S., Reddy, S. M., Ghosh, S., \& Chakrabarti, D. (2014). Usability is more valuable predictor than product personality for product choice in human-product physical interaction. International Journal of Industrial Ergonomics, 44(5), 697-705.

Classen, C. (1993). Worlds of Sense: Exploring the Senses in History and Across Cultures: Routledge.

Crilly, N., Moultrie, J., \& Clarkson, P. J. (2004). Seeing things: consumer response to the visual domain in product design. Design Studies, 25(6), 547-577.

Damisch, L., Stoberock, B., \& Mussweiler, T. (2010). Keep your fingers crossed! How superstition improves performance. Psychological Science, 21(7), 1014-1020.

Davidson, R. J. (1992). Prolegomenon to the structure of emotion: Gleanings from neuropsychology. Cognition \& Emotion, 6(3-4), 245-268. 
de Looze, M. P., Kuijt-Evers, L. F. M., \& van Dieen, J. (2003). Sitting comfort and discomfort and the relationships with objective measures. Ergonomics, 46(10), 985997. doi: 10.1080/0014013031000121977

den Ouden, E., Yuan, L., Sonnemans, P. J., \& Brombacher, A. C. (2006). Quality and reliability problems from a consumer's perspective: an increasing problem overlooked by businesses? Quality and Reliability Engineering International, 22(7), 821-838.

Desmet, P. M. (2003). Measuring emotion: Development and application of an instrument to measure emotional responses to products Funology (pp. 111-123): Springer.

Desmet, P. M. (2012). Faces of product pleasure: 25 positive emotions in human-product interactions. International Journal of Design, 6(2), 1-29.

Desmet, P. M., \& Hekkert, P. (2007). Framework of product experience. International Journal of Design, 1(1), 57-66.

Desmet, P. M., Hekkert, P., \& Jacobs, J. J. (2000). When a car makes you smile: Development and application of an instrument to measure product emotions. Advances in Consumer Research, Vol 27, 27, 111-117.

Desmet, P. M., Nicolás, J. C. O., \& Schoormans, J. P. (2008). Product personality in physical interaction. Design Studies, 29(5), 458-477. doi: 10.1016/j.destud.2008.06.003

Desmet, P. M., Overbeeke, K., \& Tax, S. (2001). Designing products with added emotional value: Development and appllcation of an approach for research through design. The design journal, 4(1), 32-47.

Desmet, P. M., \& Schifferstein, H. N. (2012). Emotion research as input for product design Product innovation toolbox: A field guide to consumer understanding and research (pp. 149-175).

DiSalvo, C., Hanington, B., \& Forlizzi, J. (2002). An accessible framework of emotional experiences for new product conception. Design and Emotion, 251-255.

Donohue, S. E., Woldorff, M. G., \& Mitroff, S. R. (2010). Video game players show more precise multisensory temporal processing abilities. Attention, Perception, \& Psychophysics, 72(4), 1120-1129.

Dorey, J., \& Guastavino, C. (2011). Moving forward: conceptualizing comfort in information sources for enthusiast cyclists. American Society for Information Science and Technology, 48(1), 1-9.

Dreiskaemper, D., Strauss, B., Hagemann, N., \& Busch, D. (2013). Influence of red jersey color on physical parameters in combat sports. Journal of Sport \& Exercise Psychology, 35(1), 44-49. doi: 10.1123/jsep.35.1.44

Ekkekakis, P. (2012). Affect, mood, and emotion. Measurement in sport and exercise psychology, 321-332.

Ekman, P. (1999). Basic emotions. Handbook of cognition and emotion, 98, 45-60.

Ekman, P., \& Friesen, W. V. (1971). Constants across cultures in the face and emotion. Journal of personality and social psychology, 17(2), 124.

Ellegast, R. P., Kraft, K., Groenesteijn, L., Krause, F., Berger, H., \& Vink, P. (2012). Comparison of four specific dynamic office chairs with a conventional office chair: Impact upon muscle activation, physical activity and posture. Applied ergonomics, 43(2), 296-307. doi: 10.1016/j.apergo.2011.06.005

Elliot, A. J., \& Aarts, H. (2011). Perception of the color red enhances the force and velocity of motor output. Emotion, 11(2), 445. 
Elliot, A. J., \& Maier, M. A. (2014). Color psychology: Effects of perceiving color on psychological functioning in humans. Annual review of psychology, 65, 95-120.

Ericsson, K. A., Krampe, R. T., \& Tesch-Römer, C. (1993). The role of deliberate practice in the acquisition of expert performance. Psychological review, 100(3), 363.

Ernst, H. (2002). Success factors of new product development: A review of the empirical literature. International Journal of Management Reviews, 4(1), 1-40. doi: 10.1111/1468-2370.00075

Essa, I. A., \& Pentland, A. P. (1997). Coding, analysis, interpretation, and recognition of facial expressions. Pattern Analysis and Machine Intelligence, IEEE Transactions on, 19(7), 757-763.

Faul, F., Erdfelder, E., Buchner, A., \& Lang, A.-G. (2009). Statistical power analyses using $\mathrm{G}^{*}$ Power 3.1: Tests for correlation and regression analyses. Behavior research methods, 41(4), 1149-1160.

Feltman, R., \& Elliot, A. J. (2011). The influence of red on perceptions of relative dominance and threat in a competitive context. Journal of Sport and Exercise Psychology, 33(2), 308-314.

Fenko, A., Schifferstein, H. N., \& Hekkert, P. (2010). Shifts in sensory dominance between various stages of user-product interactions. Applied ergonomics, 41(1), 34-40.

Filingeri, D., Redortier, B., Hodder, S., \& Havenith, G. (2014). Thermal and tactile interactions in the perception of local skin wetness at rest and during exercise in thermo-neutral and warm environments. Neuroscience, 258, 121-130.

Fortier, M. S., Vallerand, R. J., Briere, N. M., \& Provencher, P. J. (1995). Competitive and recreational sport structures and gender - a test of their relationship with sport motivation. International Journal of Sport Psychology, 26(1), 24-39.

Fujisaki, W., Tokita, M., \& Kariya, K. (2015). Perception of the material properties of wood based on vision, audition, and touch. Vision Research, 109, 185-200. doi: 10.1016/j.visres.2014.11.020

Garland, R. (1990). A comparison of three forms of the semantic differential. Marketing Bulletin, 1(1), 19-24.

Gendron, M., Lindquist, K. A., Barsalou, L., \& Barrett, L. F. (2012). Emotion words shape emotion percepts. Emotion, 12(2), 314.

Gibson, J. J. (1978). The ecological approach to the visual perception of pictures. Leonardo, 11(3), 227-235.

Gray, R. (2008). Multisensory information in the control of complex motor actions. Current Directions in Psychological Science, 17(4), 244-248.

Guess, M. K., Partin, S. N., Schrader, S., Lowe, B., LaCombe, J., Reutman, S., . . Mikhail, M. (2011). Women's Bike Seats: A Pressing Matter for Competitive Female Cyclists. The journal of sexual medicine, 8(11), 3144-3153.

Guo, F., Liu, W. L., Liu, F. T., Wang, H., \& Wang, T. B. (2014). Emotional design method of product presented in multi-dimensional variables based on Kansei Engineering. Journal of Engineering Design, 25(4-6), 194-212.

Guthrie, S. E. (1995). Faces in the clouds: A new theory of religion: Oxford University Press.

Hagtvet, K. A., \& Hanin, Y. L. (2007). Consistency of performance-related emotions in elite athletes: Generalizability theory applied to the IZOF model. Psychology of sport and exercise, 8(1), 47-72. 
Hanjalic, A., \& Xu, L.-Q. (2005). Affective video content representation and modeling. Multimedia, IEEE Transactions on, 7(1), 143-154.

Hassenzahl, M. (2004). The interplay of beauty, goodness, and usability in interactive products. Human-Computer Interaction, 19(4), 319-349.

Hassenzahl, M. (2010). Experience design: Technology for all the right reasons. Synthesis Lectures on Human-Centered Informatics, 3(1), 1-95.

Hassenzahl, M., Burmester, M., Koller, F., Brau, H., Diefenbach, S., Hassenzahl, M., .. . Röse, K. (2008). Der User Experience (UX) auf der Spur: Zum Einsatz von www. attrakdiff. de. Usability Professionals, 78-82.

Hassenzahl, M., Diefenbach, S., \& Göritz, A. (2010). Needs, affect, and interactive products-Facets of user experience. Interacting with computers, 22(5), 353-362.

Hassenzahl, M., \& Tractinsky, N. (2006). User experience-a research agenda. Behaviour \& information technology, 25(2), 91-97.

Haug, A. (2016). A Framework for the Experience of Product Aesthetics. The design journal, 19(5), 809-826.

Hawley, J. A., \& Stepto, N. K. (2001). Adaptations to training in endurance cyclists. Sports Medicine, 31(7), 511-520.

Hekkert, P., \& Leder, H. (2008). Product aesthetics. In Hendrik N. J. Schifferstein \& P. Hekkert (Eds.), Product Experience (pp. 259-285): Elsevier.

Hoegg, J., Alba, J. W., \& Dahl, D. W. (2010). The good, the bad, and the ugly: Influence of aesthetics on product feature judgments. Journal of Consumer Psychology, 20(4), 419-430.

Hornbæk, K., \& Law, E. L.-C. (2007). Meta-analysis of correlations among usability measures. Paper presented at the SIGCHI conference on Human factors in computing systems.

Hsiao, K. A., \& Chen, L. L. (2006). Fundamental dimensions of affective responses to product shapes. International Journal of Industrial Ergonomics, 36(6), 553-564.

Hsiao, S. W., \& Ko, Y. C. (2013). A study on bicycle appearance preference by using FCE and FAHP. International Journal of Industrial Ergonomics, 43(4), 264-273.

Huang, Y., Chen, C.-H., \& Khoo, L. P. (2012a). Kansei clustering for emotional design using a combined design structure matrix. International Journal of Industrial Ergonomics, 42(5), 416-427.

Huang, Y., Chen, C.-H., \& Khoo, L. P. (2012b). Products classification in emotional design using a basic-emotion based semantic differential method. International Journal of Industrial Ergonomics, 42(6), 569-580. doi: 10.1016/j.ergon.2012.09.002

Ishihara, S., Ishihara, K., Nagamachi, M., \& Matsubara, Y. (1997). An analysis of Kansei structure on shoes using self-organizing neural networks. International Journal of Industrial Ergonomics, 19(2), 93-104.

Iwatsuki, A., Hirayama, T., \& Mase, K. (2013). Analysis of soccer coach's eye gaze behavior. Paper presented at the Pattern Recognition (ACPR), 2013 2nd IAPR Asian Conference on.

Jakesch, M., Zachhuber, M., Leder, H., Spingler, M., \& Carbon, C. C. (2011). Scenariobased touching: on the influence of top-down processes on tactile and visual appreciation. Research in Engineering Design, 22(3), 143-152.

Jones, M. V. (2003). Controlling emotions in sport. The Sport Psychologist, 17, 471-486. 
Jones, M. V., Lane, A. M., Bray, S. R., Uphill, M., \& Catlin, J. (2005). Development and validation of the sport emotion questionnaire. Journal of Sport and Exercise Psychology, 27, 407-431.

Jones, M. V., Meijen, C., McCarthy, P. J., \& Sheffield, D. (2009). A theory of challenge and threat states in athletes. International Review of Sport and Exercise Psychology, 2(2), 161-180.

Jordan, P. W. (1998). Human factors for pleasure in product use. Applied ergonomics, 29(1), 25-33.

Jordan, P. W., \& Persson, S. (2007). Exploring users' product constructs: how people think about different types of product. CoDesign, 3(S1), 97-106.

Kamoen, N., Holleman, B., \& van den Bergh, H. (2013). Positive, negative, and bipolar questions: The effect of question polarity on ratings of text readability. Survey Research Methods, 7(3), 181-189.

Karapanos, E. (2013). User experience over time Modeling Users' Experiences with Interactive Systems (pp. 57-83): Springer.

Karapanos, E., Martens, J.-B., \& Hassenzahl, M. (2009). Accounting for diversity in subjective judgments. Paper presented at the SIGCHI Conference on Human Factors in Computing Systems.

Karapanos, E., \& Martens, J. (2008, April 5-10). The quantitative side of the Repertory Grid Technique: some concerns. Paper presented at the 26th Annual ACM Conference on Human Factors in Computing Systems, Florence, Italy.

Karapanos, E., Zimmerman, J., Forlizzi, J., \& Martens, J. B. (2010). Measuring the dynamics of remembered experience over time. Interacting with computers, 22(5), 328-335.

Kavakli, M., \& Gero, J. S. (2002). The structure of concurrent cognitive actions: a case study on novice and expert designers. Design Studies, 23(1), 25-40.

Kelly, G. A. (1955). The psychology of personal constructs. Volume 1: A theory of personality: WW Norton and Company.

Khalid, H. M., \& Helander, M. G. (2006). Customer emotional needs in product design. Concurrent Engineering, 14(3), 197-206.

Köhler, M., Falk, B., \& Schmitt, R. (2013). Objectifying user attention caused by visually perceived product components. Paper presented at the 16th International Congress of Metrology.

Köhler, M., Falk, B., \& Schmitt, R. (2014, June 11-13). Applying eye-tracking in Kansei engineering methodology for design evaluations in product development. Paper presented at the International Conference on Kansei Engineering and Emotion Research Linköping

Kooijman, J., \& Schwab, A. (2013). A review on bicycle and motorcycle rider control with a perspective on handling qualities. Vehicle System Dynamics, 51(11), 1722-1764.

Krippendorff, K. (2005). The semantic turn: A new foundation for design: CRC Press.

Kujala, S. (2003). User involvement: a review of the benefits and challenges. Behaviour \& information technology, 22(1), 1-16.

Kujala, S., Roto, V., Vaananen-Vainio-Mattila, K., Karapanos, E., \& Sinnela, A. (2011). UX Curve: A method for evaluating long-term user experience. Interacting with computers, 23(5), 473-483. doi: 10.1016/J.Intcom.2011.06.005 
Kumar, M., \& Garg, N. (2010). Aesthetic principles and cognitive emotion appraisals: How much of the beauty lies in the eye of the beholder? Journal of Consumer Psychology, 20(4), 485-494.

Kuo, J.-Y., Chen, C.-H., \& Roberts, J. (2014). The Differences in Positive Emotional Demands on Bicycle Components between Expert and Novice Cyclists. Paper presented at the 1st International Conference in Sports Science \& Technology, Singapore.

Kuo, J.-Y., Chen, C.-H., \& Roberts, J. (2016). An Elicitation Technique for Customer Emotional Requirements Based on Multi-Sensory User Experience. Paper presented at the 23rd ISPE International Conference on Transdisciplinary Engineering, Brazil.

Kuru, A., \& Erbuğ, Ç. (2013). Explorations of perceived qualities of on-body interactive products. Ergonomics, 56(6), 906-921.

Kuutti, K. (1996). Activity theory as a potential framework for human-computer interaction research. Context and consciousness: Activity theory and human-computer interaction, 17-44.

Laborde, S., Brull, A., Weber, J., \& Anders, L. S. (2011). Trait emotional intelligence in sports: A protective role against stress through heart rate variability? Personality and Individual Differences, 51(1), 23-27. doi: 10.1016/j.paid.2011.03.003

Laborde, S., \& Raab, M. (2013). The tale of hearts and reason: The influence of mood on decision making. Journal of Sport \& Exercise Psychology, 35(4), 339-357.

Laios, L., \& Giannatsis, J. (2010). Ergonomic evaluation and redesign of children bicycles based on anthropometric data. Applied ergonomics, 41(3), 428-435.

Laurans, G., \& Desmet, P. M. (2012). Introducing PREMO2: New directions for the nonverbal measurement of emotion in design. Paper presented at the Out of Control: Proceedings of the 8th International Conference on Design and Emotion, London, UK, 11-14 September 2012.

Law, E. L.-C., van Schaik, P., \& Roto, V. (2014). Attitudes towards user experience (UX) measurement. International Journal of Human-Computer Studies, 72(6), 526-541.

Lazarus, R. S. (2000). How emotions influence performance in competitive sports. The Sport Psychologist, 14(3), 229-252.

Lee, H.-H., Kim, S.-J., \& Lee, S.-K. (2009). Design of new sound metric and its application for quantification of an axle gear whine sound by utilizing artificial neural network. Journal of mechanical science and technology, 23(4), 1182-1193.

Lee, S., Harada, A., \& Stappers, P. J. (2002). Design based on Kansei. In W. S. Green \& P. W. Jordan (Eds.), Pleasure With Product: Beyond Usability (pp. 219-229). London: Taylor \& Francis.

Lench, H. C., Flores, S. A., \& Bench, S. W. (2011). Discrete emotions predict changes in cognition, judgment, experience, behavior, and physiology: a meta-analysis of experimental emotion elicitations. Psychological bulletin, 137(5), 834.

Lin, Y.-F., \& Lu, C.-H. (2007). Comparison between Product Images Created by Global and Local Features of Bicycle. (master), Shih Chien University, Taiwan.

Lindgaard, G., Fernandes, G., Dudek, C., \& Brown, J. (2006). Attention web designers: You have 50 milliseconds to make a good first impression! Behaviour \& information technology, 25(2), 115-126.

Lindquist, K. A., \& Gendron, M. (2013). What's in a word? Language constructs emotion perception. Emotion Review, 5(1), 66-71. 
Liu, C. H., \& Chang, Y. M. (2009). Exploring the visual cognition on form features of bicycles frames by using eye-tracking system. (master), National Cheng Kung University, Taiwan.

Lyon, R. H. (2003). Product sound quality-From perception to design. Sound and vibration, 37(3), 18-23.

Macdermid, P., Fink, P., \& Stannard, S. (2015). The effects of vibrations experienced during road vs. off-road cycling. International journal of sports medicine, 94(10), 783-788.

Mann, D. T., Williams, A. M., Ward, P., \& Janelle, C. M. (2007). Perceptual-cognitive expertise in sport: A meta-analysis. Journal of Sport and Exercise Psychology, $29(4), 457$.

Marcus, A. (2006). Cross-cultural user-experience design. Paper presented at the International Conference on Theory and Application of Diagrams.

Martens, R., Vealey, R., \& Burton, D. (1990). Competitive anxiety in sport: Human Kinetics.

Martin, K. A., Moritz, S. E., \& Hall, C. R. (1999). Imagery use in sport: a literature review and applied model. The Sport Psychologist.

Maslow, A. H., Frager, R., Fadiman, J., McReynolds, C., \& Cox, R. (1970). Motivation and personality (Vol. 2): Harper \& Row New York.

Mauss, I. B., \& Gross, J. J. (2004). Emotion suppression and cardiovascular: Is hiding your feelings bad for your heart? In I. Nyklicek, L. R. Temoshok \& A. Vingerhoets (Eds.), Emotion Expression and Health (pp. 62-81). New York: Brunner-Routledge.

Mauss, I. B., Levenson, R. W., McCarter, L., Wilhelm, F. H., \& Gross, J. J. (2005). The tie that binds? Coherence among emotion experience, behavior, and physiology. Emotion, 5(2), 175.

Maximilian, M., Veit, S., \& Udo, L. (2007, 28-31 July). Specific Characteristics of Sports Equipment. Paper presented at the 16th International Conference on Engineering Design, Paris, France.

McCarthy, P. J., \& Jones, M. V. (2007). A qualitative study of sport enjoyment in the sampling years. The Sport Psychologist, 21(4), 400.

Merchel, S., Altinsoy, M. E., \& Stamm, M. (2012). Touch the Sound: Audio-Driven Tactile Feedback for Audio Mixing Applications. Journal of the Audio Engineering Society, 60(1-2), 47-53.

Miller, M. G., \& Berry, D. C. (2007). Back in the saddle again: How to prevent cycling saddle sores. Athletic Therapy Today, 12(4), 19-21.

Miniukovich, A., \& De Angeli, A. (2014). Visual impressions of mobile app interfaces. Paper presented at the 8th Nordic Conference on Human-Computer Interaction: Fun, Fast, Foundational.

Miura, T. (2000). Eye movements in apprehension of bonsais: The effect of knowledge and experience. Paper presented at the 16th Congress of the International Association of Empirical Aesthetics.

Mugge, R., Govers, P. C., \& Schoormans, J. P. (2009). The development and testing of a product personality scale. Design Studies, 30(3), 287-302. doi: 10.1016/j.destud.2008.10.002

Mugge, R., \& Schoormans, J. P. (2012). Product design and apparent usability. The influence of novelty in product appearance. Applied ergonomics, 43(6), 1081-1088. 
Mugge, R., Schoormans, J. P., \& Schifferstein, H. N. (2009). Emotional bonding with personalised products. Journal of Engineering Design, 20(5), 467-476. doi: $10.1080 / 09544820802698550$

Nagamachi, M. (2002). Kansei engineering as a powerful consumer-oriented technology for product development. Applied ergonomics, 33(3), 289-294.

Nagamachi, M. (2011). Methods of Kansei/Affective engineering and specific cases of kansei products. In M. Nagamachi (Ed.), Kansei/Affective Engineering (pp. 13-30). Boca Raton, Florida: CRC Press, Taylor \& Francis Group.

Nagamachi, M., \& Lokman, A. M. (2011). Kansei engineering case study Innovations of Kansei Engineering (pp. 11-21). Boca Raton, FL: CRC Press.

Nagamachi, M., \& Lokman, A. M. (2016). Types of Kansei Engineering Technique Innovations of Kansei Engineering (pp. 23-47): CRC Press.

Nardi, B. A. (1996). Context and consciousness: activity theory and human-computer interaction: MIT Press.

Nieuwenhuys, A., Hanin, Y. L., \& Bakker, F. C. (2008). Performance-related experiences and coping during races: A case of an elite sailor. Psychology of sport and exercise, 9(1), 61-76. doi: 10.1016/j.psychsport.2006.12.007

Norman, D. A. (1988). The psychology of everyday things: Basic books.

Norman, D. A. (2002). Emotion \& design: attractive things work better. interactions, 9(4), 36-42.

Norman, D. A. (2004). Emotional design: Why we love (or hate) everyday things: Basic books.

Nosek, B. A., Sriram, N., \& Umansky, E. (2012). Presenting survey items one at a time compared to all at once decreases missing data without sacrificing validity in research with internet volunteers. Plos One, 7(5).

Olsen, A. (2012). The tobii i-vt fixation filter. Tobii Technology.

Ortony, A. (1990). The cognitive structure of emotions: Cambridge University Press.

Osgood, C. E. (1957). The measurement of meaning: University of Illinois Press.

Parizet, E., Guyader, E., \& Nosulenko, V. (2008). Analysis of car door closing sound quality. Applied Acoustics, 69(1), 12-22.

Park, J., Han, S. H., Kim, H. K., Moon, H., \& Park, J. (2015). Developing and verifying a questionnaire for evaluating user value of a mobile device. Human Factors and Ergonomics in Manufacturing \& Service Industries, 25(6), 724-739. doi: $10.1002 / \mathrm{hfm} .20588$

Peck, J., \& Childers, T. L. (2003). Individual differences in haptic information processing: The "Need for Touch" scale. Journal of Consumer Research, 30(3), 430-442.

Petiot, J. F., \& Yannou, B. (2004). Measuring consumer perceptions for a better comprehension, specification and assessment of product semantics. International Journal of Industrial Ergonomics, 33(6), 507-525. doi: 10.1016/j.ergon.2003.12.004

Petrov, S., Fontanari, J. F., \& Perlovsky, L. I. (2012). Subjective emotions vs. verbalizable emotions in web texts. International Journal of Psychology and Behavioral Sciences, 2(5), 173-184.

Picard, R. W. (1997). Affective computing Media Laboratory Perceptual Computing Section Technical Report: MIT Press. 
Pierre, L., Toshimasa, Y., \& Oscar, T. (2011). Psychophysiological Applications in Kansei Design. In D. Ying, C. Basabi \& S. Minghui (Eds.), Kansei Engineering and Soft Computing: Theory and Practice (pp. 266-286). Hershey, PA, USA: IGI Global.

Potter, J. J., Sauer, J. L., Weisshaar, C. L., Thelen, D. G., \& Ploeg, H. L. (2008). Gender differences in bicycle saddle pressure distribution during seated cycling. Medicine and Science in Sports and Exercise, 40(6), 1126-1134. doi: 10.1249/mss.0b013e3181666eea

Pucillo, F., \& Cascini, G. (2014). A framework for user experience, needs and affordances. Design Studies, 35(2), 160-179. doi: 10.1016/j.destud.2013.10.001

PwC. (2016). At the gat eand beyond: Outlook for the sports market in North America through 2020. from http://www.pwc.com/us/en/industry/entertainmentmedia/publications/assets/pwc-sports-outlook-2016.pdf

Rahman, O. (2012). The influence of visual and tactile Inputs on denim jeans evaluation. International Journal of Design, 6(1), 11-25.

Razza, B. M., Paschoarelli, L. C., Santos, H. M., \& Andrade, L. O. (2014). The Multisensory Experience: A Case Study with Five Different Products. Advances in Ergonomics In Design, Usability \& Special Populations: Part III, 18, 167.

Recours, R., \& Briki, W. (2015). The effect of red and blue uniforms on competitive anxiety and self-confidence in virtual sports contests. Revue Européenne de Psychologie Appliquée/European Review of Applied Psychology, 65(2), 67-69.

Reid, T. N., MacDonald, E. F., \& Du, P. (2013). Impact of product design representation on customer judgment. Journal of Mechanical Design, 135(9). doi: $10.1115 / 1.4024724$

Roberts, J., Jones, R., Harwood, C., Mitchell, S., \& Rothberg, S. (2001). Human perceptions of sports equipment under playing conditions. Journal of sports sciences, 19(7), 485-497. doi: 10.1080/026404101750238944

Roberts, J., Jones, R., Mansfield, N. J., \& Rothberg, S. (2005). Evaluation of impact sound on the 'feel'of a golf shot. Journal of sound and vibration, 287(4), 651-666.

Roberts, J., Jones, R., Rothberg, S., Mansfield, N. J., \& Meyer, C. (2006). Influence of sound and vibration from sports impacts on players' perceptions of equipment quality. Proceedings of the Institution of Mechanical Engineers, Part L: Journal of Materials Design and Applications, 220(4), 215-227.

Rodríguez Ramírez, E. R. (2014). Industrial design strategies for eliciting surprise. Design Studies, 35(3), 273-297. doi: 10.1016/j.destud.2013.12.001

Ross, T. P., Ross, L. T., Rahman, A., \& Cataldo, S. (2010). The bicycle helmet attitudes scale: using the health belief model to predict helmet use among undergraduates. Journal of American College Health, 59(1), 29-36.

Russel, J. A., Weiss, A., \& Mendelsohn, G. A. (1989). Affect grid: A single-item scale of pleasure and arousal. Journal of personality and social psychology, 57(3), 493-502.

Russell, J. A. (1980). A circumplex model of affect. Journal of personality and social psychology, 39(6), 1161.

Saariluomaand, P., \& Jokinen, J. P. P. (2014). Emotional dimensions of user experience: A user psychological analysis. International Journal of Human-Computer Interaction, 30(4), 303-320.

Scherer, K. R. (2005). What are emotions? And how can they be measured? Social science information, 44(4), 695-729. 
Schifferstein, H. N. (2006). The perceived importance of sensory modalities in product usage: A study of self-reports. Acta psychologica, 121(1), 41-64.

Schifferstein, H. N. (2009). Comparing mental imagery across the sensory modalities. Imagination, Cognition and Personality, 28(4), 371-388.

Schifferstein, H. N., \& Hekkert, P. (2011). Product experience: Elsevier.

Schmidt, A., Beigl, M., \& Gellersen, H.-W. (1999). There is more to context than location. Computers \& Graphics, 23(6), 893-901.

Schmitt, R., Köhler, M., Durá, J., \& Diaz-Pineda, J. (2013). Objectifying User Attention and Emotion Evoked by Relevant Perceived Product Components. Paper presented at the Proceedings of 11th International Symposium on Measurement Technology and Intelligent Instruments ISMTII.

Schmitt, R., Köhler, M., Durá, J., \& Diaz-Pineda, J. (2014). Objectifying user attention and emotion evoked by relevant perceived product components. Journal of Sensors and Sensor Systems, 3(2), 315.

Schuller, B., Müller, R., Eyben, F., Gast, J., Hörnler, B., Wöllmer, M., . . . Konosu, H. (2009). Being bored? Recognising natural interest by extensive audiovisual integration for real-life application. Image and Vision Computing, 27(12), 17601774.

Schütte, S. (2002). Designing feelings into products: Integrating kansei engineering methodology in product development. (doctoral dissertation), Linköping University, Sweden.

Schütte, S., \& Eklund, J. (2005). Design of rocker switches for work-vehicles - an application of Kansei Engineering. Applied ergonomics, 36(5), 557-567. doi: 10.1016/j.apergo.2005.02.002

Selby, R., Weinstein, H. M., \& Bird, T. S. (1990). The health of university athletes: Attitudes, behaviors, and stressors. Journal of American College Health, 39(1), 1118.

Seva, R. R., Gosiaco, K. G. T., Santos, M. C. E. D., \& Pangilinan, D. M. L. (2011). Product design enhancement using apparent usability and affective quality. Applied ergonomics, 42(3), 511-517. doi: 10.1016/j.apergo.2010.09.009

Shaver, P., Schwartz, J., Kirson, D., \& O'connor, C. (1987). Emotion knowledge: Further exploration of a prototype approach. Journal of personality and social psychology, 52(6), 1061.

Shieh, M.-D., \& Yeh, Y.-E. (2013). Developing a design support system for the exterior form of running shoes using partial least squares and neural networks. Computers \& Industrial Engineering, 65(4), 704-718.

Shimojo, S., \& Shams, L. (2001). Sensory modalities are not separate modalities: plasticity and interactions. Current opinion in neurobiology, 11(4), 505-509.

Sigrist, R., Rauter, G., Riener, R., \& Wolf, P. (2013). Augmented visual, auditory, haptic, and multimodal feedback in motor learning: A review. Psychonomic Bulletin \& Review, 20(1), 21-53. doi: 10.3758/s13423-012-0333-8

Singh, A., \& Das, L. K. (2009, October 18-22). A framework of biker-bike personality factors within the social culture of biking in India. Paper presented at the International Association of Societies of Design Research, Korea.

Smith, D. J. (2003). A framework for understanding the training process leading to elite performance. Sports Medicine, 33(15), 1103-1126. doi: 10.2165/00007256200333150-00003 
Solomon, R. C. (2002). Back to basics: On the very idea of "basic emotions". Journal for the theory of social behaviour, 32(2), 115-144.

Solomon, R. C., \& Stone, L. D. (2002). On "positive" and "negative" emotions. Journal for the theory of social behaviour, 32(4), 417-435.

Sonderegger, A., \& Sauer, J. (2010). The influence of design aesthetics in usability testing: Effects on user performance and perceived usability. Applied ergonomics, 41(3), 403-410.

Spence, C., \& Gallace, A. (2011). Multisensory design: Reaching out to touch the consumer. Psychology \& Marketing, 28(3), 267-308.

Spence, C., \& Zampini, M. (2006). Auditory contributions to multisensory product perception. Acta Acustica united with Acustica, 92(6), 1009-1025.

Still, J. D., \& Dark, V. J. (2013). Cognitively describing and designing affordances. Design Studies, 34(3), 285-301. doi: 10.1016/j.destud.2012.11.005

Terry, P. C., \& Lane, A. M. (2000). Normative values for the profile of mood states for use with athletic samples. Journal of Applied Sport Psychology, 12(1), 93-109.

Thelwell, R. C., \& Greenlees, I. A. (2003). Developing competitive endurance performance using mental skills training. The Sport Psychologist, 17(3), 318-337.

Tiest, W. M. B., \& Kappers, A. M. (2007). Haptic and visual perception of roughness. Acta psychologica, 124(2), 177-189.

Tomico, O., Karapanos, E., Levy, P., Mizutani, N., \& Yamanaka, T. (2009). The repertory grid technique as a method for the study of cultural differences. International Journal of Design, 3(3).

Torbic, D., El-Gindy, M., \& Elefteriadou, L. (2003). Methodology for quantifying wholebody vibration experienced by bicyclists. International journal of vehicle design, 31(4), 452-480.

Totterdell, P. (2000). Catching moods and hitting runs: mood linkage and subjective performance in professional sport teams. Journal of Applied Psychology, 85(6), 848.

Tractinsky, N., Katz, A., \& Ikar, D. (2000). What is beautiful is usable. Interacting with computers, 13(2), 127-145.

Tremoulet, P. D., \& Feldman, J. (2000). Perception of animacy from the motion of a single object. Perception, 29(8), 943-951.

Tuch, A. N., Roth, S. P., Hornbæk, K., Opwis, K., \& Bargas-Avila, J. A. (2012). Is beautiful really usable? Toward understanding the relation between usability, aesthetics, and affect in HCI. Computers in Human Behavior, 28(5), 1596-1607.

Vealey, R. S., Hayashi, S. W., Garner-Holman, M., \& Giacobbi, P. (1998). Sources of sport-confidence: Conceptualization and instrument development. Journal of Sport and Exercise Psychology, 20, 54-80.

Veen, S. v., \& Vink, P. (2016). Can Prior Experience Influence Seating Comfort Ratings? Ergonomics in Design: The Quarterly of Human Factors Applications, 24(2), 1620. doi: $10.1177 / 1064804615611268$

Vergara, M., Mondragón, S., Sancho-Bru, J. L., Company, P., \& Agost, M.-J. (2011). Perception of products by progressive multisensory integration. A study on hammers. Applied ergonomics, 42(5), 652-664.

Verma, G. K., \& Tiwary, U. S. (2014). Multimodal fusion framework: A multiresolution approach for emotion classification and recognition from physiological signals. Neuroimage, 102, 162-172. doi: 10.1016/j.neuroimage.2013.11.007 
Verma, R., Hansen, E. A., de Zee, M., \& Madeleine, P. (2016). Effect of seat positions on discomfort, muscle activation, pressure distribution and pedal force during cycling. Journal of Electromyography and Kinesiology, 27, 78-86. doi: 10.1016/j.jelekin.2016.02.003

Vink, P., \& Hallbeck, S. (2012). Comfort and discomfort studies demonstrate the need for a new model. Applied ergonomics, 43(2), 271-276.

Visschers, V. H., Hess, R., \& Siegrist, M. (2010). Health motivation and product design determine consumers' visual attention to nutrition information on food products. Public health nutrition, 13(07), 1099-1106.

Wallbott, H. G., \& Scherer, K. R. (1989). Assessing emotion by questionnaire. Emotion: Theory, research, and experience, 4, 55-82.

Wang, K. C. (2011). A hybrid Kansei engineering design expert system based on grey system theory and support vector regression. Expert Systems with Applications, 38(7), 8738-8750. doi: 10.1016/j.eswa.2011.01.083

Watson, D., Clark, L. A., \& Tellegen, A. (1988). Development and validation of brief measures of positive and negative affect: The PANNS scales. Journal of personality and social psychology, 54(6), 1063-1070. doi: 10.1037/0022-3514.54.6.1063

Webster, J., \& Roberts, J. (2009). Incorporating subjective end-user perceptions in the design process: a study of leg guard comfort in cricket. Proceedings of the Institution of Mechanical Engineers, Part P: Journal of Sports Engineering and Technology, 223(2), 49-62.

Williams, M., \& Davids, K. (1995). Declarative knowledge in sport: A by-product of experience or a characteristic of expertise. Journal of Sport \& Exercise Psychology, $17(3), 259-275$.

Woodcock, C., Cumming, J., Duda, J. L., \& Sharp, L.-A. (2012). Working within an Individual Zone of Optimal Functioning (IZOF) framework: Consultant practice and athlete reflections on refining emotion regulation skills. Psychology of sport and exercise, 13(3), 291-302.

Woodman, T., \& Hardy, L. (2003). The relative impact of cognitive anxiety and selfconfidence upon sport performance: A meta-analysis. Journal of sports sciences, 21(6), 443-457.

Wu, C.-C. (2013). Static and dynamic analyses of mountain bikes and their riders. (doctoral dissertation), University of Glasgow.

Xenakis, I., \& Arnellos, A. (2013). The relation between interaction aesthetics and affordances. Design Studies, 34(1), 57-73. doi: 10.1016/j.destud.2012.05.004

Yamada, K., Kamiyama, K., Tachiguchi, H., \& Unehara, M. (2013, 22-26 July). Designing a tastes-oriented product in total coordination using bayesian network. Paper presented at the IADIS International Conference Game and Entertainment Technologies, Czech Republic.

Yamamoto, K., Yoshikawa, T., \& Furuhashi, T. (2005, November 7-9). Division method of subjects by individuality for stratified analysis of $S D$ evaluation data. Paper presented at the 16th IEEE International Symposium on Micro-Nano Mechatronics and Human Science, Nagoya, Japan.

Yang, C.-C. (2011). A classification-based Kansei engineering system for modeling consumers' affective responses and analyzing product form features. Expert Systems with Applications, 38(9), 11382-11393. 
Yang, C.-C., \& Chang, H.-C. (2012). Selecting representative affective dimensions using Procrustes analysis: An application to mobile phone design. Applied ergonomics, 43(6), 1072-1080.

Zaichkowsky, J. L. (1994). The personal involvement inventory - Reduction, revision, and application to advertising. Journal of Advertising, 23(4), 59-70.

Zhang, L. J., Helander, M. G., \& Drury, C. G. (1996). Identifying factors of comfort and discomfort in sitting. Human Factors, 38(3), 377-389.

Zhou, F., Xu, Q., \& Jiao, R. J. (2011). Fundamentals of product ecosystem design for user experience. Research in Engineering Design, 22(1), 43-61. 


\section{Appendix A Saddle Drawings}
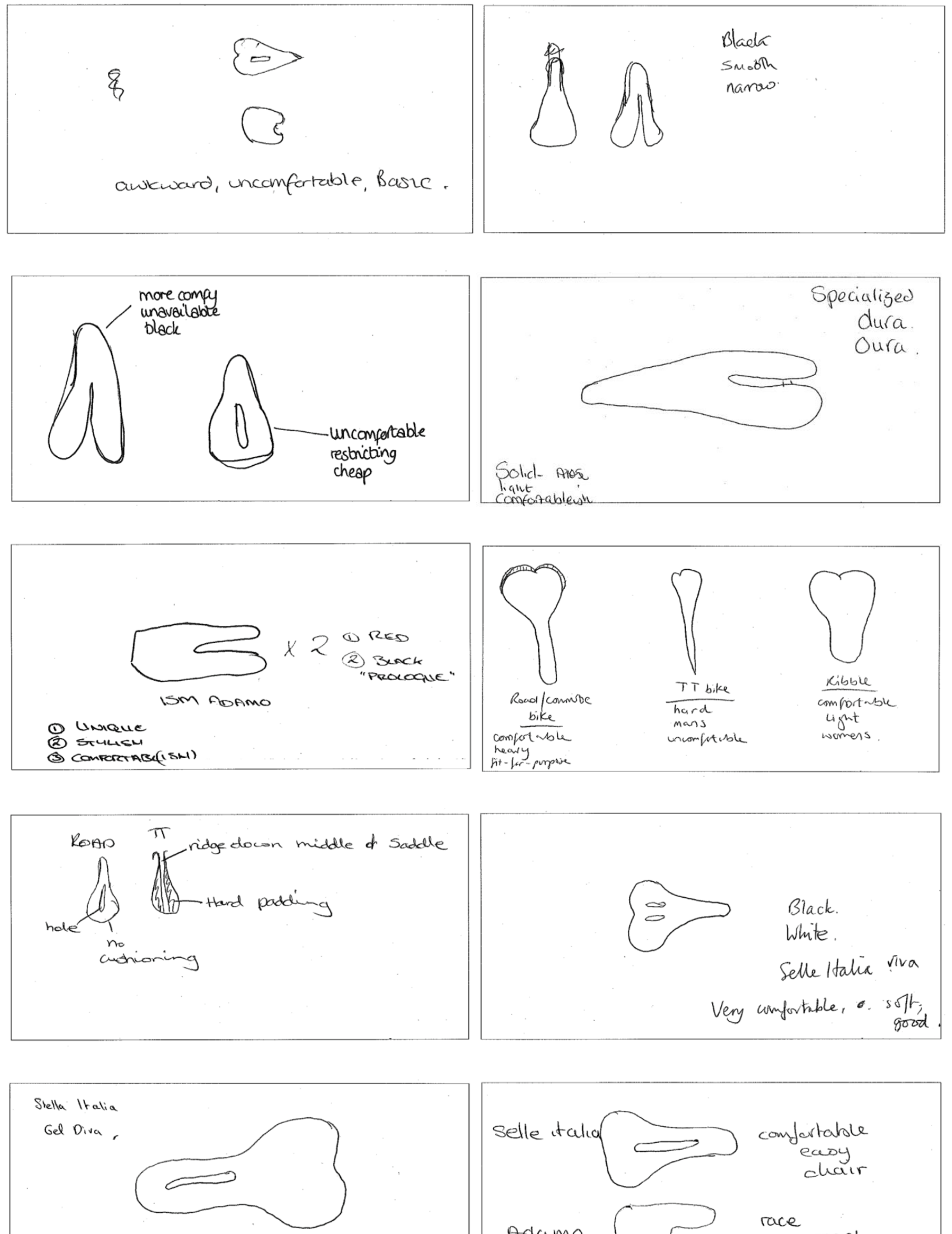

Soft, flexible, comfly.
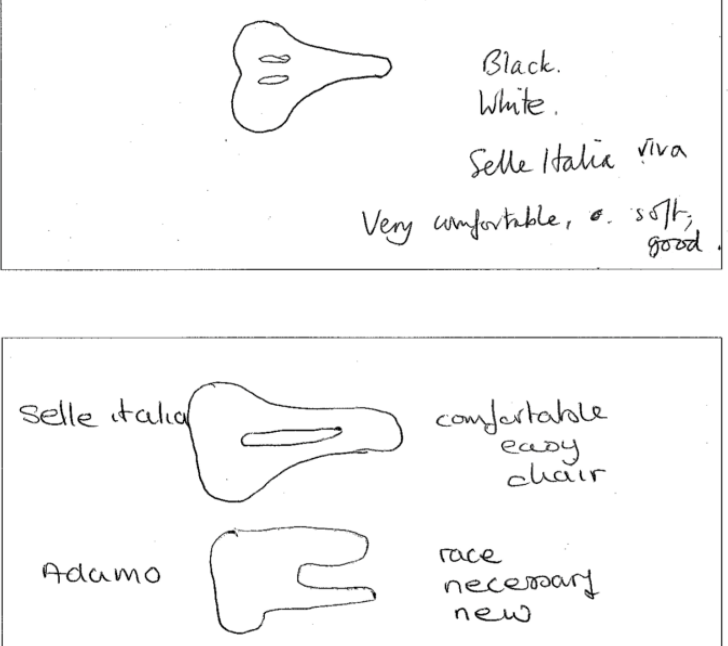

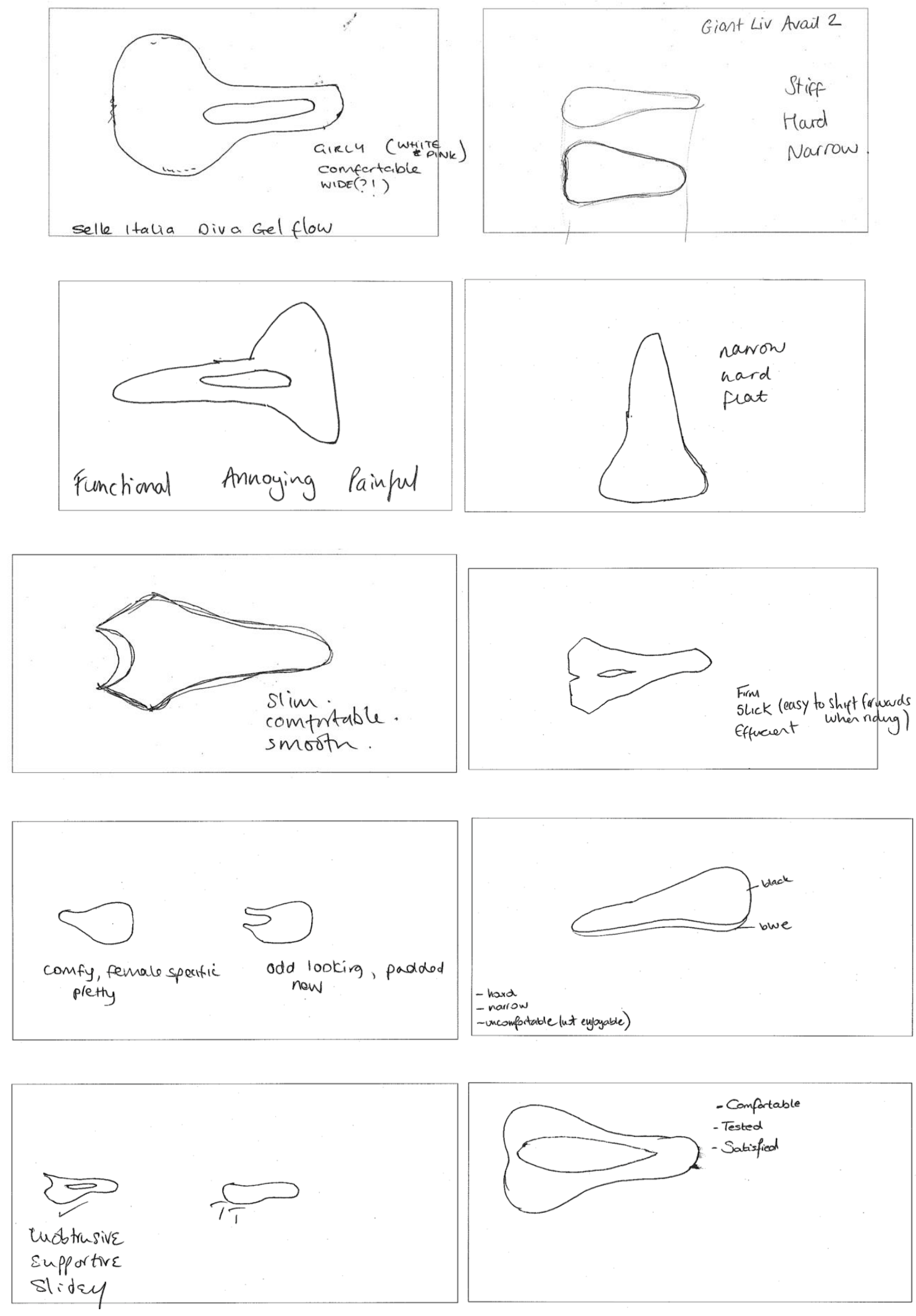

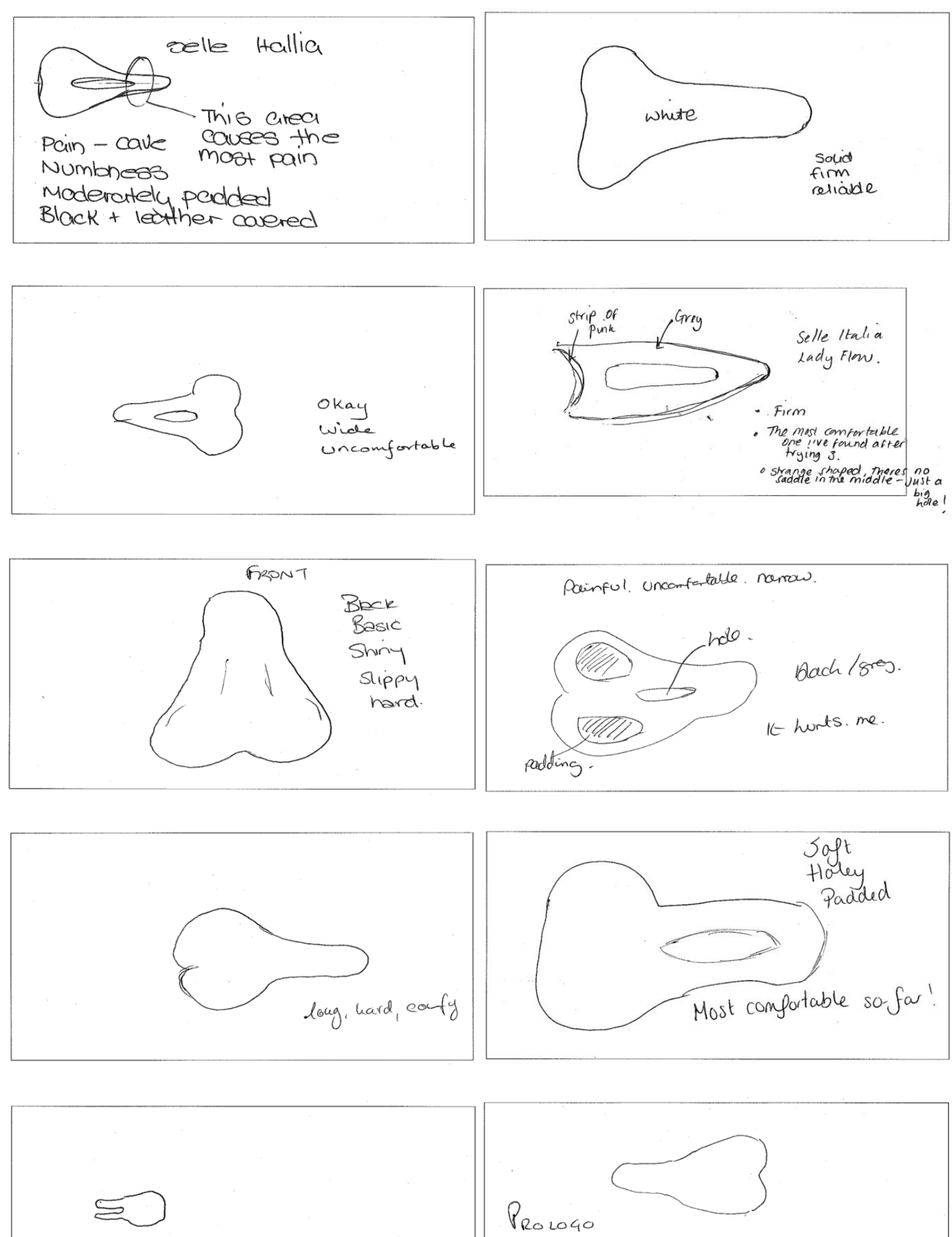

Effective, suitable, racing

Prologo

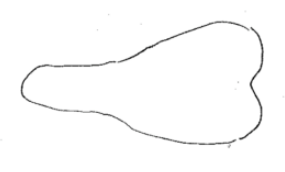

SCRATCH

After bomius it becomes ievicombrtable'.

whede makes - BAD fosition 
Appendix A

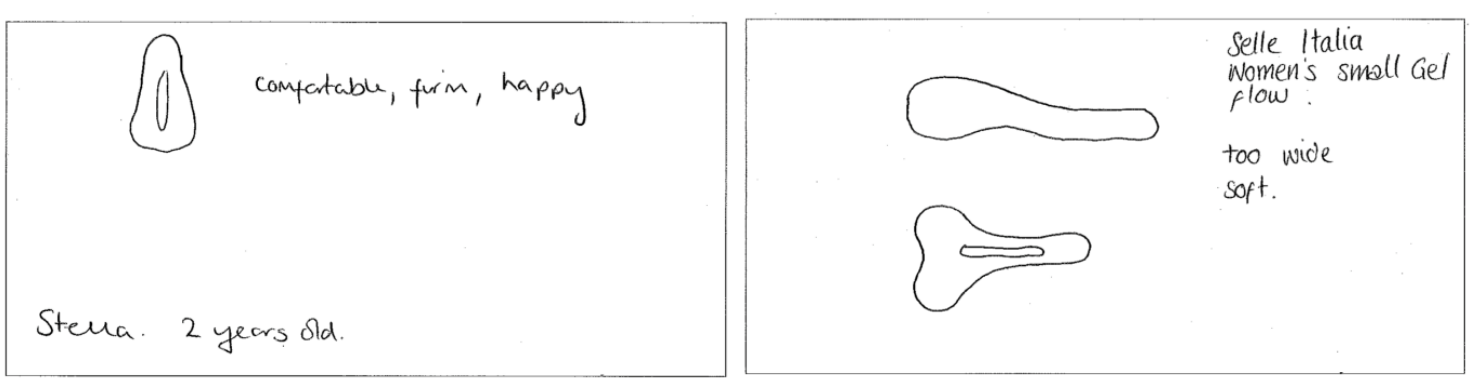

IFI sit the sweet spot it wanks

it not, I have issues. 


\section{Appendix B Eye Tracking Experimental Data}

Table 6.1 Estimated marginal means of fixation count for four categories

\begin{tabular}{|c|c|c|c|c|c|c|c|c|c|c|c|c|c|c|c|c|c|}
\hline & \multirow[b]{2}{*}{ Component } & \multicolumn{4}{|c|}{ Expert Beauty } & \multicolumn{4}{|c|}{ Novice Beauty } & \multicolumn{4}{|c|}{ Expert Confidence } & \multicolumn{4}{|c|}{ Novice Confidence } \\
\hline & & Mean & $\mathrm{SE}$ & Lower & Upper & Mean & SE & Lower & Upper & Mean & $\mathrm{SE}$ & Lower & Upper & Mean & $\mathrm{SE}$ & Lower & Upper \\
\hline 1 & Brake lever & 2.04 & 0.51 & 1.02 & 3.06 & 1.67 & 0.47 & 0.73 & 2.60 & 3.08 & 0.52 & 2.03 & 4.13 & 1.90 & 0.48 & 0.94 & 2.86 \\
\hline 2 & Cassette & 8.28 & 1.35 & 5.57 & 10.99 & 10.07 & 1.24 & 7.59 & 12.54 & 9.76 & 1.14 & 7.47 & 12.05 & 7.90 & 1.04 & 5.81 & 9.99 \\
\hline 3 & Crank set & 31.08 & 2.08 & 26.90 & 35.26 & 20.53 & 1.90 & 16.72 & 24.35 & 37.88 & 2.78 & 32.30 & 43.46 & 26.27 & 2.54 & 21.17 & 31.36 \\
\hline 4 & Chain stay & 2.84 & 0.51 & 1.82 & 3.86 & 3.33 & 0.46 & 2.41 & 4.26 & 3.20 & 0.47 & 2.25 & 4.15 & 3.33 & 0.43 & 2.47 & 4.20 \\
\hline 5 & Down tube & 29.76 & 2.20 & 25.35 & 34.17 & 25.83 & 2.01 & 21.81 & 29.86 & 23.20 & 2.34 & 18.52 & 27.88 & 20.33 & 2.13 & 16.06 & 24.61 \\
\hline 6 & Fork & 10.56 & 1.22 & 8.10 & 13.02 & 12.40 & 1.12 & 10.16 & 14.64 & 9.88 & 0.91 & 8.05 & 11.71 & 9.70 & 0.83 & 8.03 & 11.37 \\
\hline 7 & Front brake & 2.72 & 0.45 & 1.82 & 3.62 & 3.17 & 0.41 & 2.35 & 3.99 & 3.72 & 0.52 & 2.67 & 4.77 & 3.17 & 0.48 & 2.21 & 4.12 \\
\hline 8 & Front d & 2.96 & 0.49 & 1.99 & 3.93 & 3.03 & 0.44 & 2.14 & 3.92 & 2.56 & 0.44 & 1.67 & 3.45 & 3.13 & 0.41 & 2.32 & 3.95 \\
\hline 9 & & 12.52 & 1.13 & 10.26 & 14.78 & 9.57 & 1.03 & 7.51 & 11.63 & 17.36 & 1.57 & 14.21 & 20.51 & 11.00 & 1.43 & 8.12 & 13.88 \\
\hline 10 & & 8.24 & 1.14 & 5.96 & 10.52 & 10.07 & 1.04 & 7.98 & & 9.12 & 1.55 & 6.01 & & 10.87 & 1.41 & 8.03 & 13.70 \\
\hline 11 & Head tube & 8.84 & 0.85 & 7.14 & 10.54 & 9.50 & 0.77 & 7.95 & 11.05 & 7.08 & 0.77 & 5.53 & 8.63 & 9.37 & 0.70 & 7.95 & 10.78 \\
\hline 12 & Pedal & 0.32 & 0.14 & 0.04 & 0.60 & 0.40 & 0.13 & 0.14 & 0.66 & 0.60 & 0.16 & 0.28 & 0.92 & 0.43 & 0.14 & 0.14 & 0.72 \\
\hline 13 & Rear brake & 2.56 & 0.45 & 1.66 & 3.46 & 3.23 & 0.41 & 2.41 & 4.05 & 2.76 & 0.49 & 1.77 & 3.75 & 2.50 & 0.45 & 1.59 & 3.41 \\
\hline 14 & Rear d & 5.40 & 0.77 & 3.86 & 6.94 & 1.97 & 0.70 & 0.56 & 3.37 & 7.20 & 1.10 & 4.99 & 9.41 & 3.53 & 1.00 & 1.52 & 5.55 \\
\hline 15 & Rear tire & 12.84 & 1.23 & 10.38 & 15.30 & 15.67 & 1.12 & 13.42 & 17.91 & 16.40 & 1.52 & 13.36 & 19.44 & 15.10 & 1.38 & 12.33 & 17.87 \\
\hline 16 & Saddle & 5.08 & 1.03 & 3.02 & 7.14 & 6.70 & 0.94 & 4.82 & 8.58 & 3.60 & 0.89 & 1.82 & 5.38 & 5.77 & 0.81 & 4.14 & 7.39 \\
\hline 17 & Seat post & 8.28 & 0.93 & 6.42 & 10.14 & 11.97 & 0.85 & 10.27 & 13.66 & 7.08 & 1.17 & 4.74 & 9.42 & 10.97 & 1.07 & 8.83 & 13.11 \\
\hline 18 & Seat stay & 3.76 & 0.46 & 2.85 & 4.67 & 4.10 & 0.42 & 3.27 & 4.93 & 4.04 & 0.44 & 3.15 & 4.93 & 3.77 & 0.41 & 2.95 & 4.58 \\
\hline 19 & Seat tube & 15.08 & 1.21 & 12.64 & 17.52 & 13.43 & 1.11 & 11.21 & 15.66 & 13.44 & 1.29 & 10.86 & 16.02 & 11.27 & 1.17 & 8.91 & 13.62 \\
\hline 20 & Stem & 4.88 & 0.65 & 3.59 & 6.17 & 3.10 & 0.59 & 1.92 & 4.28 & 3.44 & 0.85 & 1.74 & 5.14 & 3.60 & 0.77 & 2.05 & 5.15 \\
\hline 21 & Top tube & 12.88 & 1.20 & 10.48 & 15.28 & 11.10 & 1.09 & 8.91 & 13.29 & 8.08 & 1.07 & 5.93 & 10.23 & 9.00 & 0.98 & 7.04 & 10.96 \\
\hline
\end{tabular}




\section{Appendix B}

Table 6.2 Estimated marginal means of fixation duration for four categories

\begin{tabular}{|c|c|c|c|c|c|c|c|c|c|c|c|c|c|c|c|c|c|}
\hline & \multirow[b]{2}{*}{ Component } & \multicolumn{4}{|c|}{ Expert Beauty } & \multicolumn{4}{|c|}{ Novice Beauty } & \multicolumn{4}{|c|}{ Expert Confidence } & \multicolumn{4}{|c|}{ Novice Confidence } \\
\hline & & Mean & SE & Lower & Upper & Mean & SE & Lower & Upper & Mean & $\mathrm{SE}$ & Lower & Upper & Mean & SE & Lower & Upper \\
\hline 1 & Brake lever & .58 & .14 & .29 & .87 & .45 & .13 & .19 & .72 & .98 & .24 & .50 & 1.46 & 1.79 & .22 & 1.35 & 2.23 \\
\hline 2 & Cassette & 2.32 & .48 & 1.36 & 3.28 & 2.79 & .44 & 1.91 & 3.66 & 2.86 & .53 & 1.79 & 3.93 & 5.87 & .49 & 4.90 & 6.85 \\
\hline 3 & Crank set & 7.45 & .53 & 6.39 & 8.51 & 4.87 & .48 & 3.90 & 5.83 & 10.23 & .72 & 8.79 & 11.68 & 1.97 & .66 & .65 & 3.29 \\
\hline 4 & Chain stay & 1.77 & .25 & 1.27 & 2.26 & 1.31 & .23 & .85 & 1.76 & .81 & .42 & -.02 & 1.65 & 4.09 & .38 & 3.32 & 4.85 \\
\hline 5 & Down tube & 6.58 & .53 & 5.51 & 7.65 & 5.86 & .49 & 4.89 & 6.84 & 4.83 & .37 & 4.08 & 5.58 & 2.48 & .34 & 1.79 & 3.16 \\
\hline 6 & Fork & 2.54 & .32 & 1.89 & 3.19 & 2.86 & .30 & 2.27 & 3.45 & 2.12 & .20 & 1.73 & 2.52 & 1.11 & .18 & .75 & 1.47 \\
\hline 7 & Front brake & .66 & .12 & .41 & .90 & .82 & .11 & .60 & 1.04 & .96 & .14 & .68 & 1.25 & .83 & .13 & .57 & 1.09 \\
\hline 8 & Front $d$ & .94 & .15 & .64 & 1.23 & .89 & .13 & .62 & 1.16 & .84 & .18 & .48 & 1.21 & 2.16 & .17 & 1.82 & 2.49 \\
\hline 9 & Front tire & 3.18 & .30 & 2.58 & 3.78 & 2.34 & .27 & 1.79 & 2.89 & 3.95 & .39 & 3.17 & 4.73 & 2.34 & .35 & 1.63 & 3.05 \\
\hline 10 & Handlebar & 2.16 & .30 & 1.55 & 2.77 & 2.54 & .28 & 1.98 & 3.10 & 2.24 & .31 & 1.62 & 2.86 & 2.72 & .28 & 2.15 & 3.29 \\
\hline 11 & Head tube & 2.15 & .22 & 1.71 & 2.59 & 2.28 & .20 & 1.87 & 2.68 & 1.68 & .15 & 1.38 & 1.98 & .71 & .14 & .44 & .98 \\
\hline 12 & Pedal & .07 & .03 & .02 & .13 & .08 & .03 & .03 & .13 & .17 & .09 & .00 & .34 & .46 & .08 & .30 & .62 \\
\hline 13 & Rear brake & .58 & .12 & .34 & .82 & .75 & .11 & .54 & .97 & .73 & .20 & .33 & 1.13 & .97 & .18 & .60 & 1.34 \\
\hline 14 & Rear d & 2.06 & .23 & 1.59 & 2.52 & .57 & .21 & .15 & .99 & 2.44 & .33 & 1.77 & 3.11 & 2.82 & .30 & 2.21 & 3.43 \\
\hline 15 & Rear tire & 2.66 & .29 & 2.07 & 3.24 & 3.60 & .27 & 3.07 & 4.14 & 3.25 & .39 & 2.47 & 4.02 & 2.62 & .35 & 1.92 & 3.33 \\
\hline 16 & Saddle & 1.54 & .24 & 1.07 & 2.01 & 1.78 & .21 & 1.35 & 2.21 & 1.32 & .21 & .91 & 1.73 & 2.12 & .19 & 1.74 & 2.50 \\
\hline 17 & Seat post & 1.99 & .22 & 1.55 & 2.44 & 2.99 & .20 & 2.58 & 3.39 & 1.46 & .19 & 1.09 & 1.83 & 1.56 & .17 & 1.22 & 1.90 \\
\hline 18 & Seat stay & 1.05 & .12 & .81 & 1.29 & .84 & .11 & .63 & 1.06 & 1.17 & .21 & .74 & 1.59 & 1.90 & .19 & 1.52 & 2.29 \\
\hline 19 & Seat tube & 3.07 & .31 & 2.46 & 3.68 & 3.04 & .28 & 2.48 & 3.60 & 3.07 & .28 & 2.51 & 3.62 & 1.74 & .25 & 1.23 & 2.25 \\
\hline 20 & Stem & 1.68 & .17 & 1.34 & 2.01 & .84 & .15 & .53 & 1.14 & 1.30 & .21 & .88 & 1.73 & 1.80 & .19 & 1.41 & 2.18 \\
\hline 21 & Top tube & 2.78 & .30 & 2.19 & 3.38 & 2.48 & .27 & 1.94 & 3.03 & 1.80 & .22 & 1.35 & 2.25 & .81 & .21 & .40 & 1.23 \\
\hline
\end{tabular}


Appendix B

\section{Heat Maps}

四

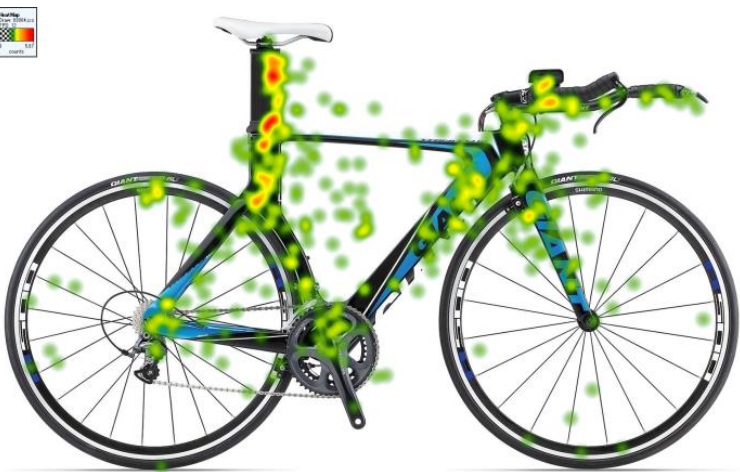

.

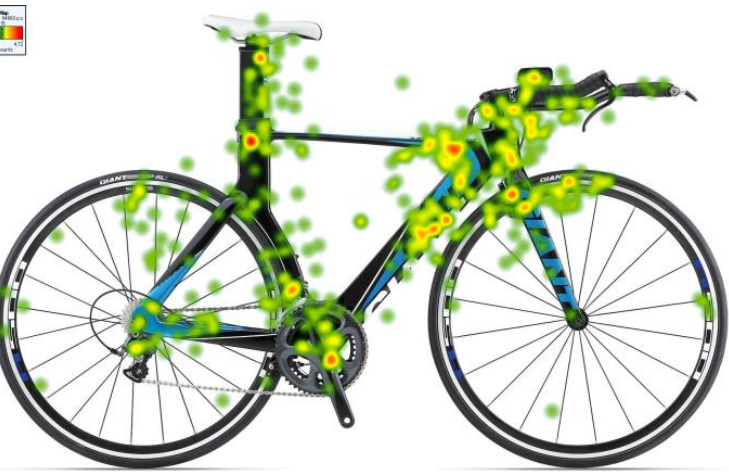

湔
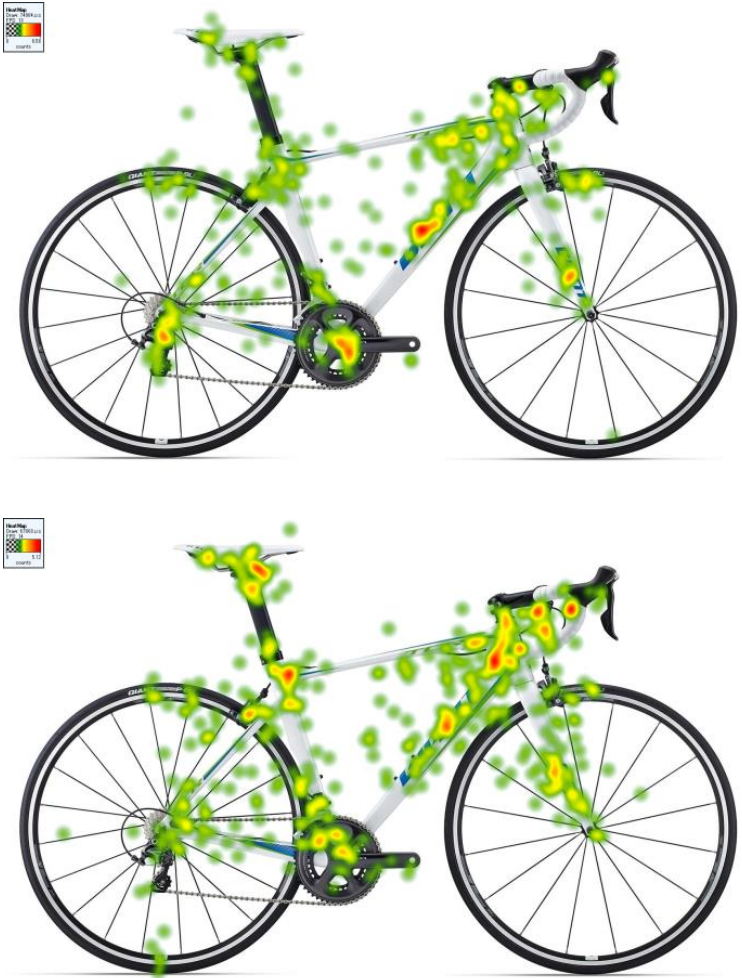
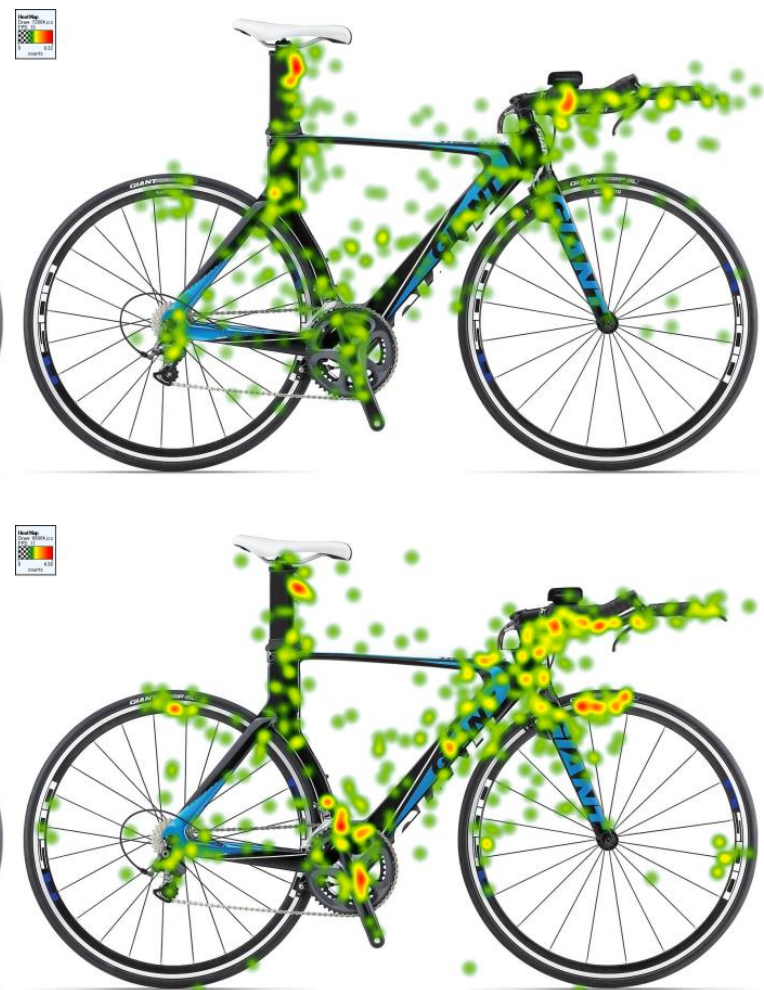

原-
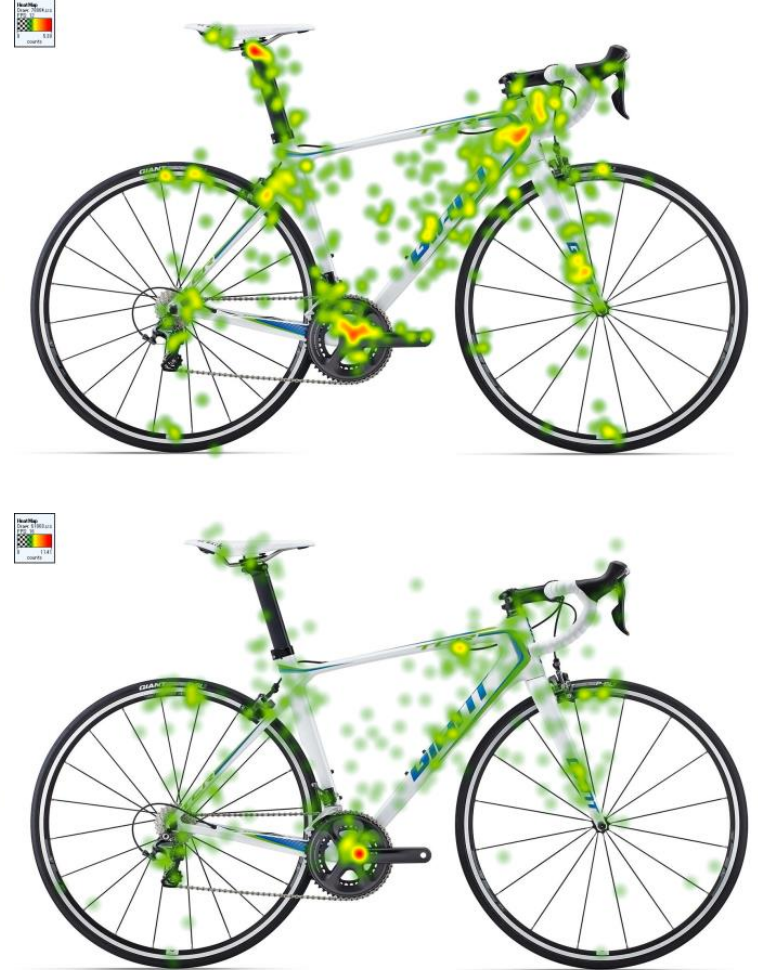
Appendix B
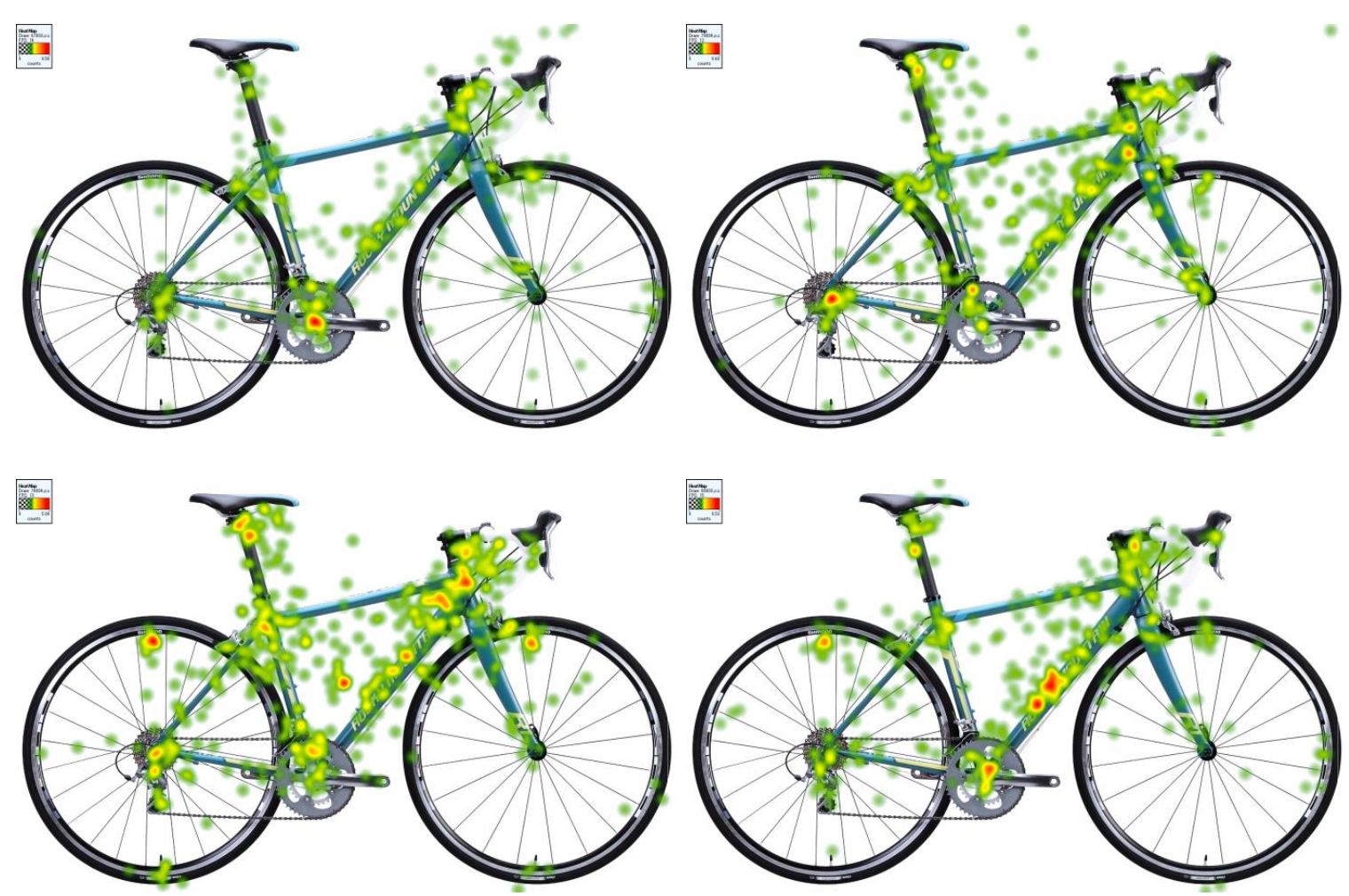

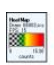

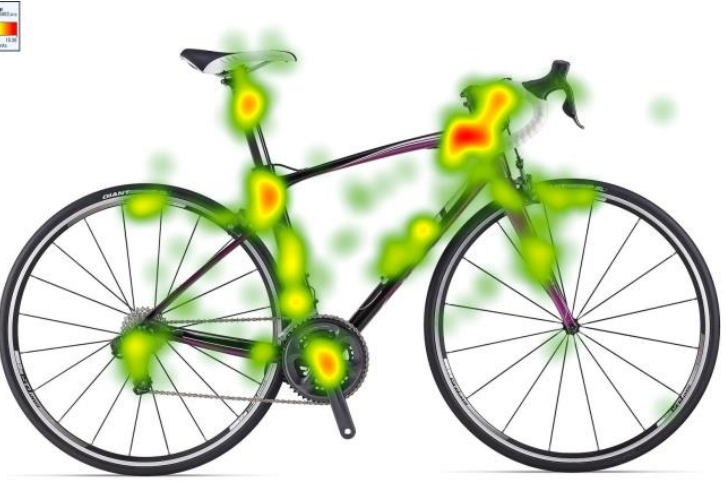

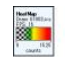
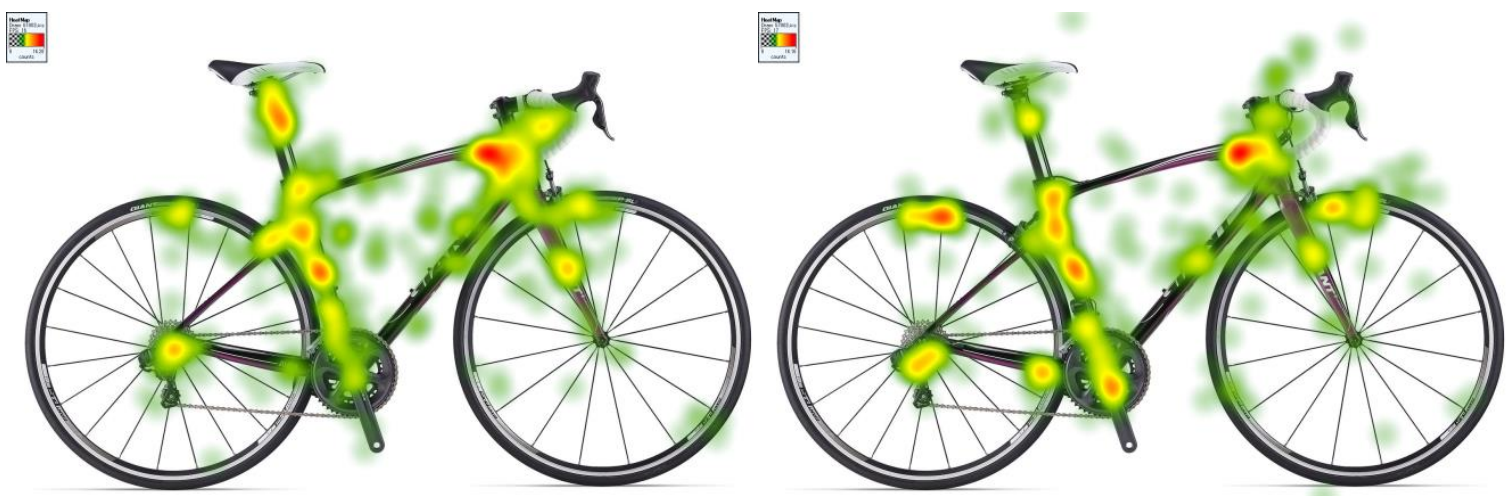
Appendix B
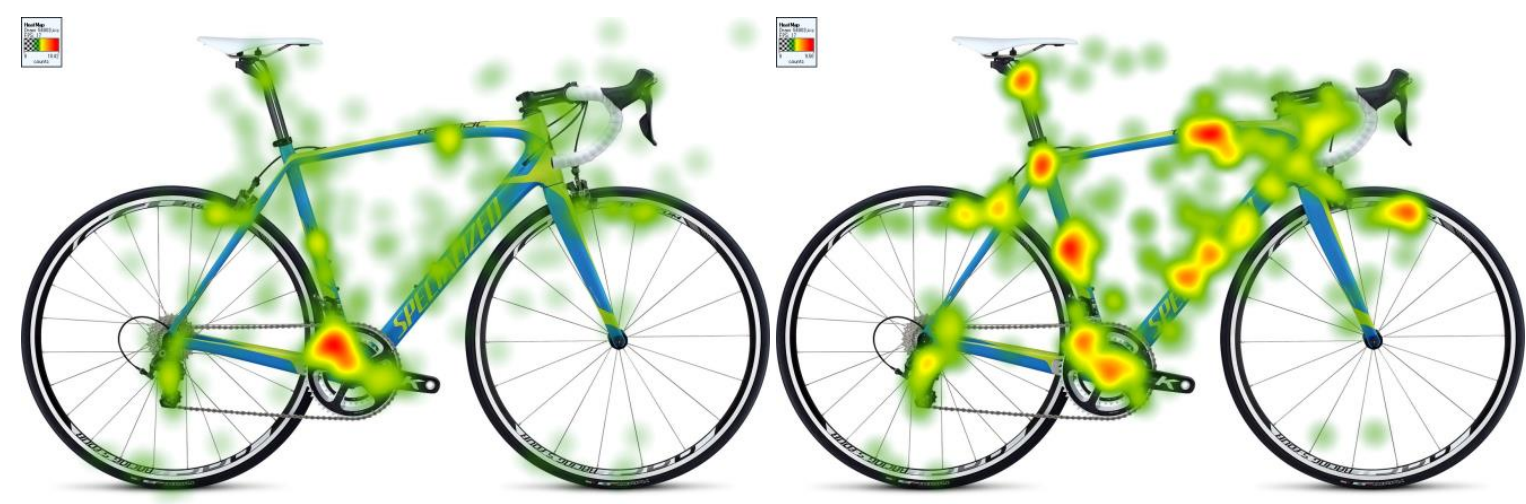

济

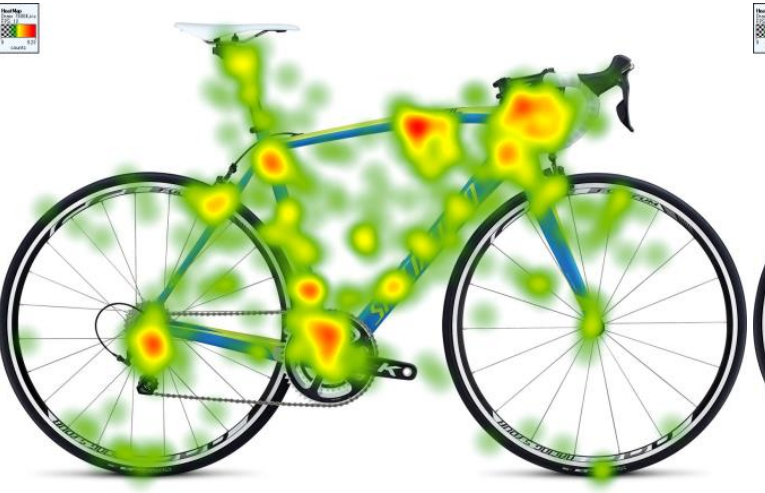

湆

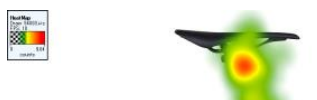

国
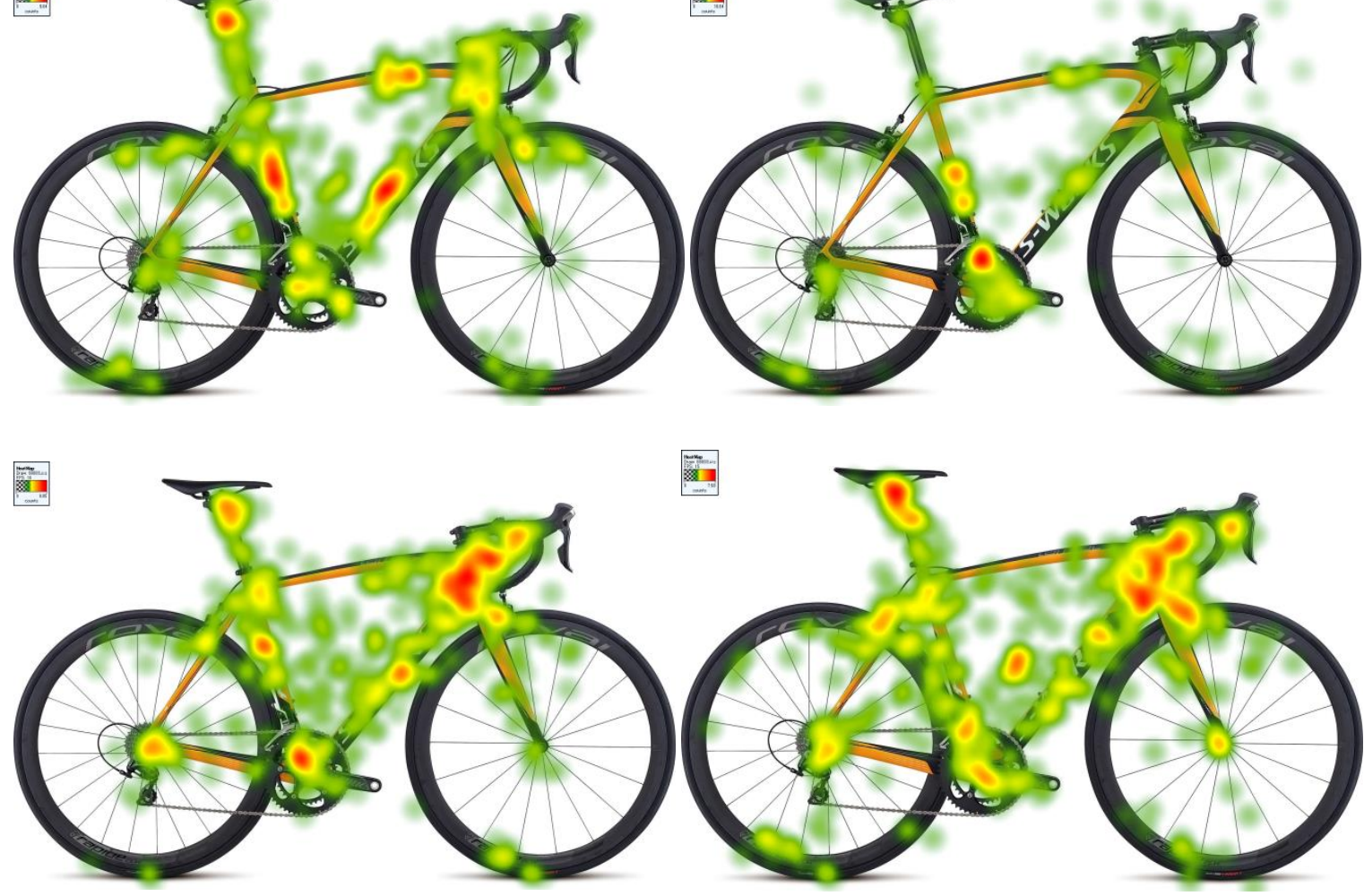
Appendix B
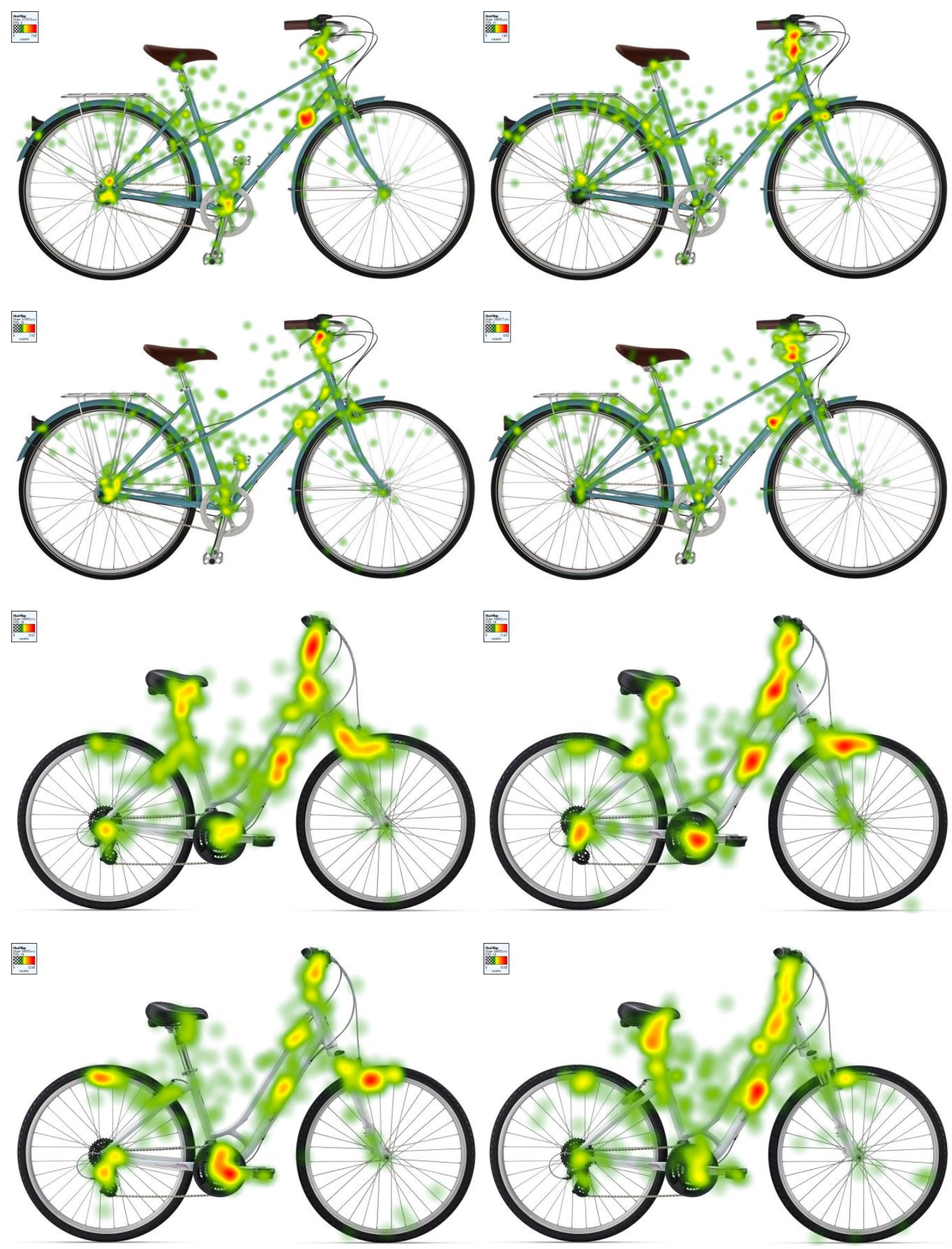
Appendix B
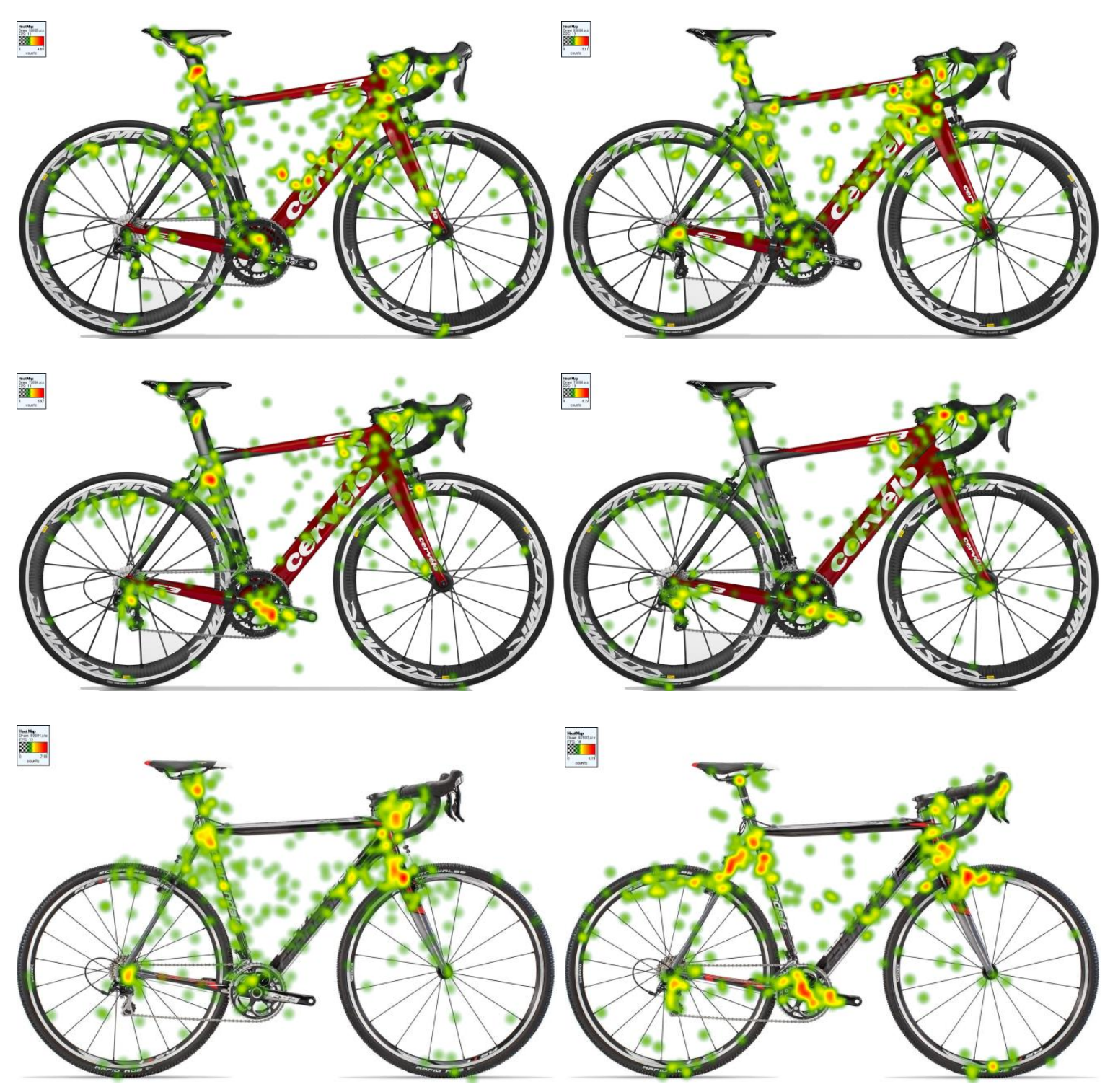

-
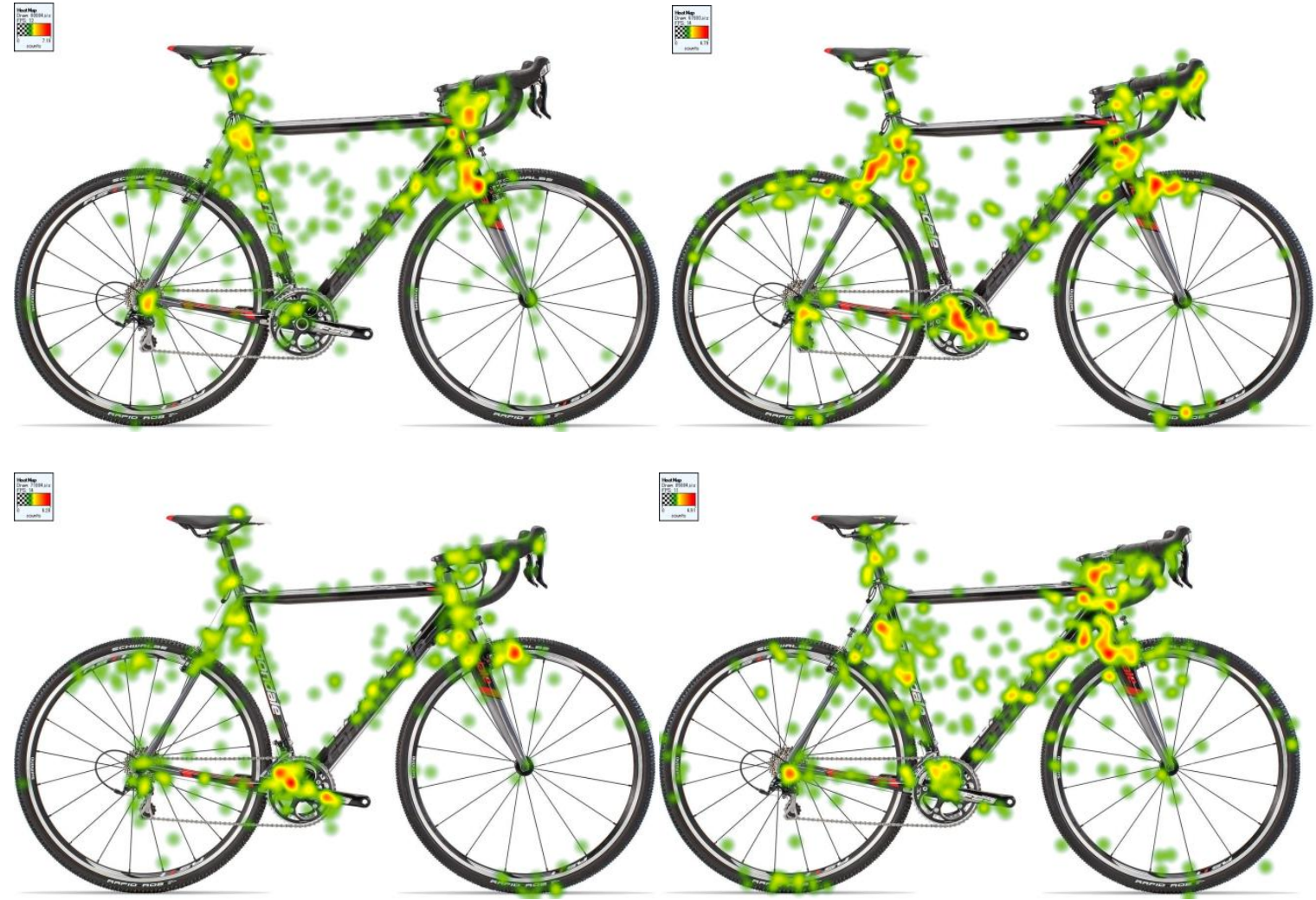
Appendix B

\section{Pilot test image pool}
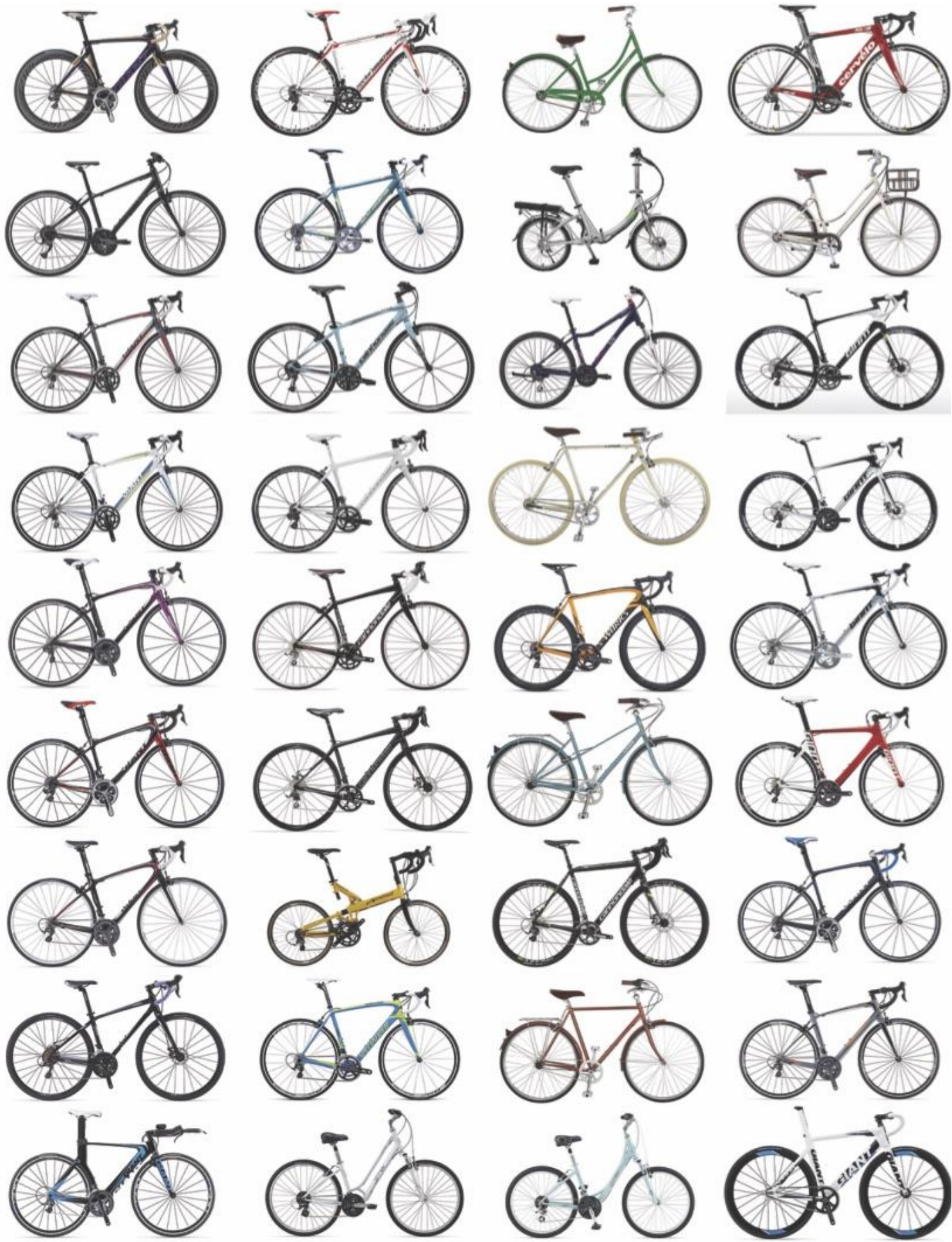

1े
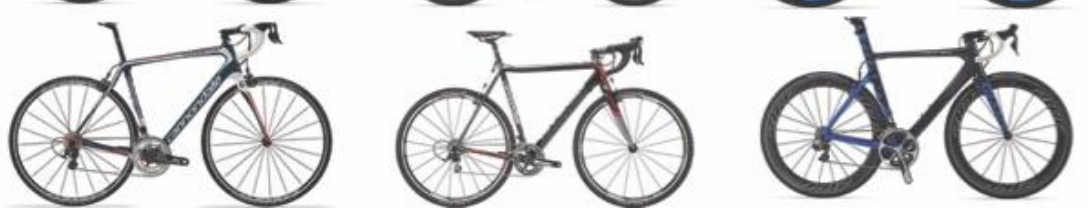


\section{Appendix C Semantic Differential Scale}

\section{Vision}

Q: How do you feel about this saddle?

Please use the symbol on the screen, and rate the saddles on the following scale respectively.

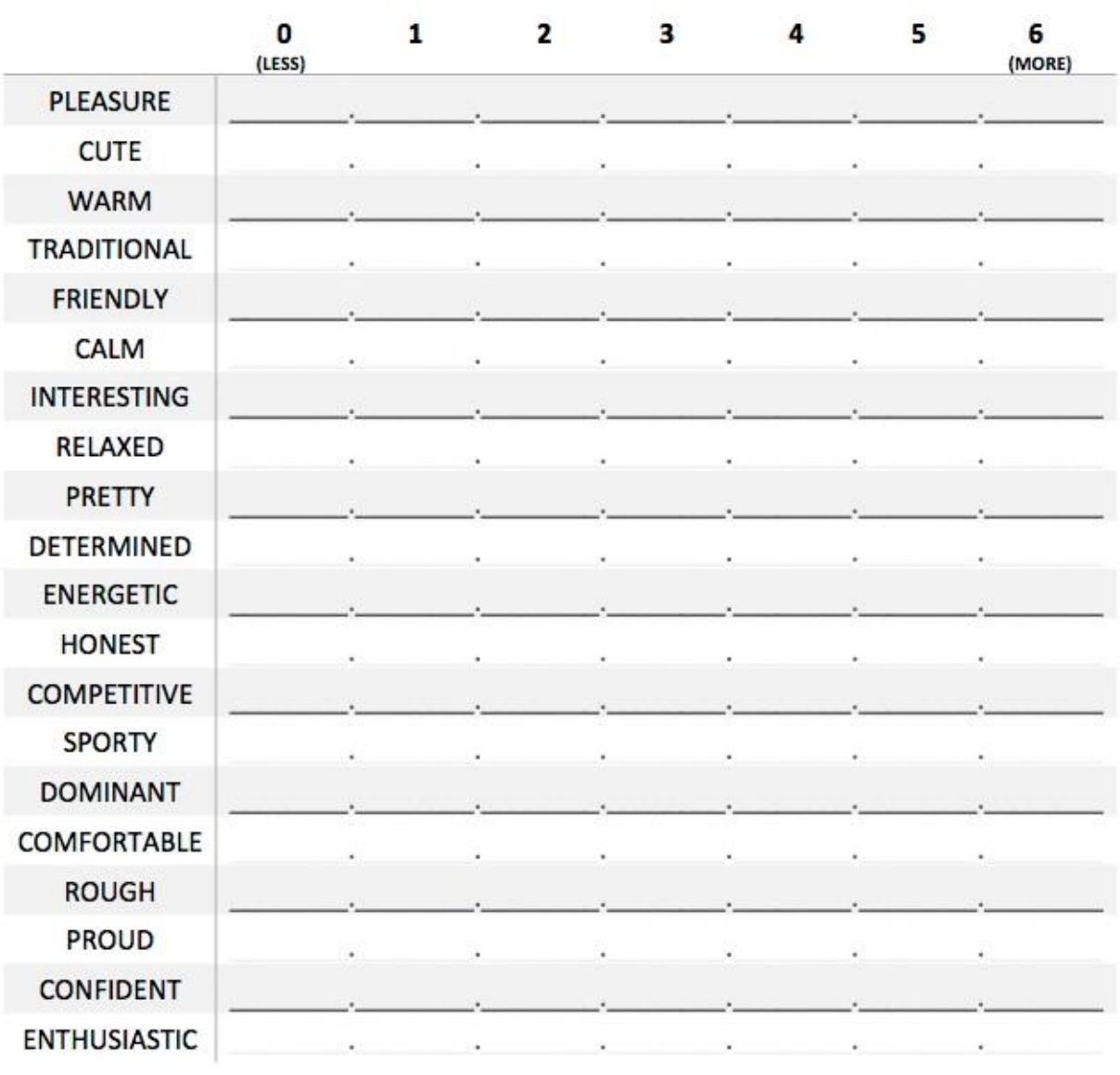

Q: How did you compare the saddles? 


\section{Touch}

\section{Q: How do you feel about this saddle?}

Please use the same symbol, and rate the saddles respectively..

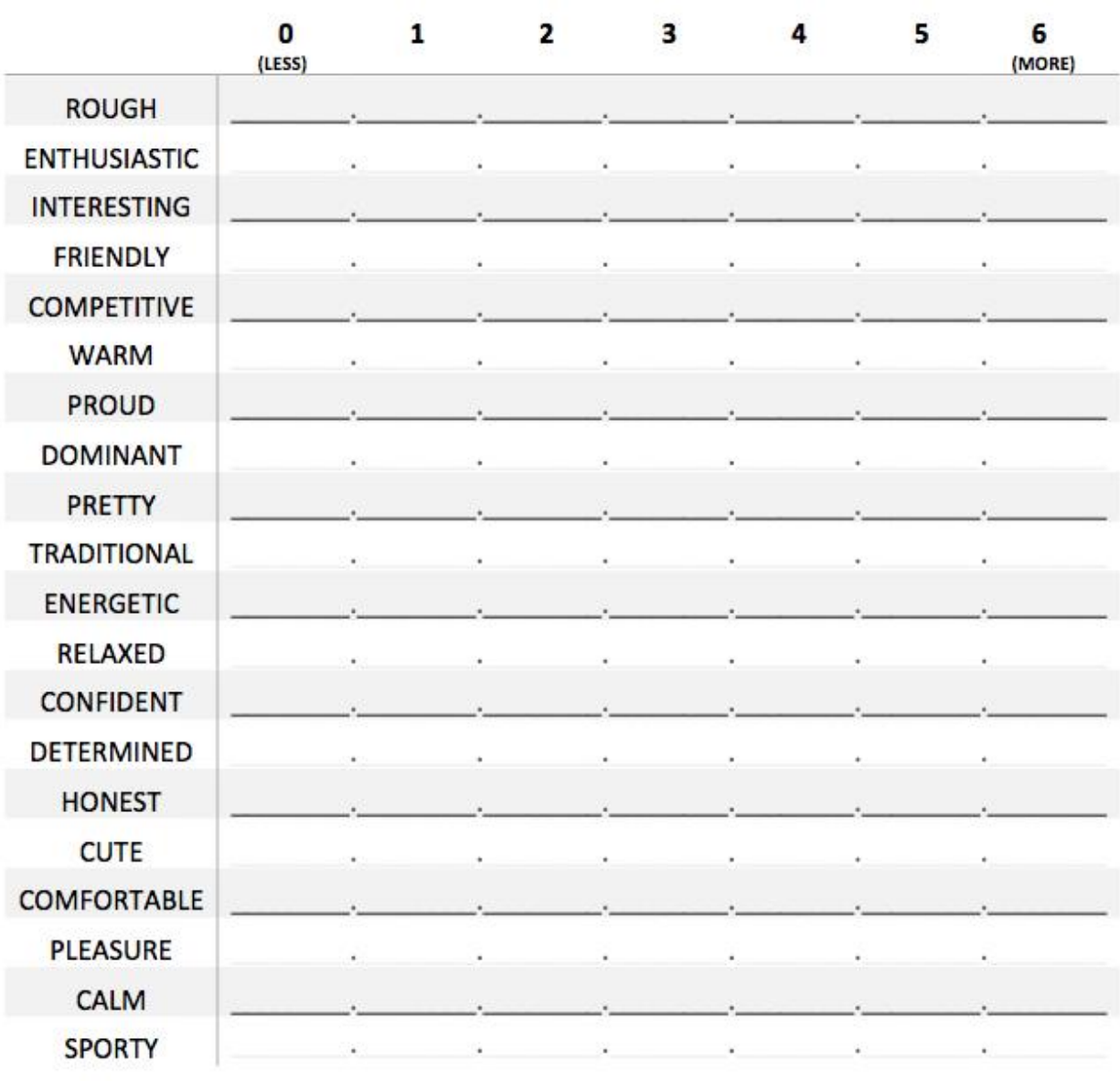

Q: How did you compare the saddles? 


\section{Cycling}

\section{Q: How do you feel about this saddle?}

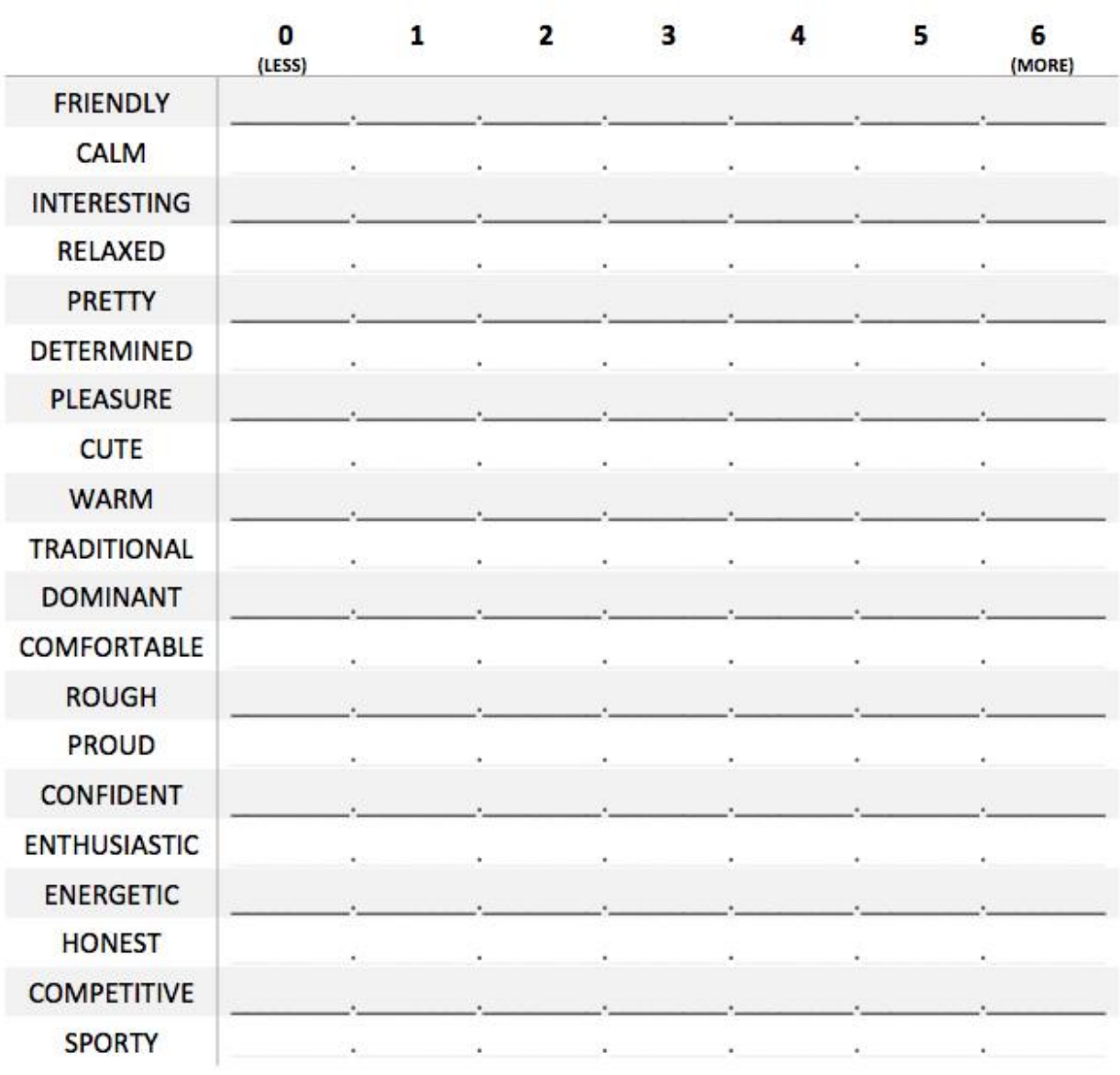

Q: How did you compare the saddles? 


\section{Appendix D Experimental Data}

Table 6.3 Estimated marginal means of 20 K-words through perceptions for Saddle A

\begin{tabular}{|c|c|c|c|c|c|c|c|c|c|c|c|c|c|c|c|c|}
\hline & \multicolumn{4}{|c|}{ Vision } & \multicolumn{4}{|c|}{ Vision + Touch } & \multicolumn{4}{|c|}{ Cycling + Vision } & \multicolumn{4}{|c|}{ Cyclingï Vision } \\
\hline & Mean & SE & Lower & Upper & Mean & SE & Lower & Upper & Mean & SE & Lower & Upper & Mean & SE & Lower & Upper \\
\hline pleasure & 3.03 & 0.17 & 2.68 & 3.38 & 2.98 & 0.24 & 2.50 & 3.46 & 2.88 & 0.35 & 2.17 & 3.58 & 2.22 & 0.34 & 1.52 & 2.92 \\
\hline calm & 2.33 & 0.18 & 1.96 & 2.69 & 2.21 & 0.21 & 1.79 & 2.64 & 1.96 & 0.30 & 1.35 & 2.57 & 1.97 & 0.30 & 1.37 & 2.57 \\
\hline relaxed & 2.31 & 0.21 & 1.88 & 2.74 & 2.18 & 0.22 & 1.73 & 2.62 & 2.25 & 0.28 & 1.68 & 2.82 & 1.69 & 0.28 & 1.13 & 2.25 \\
\hline determined & 4.56 & 0.16 & 4.24 & 4.88 & 4.78 & 0.17 & 4.45 & 5.12 & 3.79 & 0.36 & 3.07 & 4.51 & 3.02 & 0.35 & 2.30 & 3.73 \\
\hline energetic & 4.32 & 0.17 & 3.98 & 4.66 & 4.76 & 0.22 & 4.32 & 5.21 & 3.85 & 0.42 & 3.00 & 4.70 & 3.02 & 0.41 & 2.18 & 3.85 \\
\hline competitive & 5.00 & 0.10 & 4.79 & 5.21 & 5.14 & 0.22 & 4.69 & 5.59 & 4.27 & 0.41 & 3.44 & 5.10 & 3.06 & 0.40 & 2.24 & 3.88 \\
\hline comfortable & 3.18 & 0.22 & 2.74 & 3.61 & 3.03 & 0.25 & 2.53 & 3.53 & 3.42 & 0.45 & 2.51 & 4.32 & 1.75 & 0.44 & 0.86 & 2.64 \\
\hline proud & 3.46 & 0.24 & 2.98 & 3.94 & 3.88 & 0.24 & 3.40 & 4.35 & 3.44 & 0.32 & 2.80 & 4.08 & 2.29 & 0.31 & 1.66 & 2.92 \\
\hline confident & 4.32 & 0.16 & 4.00 & 4.65 & 4.61 & 0.19 & 4.23 & 4.99 & 3.52 & 0.40 & 2.71 & 4.33 & 2.54 & 0.39 & 1.74 & 3.33 \\
\hline enthusiastic & 3.94 & 0.20 & 3.54 & 4.34 & 4.49 & 0.19 & 4.10 & 4.88 & 3.44 & 0.47 & 2.49 & 4.39 & 2.94 & 0.46 & 2.00 & 3.88 \\
\hline cute & 1.73 & 0.22 & 1.28 & 2.19 & 2.24 & 0.25 & 1.73 & 2.75 & 1.60 & 0.30 & 0.99 & 2.22 & 1.21 & 0.30 & 0.60 & 1.81 \\
\hline warm & 1.59 & 0.21 & 1.16 & 2.02 & 2.33 & 0.23 & 1.87 & 2.80 & 2.25 & 0.31 & 1.62 & 2.88 & 1.91 & 0.31 & 1.30 & 2.53 \\
\hline traditional & 2.41 & 0.22 & 1.95 & 2.86 & 2.72 & 0.26 & 2.19 & 3.26 & 2.58 & 0.30 & 1.98 & 3.19 & 3.16 & 0.30 & 2.56 & 3.76 \\
\hline friendly & 2.20 & 0.19 & 1.82 & 2.59 & 2.49 & 0.21 & 2.06 & 2.92 & 2.17 & 0.30 & 1.56 & 2.77 & 1.69 & 0.29 & 1.10 & 2.29 \\
\hline interesting & 3.64 & 0.23 & 3.18 & 4.10 & 4.17 & 0.21 & 3.74 & 4.60 & 3.04 & 0.38 & 2.27 & 3.81 & 2.69 & 0.37 & 1.94 & 3.45 \\
\hline pretty & 2.44 & 0.26 & 1.91 & 2.96 & 2.86 & 0.28 & 2.29 & 3.43 & 2.33 & 0.34 & 1.64 & 3.03 & 1.44 & 0.34 & 0.76 & 2.13 \\
\hline honest & 3.34 & 0.19 & 2.96 & 3.72 & 3.39 & 0.24 & 2.90 & 3.88 & 3.15 & 0.36 & 2.43 & 3.87 & 2.76 & 0.35 & 2.05 & 3.47 \\
\hline sporty & 5.12 & 0.11 & 4.89 & 5.35 & 5.27 & 0.15 & 4.97 & 5.57 & 4.33 & 0.39 & 3.54 & 5.13 & 3.11 & 0.39 & 2.33 & 3.89 \\
\hline dominant & 4.65 & 0.14 & 4.36 & 4.93 & 4.89 & 0.23 & 4.43 & 5.35 & 3.94 & 0.40 & 3.13 & 4.75 & 3.01 & 0.39 & 2.21 & 3.80 \\
\hline rough & 2.46 & 0.25 & 1.95 & 2.97 & 2.24 & 0.29 & 1.65 & 2.83 & 3.04 & 0.39 & 2.25 & 3.83 & 1.96 & 0.38 & 1.18 & 2.73 \\
\hline
\end{tabular}


Appendix D

Table 6.4 Estimated marginal means of 20 K-words through perceptions for Saddle B

\begin{tabular}{|c|c|c|c|c|c|c|c|c|c|c|c|c|c|c|c|c|}
\hline & \multicolumn{4}{|c|}{ Vision } & \multicolumn{4}{|c|}{ Vision + Touch } & \multicolumn{4}{|c|}{ Cycling + Vision } & \multicolumn{4}{|c|}{ Cyclingï Vision } \\
\hline & Mean & SE & Lower & Upper & Mean & SE & Lower & Upper & Mean & SE & Lower & Upper & Mean & SE & Lower & Upper \\
\hline pleasure & 2.98 & 0.23 & 2.53 & 3.44 & 3.37 & 0.29 & 2.79 & 3.96 & 3.20 & 0.33 & 2.54 & 3.86 & 2.87 & 0.32 & 2.22 & 3.52 \\
\hline calm & 2.49 & 0.26 & 1.96 & 3.02 & 3.21 & 0.30 & 2.61 & 3.81 & 2.68 & 0.37 & 1.92 & 3.43 & 2.42 & 0.37 & 1.68 & 3.17 \\
\hline relaxed & 2.63 & 0.31 & 2.01 & 3.26 & 3.69 & 0.27 & 3.14 & 4.24 & 3.26 & 0.35 & 2.56 & 3.97 & 2.60 & 0.34 & 1.90 & 3.29 \\
\hline determined & 2.50 & 0.23 & 2.03 & 2.97 & 2.71 & 0.23 & 2.25 & 3.18 & 2.91 & 0.31 & 2.28 & 3.54 & 3.02 & 0.31 & 2.39 & 3.64 \\
\hline energetic & 2.46 & 0.20 & 2.06 & 2.86 & 2.85 & 0.24 & 2.37 & 3.34 & 3.13 & 0.31 & 2.50 & 3.75 & 3.19 & 0.30 & 2.58 & 3.81 \\
\hline competitive & 2.57 & 0.23 & 2.10 & 3.04 & 2.73 & 0.21 & 2.30 & 3.16 & 3.50 & 0.33 & 2.83 & 4.16 & 3.46 & 0.32 & 2.80 & 4.11 \\
\hline comfortable & 3.10 & 0.30 & 2.50 & 3.71 & 3.43 & 0.29 & 2.85 & 4.01 & 3.43 & 0.45 & 2.53 & 4.34 & 2.83 & 0.44 & 1.94 & 3.73 \\
\hline proud & 2.54 & 0.26 & 2.01 & 3.07 & 3.06 & 0.22 & 2.62 & 3.50 & 2.80 & 0.32 & 2.16 & 3.44 & 2.48 & 0.31 & 1.84 & 3.11 \\
\hline confident & 2.92 & 0.24 & 2.42 & 3.41 & 3.06 & 0.22 & 2.62 & 3.50 & 3.15 & 0.32 & 2.51 & 3.79 & 3.27 & 0.31 & 2.64 & 3.91 \\
\hline enthusiastic & 2.55 & 0.24 & 2.07 & 3.03 & 2.66 & 0.22 & 2.21 & 3.11 & 3.08 & 0.35 & 2.37 & 3.79 & 3.35 & 0.35 & 2.65 & 4.05 \\
\hline cute & 1.26 & 0.22 & 0.82 & 1.70 & 2.04 & 0.26 & 1.52 & 2.57 & 1.78 & 0.29 & 1.19 & 2.37 & 1.68 & 0.29 & 1.10 & 2.26 \\
\hline warm & 2.02 & 0.25 & 1.52 & 2.52 & 2.93 & 0.29 & 2.35 & 3.52 & 2.07 & 0.29 & 1.48 & 2.65 & 2.60 & 0.28 & 2.02 & 3.17 \\
\hline traditional & 2.91 & 0.29 & 2.33 & 3.49 & 3.49 & 0.26 & 2.97 & 4.00 & 2.79 & 0.29 & 2.20 & 3.37 & 3.26 & 0.28 & 2.69 & 3.84 \\
\hline friendly & 2.71 & 0.26 & 2.19 & 3.24 & 3.40 & 0.25 & 2.89 & 3.92 & 2.78 & 0.33 & 2.12 & 3.45 & 2.49 & 0.32 & 1.83 & 3.14 \\
\hline interesting & 2.64 & 0.26 & 2.12 & 3.16 & 2.60 & 0.26 & 2.08 & 3.12 & 3.08 & 0.34 & 2.39 & 3.77 & 2.81 & 0.33 & 2.13 & 3.49 \\
\hline pretty & 1.81 & 0.24 & 1.32 & 2.31 & 2.22 & 0.28 & 1.65 & 2.79 & 2.13 & 0.43 & 1.26 & 3.00 & 2.21 & 0.42 & 1.36 & 3.07 \\
\hline honest & 2.54 & 0.23 & 2.08 & 3.01 & 3.34 & 0.25 & 2.84 & 3.83 & 3.31 & 0.36 & 2.58 & 4.03 & 2.89 & 0.35 & 2.18 & 3.60 \\
\hline sporty & 2.69 & 0.26 & 2.16 & 3.21 & 2.79 & 0.25 & 2.28 & 3.31 & 3.54 & 0.34 & 2.84 & 4.24 & 3.13 & 0.34 & 2.44 & 3.81 \\
\hline dominant & 2.91 & 0.25 & 2.40 & 3.41 & 2.70 & 0.22 & 2.25 & 3.14 & 3.26 & 0.35 & 2.56 & 3.96 & 3.01 & 0.34 & 2.31 & 3.70 \\
\hline rough & 2.35 & 0.26 & 1.82 & 2.89 & 2.14 & 0.24 & 1.65 & 2.62 & 1.95 & 0.34 & 1.26 & 2.65 & 2.15 & 0.34 & 1.46 & 2.83 \\
\hline
\end{tabular}


Table 6.5 The sports performance for all participants

\begin{tabular}{|c|c|c|c|c|c|c|}
\hline \multirow[b]{2}{*}{ No. } & \multicolumn{3}{|c|}{ Saddle A (hoods) } & \multicolumn{3}{|c|}{ Saddle B (hoods) } \\
\hline & cadence & power & pressure & cadence & power & pressure \\
\hline 1 & 102 & 114 & $30: 70$ & 99 & 110 & $32: 68$ \\
\hline 2 & 98 & 135 & $60: 40$ & 96 & 128 & $62: 39$ \\
\hline 3 & 89 & 106 & $42: 59$ & 86 & 79 & $38: 62$ \\
\hline 4 & 61 & 38 & $53: 47$ & 62 & 38 & $53: 47$ \\
\hline 5 & 93 & 135 & $34: 66$ & 93 & 132 & $41: 59$ \\
\hline 6 & 102 & 195 & $73: 27$ & 103 & 194 & $69: 31$ \\
\hline 7 & 89 & 101 & $59: 42$ & 92 & 109 & 61:39 \\
\hline 8 & 109 & 167 & $47: 53$ & 103 & 147 & $55: 45$ \\
\hline 9 & 95 & 124 & $54: 46$ & 95 & 123 & $56: 44$ \\
\hline 10 & 84 & 93 & $33: 67$ & 82 & 87 & $58: 42$ \\
\hline 11 & 96 & 128 & $41: 59$ & 100 & 107 & $60: 40$ \\
\hline 12 & 98 & 138 & $36: 65$ & 105 & 163 & $49: 51$ \\
\hline 13 & 84 & 99 & $39: 61$ & 85 & 102 & $38: 62$ \\
\hline 14 & 92 & 148 & $41: 59$ & 95 & 159 & $68: 32$ \\
\hline 15 & 64 & 50 & $69: 31$ & 64 & 53 & $74: 26$ \\
\hline 16 & 107 & 172 & $45: 55$ & 109 & 181 & $59: 41$ \\
\hline 17 & 100 & 148 & $73: 28$ & 93 & 132 & - \\
\hline 18 & 91 & 122 & $77: 23$ & 90 & 118 & $73: 27$ \\
\hline 19 & 94 & 133 & $48: 52$ & 95 & 137 & $62: 38$ \\
\hline 20 & 93 & 120 & $33: 67$ & 91 & 115 & $45: 55$ \\
\hline 21 & 94 & 125 & $68: 32$ & 95 & 128 & $63: 37$ \\
\hline 22 & 81 & 92 & $67: 33$ & 83 & 95 & $46: 54$ \\
\hline 23 & 103 & 161 & $49: 51$ & 95 & 135 & $47: 53$ \\
\hline 24 & 107 & 163 & $66: 34$ & 101 & 142 & $76: 24$ \\
\hline 25 & 87 & 114 & $46: 54$ & 90 & 124 & $59: 41$ \\
\hline 26 & 90 & 136 & $65: 35$ & 92 & 144 & $63: 37$ \\
\hline 27 & 78 & 109 & $39: 61$ & 76 & 103 & $61: 39$ \\
\hline 28 & 92 & 141 & $77: 23$ & 95 & 154 & $74: 26$ \\
\hline 29 & 75 & 100 & $59: 42$ & 76 & 105 & $63: 37$ \\
\hline 30 & 76 & 105 & $60: 40$ & 76 & 107 & $56: 44$ \\
\hline 31 & 85 & 121 & $39: 61$ & 88 & 134 & $49: 51$ \\
\hline 32 & 90 & 132 & $69: 31$ & 92 & 139 & $66: 34$ \\
\hline 33 & 98 & 161 & $32: 68$ & 98 & 160 & $45: 55$ \\
\hline 34 & 91 & 124 & $64: 36$ & 92 & 129 & $65: 35$ \\
\hline 35 & 88 & 117 & $48: 52$ & 86 & 111 & $59: 42$ \\
\hline 36 & 87 & 114 & $66: 34$ & 86 & 109 & $82: 18$ \\
\hline 37 & 91 & 128 & $46: 54$ & 91 & 129 & $50: 50$ \\
\hline 38 & 91 & 128 & $53: 47$ & 95 & 139 & $49: 51$ \\
\hline 39 & 84 & 126 & $51: 50$ & 78 & 106 & $47: 53$ \\
\hline 40 & 92 & 133 & $64: 36$ & 94 & 143 & $50: 50$ \\
\hline
\end{tabular}




\section{Appendix E A Review of Bike Sizing and Bike Fitting}

A safe and comfortable cycling position can prevent injury and maximise a user's performance. In order to set up properly, it needs to take into account of cyclist's anthropometric profile, muscle/hamstring flexibility, injury history and the geometry of bike frame, etc. Depending on the cycling activity, the requirements of aerodynamics comfort and power in related to the riding posture can be different. For instance, the track bikes are designed with better aerodynamics in mind while the road bikes need more of comfort for a longer distance. Despite limited scientific evidence to support the different bike sizing and fitting methodologies, the following categories are applied to fit a road bike in practice:

I Anthropomatry. This is called the 'static fitting' approach. It translates the rider's body dimensions (e.g., height, inseam length, torso length and arm length) into bike position by following the common physiological principles with the assumption of which riding posture can generalise the optimal power output. For example, the method of knee over pedal spindle (KOPS), which suggests a plumb line dropping from the front of the rider's knee should align the pedal axle when the crank is in the horizontal position (i.e., the foot at three o'clock position). Another common principle is the heel method, which suggests that the rider's heel is in contact with the pedal with the leg being fully extended at the six o'clock position. If the riders sit on the correct saddle height, their feet are not supposed to touch the ground (stand-over height). Next, the LeMond method was popularised by the Tour de France champion, Greg LeMond, who collected the empirical data from professional cyclists. It showed that the optimal distance from the centre of the bottom bracket to the top of the saddle 
can be determined by multiplying 0.883 by the rider's inseam.

The aforementioned methods are starting points to help the rider choose the appropriate size of modern bike frame (i.e., sloping top tube), which does not usually have plenty of size options like the traditional bike frame used to. One of the reasons is the utility of new material (e.g., carbon fibres-lightweight and strong but expensive), therefore the manufacturers produce 'compact' bike frame and limited models for the market strategy. For a given height, humans can have different body proportions such as longer torso or longer legs. Since the bicycle is a multicomponent product, the riders can choose suitable stem and handlebar to match personal torso length (i.e., the reach of a bike). The length of stem and the shape of the handlebar (i.e., hoods, brake levers and handlebar reach) can affect the feeling of steering; however, considering the Wattbike is a stationary ergometer, the author would like to focus on the discussion of the rider's lower body posture.

On the other hand, the bike sizing and fitting can also be conducted from a joint angle perspective (Figure 6.1), with the help of a goniometer, measuring the rider's elbow angle, shoulder angle, and knee angle extension, etc., while positioning the hands on the hoods. The shoulder angle, for instance, is expected to be slightly less than $90^{\circ}$. According to the different riding purposes and hamstrings flexibility, the knee angle extension can range from $150^{\circ}-155^{\circ}$ (fit for racing) to $140^{\circ}-145^{\circ}$ (fit for leisure). Neck pain and back pain can happen if the hip/torso/trunk angle is too big or too small, which also implies that the reach is not correct. It is correlated to the rider's back curvature as well as the saddle tilt and position. Finally, the fine-tuning part in a bike fit is adjusting the position of cleats, shoes and pedals. In this 
experiment, the participants were asked to wear the trainers; hence no further adjustment is needed.

I Motion analysis The bike fit can be supported by a dynamic method (2D or 3D). Despite most of the riders finding comfortable if their body fits the bike position, other variables such as the personal core strength/flexibility and pedalling technique (toe-down, heel-down) can affect the rider's cycling experience. In this regard, the digital analysis can capture and record what the human eye cannot notice, e.g., knee alignment. Subsequently, a better cleat position/angle can be advised in bids to improve the riding posture and generate the power more efficiently. Noted that the influence of the thermal comfort is beyond the scope of this research.

I Presure mapping In a seated cycling activity, there are five contact points (the handlebar/hands, the saddle/pelvis and the pedals/feet) on the road bike. With the help of pressure mapping method, it can eliminate the guess work and visualise where the load is carried. Since the gebioMized system that used in this study can record the real-time interaction, the investigator is able to evaluate the riding stability. However, the pressure level should not be interpreted directly since everyone weights differently and has different level of endurance for discomfort. In this regard, the percentage of the loaded pressures between the front and back area of the saddle can shed a light on the riding position. Also, it can show whether the pressure is evenly distributed on the left and right side of the saddle during cycling. Noted that the average female pelvis is larger and wider than average male pelvis and they have a different centre of mass on the back.

If Physidogical signals In addition to reducing the chance of injury, the goal of a bike fit is to maximise the rider's sports performance, which can be assessed by measuring 
the physiological signals (e.g., muscle fatigue and oxygen consumption). This topic is however beyond the scope of this review.

Overall, it is recommended to always apply several methods since each of them has its pros and cons. In this experiment, the general bike fit protocol was based on the instruction on Wattbike website ${ }^{2}$ to match the geometry of Wattbike trainer model, which seat post angle is $75^{\circ}$. The suggested bike fitting sequence starts from the saddle height, saddle position, handlebar height, and then handlebar position.

As shown in Figure 6.1, the Wattbike saddle height (SH) can be adjusted by the seat post ranging from $45 \mathrm{~cm}$ to $82 \mathrm{~cm}$; it is measured from the top of the seat to the centre of the crank (bottom bracket) and includes the crank length. The saddle position (SP) is also called the saddle 'setback' referring to how far it is behind the bottom bracket. The handlebar height $(\mathrm{HH})$ is measured from the centre of the flywheel ranging from $49 \mathrm{~cm}$ to $74 \mathrm{~cm}$. The handlebar position (HP) is also called the 'reach' of a bike, which is measured from the saddle nose to the centre of the handlebar.
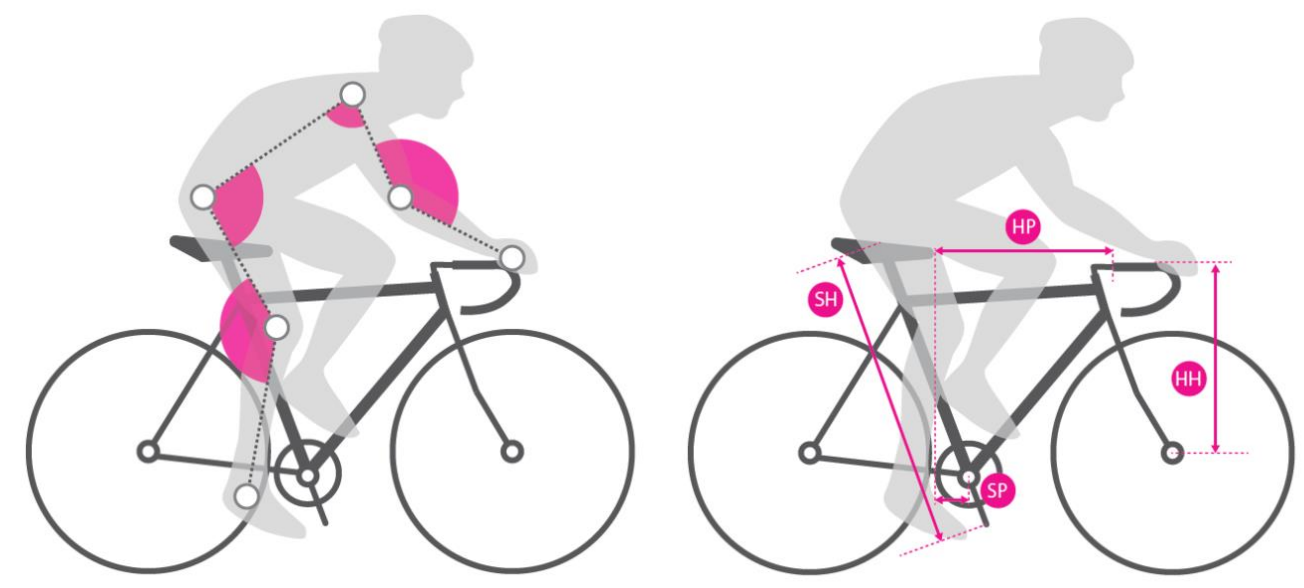

Figure 6.1 The bike fit method from a joint angle and anthropometry perspective

\footnotetext{
${ }^{2}$ Retrieved from https://cdn.wattbike.com/uploads/uk/docs/wb_bike_fit_10042012.pdf
} 